\title{
III. Außenminister unter Bundeskanzler Ludwig Erhard 1963-1966
}

\section{Gerhard Schröders „Öffnung zum Osten“}

\section{Die Konzeption der "neuen Ostpolitik“}

Den Regierungswechsel im Oktober 1963 nutzte Schröder, um der unter Adenauer begonnenen Neuausrichtung der Ostpolitik, deren herausragendster Schritt die Errichtung einer Handelsmission in Polen war, eine stärkere politische Akzentuierung zu geben. Bislang hatte Bonn den Eindruck zu vermeiden gesucht, es handele sich bei der Handelsvertretung ,in Wirklichkeit um eine getarnte diplomatische Mission" ${ }^{1}$. Nun beendete der Außenminister die Beschränkung der Kontakte auf einen "rein fachlich-technischen Charakter", da er einen "Wandel" in der Ostpolitik beabsichtigte ${ }^{2}$. Er plante, „in den Grenzen, die uns unsere Nichtanerkennungspolitik setzt, auch das politische Verhältnis mit den Satellitenstaaten aufzulockern" ${ }^{3}$. Die zu errichtenden Handelsvertretungen sollten „einen betont politischen Charakter" erhalten. Infolgedessen hatte auch das Bundesministerium für Wirtschaft die Federführung bei den diesbezüglichen Verhandlungen mit den osteuropäischen Staaten an das Auswärtige Amt abzugeben 4 .

Welche Ziele verfolgte Schröder mit der Neugestaltung der politischen Beziehungen zu den Staaten Ostmittel- und Südosteuropas? Ausgangspunkt für seine Überlegungen war die Auffassung, daß das Nationalbewußtsein der Osteuropäer zugenommen habe und ihre Regierungen nicht länger nur die Sache Moskaus, sondern verstärkt die eigenen Interessen verfolgten. Man hatte im Westen aufmerksam beobachtet, daß der Freiraum dieser Staaten gegenüber der UdSSR in den vergangenen Jahren spürbar gewachsen war. $Z$ war standen sie auch weiterhin unter der Kontrolle des Kreml, doch schien die sowjetische Regierung die Satellitenstaaten nicht mehr nach Belieben lenken zu können wie noch in der Ära Stalin. Schröder hatte vor, die polyzentristischen Tendenzen im Ostblock zu fördern' ${ }^{5}$. Seine Ostpolitik zielte darauf ab, die Bindung der osteuropäischen Staaten „an

1 Aufzeichnung des Ministerialdirektors Krapf, vom 15.6. 1962, PA/AA, B 150, Aktenkopien 1962.

2 Vgl. das Schreiben des Bundesministers Schröder an Bundesminister Schmücker vom 9. 12. 1963, in: AAPD 1963, Dok. 458, S. 1573.

3 Ebenda, S. $1573 \mathrm{f}$.

4 Ebenda, S. 1574.

5 Vgl. dazu die Rede des Bundesministers Schröder auf dem 13. Bundesparteitag der CDU am 30. 3. 1965 in Düsseldorf, in: DzD IV/11, S. 341. Vgl. auch die Ausführungen Schröders gegenüber Abgeordneten des Bundestags am 12.7. 1963 sowie gegenüber dem japanischen Außenminister Ohira am 7.11. 1963 in Tokio, in: AAPD 1963, Dok. 225, S. 745750, bzw. Dok. 410, S. 1421. 
einen monolithischen Block etwas zu lockern"6. Ein weiteres Motiv war der Wunsch der Verbündeten nach einem größeren Engagement der Bundesrepublik in Osteuropa ${ }^{7}$. Bonn sollte einen eigenständigen Beitrag dazu leisten, die Spannungen zwischen Ost und West abzubauen. Aufgrund dieses entspannungspolitischen Ansatzes war auch unter Kanzler Erhard die offizielle Zielsetzung der Osteuropa-Politik der Bundesregierung, das von der kommunistischen Propaganda aufgebaute "Zerrbild eines kriegs- und revanchelüsternen Deutschland [zu] beseitigen“ und die „durch Krieg und Kriegsfolgen zerrissenen wirtschaftlichen und kulturellen Bande neu zu knüpfen“. Ein Vertrauensverhältnis zu den osteuropäischen Völkern sollte aufgebaut und die Teilung Europas dadurch gemildert wer$\operatorname{den}^{8}$.

Die Handelsvertretungen der Bundesrepublik in Warschau, Budapest, Sofia oder Bukarest hatten zudem die Aufgabe, bei den Gastregierungen das Verständnis für die deutschlandpolitischen Ziele der Bundesregierung zu fördern ${ }^{9}$. Schröder wollte sie davon überzeugen, „daß wir nur friedliche Absichten verfolgten und lediglich das Ziel hätten, auf der Basis der friedlichen Verwirklichung des Selbstbestimmungsrechts die Einheit unseres Landes wieder herzustellen“. Die Diplomaten der Bundesrepublik sollten den Verantwortlichen in den sozialistischen Staaten Osteuropas vermitteln, daß die Wiedervereinigung Deutschlands keine nachteiligen Folgen für sie habe ${ }^{10}$. Anders als die amerikanische Entspannungspolitik, die eine Verbesserung des Klimas zwischen Ost und West durch die vorläufige Hinnahme des Status quo erreichen wollte, blieben die Wiedervereinigung und damit die Änderung der bestehenden politischen Verhältnisse in Mitteleuropa die unveränderte Zielsetzung Bonns. Das Streben nach der Einheit Deutschlands war die eigentliche Triebfeder für die ostpolitischen Neuerungen der Bundesrepublik. Am 24. Mai 1965 bekannte Schröder gegenüber Couve de Murville: „Die gesamte Osteuropapolitik der Bundesregierung bestehe darin klarzulegen, daß ein wiedervereinigtes Deutschland auch für die osteuropäischen Länder besser wäre als ein Deutschland, welches ständige Quelle der Spannung sei. " 11 Die Bereitschaft der Bundesrepublik, für die Wiederherstellung der Einheit „Opfer zu bringen“, sollte die Staaten Ostmittel- und Südosteuropas auf die Seite Bonns ziehen. Umfangreiche ökonomische und finanzielle Hilfen wurden ihnen in Aussicht gestellt. Auch hinsichtlich des militärischen Status eines vereinigten

6 Gespräch des Bundesministers Schröder mit Premierminister Macmillan am 14. 8. 1963 in London, in: ebenda, Dok. 300, S. 1018.

7 Vgl. die deutsch-norwegischen Regierungsbesprechungen am 23./25. 3. 1965, in: AAPD 1965, Dok. 143, S. 591.

8 Interview Schröders mit der Zeitschrift „Die Entscheidung“ der Jungen Union, in: BuLLETIN 1964, S. 1280. Vgl. auch die Rede Schröders vor dem NATO-Ministerrat am 15. 12. 1964, in: ebenda, S. $1728 \mathrm{f}$.

9 Vgl. die Rede des Bundesministers Schröder auf dem 13. Bundesparteitag der CDU am 30. 3. 1965 in Düsseldorf, in: DzD IV/11, S. 341.

10 Deutsch-norwegische Regierungsbesprechungen am 23./25.3. 1965, in: AAPD 1965, Dok. 143, S. 591. Vgl. auch die Rede des Bundesministers Schröder auf dem 13. Bundesparteitag der CDU am 30. 3. 1965 in Düsseldorf, in: DzD IV/11, S. 347.

11 Gespräch des Bundesministers Schröder mit dem französischen Außenminister Couve de Murville am 24. 5. 1965, in: AAPD 1965, Dok. 217, S. 873. 
Deutschlands und der Oder-Neiße-Linie deutete Schröder Konzessionen an, die er aber nicht näher präzisierte ${ }^{12}$. Die Perspektive einer engen und lukrativen $\mathrm{Zu}$ sammenarbeit mit einem wiedervereinigten Deutschland sollte die osteuropäischen Regierungen zu der Einsicht bringen, die Fortdauer der Teilung Deutschlands liege nicht in ihrem Interesse ${ }^{13}$. Das Auswärtige Amt hoffte, daß es langfristig gelingen könnte, sie gegenüber Moskau als Fürsprecher für die Wiedervereinigung zu gewinnen. Zunächst mußte die Bundesrepublik jedoch Vertrauenskapital aufbauen und auf eine politische Klimaverbesserung hinwirken, denn solange die östlichen Nachbarn in der Teilung Deutschlands den besten Schutz für ihre Sicherheit sahen, ließen sich die langfristigen deutschlandpolitischen Ziele Bonns nicht verwirklichen.

Schröders Ansatz, die Ostpolitik in den Dienst der Deutschland-Politik zu stellen, wurde von Erhard vorbehaltlos unterstützt. Der Kanzler erwartete ebenfalls, „daß die wirtschaftlichen Kontakte mit Osteuropa der Lösung der deutschen Frage förderlich sein könnten“. Die Handelsmissionen der Bundesrepublik hätten vor allem eine deutschlandpolitische Zielsetzung, äußerte er im Januar 1965 gegenüber de Gaulle ${ }^{14}$. Von Anfang an warnte Schröder allerdings davor, zu hohe Erwartungen mit der Intensivierung der Kontakte zu den osteuropäischen Staaten zu verbinden: „[...] unsere Anwesenheit, unsere verstärkten Wirtschafts- und Kulturkontakte werden den kommunistischen Regierungen nicht den Kommunismus abkaufen können"15. Man dürfe nicht damit rechnen, daß sich ihre $\mathrm{Hal}$ tung kurzfristig ändern werde: „Sie werden nicht über Nacht der Deutschlandpolitik des Kreml die Gefolgschaft aufsagen. "16 Schröder hielt es aber für wichtig, auch die längerfristigen Entwicklungen im Ostblock im Auge zu behalten und nach Möglichkeit darauf Einfluß zu nehmen. Die Selbständigkeitsbestrebungen der Satellitenstaaten, die gesteigerten Lebensansprüche der Bevölkerung sowie der sowjetisch-chinesische Gegensatz sollten gefördert werden, um die Position des Westens zu verbessern ${ }^{17}$. Diese Faktoren, so seine Hoffnung, könnten auf lange Sicht die UdSSR dazu bringen, ihre Deutschland-Politik zu modifizieren ${ }^{18}$.

Darüber hinaus beobachtete der Außenminister die zunehmende Unterhöhlung des Alleinvertretungsanspruchs der Bundesrepublik mit Sorge. Die Bundesrepublik tat sich immer schwerer, die neutralen und blockfreien Staaten deutschlandpolitisch bei der Stange zu halten. Bonn sah sich mit einer schleichenden Aufwertung der DDR konfrontiert. Da die Deutschland-Politik der Bundesrepublik

12 Vgl. den Drahtbericht des Staatssekretärs Carstens, z.Z. Paris, an das Auswärtige Amt vom 14. 12. 1965, in: ebenda, Dok. 459, S. 1892.

13 Vgl. das Gespräch des Bundesministers Schröder mit dem französischen Außenminister Couve de Murville am 24. 5. 1965, in: ebenda, Dok. 217, S. 837.

14 Gespräch des Bundeskanzlers Erhard mit Staatspräsident de Gaulle am 20.1. 1965 in Rambouillet, in: ebenda, Dok. 26, S. 155.

15 Interview Schröders mit der Zeitschrift „Die Entscheidung“ der Jungen Union, in: BuLLETIN 1964, S. 1280.

16 Ebenda, S. 1281.

$17 \mathrm{Vgl}$. die Ausführungen Schröder gegenüber dem japanischen Außenminister Ohira am 7. 11. 1963 in Tokio, in: AAPD 1963, Dok. 410, S. 1421.

18 Vgl. dazu das Interview Schröders mit dem NDR am 4.11. 1963, in: Bulletin 1963, S. 1737. 
aber auf dem Grundsatz der Nichtanerkennung der DDR beruhte, galt es, dieser Entwicklung gegenzusteuern ${ }^{19}$. Mit der Errichtung von Handelsvertretungen wollte Schröder seinerseits in die Offensive gehen. Die Bundesrepublik, so der Außenminister, könne es sich nicht länger erlauben, jenseits der Oder „das Feld allein den Kommunisten aus Pankow zu überlassen"20. Sie sollte den Kampf mit der DDR nicht länger nur in der Dritten Welt, sondern auch direkt im sowjetischen Machtbereich aufnehmen. Schröder versprach sich davon positive Rückwirkungen bezüglich der Stellung der Bundesrepublik auf dem internationalen Parkett: Dem seit dem 20. Oktober 1963 im Amt befindlichen, neuen britischen Außenminister, Richard Butler, vertraute er an, mit der von ihm initiierten Ostpolitik bezwecke er, „eine Aufwertung Pankows zu verhindern und die eigene Position zu stärken" ${ }^{21}$. Bewußt bezog er die DDR nicht in seine Entspannungsbemühungen ein, da die Ostpolitik der Bundesregierung letztendlich gegen OstBerlin gerichtet war und das Ziel hatte, die Stellung der DDR im Ostblock zu untergraben. Die „ostpolitische Doktrin“ des Außenministers formulierte Wolfgang Schollwer folgendermaßen: „Erst Ausbau der Kontakte und Beziehungen zu den osteuropäischen Staaten, bevor man auf dem innerdeutschen Gebiet aktiv wird. “22 Wie Schröder im Frühjahr 1964 intern erläuterte, habe die Bundesregierung im Hinblick auf die Hallstein-Doktrin zwar durch die Errichtung von Handelsvertretungen „in der Theorie etwas zurückgesteckt, dafür aber viel gewonnen“, da dadurch "das einzige Operationsfeld im Rücken der Sowjetzone“ erschlossen worden sei23. Durch die Präsenz Bonns in den osteuropäischen Hauptstädten würde „zwischen die Zone, als dem derzeit starrsten Vorposten der Sowjetunion, und die Sowjetunion selbst ein Gürtel von Ländern gelegt, die Beziehungen mit der Bundesrepublik hätten“24. Er beabsichtigte, „eine Entspannungspolitik hinter dem Rücken der SBZ“ zu betreiben ${ }^{25}$ und den Tatbestand auszunützen, daß die osteuropäischen Staaten „der Bundesrepublik gegenüber positiver eingestellt seien als Pankow gegenüber"26. Mit der Zeit sollten die Aktivitäten der Bundesrepublik in Osteuropa „zu einer gewissen Isolierung der SBZ“ im Ostblock führen. Der Außenminister spekulierte darauf, daß die osteuropäischen Regierungen schließlich Ulbricht dazu drängen würden, von seinem stalinistischen Regie-

19 Vgl. dazu die Rede des Bundesministers Schröder auf dem 12. Bundesparteitag der CDU am 16. 3. 1964 in Hannover, in: DzD IV/10, S. 423.

20 Interview Schröders mit der Zeitschrift „Die Entscheidung“ der Jungen Union, in: BuLLETIN 1964, S. 1280.

21 Gespräch des Bundesministers Schröder mit dem britischen Außenminister Butler am 9. 12. 1963, in: AAPD 1963, Dok. 459, S. 1586.

22 SCHOLLWER, FDP im Wandel, Eintrag vom 8. 1. 1964, S. 181.

23 Botschafterkonferenz am 21. 4. 1964, in: AAPD 1964, Dok. 105, S. 465.

24 Gespräch des Bundesministers Schröder mit dem amerikanischen Außenminister Rusk am 20. 9. 1963 in Washington, in: AAPD 1963, Dok. 349, S. 1170.

25 Gespräch des Bundesministers Schröder mit Premierminister Macmillan am 14. 8. 1963 in London, in: ebenda, Dok. 300, S. 1018.

26 Gespräch des Bundesministers Schröder mit dem britischen Außenminister Butler am 9. 12. 1963, in: ebenda, Dok. 459, S. 1586. 
rungssystem abzurücken und der Bevölkerung mehr Freiheit zu gewähren ${ }^{27}$. Der Druck wäre nach seiner Einschätzung "wirksamer", wenn er, anstatt wie bisher vom Westen, von den Verbündeten der DDR selbst käme ${ }^{28}$. Diese deutschlandpolitische Zielrichtung durfte aber nicht öffentlich breitgetreten werden, da andernfalls zu befürchten war, daß die UdSSR die osteuropäischen Staaten wegen ihrer Kontakte zur Bundesrepublik zur Rechenschaft zöge ${ }^{29}$. Der Öffentlichkeit blieb daher verborgen, daß Schröder letzten Endes die Absicht verfolgte, die DDR im Ostblock zu isolieren.

Dem Außenminister war sehr wohl bewußt, daß ein solches Unternehmen einen langen Atem erforderte. Gegenüber seinen westlichen Gesprächspartnern betonte er stets, es handle sich um eine "langfristig angelegte Politik" 30 von der keine schnellen Resultate zu erwarten seien ${ }^{31}$. Er war aber davon überzeugt, durch die von ihm initiierte Ostpolitik die Rahmenbedingungen für die Wiederherstellung der staatlichen Einheit Deutschlands zu schaffen. Wie er im Dezember 1964 Couve de Murville darlegte, zielte seine Osteuropa-Politik darauf ab, „die Lage zu normalisieren und allmählich den Eisernen Vorhang abzubauen“, was eine „unerläßliche Voraussetzung " wäre, um die deutsche Frage im Sinne Bonns zu lösen ${ }^{32}$. Eine logische Konsequenz des Isolierungskonzepts war, daß die Verbündeten der Bundesrepublik ebenfalls keine Kontakte zu Pankow unterhalten durften, da dies den gegenteiligen Effekt einer Stabilisierung der DDR zur Folge hätte. Um den

27 Gespräch des Bundesministers Schröder mit dem britischen Außenminister Butler am 16. 1.1964 in London, in: AAPD 1964, Dok. 15, S. 76.

28 Gespräch des Bundesministers Schröder mit dem amerikanischen Außenminister Rusk am 20.9. 1963 in Washington, in: AAPD 1963, Dok. 349, S. 1170.

$29 \mathrm{Vgl}$. dazu Schröders Ausführungen auf der Botschafterkonferenz am 21.4. 1964, in: AAPD 1964, Dok. 105, S. 465.

30 Gespräch des Bundesministers Schröder mit dem amerikanischen Außenminister Rusk am 23.11. 1964 in Washington, in: ebenda, Dok. 353, S. 1382. Vgl. auch das Gespräch des Bundesministers Schröder mit dem französischen Außenminister Couve de Murville am 9. 12. 1964 in Paris, in: ebenda, Dok. 377, S. 1468.

$31 \mathrm{Vgl}$. Schröders Ausführungen in der deutsch-amerikanischen Regierungsbesprechung am 28. 12. 1963 in Stonewall, Texas, in: AAPD 1963, Dok. 487, S. 1685. Schröders Konzeption ähnelt frappierend einem Plan, den der damalige Berater des Planungsstabs des State Department und spätere Sicherheitsberater des Präsidenten Carter, der amerikanische Politologe Zbigniew Brzezinski, in seinem Buch „Alternative to Partition“ entwickelte. Brzezinski plädierte ebenfalls für eine diplomatische Offensive der Bundesrepublik gegenüber den Staaten Ostmittel- und Südosteuropas, die die Normalisierung der Beziehungen zum Ziel haben sollte. Ebenso wie Schröder schlug er vor, die DDR nicht in diese $\mathrm{Be}-$ mühungen einzubeziehen und statt dessen den Versuch zu unternehmen, sie im Kreise ihrer Verbündeten zu isolieren. Brzezinski nahm an, eine solche Politik könnte im Laufe der Zeit die Einheit Deutschlands herbeiführen, da das Interesse der Osteuropäer an einer Fortexistenz der DDR abnehmen würde. Da die Studie aber erst 1965 erschien, ist die in der Literatur oft zu findende Darstellung unzutreffend, Schröder habe den als „Zwei-Zangen-Theorie“ bezeichneten Plan Brzezinskis übernommen. Dies behauptet z. B. Adrian Schertz (SCHERTZ, Die Deutschlandpolitik Kennedys und Johnsons, S. 199). Sogar HansPeter Schwarz bezeichnet Schröders Osteuropa-Politik als die „Konkretisierung“ von Brzezinskis Thesen. Vgl. SCHWARZ, Supermacht und Juniorpartner, S. 177.

32 Gespräch des Bundesministers Schröder mit dem französischen Außenminister Couve de Murville am 9. 12. 1964 in Paris, in: AAPD 1964, Dok. 377, S. 1468. 
Erfolg seiner Politik zu sichern, verlangte Schröder daher von ihnen, sie müßten „jede Maßnahme unterlassen, die dem Pankow-Regime auf internationaler Ebene

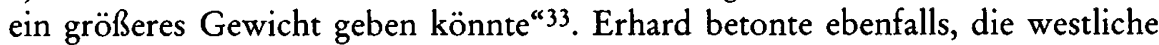
Entspannungspolitik müßte zwischen der DDR und den osteuropäischen Staaten einen Unterschied machen ${ }^{34}$. Die Bundesregierung legte deshalb auch sehr viel Wert darauf, daß der Westen Ost-Berlin keine staatlich abgesicherten Kredite gewährte 35 .

Christian Hacke charakterisiert Schröders Ostpolitik treffend als „ambivalent" 36: Sie hatte sowohl eine entspannungs- wie eine deutschlandpolitische Dimension. Die Bundesregierung leistete damit einerseits einen Beitrag zum Abbau der Spannungen zwischen West und Ost und kam damit einem dringenden Wunsch ihrer NATO-Partner nach. Sie bewies dadurch der Weltöffentlichkeit, daß die kommunistische Propaganda, Bonn wolle die Entspannung verhindern, nicht zutraf. Andererseits verfügte die Bundesrepublik durch die Herstellung eines direkten Drahts zu den Regierungen Ostmittel- und Südosteuropas nun über die Möglichkeit, ihren politischen Standpunkt gegenüber den Verbündeten der Sowjetunion unter vier Augen zu vertreten. Sie konnte den osteuropäischen Regierungen jetzt im direkten Gespräch ihre Deutschland-Politik darlegen, gleichzeitig aber auch deren Unabhängigkeitsbestrebungen unterstützen und damit zu einer Aufweichung des Ostblocks beitragen. Die Isolierung der DDR sollte einerseits einer weiteren Aufwertung Ost-Berlins einen Riegel vorschieben und andererseits Ulbricht zu Konzessionen zwingen. Die Ostpolitik des Außenministers war somit ein Teil seiner Wiedervereinigungspolitik, die auf mehreren Faktoren beruhte. Die Aktivitäten der Bundesrepublik im Rücken der DDR, die Auflockerungstendenzen im Ostblock und der wachsende sowjetisch-chinesische Gegensatz sollten den Weg für die Wiederherstellung der staatlichen Einheit Deutschlands bereiten ${ }^{37}$.

Wie Schröder selbst erkannte, gab es zwischen seiner Osteuropa-Politik und der offiziellen Deutschland-Politik der Bundesrepublik gewisse Widersprüche. Bonn errichtete in Staaten, welche die DDR völkerrechtlich anerkannt hatten und mit ihr diplomatische Beziehungen pflegten, offizielle Vertretungen. Zwar rangierten die Handelsvertretungen völkerrechtlich unterhalb der diplomatischen Ebene, doch wurden dadurch ohne Zweifel amtliche Beziehungen aufgenommen. Außerdem sollten diese lediglich den Auftakt zu einem noch stärkeren ostpolitischen Engagement der Bundesregierung bilden. Als nächster Schritt war die vollständige Normalisierung des Verhältnisses, also die Aufnahme diplomatischer Be-

33 Gespräch des Bundesministers Schröder mit dem amerikanischen Außenminister Rusk am 23. 11. 1964 in Washington, in: ebenda, Dok. 353, S. 1382.

34 Vgl. die deutsch-dänischen Regierungsbesprechungen am 9./10.6. 1965, in: AAPD 1965, Dok. 238, S. 988.

35 Vgl. dazu den Drahtbericht des Staatssekretärs Carstens, z.Z. Paris, an das Auswärtige Amt vom 14. 12. 1965, in: ebenda, Dok. 459, S. 1892.

36 HACKE, Weltmacht, S. 125.

37 Vgl. dazu das Gespräch des Bundesministers Schröder mit dem kanadischen Außenminister Martin am 21.9. 1963 in Washington, in: AAPD 1963, Dok. 353, S. 1182. 
ziehungen, vorgesehen ${ }^{38}$ - mit der Folge, daß in den Hauptstädten Osteuropas jeweils zwei deutsche Botschaften - eine der Bundesrepublik und eine der DDR präsent gewesen wären. Andererseits pochte Bonn weiterhin energisch auf den Alleinvertretungsanspruch. Die Bundesregierung forderte von allen Staaten, eine Anerkennung der DDR zu unterlassen und auf jeden offiziellen Kontakt mit OstBerlin zu verzichten. Die ostpolitischen Aktivitäten Schröders konnten folglich den Anschein erwecken, als ob die Bundesrepublik von anderen Staaten etwas verlangte, was sie selbst nicht einhalten wollte. Aufgrund dieses Widerspruchs zur bisherigen deutschlandpolitischen Linie regte sich in den Reihen von CDU und CSU Widerstand gegen eine Ausweitung der bilateralen Beziehungen mit den kommunistischen Staaten Osteuropas. Schröders Kritiker sahen das Instrument der Bonner Nichtanerkennungspolitik, die Hallstein-Doktrin, die bislang erfolgreich eine Aufwertung der DDR und ihre völkerrechtliche Anerkennung verhindert hatte, durch seine Politik in Frage gestellt. In ihren Augen schien der Außenminister zu einem Zeitpunkt, da sich die Teilung Deutschlands immer mehr verfestigte, die Prinzipien der Deutschland-Politik über Bord zu werfen. Für Schröder war es schwierig, sich überzeugend gegen diese Vorwürfe zu wehren. Daß er mit seiner Ostpolitik letztendlich das Ziel verfolgte, die Chancen für die Wiedervereinigung zu erhöhen, konnte er nicht öffentlich darlegen, um sie in Warschau, Prag oder Budapest, vor allem aber in Moskau, nicht von vornherein in Mißkredit zu bringen. Daher suchte er, wie bereits dargestellt, die von ihm unternommenen Schritte zunächst mit Hilfe der Geburtsfehlertheorie zu verteidigen. Des weiteren erinnerte er an einen gemeinsamen Beschluß aller Fraktionen des Bundestags vom 14. Juni 1961, in dem die Bundesregierung dazu angehalten worden war, eine aktivere Ostpolitik zu betreiben ${ }^{39}$. Er machte ferner darauf aufmerksam, daß die Verantwortlichen in Ost-Berlin den Beginn eines Dialogs der Bundesrepublik mit ihren Verbündeten „mit äußerstem Mißvergnügen“ betrachteten ${ }^{40}$.

Unklar bleibt an Schröders Konzept jedoch, wie mittels einer Verbesserung des Verhältnisses zu den osteuropäischen Staaten die Teilung Deutschlands überwun-

$38 \mathrm{Vgl}$. dazu z. B. das Interview des Bundesministers Schröder mit dem ZDF am 21. 5. 1965, in: DzD IV/11, S. 610. Auf diesen Punkt wird später noch ausführlich eingegangen werden.

39 Vgl. dazu z. B. Schröders Ausführungen im Bundestag am 10. 3. 1965: BT STENOGRAPHISCHE BERICHTE, Bd. 57, S. 8508 f.; sowie sein Gespräch mit Abgeordneten des Bundestags am 12. 7. 1963, in: AAPD 1963, Dok. 225, S. 746. In der Entschließung des Bundestags vom 14.6. 1961 wurde die Bundesregierung aufgefordert, „ohne Preisgabe lebenswichtiger deutscher Interessen zu einer Normalisierung der Beziehungen zwischen der Bundesrepublik und den osteuropäischen Staaten zu gelangen“. Vgl. DIE AuswärTIGE POLITIK, Dok. 140, S. 445. Hans-Jürgen Grabbe urteilt, daß dieser Beschluß „die Hallstein-Doktrin so weit aushöhlte, daß der Boden für den später durch Schröder vorgenommenen Austausch von Handelsmissionen geebnet wurde" Vgl. GRABBE, Unionsparteien, S. 382. Wie Mechthild Lindemann aber treffend feststellt, wurde der Spielraum der Bundesregierung durch die Resolution nicht größer, da sie damit gezwungen war, an der Nichtanerkennungspolitik und am Rechtsvorbehalt bezüglich der Oder-Neiße-Linie festzuhalten. Sie konnte somit nicht als Rechtfertigung für die Aufnahme diplomatischer Beziehungen zu den Staaten Ostmittel- und Südosteuropas dienen. Vgl. LINDEMANN, Anfänge, S. 54.

40 Rede des Bundesministers Schröder auf dem 12. Bundesparteitag der CDU am 16. 3.1964 in Hannover, in: DzD IV/10, S. 424. 
den werden konnte. Zwar mochten die Offerten Schröders, wie zum Beispiel die Aussicht auf eine großzügige finanzielle Hilfe, für die osteuropäischen Regierungen durchaus attraktiv sein, doch lag der Schlüssel zur Wiedervereinigung definitiv in Moskau. Die Teilung Deutschlands würde folglich solange andauern, wie die Existenz zweier deutscher Staaten im sowjetischen Interesse lag. War Schröders Ostpolitik also nicht doch nur eine jener deutschlandpolitischen „Halb-Utopien“41, die die politische Realität unberücksichtigt ließ? In der Tat war die Erwartung, daß die osteuropäischen Regierungen dazu gebracht werden konnten, gegen den Willen Moskaus den deutschlandpolitischen Standpunkt Bonns einzunehmen, ebenso wenig wahrscheinlich wie die Hoffnung, sie könnten sich allmählich aus dem sowjetischen Machtbereich lösen. Die politische Handlungsfreiheit der osteuropäische Regierungen war begrenzt, da sie sich weitgehend, wenn nicht - wie vor allem im Fall der DDR - sogar ausschließlich dank der Rückendeckung durch die UdSSR an der Macht hielten. Sie konnten es nicht riskieren, sich von Moskau loszusagen, ohne ihre eigene Herrschaft zu gefährden. Schröder überschätzte ihre Bewegungsfreiheit, wenn er die Erwartung hegte, durch die Aktivitäten der Bundesrepublik könnte die DDR im Ostblock isoliert werden. Davon abgesehen, bestanden zwischen Ost-Berlin und seinen Verbündeten sowohl sehr enge politische und ökonomische, als auch militärische Beziehungen, auf deren Gestaltung Bonn keinerlei Einfluß hatte. Auch war nicht zu erwarten, daß die UdSSR einer Aufweichung der Verbindungen zwischen der DDR und den anderen Staaten des Warschauer Pakts tatenlos zusehen, sondern jegliche Tendenzen, die auf eine Isolierung Pankows durch die Länder Ostmittel- und Südosteuropas hindeuteten, frühzeitig unterbinden würde. Kritisch betrachtet, setzte der Außenminister also die Hallstein-Doktrin aufs Spiel, ohne eine Garantie zu haben, dadurch der Einheit Deutschlands näherzukommen. Doch Schröder hielt die Doktrin sowieso für eine Fessel, die den Spielraum der Außenpolitik der Bundesrepublik einschränkte ${ }^{42}$. Mußte man nicht, nachdem die bisherige Deutschland-Politik keine Fortschritte in Richtung Wiedervereinigung vorzuweisen hatte, nach neuen Wegen suchen? Er war fest davon überzeugt, daß durch die von ihm vorgenommene Kursänderung nichts verloren, wohl aber einiges gewonnen werden konnte. Einwände gegen die Konzeption seiner Ostpolitik nahm er deshalb gelassen hin: „Ich vermag kein besseres Rezept in den Händen der Kritiker zu sehen. “43

\section{Die Handelsabkommen mit den kommunistischen Staaten}

Noch während der Kanzlerschaft Adenauers konnte am 7. März 1963 das bereits erwähnte Handelsabkommen mit Polen geschlossen werden, das zur Errichtung einer Handelsmission in Warschau führte. Nach der Regierungsübernahme durch Ludwig Erhard folgten Abschlüsse mit Rumänien (17. Oktober $1963^{44}$ und

41 So die Einschätzung Horst Osterhelds (ZeITZeugenbefragung Osterheld).

42 ZeITZEUGENBEFRAGUNG Krapf.

43 Interview Schröders mit der Zeitschrift „Die Entscheidung“ der Jungen Union, in: BulLETIN 1964, S. 1280.

44 Für den Wortlaut des Protokolls vom 17.10. 1963 zwischen der Bundesrepublik und 
24. Dezember $1963^{45}$ ) sowie Ungarn (10. November 196346). Schon Anfang des Jahres 1964 sprach die Bundesregierung von einer „Klimaverbesserung“, die im Verhältnis zu den osteuropäischen Staaten eingetreten sei ${ }^{47}$. Als großen Erfolg wertete Schröder zunächst einmal die Abkommen selbst, da sich ihr Geltungsbereich auch auf Berlin (West) erstreckte. Seiner Auslegung zufolge war es damit gelungen, die von der UdSSR bestrittene These, die Stadt sei ein Teil der Bundesrepublik, gegenüber den Verbündeten Moskaus durchzusetzen ${ }^{48}$. Die Einfügung dieser sogenannten Berlin-Klausel gelang allerdings nur indirekt. So verwies das Handelsabkommen mit Polen auf ein am 16. November 1956 geschlossenes Protokoll über den bilateralen Zahlungsverkehr, in dem als Anwendungsgebiet der Währungsbereich der DM-West festgelegt wurde ${ }^{49}$. Die rumänische Regierung zeigte sich hinsichtlich der Berlin-Klausel am entgegenkommendsten ${ }^{50}$. Das deutsch-rumänische Protokoll vom 17. Oktober 1963 nahm nicht auf einen früheren Vertrag Bezug, sondern in einem beigefügten Briefwechsel wurde festgelegt, daß die Handelsvertretungen ihre „Aufgaben in den Währungsgebieten der DMWest und des Leu ausüben" würden ${ }^{51}$. Eine ähnliche Regelung fand sich auch im Abkommen mit Ungarn ${ }^{52}$. Durch diese Klauseln sah das Auswärtige Amt sichergestellt, daß die völkerrechtliche Vertretung von Berlin (West) durch die Bundesrepublik von den osteuropäischen Staaten anerkannt und die sowjetische These von der Existenz eines unabhängigen Völkerrechtssubjekts Berlin (West) im Machtbereich des Kreml keine Unterstützung fand. Die Akzeptierung der BerlinKlausel durch Polen, Rumänien und Ungarn interpretierte Schröder als Beleg für die Richtigkeit seiner Auffassung, daß die osteuropäischen Staaten über mehr politischen Freiraum verfügten als früher ${ }^{53}$. Zufrieden registrierte er, daß die Ak-

Rumänien über die Errichtung von Handelsvertretungen sowie des vertraulichen Briefwechsels zum Protokoll vgl. PA/AA, B 150, Aktenkopien 1963.

45 Für den Wortlaut des Abkommens vom 24. 12. 1963 zwischen der Bundesrepublik und Rumänien über den Warenverkehr vgl. BUNDESANZEIGER, Nr. 57 vom 21. 3. 1964, S. $1 \mathrm{f}$.

46 Für den Wortlaut des Abkommens vom 10.11. 1963 zwischen der Bundesrepublik und Ungarn über den Waren- und Zahlungsverkehr sowie des vertraulichen Briefwechsels über die Errichtung von Handelsvertretungen vgl. PA/AA, B 150, Aktenkopien 1963. Vgl. ferner BUNDESANZEIGER, Nr. 14 vom 22. 1. 1964, S. $1 \mathrm{f}$.

47 Deutsch-britische Regierungsbesprechung am 15.1. 1964 in London, in: AAPD 1964, Dok. 13, S. 55. Zum Verlauf der Verhandlungen mit Polen, Rumänien und Ungarn vgl. LindemanN, Anfänge, S. 68-73 und S. 79-86.

$48 \mathrm{Vgl}$. die deutsch-britische Regierungsbesprechung am 15.1. 1964 in London, in: AAPD 1964, Dok. 13, S. 55.

49 Vgl. dazu Artikel 5 des Protokolls vom 16.11. 1956 zwischen der Bundesrepublik und Polen, in: BundesANZEIGER, Nr. 1 vom 3. 1. 1957, S. 2.

50 So das Urteil der Führungsspitze des Auswärtigen Amts. Vgl. die deutsch-britische Regierungsbesprechung am 15.1. 1964 in London, in: AAPD 1964, Dok. 13, S 56, sowie das Gespräch des Staatssekretärs Carstens mit Vertretern der Drei Mächte am 12. 5. 1964 in Den Haag, in: ebenda, Dok. 126, S. 529.

51 Vertraulicher Briefwechsel zum Protokoll vom 17. 10. 1963, PA/AA, B 150, Aktenkopien 1963.

52 Für den Wortlaut des vertraulichen Briefwechsels zum Abkommen vom 10.11. 1963 vgl. PA/AA, B 150, Aktenkopien 1963.

53 Vgl. die deutsch-britische Regierungsbesprechung am 15.1. 1964 in London, in: AAPD 1964, Dok. 13, S. 55. 
tivitäten Bonns Ulbricht „außerordentlich unruhig“ gemacht hätten ${ }^{54}$. In der Tat war der Vorsitzende des Staatsrats der DDR extrem verärgert, daß seine Verbündeten in den Abmachungen mit Bonn auf die Drei-Staaten-Theorie, derzufolge es neben den Völkerrechtssubjekten Bundesrepublik und DDR, auch ein eigenständiges Völkerrechtssubjekt Westberlin gab, keine Rücksicht nahmen ${ }^{55}$.

Nach Verhandlungen von nur einem Monat Dauer konnte am 6. März 1964 mit Bulgarien ebenfalls eine Übereinkunft erzielt werden ${ }^{56}$. Obwohl Ost-Berlin im Vorfeld verkündet hatte, bereits die Verwendung des Begriffes „Währungsgebiet“ stelle eine Identifikation mit der Bonner Berlin-Politik dar, akzeptierte Sofia eine indirekte Einbeziehung von Berlin (West) in das Abkommen ${ }^{57}$. Gegenüber der ČSSR konnte die Bundesregierung jedoch ihr Ziel, „von allen kommunistischen Staaten Berlin-Erklärungen zu erhalten, die sich von der Stellungnahme der sowjetischen Regierung und der sowjetischen Zone zu diesem Problem unterscheiden" ${ }^{58}$, nicht mehr erreichen. Die DDR übte starken Druck auf Prag aus, unter keinen Umständen eine Berlin-Klausel in einer Handelsvereinbarung hinzunehmen ${ }^{59}$. Im Gegensatz zu den anderen osteuropäischen Staaten hatte die tschechoslowakische Regierung nicht ein derart vitales Interesse an der Errichtung einer Handelsmission der Bundesrepublik, daß sie bereit war, Bonn in dieser Frage entgegenzukommen ${ }^{60}$. Sie wollte sich auch nicht mit Beziehungen unterhalb der diplomatischen Ebene abfinden, sondern bestand auf einer Normalisierung der Beziehungen. Falls die Bundesregierung den Austausch von Botschaftern ablehnen würde, sollten nach den Vorstellungen Prags den Handelsvertretungen zumindest konsularische Befugnisse übertragen werden. Das konnte wiederum die Bundesregierung aus Rücksicht auf die Hallstein-Doktrin nicht akzeptieren $^{61}$.

54 Ebenda, S. 56.

55 Vgl. HACKER, Der Ostblock, S. 724, Anm. 6.

56 Für den Wortlaut des Abkommens vom 6. 3. 1964 zwischen der Bundesrepublik und Bulgarien über den Waren- und Zahlungsverkehr und die Errichtung von Handelsvertretungen vgl. BuNDESANZEIGER, Nr. 148 vom 13. 8. 1964, S. 1-3.

$57 \mathrm{Vgl}$. LindemanN, Anfänge, S. $90 \mathrm{f}$. Auch in diesem Fall fügte man dem Abkommen einen vertraulichen Briefwechsel bei, der als Anwendungsgebiet der Vereinbarung die jeweiligen Währungsgebiete vorsah. Für den Wortlaut der Schreiben vom 6.3. 1964 vgl. PA/AA, B 150, Aktenkopien 1964.

58 Deutsch-französische Regierungsbesprechung am 3. 7. 1964, in: AAPD 1964, Dok. 183, S. 741.

59 Vgl. die deutsch-französische Regierungsbesprechung am 19.1.1965 in Paris, in: AAPD 1965, Dok. 23, S. 126.

60 Es war vor allem das große Interesse der osteuropäischen Staaten an einer Ausweitung des Handels mit der Bundesrepublik, das sie dazu brachte, die Berlin-Klausel zu akzeptieren. Vgl. HACKER, Der Ostblock, S. 724. Wie der damalige Verhandlungsleiter, Ministerialdirektor Krapf, im Rücklick betont, zeigte sich das Auswärtige Amt in dieser Frage unnachgiebig, da man damit rechnete, daß die Osteuropäer über kurz oder lang nachgeben würden. Im Verlauf der Verhandlungen erwies sich, daß Krapf mit dieser Prognose richtig lag (ZEITZEUGENBEFRAGUNG Krapf).

$61 \mathrm{Vgl}$. das Gespräch des Bundesministers Schröder mit dem französischen Außenminister Couve de Murville am 3. 7. 1964, in: AAPD 1964, Dok. 181, S. 730. 
Ein weiteres Problem, das die Verhandlungen erschwerte, war das sogenannte Münchener Abkommen vom 29. September 1938, mit dem Hitler die Abtretung des Sudetenlandes erzwungen hatte ${ }^{62}$. Die ČSSR verlangte eine Erklärung, daß die Bundesrepublik dieses Abkommen ab initio als nichtig erachte ${ }^{63}$. Zwar hatte Erhard am 11. Juni 1964 vor dem Council on Foreign Relations in New York erklärt, das Münchener Abkommen sei „von Hitler zerrissen worden“, weshalb die Bundesrepublik „keinerlei territoriale Forderungen“ gegenüber Prag habe ${ }^{64}$, doch stellte sich Bonn weiterhin auf den Standpunkt, der Vertrag sei erst mit der Zerschlagung der Tschechoslowakei im März 1939 ungültig geworden. Die von den Tschechen und Slowaken gewünschte Erklärung, das Münchener Abkommen sei von Anfang an wider das Völkerrecht gewesen, da es zu Lasten eines nichtbeteiligten Dritten geschlossen wurde, war für die Bundesregierung problematisch, da sich die deutsche Staatsangehörigkeit der Sudetendeutschen von diesem Vertrag ableitete ${ }^{65}$. Die unterschiedliche Bewertung des Münchener Abkommens und die Forderung Prags nach einer Aufnahme diplomatischer Beziehungen komplizierten die Verhandlungen ${ }^{66}$. Nachdem auch im Januar 1965 noch keine Einigung mit der tschechoslowakischen Regierung in Sicht war ${ }^{67}$, beschloß das Auswärtige Amt, die andere Seite stärker unter Druck zu setzen und mit der Schließung des tschechoslowakischen Außenhandelsbüros in Frankfurt zu drohen ${ }^{68}$. Diese Taktik hatte sich bereits in den Gesprächen mit Warschau als effizient erwiesen ${ }^{69}$. Doch jetzt blieb sie wirkungslos. Hinsichtlich des Münchener Abkommens schien zwar ein Kompromiß möglich, in der Frage der Berlin-Klausel gab es indessen keinerlei Bewegung. Der Außenminister machte dafür die ständigen Interventionen Ost-Berlins in Prag verantwortlich ${ }^{70}$. Während Schröders Amtszeit gelang es nicht mehr, eine Einigung mit der ČSSR zu erzielen. Die 1965 unterbrochenen Verhandlungen wurden schließlich von der Großen Koalition wieder aufgenommen. So konnte erst am 3. August 1967 ein Handelsabkommen geschlossen und eine Vereinbarung über die Errichtung von Handelsvertretungen getroffen werden ${ }^{71}$.

62 Für den Wortlaut des Abkommens vom 29.9. 1938 zwischen dem Deutschen Reich, Großbritannien, Frankreich und Italien vgl. ADAP, Serie D, II, Dok. 675, S. 812-814.

$63 \mathrm{Vgl}$. die Aufzeichnung der Legationsrätin I. Klasse Finke-Osiander vom 21.1. 1965, in: AAPD 1965, Dok. 28, S. 159-163.

64 Bulletin 1964, S. 851.

65 Vgl. LindemanN, Anfänge, S. 89.

66 Vgl. das Gespräch des Bundesministers Schröder mit dem französischen Außenminister Couve de Murville am 3. 7. 1964, in: AAPD 1964, Dok. 181, S. 730.

$67 \mathrm{Vgl}$. die Aufzeichnung des Botschafters Freiherr von Mirbach vom 16. 1. 1965, in: AAPD 1965, Dok. 19, S. 87-89.

68 Vgl. den Drahterlaß des Staatssekretärs Carstens an Botschafter Freiherr von Mirbach, z.Z. Prag, vom 20. 2. 1965, in: ebenda, Dok. 87, S. 362 f.

69 Vgl. ebenda.

70 Vgl. die deutsch-dänischen Regierungsbesprechungen am 9./10.6. 1965, in: ebenda, Dok. 238, S. 987. Zu den Verhandlungen mit der ČSSR vgl. auch die Aufzeichnung des Ministerialdirektors Krapf vom 23. 3. 1965, in: ebenda, Dok. 144, S. 596-600.

71 Für den Wortlaut des Abkommens vom 3. 8. 1967 zwischen der Bundesrepublik und der CSSR über den Waren- und Zahlungsverkehr sowie über den Austausch von Handelsvertretungen vgl. BUNDESANZEIGER, Nr. 61 vom 27. 3. 1968, S. $1 \mathrm{f}$. 
Weil das Bonner Beharren auf der Berlin-Klausel die Bonner Ostpolitik zu blockieren drohte, schlug Schröder am 25. November 1965 dem Kanzler eine Änderung des Beschlusses der Drei Mächte vom 21. Mai $1952^{72}$ vor, demzufolge die außenpolitische Vertretung von Berlin (West) durch die Bundesrepublik in allen internationalen Verträgen, die Bonn schloß, fixiert werden mußte ${ }^{73}$. Die Westmächte sollten die Bestimmung dahingehend ändern, daß „Berlin grundsätzlich in alle Verträge, die die Bundesrepublik Deutschland schließt, einbezogen ist, außer wenn das Gegenteil von uns ausdrücklich erklärt wird“. Ein derartiges Vorgehen hätte die Politik Bonns gegenüber den osteuropäischen Staaten erheblich erleichtert, da der Zwang weggefallen wäre, die Berlin-Klausel in Abmachungen mit ihnen durchzusetzen. Schröder wies darauf hin, daß die Klausel nicht nur eine Einigung mit der ČSSR blockierte, sondern auch den Abschluß eines neuen Handelsbzw. Kulturabkommens mit der UdSSR. Er sagte ferner voraus, daß die Einbeziehung Berlins im Falle von weiteren Vertragsverhandlungen mit Bulgarien, Polen, Rumänien und Ungarn erneut große Schwierigkeiten bereiten werde. Die Änderung der Berlin-Politik versuchte er Erhard mit dem Argument schmackhaft zu machen, daß sie mit dem Standpunkt der Bundesregierung, Berlin (West) habe den Status eines Bundeslandes, „voll vereinbar“ sei, während die bisherige Vorgehensweise, Berlin (West) gesondert in völkerrechtlichen Verträgen zu erwähnen, ihm „eher abträglich“ sei ${ }^{74}$. Der Kanzler wich jedoch einer Entscheidung aus. Er lehnte Schröders Ansinnen nicht von vornherein ab, verlangte aber zunächst eine detaillierte Vorlage des Auswärtigen Amts, welche Konsequenzen die Neuregelung mit sich bringen würde ${ }^{75}$. Die Angelegenheit wurde damit vertagt und später von Erhard auch nicht mehr aufgegriffen.

Neben den Schwierigkeiten mit der ČSSR bereitete auch das politische Verhältnis zu Polen Schröder Sorgen. Die Beziehungen entwickelten sich nicht auf die von ihm erhoffte Weise. Warschaus Interesse beschränkte sich auf eine Auswei-

72 Für den Wortlaut der Erklärung der Alliierten Kommandantur vom 21. 5. 1952 vgl. DoKUMENTE ZUR BERLIN-FrAGE, Dok. 138, S. 175-177.

$73 \mathrm{Vgl}$. das Schreiben des Bundesministers Schröder an Bundeskanzler Erhard vom 25. 11. 1965, in: AAPD 1965, Dok. 435, S. 1817-1819. Bereits am 9.7. 1965 berichtete die Presse über Pläne des Auswärtigen Amts, eine Art negative Berlin-Klausel einzuführen. Vgl. den Artikel von Theo M. Loch: „Die Berlinklausel soll gestrichen werden. Ein Vorstoß mit gefährlichen Konsequenzen“, in: RHEINISCHER MERKUR vom 9. 7. 1965, S. 1. Heftige Proteste, vor allem aus den Reihen der Union, waren die Folge. Vgl. dazu HuYN, Die Sackgasse, S. 305-311; HiLDEBRAND, Von Erhard zur Großen Koalition, S. 91. Im Auswärtigen Amt verdächtigte man den Legationsrat Graf Huyn, die Presse informiert zu haben. Vgl. HuYN, Die Sackgasse, S. 404 f. Schröder reagierte auf die Veröffentlichung ungewöhnlich aggressiv. In einem Interview mit dem RIAS meinte er, dies sei „ein ganz übler Versuch [...] der [...] Sabotage" (zitiert nach ADG 1965, S. 11969). Auch Zeitgenossen empfanden den Artikel als einen „gezielten Schuß gegen die Deutschland- und Ostpolitik Schröders“. Vgl. SCHOLLWER, FDP im Wandel, Eintrag vom 16. 7. 1965, S. 268.

74 Schreiben des Bundesministers Schröder an Bundeskanzler Erhard vom 25.11. 1965, in: AAPD 1965, Dok. 435, S. 1818.

75 Vgl. das Schreiben Erhards an Schröder vom 3. 12. 1965, PA/AA, B 150, Aktenkopien 1963. 
tung des Handels mit der Bundesrepublik ${ }^{76}$. Um die Kontakte nicht allein auf Wirtschaftsfragen einzuengen, zog der Außenminister daher im Dezember 1964 in Erwägung, „Polen den Abschluß eines politischen Vertrages anzubieten “77. Er dachte dabei an ein Abkommen über einen generellen Gewaltverzicht zwischen den beiden Staaten. Die von der polnischen Regierung geforderte Anerkennung der Oder-Neiße-Linie kam für Schröder allerdings nicht in Frage. Die Problematik der polnischen Westgrenze konnte seiner Überzeugung nach erst im Zuge der Wiederherstellung der Einheit Deutschlands abschließend geregelt werden ${ }^{78}$. Am 23. Dezember beauftragte er den Botschafter der Bundesrepublik in Ankara, Gebhardt von Walther, mit seinem polnischen Kollegen Kontakt aufzunehmen und zu sondieren, ob Warschau an einem Gewaltverzichtsabkommen interessiert sei ${ }^{79}$. Die Antwort fiel allerdings mehr als enttäuschend aus. Die polnische Regierung stellte unannehmbare Vorbedingungen: So sollte Bonn vor Beginn der Verhandlungen die Grenze an Oder und Neiße anerkennen, die Aufnahme diplomatischer Beziehungen mit Warschau beschließen sowie die völkerrechtliche Anerkennung der DDR vollziehen. Polen - so sah es auch von Walther - hatte damit dem Vorhaben des Außenministers „eine klare Absage“ erteilt ${ }^{80}$. Die Tätigkeit der Handelsvertretung in Warschau blieb weiterhin auf wirtschaftliche Fragen beschränkt ${ }^{81}$. Schröder berichtete Mitte Dezember dem amerikanischen Außenminister, daß die Polen die Handelsvertretung „nicht als möglichen Ansatzpunkt für politische Gespräche“ betrachteten und sogar die gesellschaftliche Bewegungsfreiheit ihres Leiters beschnitten ${ }^{82}$.

Ebenfalls problematisch blieb das Verhältnis Bonns zu Jugoslawien. 1957 hatte die Bundesrepublik die diplomatischen Beziehungen abgebrochen, nachdem die jugoslawische Regierung die DDR völkerrechtlich anerkannt hatte. Es bestanden aber zwischen Bonn und Belgrad noch konsularische Beziehungen. Da sich Tito die sowjetische Zwei-Staaten-These zu eigen gemacht hatte und diese auch nach außen offensiv vertrat, blieb die Atmosphäre gespannt. Im Zuge ihrer Entspannungspolitik drängten die USA aber die Bundesregierung, ihr Verhältnis zu Belgrad wieder zu normalisieren. Am 9. April 1964 wandte sich Rusk an Schröder mit der Bitte, die damalige Entscheidung, die Beziehungen abzubrechen, zu überdenken. Bonn solle zudem die jugoslawische Forderung nach Wiedergutma-

76 Vgl. die deutsch-britische Regierungsbesprechung am 15.1. 1964 in London, in: AAPD 1964, Dok. 13, S. 56.

77 Drahterlaß des Bundesministers Schröder an Botschafter von Walther, Ankara, vom 23. 12. 1964, in: ebenda, Dok. 397, S. 1560.

78 Vgl. den Entwurf vom 4. 10. 1964 für die Führung eines Sondierungsgesprächs, PA/AA, B 150, Aktenkopien 1964.

79 Vgl. den Drahterlaß des Bundesministers Schröder an Botschafter von Walther, Ankara, vom 23. 12. 1964, in: ebenda, Dok. 397, S. 1560 f.

80 Aufzeichnung des Botschafters von Walther, z.Z. Bonn, vom 21. 1. 1965, in: AAPD 1965, Dok. 29, S. 165.

81 Vgl. die deutsch-dänische Regierungsbesprechungen am 9./10.6. 1965, in: ebenda, Dok. 238, S. 987.

$82 \mathrm{Vgl}$. das Gespräch des Bundesministers Schröder mit dem amerikanischen Außenminister Rusk am 15. 12. 1965 in Paris, in: ebenda, Dok. 461, S. 1898. 
chungsleistungen in Höhe von 100 Millionen US-Dollar wohlwollend prüfen ${ }^{83}$. Schröder lehnte dies jedoch entschieden ab und verwies auf die fortwährenden politischen Kampagnen Belgrads gegen die Bundesrepublik. Der Außenminister unterstrich zwar sein Interesse an einer Verbesserung des bilateralen Verhältnisses, bezweifelte aber, daß Geld aus Bonn Tito veranlassen könnte, seine Deutschland-Politik zu ändern ${ }^{84}$. Zumindest schloß die Bundesrepublik am 16. Juli 1964 mit Jugoslawien eine Zusatzvereinbarung zum Warenabkommen vom 11. Juni 1952 ${ }^{85}$. Im Zuge der damit verbundenen Ausweitung des beiderseitigen Handels kam es auch zu einer Entkrampfung der politischen Beziehungen, die in einem Besuch von Staatssekretär Lahr Anfang September 1964 in der jugoslawischen Hauptstadt ihren Ausdruck fand. Aus jugoslawischen Regierungskreisen wurde ihm dabei versichert, Belgrad werde mit seiner Interpretation der DeutschlandFrage künftig weder im Kreise der Blockfreien noch in der UNO hausieren gehen ${ }^{86}$.

Einen Sonderfall stellten auch die Verhandlungen über ein Warenabkommen mit der Volksrepublik China dar. Zum einen fanden diese Gespräche, anders als die Kontakte zu den osteuropäischen Staaten, gegen den ausdrücklichen Willen der USA statt, zum anderen verfolgte die Bundesregierung dabei nicht das Ziel, die Errichtung von Handelsvertretungen zu vereinbaren. Da sowohl Taipeh wie Peking den Anspruch erhoben, China zu repräsentieren, wollte sich Bonn nicht zwischen die Stühle setzen und den eigenen Alleinvertretungsanspruch indirekt in Frage stellen. Trotz dieser Problematik war man aber daran interessiert, amtliche Wirtschaftsbeziehungen mit Peking aufnehmen, um der Volksrepublik China wirtschaftlich den Rücken zu stärken und damit zu einer Fortdauer des sowjetisch-chinesischen Konflikts beizutragen. Der chinesische Druck sollte langfristig Moskau dazu bewegen, seine Einstellung zum Westen im allgemeinen und zur Deutschland-Frage im besonderen zu überdenken. Das Nahziel des Auswärtigen Amts war jedoch, die Verhandlungen über ein Handelsabkommen mit der UdSSR positiv zu beeinflussen, falls Peking die Berlin-Klausel akzeptierte. Am Rhein war man zu dem Schluß gekommen, der Kreml sperre sich bislang gegen die Einbeziehung von Berlin (West), um nicht von der chinesischen Regierung beschuldigt zu werden, er gebe kommunistische Positionen auf ${ }^{87}$. Da auch von chinesischer Seite Interesse an einem Wirtschaftsabkommen bestand, sprachen sich der Leiter des Referats „Politische und sozialökonomische Fragen des Ostblocks“ im Auswärtigen Amt, Erwin Wickert, und sein Vorgesetzter, Ministerialdirektor Krapf, dafür

83 Vgl. OSterheld, Außenpolitik, S. 84.

84 Vgl. das Schreiben des Bundesministers Schröder an den amerikanischen Außenminister Rusk vom 22.4.64, in: AAPD 1964, Dok. 107, S. 470-474.

85 Für den Wortlaut der fünften Zusatzvereinbarung vom 16. 7. 1964 vgl. BUNDESANZEIGER, Nr. 17 vom 27. 1. 1965, S. 1-3.

86 Vgl. die Aufzeichnung des Staatssekretärs Lahr vom 8. 9. 1964, in: AAPD 1964, Dok. 243, S. $1001-1003$.

87 Vgl. die Aufzeichnung des Legationsrats I. Klasse Wickert vom 11. 12. 1963, in: AAPD 1963, Dok. 465, S. 1617-1619. 
aus, Sondierungsgespräche einzuleiten ${ }^{88}$. Krapf erwartete, daß ein deutsch-chinesisches Abkommen nicht nur "das Schisma im Ostblock zweifellos vergrößern“, sondern auch das politische Gewicht der Bundesrepublik sowohl in Washington als auch in Moskau stärken würde ${ }^{89}$. Obwohl die Amerikaner das Vorhaben Bonns „zurückhaltend bis negativ" beurteilten, da sie der Ansicht waren, China als engster Verbündeter Vietnams dürfe nicht unterstützt werden ${ }^{90}$, befürwortete Schröder eine Kontaktaufnahme. Mitte Mai 1964 konnte er den Kanzler überzeugen, die Einleitung von Sondierungen zu genehmigen ${ }^{91}$. Ort der Gespräche sollte Bern sein, wo beide Staaten diplomatische Vertretungen unterhielten. Schröder wollte die Sondierungen auf möglichst niedriger Ebene führen und die $\mathrm{Ge}-$ sprächsführung dem Gesandten der Bundesrepublik in Bern, Niels Hansen, übertragen ${ }^{92}$. Krapf dehnte jedoch die Weisung aus und entsandte Wickert in die Schweizer Hauptstadt, damit dieser Hansen zur Seite stand ${ }^{93}$. Schon am 26. Mai 1964 fand das erste Gespräch mit dem chinesischen Botschaftsrat Tsui statt. Dieser wollte wissen, ob die Bundesrepublik damit einverstanden wäre, wenn zur Festlegung des Geltungsbereichs des Abkommens die Bezeichnung "Währungsgebiet DM-West" verwendet würde. Wickert meinte jedoch, dies sei eine Formel, welche die osteuropäischen Staaten mit Rücksicht auf Moskau benützten. Peking sei jedoch in seinen Entscheidungen frei und bräuchte sich um den sowjetischen Standpunkt nicht zu kümmern. Tsui bestätigte dies, sah aber Probleme, falls die Deutschen „Berlin ausdrücklich und obne Umschreibung in einem Abkommen haben wollten"94.

Als sich Mitte Juni 1964 Schröder und Erhard zu politischen Gesprächen in Washington aufhielten, sahen sie sich mit massiver Kritik wegen ihrer Kontakte zu Peking konfrontiert ${ }^{95}$. Rusk gab zu bedenken, die Volksrepublik China könnte eine Handelsvereinbarung als Signal auffassen, ihre Aggressionspolitik fortzusetzen. Schröder war aber fest entschlossen, sich noch in diesem Jahr über den Abschluß eines Abkommens zu verständigen. Er verwies unter anderem auf das starke Interesse Bonns an der Berlin-Klausel96. Dann beging Erhard jedoch einen

88 Vgl. ebenda sowie die Aufzeichnung des Ministerialdirektors Krapf vom 19.5. 1964, in: AAPD 1964, Dok. 131, S. 542-547. Vgl. auch MAJONICA, Bonn - Peking, S. 90.

89 Aufzeichnung des Ministerialdirektors Krapf vom 19.5. 1964, in: AAPD 1964, Dok. 131, S. $544 \mathrm{f}$.

90 Vgl. ebenda, S. 545; sowie das Gespräch des Staatssekretärs Carstens mit Vertretern der Drei Mächte am 12. 5. 1964 in Den Haag, in: ebenda, Dok. 126, S. 528-533.

91 Vgl. WiCKERT, Zwischen Bonn und Peking, S. 117.

$92 \mathrm{Vgl}$. ebenda.

93 ZEITZEUGENBEFRAGUNG Krapf.

94 Aufzeichnung des Ministerialdirektors Krapf vom 30. 5. 1964, in: AAPD 1964, Dok. 143, S. 585-590 (Zitate auf S. 587; Hervorhebung im Original). Vgl. auch WICKERT, Zwischen Bonn und Peking, S. 117 f.; MAJONICA, Bonn - Peking, S. 94-96.

95 McGhee versuchte vergeblich, das State Department von den Vorteilen eines deutsch-chinesischen Handelsabkommens zu überzeugen. Er wies darauf hin, daß dadurch die Isolierung der DDR verstärkt, Ulbrichts Position geschwächt, der chinesisch-sowjetische Gegensatz verschärft und die Position Bonns gegenüber der UdSSR verbessert würde. Vgl. FRUS 1964-1968, XV, Dok. 45, S. $101 \mathrm{f}$.

96 Vgl. ebenda, Dok. 51, S. $119 \mathrm{f}$. 
fatalen Fehler. Er führte am 13. Juni in einer Pressekonferenz in Washington aus, Bonn unterhalte keine Beziehungen zu China und habe bislang keinen Handelsvertrag abgeschlossen; die Bundesregierung denke im Moment auch nicht daran, ihre Haltung gegenüber Peking zu ändern. Anschließend fügte er hinzu, es sei nicht geplant, eine Vereinbarung über den bilateralen Handel zu schließen. Den Buchstaben nach war die Aussage des Kanzlers korrekt, denn es wurde in Bern nicht über ein Handels-, sondern über ein Warenabkommen verhandelt. Die chinesische Regierung mußte allerdings den Eindruck gewinnen, als ob die Bundesrepublik niemals ernsthaft im Sinn gehabt hätte, amtliche Wirtschaftsbeziehungen aufzunehmen, da Erhards Statement wie eine "offizielle Absage an China“ wirkte ${ }^{97}$. In der Tat zeigte sich Tsui am 21. Juli 1964 gegenüber Hansen über die Äußerungen des Bundeskanzlers ungehalten. Nach seiner Ansicht bewiesen sie, daß Bonn sich im Fahrwasser Washingtons befinde und „Peking gegenüber eine feindselige Haltung einnehme “98. Auch die beiden nächsten Gespräche am 3. Oktober und 23. November brachten keine Fortschritte, da sich die chinesische Position völlig verhärtet hatte. Tsui schloß jetzt eine Einbeziehung von Berlin (West) in ein Abkommen strikt aus ${ }^{99}$. Erhard hatte mit seinem Dementi die Chinesen unnötigerweise vor den Kopf gestoßen und damit den Gesprächsfaden zerschnitten ${ }^{100}$. Die Berner Gespräche kamen nicht über das Stadium unverbindlicher Sondierungen hinaus. Rückblickend waren sie nicht mehr als eine Randepisode in den deutsch-chinesischen Beziehungen. Schröder blieb aber Peking als der Mann in Erinnerung, der die Kontaktsperre zwischen Bonn und Peking durchbrach. Sechs Jahre später konnte er deshalb als Vorsitzender des Auswärtigen Ausschusses des Bundestags den Boden zur Aufnahme diplomatischer Beziehungen bereiten ${ }^{101}$.

Anfang 1965 waren also die Sondierungen mit Peking geplatzt, die Verhandlungen mit der ČSSR auf unbestimmte Zeit vertagt und von Polen Gespräche über ein Gewaltverzichtsabkommen abgelehnt worden. Positiver entwickelten sich hingegen die Beziehungen zu Rumänien und Ungarn. Die Durchführung einer Industrieausstellung der Bundesrepublik in Bukarest und die Beteiligung an der Internationalen Messe in Budapest im Mai 1965 wertete Schröder als ein deutliches Zeichen für eine Klimaverbesserung ${ }^{102}$. Es gelang der Bundesregierung allerdings nicht, das ihr von den osteuropäischen Regierungen entgegengebrachte Mißtrauen abzubauen. Diese warfen Bonn vor, es gehe der Bundesrepublik nur vordergründig um eine Entspannung der Atmosphäre, in Wahrheit wolle sie ihre deutschlandpolitischen Positionen durchsetzen. Ende Juni 1965 berichtete Schröder dem Ministerrat der WEU, Budapest und Warschau seien der Ansicht, Bonn bezwecke „das Ausspielen der osteuropäischen Staaten untereinander und gegen

97 Vgl. MajONICA, Bonn - Peking, S. 101.

98 Aufzeichnung des Legationsrats I. Klasse Hansen, Bern, vom 21. 7. 1964, in: AAPD 1964, Dok. 206, S. 871-873 (872).

99 Vgl. MajONICA, Bonn - Peking, S. 110 f.

100 So auch das Urteil von Krapf (ZEITZEUGENBEFRAGUNG Krapf).

$101 \mathrm{Vgl}$. SCHRÖDER, Mission.

102 Vgl. die deutsch-amerikanische Regierungsbesprechung am 2.6. 1965 in Washington, in: ebenda, Dok. 229, S. 934. 
die Sowjetunion" ${ }^{103}$. Es schien, als ob seine Ostpolitik das Gegenteil von dem erreicht hätte, was Schröder beabsichtigte. Wohl um seine Politik wieder ins rechte Licht zu rücken, veröffentlichte der Außenminister in der Herbstausgabe 1965 der amerikanischen Zeitschrift Foreign Affairs einen Artikel, in dem er die offiziellen Ziele der Bonner Osteuropa-Politik darlegte ${ }^{104}$. Die Pläne, die DDR zu isolieren, erwähnte Schröder verständlicherweise nicht. Er bekräftigte in dem Aufsatz zwar das Festhalten der Bundesregierung an der Einheit Deutschlands („Eine wirkliche Entspannung erfordert [...] die Ausübung des Selbstbestimmungsrechts in ganz Deutschland “105), betonte jedoch nachdrücklich, die Ostpolitik der Bundesrepublik solle in erster Linie der Entspannung zwischen Ost und West dienen. Ein vertrauensvolles Verhältnis müßte geschaffen werden, „damit erst die kleineren, dann aber auch die größeren Spannungsherde beseitigt werden können" ${ }^{106}$. Schröder bekannte sich damit zu dem amerikanischen Entspannungskonzept, zunächst die Probleme an der Peripherie in Angriff zu nehmen. Den Vorwurf, die Bundesrepublik plane, den Ostblock auseinanderzudividieren, bestritt er energisch: „Unsere Politik gegenüber den osteuropäischen Staaten ist nicht gegen Moskau gerichtet, noch verfolgt sie den Zweck [...], die Staaten untereinander zu verfeinden oder einen Keil zwischen sie und die Sowjetunion zu treiben. [...] Keine deutsche Regierung wäre so unvernünftig, das ohnehin gespannte deutsch-sowjetische Verhältnis noch zusätzlich dadurch zu belasten, daß sie die osteuropäischen Staaten gegen ihre beherrschenden Nachbarn aufzubringen versucht." 107

Trotz dieser Beteuerungen hielt der Kreml aber weiterhin seine Verbündeten vor einer Annäherung an die Bundesrepublik zurück. Staatssekretär Carstens notierte Mitte Dezember 1965: „Die Sowjetunion mache verstärkte Anstrengungen, die anderen osteuropäischen Staaten auf der Moskauer außenpolitischen Linie zu halten." 108 Die Einmischung der UdSSR vereitelte die Bemühungen der Bundesregierung, in Osteuropa das Verständnis für die Deutschland-Politik Bonns zu fördern. Moskau ließ es sich nicht gefallen, daß Bonn versuchte, die Stellung der DDR, eines Stützpfeilers der sowjetischen Herrschaft in Osteuropa, zu untergraben. So konnten die deutschlandpolitischen Ziele, die Schröder mit der Neuorientierung der Ostpolitik verfolgte, nicht erreicht werden. Auch die Errichtung von Handelsvertretungen hatte Bonn der Einheit Deutschlands nicht näher gebracht.

103 Drahtbericht des Botschafters Blankenhorn, z.Z. Washington, an das Auswärtige Amt vom 30. 6. 1965, in: ebenda, Dok. 264, S. 1098.

104 SCHRÖDER, Germany looks at Eastern Europe. Nachfolgend wird nach der deutschen Übersetzung des Aufsatzes zitiert: DzD IV/11, S. 851-858.

105 Ebenda, S. 854.

106 Ebenda.

107 Ebenda, S. 585. Zuweilen wurde dieses Zitat angeführt, um zu belegen, daß Schröder mit seiner Ostpolitik nicht beabsichtigte, die DDR zu isolieren. Vgl. z.B. HaNRIEDER, Deutschland, S. $184 \mathrm{f}$. Angesichts der zahlreichen Aussagen des Außenministers, in denen er seinen Willen unterstrich, die polyzentristischen Tendenzen im Ostblock für die Bonner Deutschland-Politik auszunutzen, kann diese Zielsetzung wohl nicht bezweifelt werden.

108 Drahtbericht des Staatssekretärs Carstens, z.Z. Paris, an das Auswärtige Amt vom 14. 12. 1965, in: AAPD 1965, Dok 459, S. 1890. 
Obwohl der politische Freiraum der Staaten Ostmittel- und Südosteuropas gewachsen war, mußte der Außenminister zu Kenntnis nehmen, daß hinsichtlich der Wiedervereinigung das ,entscheidende Wort nur Moskau sprechen kann"109. Der Umweg über den Satellitengürtel der UdSSR blieb eine Sackgasse, da auch die osteuropäischen Staaten keinen Zugang zu dem Schlüssel für die Einheit Deutschlands besaßen. „Ohne Zustimmung Moskaus gibt es kein Selbstbestimmungsrecht in der Zone", bemerkte Schröder Anfang Juni 1966 vor dem NATO-Ministerrat und kam damit wieder zu einer realistischen Einschätzung der Machtverhältnisse im Ostblock. Während er noch im November 1964 euphorisch davon gesprochen hatte, daß seine Politik „die ersten Früchte " trage ${ }^{110}$, äußerte er sich eineinhalb Jahre später weitaus zurückhaltender. Er sei mit der Entwicklung seiner Ostpolitik „im großen und ganzen einigermaßen zufrieden“, verkündete er den NATOPartnern. Schröder gab zu, die Bemühungen Bonns seien „nicht überall gleich erfolgreich“ gewesen. Besonders enttäuscht zeigte er sich über den Zustand des deutsch-polnischen Verhältnisses: „Obwohl wir uns um das polnische Volk [...] besonders bemühten, haben wir hier die geringsten Fortschritte gemacht. Die polnische Regierung zeigt sich leider uns und dem deutschen Volk gegenüber unversöhnlich." 111

Wenn auch der Versuch, Deutschland- und Entspannungspolitik miteinander zu verbinden, letztendlich nicht als Erfolg gewertet werden kann, so wäre es dennoch nicht gerechtfertigt, Schröders Osteuropa-Politik als Fehlschlag zu bezeichnen. Mit der Errichtung von Handelsvertretungen hatte der Außenminister die Tür nach Osteuropa geöffnet und der Bundesrepublik ein Terrain erschlossen, in dem die DDR bislang eine Monopolstellung besaß. Die Bundesregierung war in einen Dialog mit den osteuropäischen Regierungen getreten und verfügte nun über die Möglichkeit, im direkten Gespräch ihre politischen Ansichten darzulegen. Die Ostpolitik der Großen Koalition, aber auch der Regierung Brandt/ Scheel, konnte auf die Kontakte, die Schröder in Osteuropa der Bundesrepublik erschlossen hatte, zurückgreifen und auf dem von ihm gelegten Fundament aufbauen.

\section{Keine Auflockerungen im deutsch-sowjetischen Verbältnis}

Am Ende seiner Amtszeit regte Bundeskanzler Adenauer gegenüber den Drei Mächten an, die momentane wirtschaftliche Notlage der Sowjetunion zur Stärkung der eigenen Position auszunutzen. Der Westen sollte der UdSSR nur Hilfen gewähren, wenn der Kreml dafür politische Zugeständnisse machen würde ${ }^{112}$. Adenauer kritisierte explizit die USA, daß sie in großen Mengen Weizen an ihren

109 Rede Schröders vor dem NATO-Ministerrat am 7. 6. 1966, in: BullETIN 1966, S. 643.

110 Gespräch des Bundesministers Schröder mit dem amerikanischen Außenminister Rusk am 23. 11. 1964 in Washington, in: AAPD 1964, Dok. 353, S. 1382.

111 Rede Schröders vor dem NATO-Ministerrat am 7. 6. 1966, in: BULLETIN 1966, S. 643.

112 Vgl. die Ausführungen des Bundeskanzlers Adenauer am 21. 9.1963 in Rambouillet, in: AAPD 1963, Dok. 355, S. 1187-1192. 
ärgsten Gegner lieferten, ohne dafür eine Gegenleistung zu verlangen ${ }^{113}$. Schröder sah in der Idee des Kanzlers eine „verlockende Aussicht“, doch erkannte er, daß der Westen ein Embargo nicht mitmachen würde ${ }^{114}$. Die neue Bundesregierung unter Erhard verfolgte dann auch diesen Gedanken nicht weiter. Adenauer warf deshalb insbesondere Schröder im CDU-Bundesvorstand am 17. Januar 1964 vor, Bonn hätte es versäumt, bei den NATO-Partnern für wirtschaftliche Maßnahmen gegen die UdSSR zu werben ${ }^{115}$. Obwohl die Regierung Erhard sich Adenauers Pläne nicht zu eigen gemacht hatte, führte der sowjetische Botschafter Smirnow den Aufruf des früheren Bundeskanzlers, man müsse die Sowjetunion „aushungern", in einer Unterredung mit Schröder am 5. Dezember 1963 als Beleg für die angeblich kriegerische Politik der Bundesrepublik an ${ }^{116}$. Der Außenminister betonte hingegen die friedlichen Absichten Bonns und warf im Gegenzug dem Kreml vor, er versuche ständig, „die Bundesrepublik als das einzige schwarze Schaf der internationalen Familie hinzustellen". Es sei allein die sowjetische Regierung, die eine Verbesserung der Beziehungen verhindere, weil sie die Teilung Deutschlands aufrechterhalte und den Ostdeutschen das Selbstbestimmungsrecht verweigere. Schröder betonte, die Bundesregierung werde sich dennoch weiterhin bemühen, die Sowjetunion zu überzeugen, daß ein wiedervereinigtes Deutschland auch in ihrem Interesse sei ${ }^{117}$. Am nächsten Tag teilte Erhard dem Botschafter mit, aus humanitären Gründen und um die Entspannungsbemühungen der Supermächte nicht zu stören, habe er sich für Getreidelieferungen an die UdSSR ausgesprochen. Ausdrücklich unterstrich der Kanzler, er wünsche zumindest eine Verbesserung der wirtschaftlichen Beziehungen, wenn schon die politischen Differenzen nicht überwunden werden könnten ${ }^{118}$.

Die neue Bundesregierung verzichtete auf eine Politik der Stärke gegenüber Moskau. Doch die sowjetische Regierung schien nicht an einem sachlichen Gespräch mit Bonn interessiert. Eine lange Erklärung, welche die Nachrichtenagentur TASS am 7. März 1964 veröffentlichte, deutete jedenfalls darauf hin. Darin wurden in aller Ausführlichkeit die bekannten sowjetischen Positionen zum Deutschland-Problem dargelegt und die Regierung Erhard beschuldigt, den gleichen "aggressiv-revanchistischen Kurs“ wie ihre Vorgängerin eingeschlagen zu haben ${ }^{119}$. Vier Tage später übergab Smirnow jedoch zur Überraschung Bonns dem Kanzler ein Aide-mémoire Chruschtschows, in dem auf aggressive Töne verzichtet wurde. Der sowjetische Ministerpräsident regte vielmehr einen intensiven

$113 \mathrm{Vgl}$. das Gespräch des amtierenden Bundeskanzlers Adenauer mit dem ehemaligen amerikanischen Hochkommissar McCloy am 16. 10. 1963, in: ebenda, Dok. 389, S. 1326; sowie das Gespräch des ehemaligen Bundeskanzlers Adenauer mit dem ehemaligen amerikanischen Außenminister Acheson am 18.10. 1963, in: ebenda, Dok. 392, S. 1335.

114 Protokoll der CDU/CSU-Fraktionssitzung am 2. 10. 1963, ACDP VIII-001-1009/3.

$115 \mathrm{Vgl}$. Protokolle des CDU-BundesvorstandS, S. $571 \mathrm{f}$.

116 Gespräch des Bundesministers Schröder mit dem sowjetischen Botschafter Smirnow am 5. 12. 1963, in: AAPD 1963, Dok. 450, S. 1551.

117 Vgl. ebenda, S. 1545-1552 (1547).

118 Vgl. das Gespräch des Bundeskanzlers Erhard mit dem sowjetischen Botschafter Smirnow am 6. 12. 1963, in: AAPD 1963, Dok. 454, S. $1558 \mathrm{f}$.

119 Erklärung der Nachrichtenagentur TASS zur Deutschlandfrage vom 7.3. 1964, in: DzD IV/10, S. 348. 
Meinungsaustausch über alle politischen Fragen an. Wenngleich daraus keine Änderung der sowjetischen Haltung abgelesen werden konnte, werteten die Experten des Auswärtigen Amts die Denkschrift dennoch als „Annäherungsversuch“ und empfahlen, den Faden aufzugreifen ${ }^{120}$. Schröder und Erhard waren dazu bereit und wiesen den Botschafter der Bundesrepublik in Moskau, Horst Groepper, an, das Gespräch mit Chruschtschow zu suchen. Er sollte dabei zunächst den Standpunkt der Bundesregierung zur deutschen Frage erläutern, dann aber dem sowjetischen Ministerpräsidenten die Anregung unterbreiten, mit dem Kanzler ein direktes Gespräch in der Bundesrepublik zu führen ${ }^{121}$. Am 13. Juni erhielt der Botschafter einen Termin im Kreml. Als Groepper das Deutschland-Problem ansprach, lehnte Chruschtschow eine Erörterung ausdrücklich ab: Dies, so erklärte er, sei eine Angelegenheit der beiden deutschen Staaten. Er zeigte sich aber an einer Begegnung mit Erhard interessiert ${ }^{122}$.

Ihm Rahmen einer Unterhaltung mit dem Kanzler am 28. Juli fragte der Schwiegersohn Chruschtschows, Alexej Adschubej, ob auch ein Treffen in Moskau oder an einem neutralen Ort, zum Beispiel in Wien, möglich sei. Erhard entgegnete jedoch, seit dem Aufenthalt Adenauers in Moskau 1955 stünde ein Gegenbesuch aus. Zudem wünsche die Bundesregierung, daß der sowjetische Ministerpräsident persönlich die Lebensverhältnisse in der Bundesrepublik kennenlerne ${ }^{123}$. Dies war in der Tat ein wesentliches Motiv für den Wunsch Bonns nach einem deutsch-sowjetischen Gipfeltreffen. Schröder rechnete nicht damit, daß es gelingen könnte, Chruschtschow unter vier Augen zu einer deutschlandpolitischen Kehrtwende zu veranlassen, wollte ihm aber während eines Aufenthalts in der Bundesrepublik vor Augen führen, daß die Deutschen sich nicht mit der Teilung ihres Landes abfinden werden ${ }^{124}$. Am 2. September überbrachte Smirnow dem Chef des Bundeskanzleramts, Ludger Westrick, die Nachricht, der sowjetische Ministerpräsident nehme die Einladung zu einem Besuch in der Bundesrepublik an ${ }^{125}$. Doch aufgrund der Absetzung Chruschtschows am 14. Oktober 1964 kam die Reise nicht zustande. Seine Entmachtung stand in keinem Zusammenhang mit der geplanten Reise in die Bundesrepublik, wie in Bonn verschiedentlich gemutmaßt wurde ${ }^{126}$. Sowohl Erhard wie Schröder betonten, die Einladung gelte auch für den Nachfolger Chruschtschows ${ }^{127}$. Am 23. Februar 1965 überreichte

120 Aufzeichnung des Ministerialdirigenten Reinkemayer vom 1.4. 1964, in: AAPD 1964, Dok. 84, S. 383-386 (386).

121 Vgl. den Entwurf für einen Sprechzettel für Botschafter Groepper, Moskau, vom 8. 6. 1964, in: ebenda, Dok. 155, S. 635-630.

122 Vgl. das Gespräch des Botschafters Groepper mit Ministerpräsident Chruschtschow am 13. 6. 1964 in Moskau, in: ebenda, Dok. 162, S. 659-667.

123 Vgl. das Gespräch des Bundeskanzlers Erhard mit Chefredakteur Adschubej am 28. 7. 1964, in: ebenda, Dok. 212, S. $903 \mathrm{f}$.

124 Vgl. das Interview Schröders mit der dpa am 1. 9. 1964, in: Bulletin 1964, S. 1270.

125 Vgl. ebenda, S. 1269.

126 Vgl. OSTERHELD, Außenpolitik, S. 115. Zu den Gründen für Chruschtschows Sturz vgl. HACKER, Der Ostblock, S. 706 mit Anm. 151.

127 Vgl. das Gespräch des Bundeskanzlers Erhard mit dem sowjetischen Botschafter Smirnow am 16.10. 1964, in: AAPD 1964, Dok. 286, S. 1160; Rede Schröders vor dem NATO-Ministerrat am 15. 12. 1964, in: BULLETIN 1964, S. 1728. 
Groepper dem neuen sowjetischen Ministerpräsidenten, Alexej Kossygin, sogar ein persönliches Einladungsschreiben des Bundeskanzlers. Kossygin bekundete Interesse, meinte aber, es seien zunächst noch einige Fragen zu klären ${ }^{128}$. Eine offizielle Antwort erhielt die Bundesregierung allerdings nicht. Mitte Juni stellte Erhard schließlich deprimiert fest, sein Schreiben sei offensichtlich „in den $\mathrm{Pa}$ pierkorb gewandert" 129 .

Während am Ende der Ära Chruschtschow zumindest ein Gipfelgespräch im Bereich des Möglichen lag, verschlechterten sich die bilateralen Beziehungen unter der Doppelführung Breschnew/Kossygin, da der Kreml eine regelrechte „Diffamierungskampagne" gegen Bonn anzettelte ${ }^{130}$. Ein wirklicher politischer $\mathrm{Ge}$ dankenaustausch konnte in dieser vergifteten Atmosphäre nicht stattfinden. Die Gespräche mit dem sowjetischen Botschafter Smirnow und seinem Nachfolger Zarapkin blieben für Bonn völlig unbefriedigend. Wie Carstens rückblickend feststellte, beschränkten sich die Unterhaltungen darauf, daß jede Seite monoton ihren Standpunkt zur deutschen Frage vortrug ${ }^{131}$. Auch die von Erhard angeregte Intensivierung der wirtschaftlichen Beziehungen konnte nicht realisiert werden. Am 31. Dezember 1963 lief das drei Jahre zuvor geschlossene Abkommen über den Waren- und Zahlungsverkehr aus ${ }^{132}$. Eine neue Vereinbarung scheiterte, weil die Sowjetunion eine Einbeziehung Berlins rigoros ablehnte ${ }^{133}$. Gespräche über ein Handels- und Kulturabkommen kamen deswegen ebenfalls nicht zustande. Erst am 4. Oktober 1966 konnten Verhandlungen über ein neues Handelsabkommen aufgenommen werden, obwohl der Kreml im Vorfeld weiterhin unmißverständlich hervorhob, daß er die Berlin-Klausel nicht akzeptieren werde ${ }^{134}$. Auch auf das in der sogenannten Friedensnote der Bundesregierung vom 25. März 1966 enthaltene Angebot zum Austausch von Gewaltverzichtserklärungen ging Moskau nicht ein ${ }^{135}$. Der Kreml verlangte statt dessen, Bonn solle endlich „die Realitäten anerkennen" und die Anerkennung der DDR aussprechen. Wie Semjon Konstantinowitsch Zarapkin am 24. Oktober 1966 gegenüber Carstens erklärte, sei nur so "eine Normalisierung der Beziehungen möglich"136.

128 Drahtbericht des Botschafters Groepper, Moskau, an Bundesminister Schröder vom 23. 2. 1965, in: AAPD 1965, Dok. 94, S. 394-402.

129 Gespräch des Bundeskanzlers Erhard mit Staatspräsident de Gaulle am 12.6. 1965, in: ebenda, Dok. 246, S. 1030.

130 HACKE, Weltmacht, S. 122.

131 Vgl. CARSTENS, Erinnerungen, S. 293.

132 Für den Wortlaut des Abkommens vom 31. 12. 1960 zwischen der Bundesrepublik und der UdSSR über den Waren- und Zahlungsverkehr vgl. BUNDESANZEIGER, Nr. 12 vom 18. 1. 1961, S. 1-3.

133 Vgl. den Drahtbericht des Botschafters Groepper, Moskau, an das Auswärtige Amt vom 22. 1. 1964, in: AAPD 1964, Dok. 19, S. 107-109.

$134 \mathrm{Vgl}$. die Aufzeichnung des Botschafters Emmel vom 29.9. 1966, in: AAPD 1966, Dok. 306, S. 1278f.; sowie die Aufzeichnung des Ministerialdirektors Harkort vom 10. 10. 1966, in: ebenda, Dok. 318, S. 1321-1323.

135 Dazu mit Nachweisen HaCKER, Der Ostblock, S. 757, Anm. 131. Auf die Note vom 25. 3. 1966 wird später noch ausführlich eingegangen.

136 Aufzeichnung des Staatssekretärs Carstens vom 24. 10. 1966, in: AAPD 1966, Dok. 349, S. 1430 f. Die Friedensnote vom 25. 3. 1966 initiierte aber zumindest einen Notenwechsel zwischen Bonn und Moskau (vgl. HACKER, Der Ostblock, S. 757, Anm. 131), der bis zum 
Das einzige bedeutsamere Ereignis in den bilateralen Beziehungen während der Regierungszeit Erhards war der Aufenthalt von Staatssekretär Carstens vom 20. bis 27. September 1965 in der Sowjetunion. Auf Wunsch Schröders und Erhards nahm er im Namen der Bundesregierung am „Deutschen Tag“ der Internationalen Ausstellung "Chemie in Industrie, Bauwesen und Landwirtschaft" in Moskau teil. Carstens war damit der höchste politische Vertreter der Bundesrepublik in der UdSSR seit dem Moskau-Besuch Adenauers im Jahr 1955. Der Staatssekretär führte mehrere Gespräche mit sowjetischen Politikern aus der zweiten Reihe, darunter der Stellvertretende Außenminister Wassilij Wassiljewitsch Kusnezow. Verständlicherweise vermochte er in Moskau nicht viel mehr auszurichten, als das Interesse Bonns an einer Verbesserung der Beziehungen zu bekräftigen ${ }^{137}$. Auf seine Frage, ob die UdSSR bereit wäre, im Falle eines Verzichts auf eine nukleare Teilhabe der Bundesrepublik über die Wiedervereinigung zu sprechen, reagierten seine Gesprächspartner zunächst nicht und bezeichneten dann ein solches Junktim als „erpresserisch“ 138 .

Obwohl die Regierung Erhard einen harten Kurs gegenüber der Sowjetunion vermied, zeichnete sich keine Annäherung zwischen Moskau und Bonn ab. Trotz aller Beteuerungen der Bundesregierung, sie wünsche eine Verbesserung der Beziehungen, gab es keine gemeinsame Basis für eine Verständigung, geschweige denn eine Gesprächsgrundlage. Bonn verlangte von den sowjetischen Machthabern, der ostdeutschen Bevölkerung das Selbstbestimmungsrecht zu gewähren, diese wiederum forderten die Bundesrepublik auf, die Teilung Deutschlands anzuerkennen. So blieb die Atmosphäre zwangsläufig "gespannt und kühl“, wie der sowjetische Außenminister Gromyko am 6. Juni 1966 gegenüber dem Nachfolger Groeppers, Botschafter von Walther, zutreffend das bilaterale Verhältnis charakterisierte ${ }^{139}$.

Sommer 1968 fortgesetzt wurde. Am 12.7. 1968 wurde er von der sowjetischen Regierung „entgegen den Vereinbarungen publiziert, brüsk abgebrochen und damit beerdigt“. Vgl. AllardT, Politik vor und hinter den Kulissen, S. 325.

137 Vgl. CARSTENS, Erinnerungen, S. 294-300; Gespräch des Staatssekretärs Carstens mit dem sowjetischen Ersten Stellvertretenden Außenminister Kusnezow am 22. 9. 1965 in Moskau sowie die Aufzeichnung des Staatssekretärs Carstens vom 30. 9. 1965, in: AAPD 1965, Dok. 361, S. 1476-1490, bzw. Dok. 373, S. 1542-1546.

138 Aufzeichnung des Staatssekretärs Carstens vom 9.2. 1966, in: AAPD 1966, Dok. 38, S. 186.

139 Drahtbericht des Botschafters von Walther, Moskau, an das Auswärtige Amt vom 6.6. 1966, in: ebenda, Dok. 181, S. 766. 


\section{Die Bundesregierung in der deutschlandpolitischen Defensive}

\section{Die weiteren Bemühungen um eine deutschlandpolitische Initiative der Westmächte}

Die neue Bundesregierung erklärte in ihrer ersten Regierungserklärung am 18. Oktober 1963, es bleibe ihre Aufgabe, „immer erneut die Aufmerksamkeit der Welt auf die ungelöste deutsche Frage zu lenken“. Die Teilung Deutschlands sei nach wie vor „eine der Hauptursachen für die Spannungen in der Welt" 1 . Im Auswärtigen Amt war man sich bewußt, wie schwer die Realisierung dieses Vorhabens sein würde. Die Weltöffentlichkeit war der deutschen Querelen überdrüssig. Ungeachtet dieser „Ermüdungserscheinungen“ wollte Schröder alle Anstrengungen unternehmen, um das Interesse an der deutschen Frage wachzuhalten ${ }^{2}$. Die in den letzten Monaten der Regierungszeit Adenauers gemachten Erfahrungen hatten gezeigt, daß selbst die Verbündeten Bonns das Problem der Teilung Deutschlands zunehmend ignorierten. Vor allem Washington und London scheuten sich, eine in ihren Augen von Anfang an zum Scheitern verurteilte deutschlandpolitische Initiative zu unterstützen und dadurch eventuell die Spannungen zwischen West und Ost zu einem Zeitpunkt anzuheizen, da man mit der Unterzeichnung des Atomteststopp-Abkommens eine Phase der Entspannung zwischen Ost und West eingeleitet $z u$ haben glaubte. Trotz des bereits geschilderten Reinfalls des Auswärtigen Amts mit dem Deutschland-Plan vom August 1963 zögerte Schröder nicht, die Drei Mächte weiterhin deutschlandpolitisch in die Pflicht zu nehmen $^{3}$. Selbst wenn „im Augenblick eine positive Deutschlandpolitik noch nicht möglich sei“, kam es nach seiner Überzeugung darauf an, zumindest einer Verschlechterung der Ausgangslage entgegenzuwirken. Dies hielt er auch im Hinblick auf die Moral der Menschen in Berlin und Ostdeutschland für notwendig4. Die Bundesregierung sah sich zudem aus innenpolitischen Gründen genötigt, die deutsche Frage nicht ruhen zu lassen. Vor allem die FDP drängte auf eine deutschlandpolitische Initiative ${ }^{5}$. Aber auch die Aktivitäten Brandts bereiteten Schröder Kopfzerbrechen. In den im Spätherbst 1963 aufgenommenen Passierschein-Verhandlungen zwischen dem Berliner Senat und Ost-Berlin, die im Mittelpunkt des

1 BT StenOgRAPHISCHE BeRICHTE, Bd. 53, S. $4194 \mathrm{f}$.

2 Runderlaß des Bundesministers Schröder vom 6. 1. 1964, in: AAPD 1964, Dok. 4, S. 15$18(15)$.

3 Vgl. Couve de Murville, Außenpolitik, S. 220.

${ }^{4}$ Gespräch des Bundesministers Schröder mit dem britischen Außenminister Butler am 9. 12. 1963, in: AAPD 1963, Dok. 459, S. 1586.

5 Vgl. das Gespräch des Bundesministers Schröder mit dem britischen Außenminister Butler am 16. 1. 1964 in London, in: AAPD 1964, Dok. 15, S. 75. So präsentierte der Vorsitzende des FDP-Landesverbandes von Berlin (West), William Borm, am 30. 11. 1963 einen Deutschland-Plan, dessen Kern die Einrichtung eines Vier-Mächte-Organs zur Erörterung der deutschen Frage war. Für den Wortlaut des Borm-Plans vgl. DzD IV/9, S. 960964. Schließlich forderte am 9.1.1964 die FDP-Bundestagsfraktion von der Bundesregierung verstärkte deutschlandpolitische Aktivitäten. Vgl. BT STENOGRAPHISCHE BERICHTE, Bd. 54, S. 4898 f. 
folgenden Kapitels stehen, sah er eine Gefährdung der Deutschland-Politik der Bundesregierung: „In Berlin gebe es Bestrebungen, eine andere Politik einzuführen“, warnte er Anfang Dezember 1963 den britischen Außenminister Butler. Die Präsentation eines neuen Deutschland-Plans sei "vielleicht die einzige Chance“, daß die Bundesregierung ihr Monopol in der Deutschland-Politik noch verteidigen könné.

Angesichts der Entwicklungen in Berlin rief Schröder die Westmächte auf, einer neuen deutschlandpolitischen Initiative ihren Segen zu geben. Am 15. Dezember 1963 griff er auf dem traditionellen Treffen mit den Außenministern der Drei Mächte am Vorabend einer NATO-Ministerratstagung einen Gedanken aus der Regierungserklärung vom 18. Oktober 1963 auf und regte an, der UdSSR die Einrichtung eines Ständigen Rats der Vier Mächte vorzuschlagen. Dieses Gremium sollte nach dem Vorbild der in der Saar-Frage zwischen der Bundesrepublik und Frankreich gefundenen Lösung einen Zeitplan für die Wiedervereinigung erstellen, sowie Maßnahmen zur europäischen Sicherheit entwerfen. Nach den Vorstellungen Schröders hatte der Vier-Mächte-Rat vorrangig ein Gesetz für die Abhaltung von Wahlen zu einem gesamtdeutschen Parlament auszuarbeiten, über dessen Annahme dann per Volksabstimmung zu entscheiden war. Außerdem regte der Außenminister an, in dem Gremium ein Schlichtungsverfahren für den Fall zu konzipieren, daß sich die Vier Mächte nicht auf einen gemeinsamen Entwurf einigen konnten. Das Gremium sollte ferner innerdeutsche Kommissionen einsetzen, die über humanitäre und wirtschaftliche Sofortmaßnahmen zur Linderung der aus der Teilung Deutschlands resultierenden Probleme zu beraten hatten ${ }^{7}$. Der Vorschlag basierte also auf dem ursprünglichen Konzept der Bundesregierung, drei gesamtdeutsche Kommissionen unter Aufsicht der Vier Mächte arbeiten zu lassen, stellte aber durch die Einberufung eines ständigen Gremiums der Vier Mächte, unter dessen Dach die Kommissionen tätig werden sollten, die VierMächte-Verantwortung für Gesamtdeutschland deutlicher heraus ${ }^{8}$. Schröder ersuchte Butler, Couve de Murville und Rusk, den Vier-Mächte-Rat als zentrales Element in einen neuen Friedensplan für Deutschland aufzunehmen, der die Position des Westens zur deutschen Frage zusammenfassend aufzeigte. Es war vor-

6 Gespräch des Bundesministers Schröder mit dem britischen Außenminister Butler am 16. 1. 1964 in London, in: AAPD 1964, Dok. 15, S. 75.

7 Vgl. das Gespräch des Bundesministers Schröder mit den Außenministern der Drei Mächte, Butler, Couve de Murville und Rusk, am 15.12. 1963 in Paris, in: AAPD 1963, Dok. 473, S. 1640 f.; sowie die deutsch-britische Regierungsbesprechung am 15.1. 1964 in London, in: AAPD 1964, Dok. 13, S. 52 f. Der Gedanke, daß sich die Kommissionen mit humanitären Fragen beschäftigen sollten, ging auf einen Vorschlag des Kuratoriums Unteilbares Deutschland zurück, den es am 30.9.1963 der Menschenrechtskommission der UNO unterbreitet hatte. Für den Wortlaut vgl. DzD IV/9, S. 733-735. Zur Diskussion des Memorandums im Kabinett vgl. das Schreiben des Bundesministers Schröder an den CDU/CSU-Fraktionsvorsitzenden von Brentano vom 23.10.1963, in: AAPD 1963, Dok. 400, S. 1380-1382. Schließlich griff die Bundesregierung den Gedanken in ihrer Regierungserklärung vom 18. 10. 1963 auf. Vgl. BT STENOGRAPHISCHE BERICHTE, Bd. 53, S. 4195.

8 Vgl. die deutsch-britische Regierungsbesprechung am 15.1. 1964 in London, in: AAPD 1964, Dok. 13, S. 53. 
gesehen, den Plan entweder ohne weitere Verzögerung der UdSSR zu übermitteln oder für den Fall, daß Moskau eine neue Kampagne zur deutschen Frage entfachen würde, in Reserve zu halten'.

Die Reaktionen auf Schröders Idee waren anfangs nicht ausdrücklich ablehnend. Rusk stimmte spontan der Aufnahme von Beratungen in der Washingtoner Botschaftergruppe $\mathrm{zu}^{10}$. Doch Lyndon B. Johnson, der nur wenige Wochen zuvor, am 22. November 1963, nach der Ermordung Kennedys das Präsidentenamt übernommen hatte, zeigte wenig Neigung, sich mit dem komplexen Deutschland-Problem zu beschäftigen. Dies erfuhren Erhard und Schröder, als sie Ende Dezember $1963 \mathrm{zu}$ Besprechungen in die texanische Heimat des neuen Präsidenten reisten. Als der Kanzler am 29. Dezember 1963 Johnson seine Vorstellungen zur Lösung der deutschen Frage erläutern wollte, brüskierte ihn dieser und verließ das Besprechungszimmer, noch bevor dessen Ausführungen zu Ende übersetzt waren ${ }^{11}$. Anschließend deutete Rusk an, daß die USA nicht die Initiative zu Gesprächen über das geteilte Deutschland ergreifen wollten ${ }^{12}$. Er hielt Verhandlungen mit der Sowjetunion für sinnlos, da man „bald auf einen toten Punkt“ käme. Statt dessen sollte man gegenüber der UdSSR vorerst nur „ein oder zwei“ humanitäre Probleme ansprechen. Obendrein war der amerikanische Außenminister skeptisch, ob die ostdeutsche Bevölkerung im Fall einer Volksabstimmung tatsächlich für die Wiedervereinigung votieren würde ${ }^{13}$.

Trotz der sichtlichen Vorbehalte der USA übergab Bonn den Drei Mächten am 15. Januar 1964 eine revidierte Fassung des Deutschland-Plans vom August 1963, in die die neuen Vorschläge der Bundesregierung eingearbeitet worden waren ${ }^{14}$. Erwartungsgemäß fiel die britische und die amerikanische Reaktion sehr abweisend aus. Butler bemängelte vor allem, daß in dem Plan von einem Heimatrecht der Vertriebenen die Rede war. Er unterstellte der Bundesregierung, auf diesem Weg eine „deutsche Wiederbevölkerung “ der ehemaligen Ostgebiete des Deutschen Reichs anzustreben ${ }^{15}$. Der britische Außenminister stellte unmißverständ-

9 Vgl. das Gespräch des Bundesministers Schröder mit den Außenministern der Drei Mächte, Butler, Couve de Murville und Rusk, am 15.12. 1963 in Paris, in: AAPD 1963, Dok. 473, S. 1640-1645.

10 Vgl. ebenda, S. 1642.

11 Vgl. das Gespräch des Bundeskanzlers Erhard mit Präsident Johnson am 29.12. 1963 in Stonewall, Texas, in: ebenda, Dok. 490, S. 1701-1708.

12 Vgl. die deutsch-amerikanische Regierungsbesprechung am 29.12. 1963 in Stonewall, Texas, in: ebenda, Dok. 491, S. 1708-1711.

13 Ebenda, S. 1709. Seine Zweifel hinsichtlich des Wiedervereinigungswillens der Menschen in der DDR wiederholte Rusk am 5.6.1964 gegenüber Botschafter Knappstein. Vgl. den Drahtbericht des Botschafters Knappstein, Washington, an das Auswärtige Amt vom 5. 6. 1964, in: AAPD 1964, Dok. 152, S. $605 \mathrm{f}$.

14 Für den Wortlaut der Deutschland-Initiative (erste Fassung) vom 3.1. 1964 vgl. AAPD 1964, Dok. 3, S. 10-15. Der Plan wurde am 15.1.64 der Washingtoner Botschaftergruppe vorgelegt. Anschließend berichtete Knappstein nach Bonn, die Initiative wäre überaus reserviert aufgenommen worden Vgl. den Drahtbericht des Botschafters Knappstein, Washington, an das Auswärtige Amt vom 15. 1. 1964, PA/AA, B 150, Aktenkopien 1964. Vgl. auch den Artikel „Bonn legt Deutschland-Plan vor“, in: DIE WELT vom 16.1. 1964, S. 1 f.

15 Deutsch-britische Regierungsbesprechung am 15.1. 1964 in London, in: AAPD 1964, Dok. 13, S. 53. 
lich fest: „Bisher war unter Wiedervereinigung begrifflich nur die Vereinigung der Bundesrepublik Deutschland und der DDR gedacht. Weiteres war mit dem Begriff Wiedervereinigung nicht verbunden." Erhard beteuerte jedoch, das Problem der deutschen Ostgrenze würde von einer gesamtdeutschen Regierung in einem Friedensvertrag ,in durchaus versöhnlichem Geiste geregelt werden“. Bonn sei es aber nicht möglich, vor einer Friedenskonferenz schon einen endgültigen Gebietsverzicht auszusprechen ${ }^{16}$. In London vermutete man, daß der Bundesregierung sehr wohl bewußt war, daß zur Zeit keine Aussichten auf Fortschritte zur Überwindung der Teilung Deutschlands bestanden, sie aber aus innenpolitischen Gründen die Westmächte vor ihren Karren spannen wollte. Schröder gab zu, dem Plan liege auch die Intention zugrunde, der SPD wieder die Initiative in der Deutschland-Politik abzunehmen, wies aber zugleich darauf hin, daß der Westen über eine gemeinsame Position verfügen müßte, falls die UdSSR von sich aus die deutsche Frage wieder ins Spiel bringe. Außerdem würde die Unterstützung des Planes durch die Drei Mächte signalisieren, daß es zwischen der Bundesrepublik und ihren Verbündeten keine Differenzen in der Deutschland-Politik gebe ${ }^{17}$. Diese Argumente überzeugten das Foreign Office allerdings nicht. Butler verlangte von der Bundesregierung, sie müßte sich „konstruktiver" verhalten ${ }^{18}$.

Auch die amerikanische Regierung hielt eine deutschlandpolitische Initiative zum momentanen Zeitpunkt für "nicht zweckmäßig“19. Die Vereinigten Staaten befürchteten, daß die UdSSR ihre Passivität an der sensiblen Grenze in Mitteleuropa beenden und die Spannungen in Berlin wieder anheizen könnte, wenn der Westen das Deutschland-Problem wieder in den Vordergrund rückte ${ }^{20}$. Gegenüber dem britischen Botschafter in Washington, Lord Harlech, beklagte Rusk, er habe sich seit mehreren Jahren bemüht, die Berlin- und Deutschland-Frage aus den Schlagzeilen der Weltpolitik zu bringen. Ausgerechnet jetzt, da dies gelungen sei und auch ein Modus vivendi in Berlin existiere, wollten nun die Deutschen das Thema wieder auf den Titelseiten sehen 21 ! Nach Einschätzung der amerikanischen Deutschland-Experten war in der von Bonn vorgeschlagenen westlichen Initiative nichts enthalten, was die UdSSR interessieren könnte. Es sei, so stellte David Klein vom Nationalen Sicherheitsrat in einer Aufzeichnung für den Sicherheitsberater des Präsidenten, Bundy, fest, der falsche Vorschlag in der falschen Form zum falschen Zeitpunkt. Er sprach sich daher dafür aus, die Bundesrepublik sollte in eigener Verantwortung mit ihrem Deutschland-Plan vor die Öffentlichkeit treten. Die sowjetische Regierung könnte ihn dann so behandeln, wie er es verdient hätte ${ }^{22}$. Klein äußerte sich bei dieser Gelegenheit tief enttäuscht über

16 Ebenda, S. 54.

17 Vgl. das Gespräch des Bundesministers Schröder mit dem britischen Außenminister Butler am 16. 1. 1964 in London, in: ebenda, Dok. 15, S. $74 \mathrm{f}$.

18 Aufzeichnung des Ministerialdirektors Sachs vom 28.4. 1964, in: ebenda, Dok. 113, S. 491.

19 Drahterlaß des Ministerialdirektors Krapf an die Botschaft in Washington vom 24.2. 1964, in: ebenda, Dok. 53, S. 266.

20 Vgl. ebenda sowie die Botschafterkonferenz am 21. 4. 1964, in: ebenda, Dok. 105, S. 465.

21 Vgl. FRUS 1964-1968, XV, Dok. 29, S. 66.

22 "The German proposal in its present form is not only uninteresting and unsatisfactory; as 
Schröders Außenpolitik: Anders als nach dem Rücktritt Adenauers zu erwarten gewesen sei, hätte dieser nicht die Kontrolle über den außenpolitischen Kurs Bonns erlangt: „In fact, under continuous attack from the right (Adenauer, Strauß, Krone, et al.), distrusted by segments of his own party, lacking Erhard's full support, having no personal political following, and losing foreign policy initiatives to Willy Brandt, Schröder's performance for the past months has been halting, ragged and unimpressive. "23 McGhee kam ebenfalls zu dem Schluß, Schröder sei es wichtiger, den Anschein von Aktivität zu erwecken, als wirklichen Fortschritt zu erzielen. Dies, so urteilte der Botschafter, sei beinahe ein Markenzeichen der Regierung Erhard ${ }^{24}$. Natürlich blieben diese vernichtenden Urteile über den Außenminister und die Deutschland-Initiative Bonns unter Verschluß. Doch auch für die Beobachter im Auswärtigen Amt war augenscheinlich, daß die USA deutschlandpolitisch eine „Politik des Immobilismus" bevorzugten 25 .

Die von den USA angeregte Alternative, den Plan selbst zu veröffentlichen und die Drei Mächte anschließend aufzufordern, auf der Grundlage der Initiative der Bundesregierung Verhandlungen mit Moskau aufzunehmen, kam für Schröder nicht in Frage. Der Außenminister wollte den Deutschland-Plan nicht ohne die Rückendeckung durch die Westmächte publizieren, da er eine negative Reaktion befürchtete: „Der Inhalt des Planes würde der Öffentlichkeit altbekannt vorkommen, und die Presse werde ihn zerreden, bevor die Sowjets geantwortet hätten. Wenn die Westmächte ihn dann nur lau unterstützen, könnte der Eindruck entstehen, die Initiative sei gescheitert."26 Eine gemeinsame Präsentation durch die Bundesrepublik, Frankreich, Großbritannien und den USA hätte hingegen eine „sehr viel größere Wirkung“. Er gab deshalb die Devise aus, notfalls eben länger als vorgesehen mit den Drei Mächten zu verhandeln ${ }^{27}$. Offensichtlich erwartete er, daß die Vereinigten Staaten schließlich doch dem Wunsch der Bundesregierung entsprechen würden. Die amerikanischen Bedenken, der Plan könnte ein Wiederaufflammen der Berlin-Krise provozieren, nahm er nach eigenem Bekunden "nicht so besonders ernst“28. Er versuchte deshalb weiterhin, Briten und Amerikaner zu überzeugen, eine Antwort auf die sowjetische Propaganda, die die deutschlandpolitischen Positionen des Kreml gebetsmühlenhaft wiederhole, sei dringend erforderlich. "Wenn der Westen auf diese politische und psychologische Offensive verzichte und sich nur zum Stillschweigen entschließe, dann verliere er unweigerlich Boden“, appellierte er am 16. April 1964 an Butler. Die eigene Posi-

a Western initiative, it would be the wrong kind of proposal, in the wrong form, at the wrong time. It has nothing of interest to the Soviets and there is nothing to indicate that the Soviets would be receptive to such a gesture. Its potential mileage is absolutely zero. [...] As an allied proposal, it makes almost no sense. As a German product, we could pass it off as a Bonn initiative, sympathetically supported by the allies, which the Soviets, in turn, could treat for what it was worth." Vgl. ebenda, Dok. 30, S. 69.

23 Vgl. ebenda, S. 68 .

24 Vgl. ebenda, Dok. 71, S. 168.

25 Drahterlaß des Ministerialdirektors Krapf an die Botschaft in Washington vom 24.2. 1964, in: AAPD 1964, Dok. 53, S. 266.

26 Vgl. die Botschafterkonferenz am 21. 4. 1964, in: ebenda, Dok. 105, S. 464.

27 Ebenda, S. 466.

28 Ebenda, S. 465. 
tion lasse sich nicht halten, wenn „man immer nur schweige, während die Sowjets ständig redeten und Vorschläge machten". Es sei daher an der Zeit, Moskau mit einem neuen Plan zu konfrontieren. Ausdrücklich hob er hervor, es gehe ihm dabei nicht um Stimmungsmache, sondern um die „Wahrung von Rechtspositionen und grundlegender Prinzipien “29. Um seiner Forderung Nachdruck zu verleihen, erklärte Schröder, eine Unterstützung des Deutschland-Plans durch die Drei Mächte sei die Voraussetzung für eine Beteiligung der Bundesrepublik an der westlichen Entspannungspolitik. Nur wenn die Bundesregierung die Gewißheit habe, daß der Westen das Ziel der Einheit Deutschlands weiterverfolge, könne sie die Verständigungsbemühungen mit dem Ostblock gutheißen, machte er seinem britischen Amtskollegen klar ${ }^{30}$.

Für die Vereinigten Staaten war aber die Deutschland-Frage im Moment nur ein nachrangiges Problem der internationalen Politik. In seiner Rede in Lexington am 23. Mai 1964 bestätigte Präsident Johnson seine Absicht, zunächst über die peripheren Probleme im Ost-West-Verhältnis mit dem Kreml eine Verständigung zu erzielen, bevor eine derart komplexe Aufgabe wie die Lösung der deutschen Frage in Angriff genommen werden sollte. Mit dieser Rede Johnsons hatte sich die Reihenfolge der außenpolitischen Aufgaben der USA auch offiziell geändert ${ }^{31}$. Kein Wunder, daß es für Bonn immer schwieriger wurde, Unterstützung für die These zu finden, die Teilung Deutschlands sei die Ursache für die Spannungen zwischen West und Ost ${ }^{32}$. Die Bundesregierung befand sich in einer Sackgasse: Indem sie eine Behandlung des Deutschland-Problems anmahnte, geriet sie in die Rolle eines Störenfrieds der internationalen Entspannungsbemühungen. Andererseits widersprach es ihrem Selbstverständnis, die deutsche Frage ruhen zu lassen. Kontroversen mit Washington waren somit praktisch unausweichlich.

Der deutschlandpolitische Dissens wurde bei den Beratungen der drei westlichen Außenminister mit ihrem Bonner Amtskollegen am 11. Mai 1964 in Den Haag im Rahmen der NATO-Ministerratstagung erneut offenkundig ${ }^{33}$. Schröder bemühte sich, Rusk nochmals vom Nutzen einer Initiative zur Lösung der deutschen Frage zu überzeugen. Er war der Meinung, es würde als eine Bestätigung der Auffassung Gromykos, Bonn blockiere die Entspannung ${ }^{34}$, aufgefaßt werden, falls der Westen der Bundesrepublik die Solidarität verweigerte. Seiner Ansicht nach bestand keine Notwendigkeit, auf die Vorlage eines Deutschland-Plans zu verzichten. Selbst wenn die Sowjetunion nicht auf den Plan einginge, wäre die In-

29 Gespräch des Bundesministers Schröder mit dem britischen Außenminister Butler am 16. 4. 1964 in Brüssel, in: ebenda, Dok. 99, S. 434.

30 Vgl. ebenda, S. 435.

31 Vgl. OSTERHELD, Außenpolitik, S. 86.

32 Vgl. die Botschafterkonferenz am 21. 4. 1964, in: AAPD 1964, Dok. 106, S. 468 f.

33 Vgl. das Gespräch des Bundesministers Schröder mit den Außenministern der Drei

Mächte, Butler, Couve de Murville und Rusk, am 11. 5. 1964 in Den Haag, in: ebenda, Dok. 124, S. 519-525.

34 In einer Rede am 19.9. 1963 vor der UNO-Generalversammlung warf der sowjetische Außenminister der Bundesrepublik vor, eine feindselige Politik gegen die DDR zu betreiben und damit den Ost-West-Konflikt zu schüren. Die Politik der Bundesregierung, so Gromyko, sei eine der „Hauptursachen der gegenwärtigen Spannungen in Europa“. Vgl.

DzD IV/9, S. 711. 
itiative kein Fehlschlag, da zumindest die Einigkeit des Westens gestärkt würde. Außerdem müsse, so erläuterte Schröder, seine Osteuropa-Politik durch eine deutschlandpolitische Initiative ergänzt werden. Beides seien nämlich „zusammenpassende Stücke derselben Politik “35. Rusk wiederholte jedoch monoton, es gebe im Moment keine Basis für Gespräche mit Moskau über die deutsche Frage. Entschieden wies er die Auffassung der Bundesregierung zurück, die Wiedervereinigung sei die Voraussetzung für eine echte Politik der Entspannung. Seine Kompromißbereitschaft beschränkte sich darauf, eine öffentliche Erklärung über die Position des Westens zum Deutschland-Problem in Erwägung zu ziehen. Er war jedoch strikt dagegen, der sowjetischen Regierung ein konkretes Verhandlungsangebot $\mathrm{zu}$ unterbreiten ${ }^{36}$.

Diese Abfuhr wollte Schröder nicht hinnehmen. Er rief seinem Gesprächspartner ins Gedächtnis, daß der Westen seit dem Herter-Plan von 1959 in bezug auf eine Lösung der deutschen Frage nichts mehr unternommen habe, obwohl sich in den letzten fünf Jahren - vor allem durch den Bau der Mauer - die Spaltung Deutschlands vertieft habe. Unverhohlen bekannte er, er könne nicht nachvollziehen, „warum gegen eine Deklaration keine Bedenken bestünden, wohl aber gegen eine Verhandlungsbereitschaft ${ }^{* 37}$. Anschließend erläuterte Schröder erneut seinen Standpunkt, die Möglichkeit, daß die Sowjetunion den Plan ablehne, dürfe keine Handlungsrichtlinie für die westliche Politik sein. Man sollte sich nicht davon beeindrucken lassen, daß der Kreml "mehrere tausend Mal westliche Vorschläge abgelehnt" habe. Er beschwor Rusk, die Vorlage eines gemeinsamen Planes durch die Drei Mächte und die Bundesrepublik nicht zu blockieren: „Zweihundert Reden können nicht den moralischen oder politischen Wert einer solchen Aktion ersetzen." Andernfalls könnte in der Tat „der Eindruck entstehen, die Dinge ent-

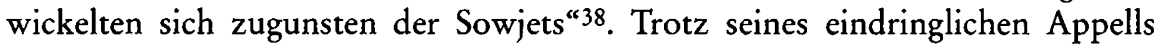
konnte er Rusk nicht zum Umdenken bewegen. Der amerikanische Außenminister verteidigte die Haltung seiner Regierung mit dem fadenscheinigen Argument, angesichts der bevorstehenden Präsidentschaftswahlen könne man sich eine Abfuhr durch die Sowjetunion nicht leisten; die Öffentlichkeit würde dies als Niederlage Johnsons auslegen. Er riet statt dessen der Bundesregierung, sich auf die von ihr begonnene Ostpolitik zu konzentrieren. Anders als die bisherige Deutschland-Politik, die Bonn der Einheit Deutschlands um „keinen Millimeter“ näher gebracht habe, würde jene die Chancen für die Wiedervereinigung erhöhen ${ }^{39}$.

Obwohl seine Bemühungen bislang erfolglos waren, gab Schröder die Forderung nach einer deutschlandpolitischen Initiative des Westens nicht auf. Gegenüber der Presse bekräftigte er den Willen der Bundesregierung, den Gedanken

35 Gespräch des Bundesministers Schröder mit den Außenministern der Drei Mächte, Butler, Couve de Murville und Rusk, am 11. 5. 1964 in Den Haag, in: AAPD 1964, Dok. 124, S. 520.

36 Vgl. ebenda, S. $522 \mathrm{f}$.

37 Ebenda, S. 523.

38 Ebenda, S. 524.

39 Ebenda. 
eines Vier-Mächte-Gremiums weiterzuverfolgen ${ }^{40}$. Die Diskussion im westlichen Bündnis um einen Deutschland-Plan wurde aber durch den Abschluß des Freundschafts- und Beistandsvertrags zwischen der UdSSR und der DDR am 12. Juni 1964 unterbrochen ${ }^{41}$. Beinahe alle politischen Beobachter nahmen an, die sowjetische Regierung bezwecke mit dem Vertrag, die DDR aufzuwerten. Sie kamen deswegen zu der Schlußfolgerung, die Deutschland-Politik des Kreml habe sich weiter verhärtet. Schröder konnte hingegen „keine neuen Konfliktstellen mit dem Westen“ ausmachen ${ }^{42}$. Vielmehr deutete er den Vertrag zu Recht als Signal Moskaus, eine Konfrontation mit dem Westen über das Deutschland- und BerlinProblem zu vermeiden. Er sah darin sogar einen Schritt der „Resignation“, da die UdSSR anstelle des seit vielen Jahren angekündigten Separatfriedensvertrages mit der DDR nun lediglich einen bilateralen Bündnispakt geschlossen hatte ${ }^{43}$. In der Tat stärkte das Abkommen zwar die Stellung Ost-Berlins, ließ aber andererseits Moskau alle Möglichkeiten zu einem Arrangement mit dem Westen offen ${ }^{44}$. Die ersten, knapp gehaltenen Stellungnahmen, mit denen Paris, London und Washington auf den Vertrag reagierten ${ }^{45}$, genügten ihm nicht. Schröder drängte auf eine gemeinsame Resolution der Westmächte und der Bundesrepublik, die die VierMächte-Verantwortung für Gesamtdeutschland deutlich herausstreichen sollte, und auf eine Erklärung der Drei Mächte, in der die Sowjetunion an ihre Mitverantwortung für Gesamtdeutschland erinnert werden sollte ${ }^{46}$. Zu diesem Zweck legte das Auswärtige Amt in der Washingtoner Botschaftergruppe einen Entwurf vor $^{47}$. Er wurde jedoch erst nach längeren Diskussionen akzeptiert. Frankreich, Großbritannien und die USA wollten aber nur ohne eine direkte Beteiligung der Bundesrepublik damit an die Öffentlichkeit treten ${ }^{48}$. Schröder blieb nichts anderes übrig, als diesen Standpunkt zur Kenntnis zu nehmen. In der am 25. Juni 1964 veröffentlichten Erklärung stellten die Drei Mächte unter anderem fest, „daß ein

40 Vgl. das Interview Schröders mit der Politisch-Sozialen Korrespondenz am 30. 5. 1964, in: BULLETIN 1964, S. $773 \mathrm{f}$.

41 Für den Wortlaut des Vertrags vom 12.6. 1964 zwischen der DDR und der UdSSR über Freundschaft, gegenseitigen Beistand und Zusammenarbeit vgl. DzD IV/10, S. 717-722. Vgl. dazu sowie zur Funktion der bilateralen Bündnispakte im Ostblock HACKER, Der Ostblock, S. 856-867 und S. 897-903.

42 Interview Schröders mit dem WDR am 14. 6. 1964, in: Bulletin 1964, S. 868.

43 Vgl. das Gespräch des Bundesministers Schröder mit dem französischen Außenminister Couve de Murville am 3. 7. 1964, in: AAPD 1964, Dok. 181, S. 727.

44 Vgl. Hildebrand, Von Erhard zur Großen Koalition, S. 85.

$45 \mathrm{Zu}$ den Stellungnahmen Frankreichs, Großbritanniens und der USA vom 15.6. 1964 vgl. ADG 1964, S. 11275.

$46 \mathrm{Vgl}$. das Gespräch des Bundesministers Schröder mit dem britischen Botschafter Roberts am 15. 9. 1964, in: AAPD 1964, Dok. 165, S. 673.

$47 \mathrm{Vgl}$. den Drahterlaß des Staatssekretärs Carstens an die Botschaft in Washington vom 15. 6. 1964, in: ebenda, Dok. 166, S. 674-677.

48 Vgl. dazu das Schreiben des Bundesministers Schröder an den französischen Außenminister Couve de Murville vom 22. 6. 1964, in: ebenda, Dok. 175, S. 698f; die Drahtberichte des Botschafters Knappstein, Washington, an das Auswärtige Amt vom 15.6. 1964 und 24. 6. 1964, in: AAPD 1964, Dok. 167, S. 677-680, bzw. PA/AA, B 150, Aktenkopien 1964; sowie den Drahtbericht des Botschafters Klaiber, Paris, an das Auswärtige Amt vom 25. 6. 1964, PA/AA, B 150, Aktenkopien 1964. 
Abkommen, das die Sowjetunion mit der sogenannten ,DDR' abschließt, die sowjetischen Verpflichtungen oder Verantwortlichkeiten aus Abkommen und Abmachungen mit den Drei Mächten über Deutschland einschließlich Berlins und des Zugangs dorthin nicht berühren kann"49.

Auch in den folgenden Monaten kamen die Gespräche über den DeutschlandPlan nicht voran. Am 1. September 1964 vertraute Schröder der Nachrichtenagentur $d p a$ an, wegen des amerikanischen Wahlkampfes sei auch in der nächsten Zeit nicht mit Fortschritten zu rechnen ${ }^{50}$. Er gab aber noch nicht auf: Zwei Wochen später machte er gegenüber Botschafter McGhee deutlich, nach den Wahlen erwarte er von Washington „eine klare, gegen den Status quo gerichtete Haltung“. Die amerikanische Regierung müsse sich sichtbar für die Einheit Deutschlands einsetzen, da sonst der Verdacht aufkäme, sie fänden sich mit der Teilung Deutschlands ab ${ }^{51}$ ! Aber weder die Absetzung Chruschtschows am 14. Oktober noch die Bestätigung Johnsons als Präsident in den Wahlen am 3. November 1964 führte zu einer Änderung der amerikanischen Haltung. Johnson war zwar durchaus gewillt, öffentlich das Problem der deutschen Teilung anzusprechen ${ }^{52}$, doch weigerte er sich, gegenüber der neuen sowjetischen Kollektivführung konkrete Schritte in die Wege zu leiten.

Ende November 1964 sah Schröder schließlich die Aussichtslosigkeit seines Unternehmens, die Drei Mächte auf einen gemeinsamen Deutschland-Plan festzulegen, ein. Um aber wenigstens das Kernstück des Plans, den Ständigen VierMächte-Rat, zu retten, regte er an, zumindest diesen Gedanken der UdSSR zu unterbreiten. Doch Rusk legte auch hier sein Veto ein. Er verwies darauf, daß man in eine unangenehme Situation geraten könnte, falls der Kreml der Einrichtung eines solchen Gremiums zustimmen würde: Die Uneinigkeit des Westens käme dann offen zum Vorschein. Schröder brachte vergeblich sein Unverständnis darüber zum Ausdruck, daß sein amerikanischer Amtskollege nicht in Ruhe die Reaktion der Sowjetunion abwarten wollte. Sollte Moskau nämlich den westlichen Vorschlag akzeptieren, blieb seines Erachtens immer noch genügend Zeit, um über eine Antwort nachzudenken ${ }^{53}$. Bei Couve de Murville, der das Vorhaben der Bundesregierung unterstützte, beklagte sich Schröder wenig später massiv über die amerikanischen Haltung, das Mandat des Vier-Mächte-Rats müßte festgelegt werden, bevor die Idee der UdSSR präsentiert werden könnte: „Die Amerikaner möchten den zweiten oder dritten Schritt schon diskutieren, ehe sie den ersten täten." 54 Entschieden wandte er sich gegen eine derartige Vorgehensweise. Wie er

49 DzD IV/10, S. 775.

50 Vgl. das Interview Schröders mit der dpa am 1. 9. 1964, in: BulleTiN 1964, S. 1270.

51 Gespräch des Bundesministers Schröder mit dem amerikanischen Botschafter McGhee am 15. 9. 1964, in: AAPD 1964, Dok. 246, S. 1015.

$52 \mathrm{Vgl}$. dazu die Ausführungen in seiner Rede am 3. 12. 1964 an der Universität Georgetown und in der "State of the Union Message" vom 4.1. 1965, in: PubliC PAPERS, JOHNSON 1963/64, S. 1633, bzw. PUblic PAPers, Johnson 1965, S. 3.

$53 \mathrm{Vgl}$. das Gespräch des Bundesministers Schröder mit dem amerikanischen Außenminister Rusk am 23. 11. 1964 in Washington, in: AAPD 1964, Dok. 353, S. $1384 \mathrm{f}$.

54 Gespräch des Bundesministers Schröder mit dem französischen Außenminister Couve de Murville am 9. 12. 1964 in Paris, in: ebenda, Dok. 377, S. 1469. 
kurz darauf dem britischen Außenminister Patrick Gordon Walker darlegte, müßte man sich - wenn man der amerikanischen Linie folgen und schon im Vorfeld die westlichen Positionen konkretisieren würde - folglich auch über mögliche Zugeständnisse an die Sowjetunion Gedanken zu machen. Falls Moskau dann aber eine Beteiligung an dem Vier-Mächte-Rat ausschlage, hätte der Westen die Konzessionen „verbraucht“, ohne irgendeine Gegenleistung erhalten zu haben 55 .

Wenige Tage vor der Tagung des NATO-Ministerrats am 15. Dezember 1964 in Paris ließ Schröder den Drei Mächten den Vorschlag zur Schaffung eines VierMächte-Rats in schriftlicher Form übergeben. Prompt fand das deutsche Papier eine „eher kühle Aufnahme“, wobei der Kommentar der amerikanischen Regierung am frostigsten ausfiel ${ }^{56}$. In Paris unternahm er einen weiteren Versuch, Washington doch noch umzustimmen. Erneut unterstrich Schröder dabei die Notwendigkeit, das Prinzip der Vier-Mächte-Verantwortung für Gesamtdeutschland als Gegengewicht zu dem sowjetischen Standpunkt, die Lösung der deutschen Frage sei die Angelegenheit der beiden deutschen Staaten, stärker hervorzuheben. Mit einer deutschlandpolitischen Initiative sei kein Risiko verbunden, wiederholte er. Sollte die UdSSR die Offerte ausschlagen, so hätte dies keine negativen Auswirkungen; würde sie wider Erwarten gesprächsbereit sein, so müßte man sich eben auf einen gemeinsamen Standpunkt einigen ${ }^{57}$. Rusk wollte aber nicht unvorbereitet in eine Diskussion mit der sowjetischen Regierung über die deutsche Frage eintreten. Er wies darauf hin, daß Moskau sicherlich Gegenvorschläge machen würde. Der Westen dürfe dann nicht mit leeren Händen dastehen. Welche Antwort sollte man zum Beispiel geben, falls das Problem der deutschen Ostgrenze angesprochen werde, fragte er seinen deutschen Amtskollegen und fügte hinzu, die Westmächte könnten sich in diesem Fall genötigt sehen, ihre der Bundesregierung bekannte Auffassung unumwunden kundzutun. Dies könnte aber für Bonn möglicherweise „nicht angenehm“" werden ${ }^{58}$. Das entscheidende Motiv für seine ablehnende Haltung war indes die Tatsache, daß auch mit den neuen sowjetischen Machthabern über das Deutschland-Problem nicht ins Gespräch zu kommen war: Zwischen Ende November und Anfang Dezember 1964 hatte Rusk sich nämlich insgesamt fünfmal mit Gromyko getroffen, der dabei zu verstehen gegeben hatte, daß der Kreml an einer Aussprache über die deutsche Frage gegen-

55 Gespräch des Bundesministers Schröder mit dem britischen Außenminister Gordon Walker am 11. 12. 1964 in Dorneywood, in: ebenda, Dok. 381, S. 1493. Nach dem Sieg der Labour-Partei bei den Unterhauswahlen am 15. 10. 1964 wurde Gordon Walker vom neuen Premierminister Harold Wilson am 18. 10. 1964 zum Außenminister berufen. Bereits am 21. 1. 1965 trat er jedoch zurück, da er die Nachwahlen in seinem Wahlbezirk Leyton verlor. Sein Nachfolger wurde der bisherige Minister für Erziehung und Wissenschaft, Michael Stewart. Vgl. ADG 1965, S. 11654.

56 So Ministerialdirigent Ruete in seinem Bericht zur Übergabe des Papiers am 12. 12. 1964. Vgl. den Drahtbericht des Ministerialdirigenten Ruete, z.Z. Paris, an das Auswärtige Amt vom 13. 12. 1964, PA/AA, B 150, Aktenkopien 1964.

57 Vgl. das Gespräch des Bundesministers Schröder mit den Außenministern der Drei Mächte, Couve de Murville, Gordon Walker und Rusk, am 14.12. 1964 in Paris, in: AAPD 1964, Dok. 387, S. 1528-1533.

58 Vgl. ebenda. 
wärtig nicht interessiert war ${ }^{59}$. So wurde im abschließenden Kommuniqué über das Treffen Schröders mit den Außenministern der Drei Mächte lediglich mitgeteilt, man beabsichtige, „eine Lösung der deutschen Frage durch Wiederaufnahme der Gespräche mit der Sowjetregierung zu suchen“. Ein Termin wurde allerdings nicht genannt ${ }^{60}$. Der geplante Zusatz, daß „es an der Zeit sei, [...] mit der Sowjetunion geeignete Schritte zu unternehmen", scheiterte am Widerstand Frankreichs ${ }^{61}$. Wie Schröder zutreffend feststellte, bedeutete dies nicht, daß sich nun auch Paris gegen eine deutschlandpolitische Initiative sperrte. Vielmehr wollte die französische Regierung auf diese Weise ihren Unmut über seine Rede vor dem NATO-Ministerrat ${ }^{62}$ zum Ausdruck bringen, in der er zum Ärger der Franzosen die große Bedeutung der MLF und der atlantischen Allianz für die Sicherheit der Bundesrepublik hervorgehoben hatte ${ }^{63}$.

Ungeachtet des erneuten Mißerfolgs bemühte er sich Anfang Januar 1965 wiederum, die amerikanische Regierung für den Ständigen Vier-Mächte-Rat zu erwärmen. Der Westen müsse in der deutschen Frage aktiv bleiben, bekräftigte er gegenüber McGhee ${ }^{64}$. Auf keinen Fall sollte man sich danach richten, ob die Sowjetunion zu Verhandlungen bereit sei oder nicht: „Genauso wie die Sowjets immer wieder ihre Position wiederholten, könne dies auch der Westen tun. "65 Die amerikanische Haltung stand jedoch unwiderruflich fest. Die USA wollten Moskau keinen Anlaß geben, in Berlin aktiv zu werden, bestätigte Rusk gegenüber Botschafter Knappstein am 7. Januar 1965. Was wäre zum Beispiel, wenn die UdSSR im Gegenzug den Rückzug der Truppen der Westmächte aus Berlin (West) verlangen würde, fragte der amerikanische Außenminister und stellte dazu fest, er wolle keine Wiederbelebung der Berlin-Krise von 1958, die den Vereinigten Staaten nur finanzielle Belastungen in Milliardenhöhe aufbürden würde ${ }^{66}$. Damit war die Diskussion über eine westliche Initiative zur deutschen Frage für die USA endgültig beendet. Während Schröder sich von den Amerikanern im Stich gelassen fühlte ${ }^{67}$, beschwerte sich Rusk über die mangelnde Einsicht des Außenmini-

59 Die Treffen fanden am 30.11. sowie am 2., 5., 9. und 19.12. 1964 statt. In den Gesprächen am 9. und 12.12. 1964 wurde die deutsche Frage ausführlich erörtert. Vgl. FRUS 19641968, XV, Dok. 74 und Dok. 78, S. 175-179 bzw. S. 185-187. Ferner führte Präsident Johnson am 9. 12. 1964 ein Gespräch mit Gromyko, in der auch auf das Deutschland-Problem eingegangen wurde. Vgl. FRUS 1964-1968, XI, Dok. 54, S. 135-140. Zu den Gesprächen Gromykos mit Johnson und Rusk vgl. auch die Aufzeichnung des Ministerialdirektors Krapf vom 8. 1. 1965, PA/AA, B 150, Aktenkopien 1965; sowie den Drahtbericht des Botschafters Knappstein, Washington, an das Auswärtige Amt vom 8.1.1965, in: AAPD 1965, Dok. 7, S. 37.

60 Für den Wortlaut des Kommuniqués vom 16. 12. 1964 vgl. DzD IV/10, S. 1223.

$61 \mathrm{Vgl}$. die Aufzeichnung des Ministerialdirigenten Ruete vom 7.12. 1964, PA/AA, B 150, Aktenkopien 1964.

62 Für den Wortlaut der Rede Schröders vom 15. 12. 1964, in: BULLETIN 1964, S. 1727-1729.

$63 \mathrm{Vgl}$. das Gespräch des Bundesministers Schröder mit dem amerikanischen Botschafter McGhee am 19. 12. 1964, in: AAPD 1964, Dok. 392, S. 1542.

64 Vgl. das Gespräch des Bundesministers Schröder mit dem amerikanischen Botschafter McGhee am 7. 1. 1965, in: AAPD 1965, Dok. 3, S. 13-23.

65 Ebenda, S. 21.

66 Vgl. FRUS 1964-1968, XV, Dok. 80, S. 193 f.

67 Vgl. ebenda, Dok. 83, S. 201. 
sters: Dieser sei zwar intelligent und ein guter Kollege, doch habe er sich noch nicht in extenso mit den Problemen beschäftigt, mit denen sich die Bundesrepublik konfrontiert sehe, schrieb er am 14. Januar McGhee. Er, Rusk, habe die deutsche Frage in jedem Gespräch mit Vertretern der sowjetischen Regierung zur Sprache gebracht, doch die Reaktion der UdSSR sei stets negativ ausgefallen. Daher müsse eine westliche Initiative substantielle Konzessionen enthalten: „We say ,serious' because we cannot rely upon the luxury of a public Western proposal made on a Wednesday, rejected by the Soviets on a Thursday, thereby leaving everybody happy on Friday." Doch zu einem ernsthaften Vorschlag, so führte der amerikanische Außenminister weiter aus, sei Bonn nicht willens. Ein Verzicht auf die Grenzen von 1937 beispielsweise genüge nicht: „It is no concession for the Federal Republic to abandon what it does not have. I know of no other country in the world which would support the frontiers of 1937." Angesichts der unrealistischen Haltung Bonns könne er dem Präsidenten keine Initiative empfehlen, die die Gefahr eines Wiederauflebens der Berlin-Krise in sich berge ${ }^{68}$.

Es stellt sich zwangsläufig die Frage, warum Schröder ebenso wie auch Erhard ${ }^{69}$ das ganze Jahr 1964 hindurch unbeirrt auf einer Behandlung des Deutschland-Problems bestanden, obwohl den amerikanischen Stellungnahmen von Anfang an zu entnehmen war, daß Washington keine diplomatische Aktion in dieser Sache gegenüber der Sowjetunion einleiten wollte. Freilich, auch der Außenminister hatte erfaßt, daß sich ,in der Welt das beherrschende und allgemeine Interesse der Friedenserhaltung vor das Teilinteresse der Wiedervereinigung geschoben“ hatte ${ }^{70}$. Trotz dieser Erkenntnis wollte er dennoch alles unternehmen, um die deutsche Frage im Gespräch der internationalen Politik zu halten ${ }^{71}$. Wie bereits ausführlich in einem der ersten Kapitel dieser Studie geschildert wurde, entsprang sein Engagement für die Wiederherstellung der staatlichen Einheit Deutschlands seiner inneren Überzeugung: Deutsche Außenpolitik hatte für ihn in erster Linie Wiedervereinigungspolitik zu sein. Folglich mußte er als Außenminister der Bundesrepublik auf eine aktive Deutschland-Politik des Westens drängen, um dieser Aufgabenstellung nachzukommen.

Erst der Besuch Gromykos in Frankreich vom 25. bis 30. April 1965 führte dazu, daß Schröder von seiner Forderung nach einer deutschlandpolitischen Initiative abließ. Am 30. April verlangte der sowjetische Außenminister auf einer Pressekonferenz in Paris, die Oder-Neiße-Linie zu fixieren und den Deutschen den Besitz atomarer Waffen zu verbieten. Derartige Bestimmungen, die nach Bon-

68 Vgl. ebenda, Dok. 84, S. 204-207.

69 So kündigte Erhard am 27.11.1964 dem CDU-Bundesvorstand an, die deutschlandpolitische Initiative der Drei Mächte werde zu Jahresbeginn erfolgen. Er führte dazu aus: „Wir werden das nicht aus dem Griff lassen. Wir werden immer wieder dafür sorgen, daß in der Welt unser deutsches Problem nicht in Vergessenheit gerät. Sie können überzeugt sein, das bleibt unser Anliegen Nummer 1, die Wiedervereinigung zu besorgen. "Vgl. PROTOKOLLE DES CDU-BUNDESVORSTANDS, S. $744 \mathrm{f}$.

70 Rede des Bundesministers Schröder auf dem 13. Bundesparteitag der CDU am 30. 3. 1965 in Düsseldorf, in: DzD IV/11, S. 341.

71 Vgl. die deutsch-französische Regierungsbesprechung am 19.1.1965 in Paris, in: AAPD 1965, Dok. 23, S. 129. 
ner Auffassung nur Teil eines Friedensvertrages mit einem vereinigten Deutschland sein konnten, sollten nach den Vorstellungen des sowjetischen Außenministers bereits für die Bundesrepublik wie für die DDR gelten. Abschließend behauptete er, Frankreich erkenne die Realität der Existenz zweier deutscher Staaten $a^{72}$. Zwar dementierte der Quai d'Orsay am 30. April, daß man die DDR anerkenne ${ }^{73}$, doch widersprach das französische Außenministerium weder den Aussagen über die Endgültigkeit der Oder-Neiße-Linie noch Gromykos Forderung nach einem Kernwaffenverbot für Deutschland. Schröder sah darin einen klaren Beweis, daß Paris die Ansichten Moskaus teilte ${ }^{74}$. Er kritisierte die französische Regierung deswegen energisch: „Wenn es mit solchen Betrachtungen weitergehe, sei das Ergebnis, daß nicht nur der Status eines wiedervereinigten Deutschlands präjudiziert würde, sondern daß sich der derzeitige Status der Bundesrepublik verschlechtern würde."75 Dieser Vorfall untermauerte seine Überzeugung, es würde dem Anliegen der Wiedervereinigung nur schaden, wenn der UdSSR bereits eine Einschränkung des militärischen Status Deutschlands offeriert würde, noch bevor der Kreml überhaupt in Gespräche über die deutsche Frage eingewilligt hätte ${ }^{76}$. Dadurch gebe man nämlich „den Gedanken des Gebens und Nehmens auf". Während sich die Sowjetunion um keinen Millimeter bewege, mache der Westen immer größere Konzessionen, beklagte der Außenminister. Da eine deutschlandpolitische Initiative letztendlich nur zu Lasten der Bundesrepublik gehen konnte, ließ er dieses Vorhaben fallen: „Solange sich die sowjetische Haltung nicht ändere, habe es keinen Sinn, neue Vorschläge zu unterbreiten, weil sie dann nur zu einer Konsolidierung des Status quo führen würden."77

$\mathrm{Zu}$ seiner Meinungsänderung trug auch die neue Einstellung des französischen Staatspräsidenten zum Deutschland-Problem bei, die unter dem Begriff Europäisierung der deutschen Frage bekannt wurde. De Gaulle hatte diesen Gedanken erstmals während einer Unterredung am 19. Januar 1965 mit Erhard auf Schloß Rambouillet aufgegriffen. Gegenüber dem Kanzler bezeichnete er das Problem der Teilung Deutschlands als „die europäische Frage par excellence"78 und verkündete, die Wiedervereinigung sei nur möglich, „wenn alle Nachbarn Deutschlands in Ost und West damit einverstanden seien"79. Auf einer Pressekonferenz am 4. Februar präzisierte der General seine Vorstellungen. Seiner Meinung nach war die Einheit Deutschlands von den europäischen Völkern gemeinsam zu regeln ${ }^{80}$. Wie Couve de Murville im Rückblick notierte, war de Gaulle zu der

$72 \mathrm{Vgl}$. ADG 1965, S. 11826.

73 Vgl. EuROPA-ARCHIV 1965, D 248.

74 Vgl. das Gespräch des Bundesministers Schröder mit dem amerikanischen Botschafter McGhee am 4. 5. 1965, in: AAPD 1965, Dok. 197, S. 785.

75 Gespräch des Bundesministers Schröder mit dem amerikanischen Außenminister Rusk am 13. 5. 1965 in London, in: ebenda, Dok. 206, S. 823.

76 Vgl. ebenda, S. 786.

77 Ebenda, S. 788.

78 Gespräch des Bundeskanzlers Erhard mit Staatspräsident de Gaulle am 19.1. 1965 in Rambouillet, in: ebenda, Dok. 22, S. 112.

79 Ebenda, S. 114.

80 Vgl. DE Gaulle, Discours IV, S. 338-342. 
Überzeugung gekommen, daß die deutsche Frage nur zu lösen war, wenn sie aus dem Kontext der Rivalität zwischen Ost und West herausgenommen und „in einen europäischen Rahmen“ gestellt würde ${ }^{81}$. Weder der Kanzler noch sein AuBenminister konnten sich mit dem Konzept des französischen Staatspräsidenten anfreunden. Im Gegenteil, Erhard befürchtete sogar, „in einem solchen Europa wäre Deutschland nichts anderes als ein französisch-russisches Protektorat" Auch Schröder erachtete de Gaulles Pläne für „außerordentlich gefährlich“, weil sie „neue Mitbestimmungsrechte“ schufen ${ }^{83}$. Es stand für ihn außer Zweifel, daß die deutschlandpolitische Ausgangsposition „ungemein erschwert würde, wenn den Osteuropäern, insbesondere den Polen, Tschechen, Ungarn, Rumänen und Bulgaren, nahegelegt würde, daß sie auch gefragt werden müßten, ob sie der deutschen Wiedervereinigung zustimmten, und daß ihre Beteiligung unerläßlich sei“. Dies könnte soweit führen, daß „dann auch andere europäische Länder, wie beispielsweise die Norweger und Dänen, vielleicht auch die Österreicher, auf die Idee [kämen], daß sie ebenfalls gefragt werden und ihre Zustimmung zur Wiedervereinigung geben müßten". Nachdrücklich wies er den Gedanken einer die deutsche Souveränität verletzenden Beteiligung weiterer Staaten am Wiedervereinigungsprozeß zurück. Lediglich die vier für Deutschland verantwortlichen Mächte hätten - unter Berücksichtigung des Rechts auf Selbstbestimmung - die Befugnis, sich der deutschen Frage anzunehmen: „Wenn die Leute in der Ostzone morgen tatsächlich bereit sein sollten, freie Wahlen abhalten zu lassen, so wäre es selbstverständlich die Pflicht der vier Hauptbeteiligten, dem zuzustimmen und das Ergebnis zu akzeptieren, ohne Rücksicht darauf, ob das den Polen, Tschechen, Dänen und anderen genehm sei. "84 Seinen Protest gegen die neue französische Position brachte er auch gegenüber Couve de Murville deutlich zum Ausdruck ${ }^{85}$.

Schröders wachsende Vorbehalte gegen eine neue Initiative Frankreichs, Großbritanniens und der USA zur Einheit Deutschlands öffnete im Frühjahr 1965 den Weg zu einer deutschlandpolitischen Erklärung der drei Staaten, wie sie Rusk bereits ein Jahr zuvor als Kompromiß vorgeschlagen hatte. Dem Ansinnen Bonns nach einem Gesprächsangebot über die deutsche Frage an die UdSSR wurde in dieser letzten gemeinsamen deutschlandpolitischen Erklärung der Drei Mächte vom 12. Mai 1965 mehr oder weniger eine Absage erteilt. Die amerikanische, britische und französische Regierung erklärten lapidar: „Die Möglichkeiten, in dieser Frage an die sowjetische Regierung heranzutreten, werden unter Berücksichtigung der Aussichten, dabei zu nützlichen Ergebnissen zu gelangen, weiterhin geprüft. "86 Das Drängen der Bundesrepublik nach konkreten Schritten zur Lösung

81 Couve De Murville, Außenpolitik, S. 225. Vgl. auch Maillard, De Gaulle und Deutschland, S. 325-328.

82 Gespräch des Bundeskanzlers Erhard mit dem amerikanischen Botschafter McGhee am 5. 5. 1965, in: AAPD 1965, Dok. 198, S. 794.

83 Protokoll der CDU/CSU-Fraktionssitzung am 4. 5. 1965, ACDP VIII-001-1010/1.

84 Gespräch des Bundesministers Schröder mit dem amerikanischen Botschafter McGhee am 4. 5. 1965, in: AAPD 1965, Dok. 197, S. 785.

85 Vgl. COUVE DE MURville, Außenpolitik, S. 222 f.

86 Vgl. DzD IV/11, S. 595. 
des Deutschland-Problems erhielt damit „ein Begräbnis dritter Klasse“87. Die Bundesregierung mußte sich damit trösten, daß die Drei Mächte in ihrer Note zumindest keine juristische oder politische Position der westlichen DeutschlandPolitik aufgaben. ${ }^{88}$ Bonn wurde zu der Einsicht gezwungen, daß die Zeit der Deutschland-Pläne vorbei war. Man konzentrierte sich deshalb in der Folgezeit darauf, die Verbündeten auf die Wahrung des bestehenden Rechtsstandpunkts zur deutschen Frage zu verpflichten.

\section{Erste innerdeutsche Kontaktaufnabmen: die Passierscheinvereinbarungen}

Für die Berliner Bevölkerung war die Abriegelung der Stadt durch die Mauer in erster Linie ein menschliches Problem. Seit dem 13. August 1961 waren Bekannte, Freunde, Verwandte, ganze Familien voneinander getrennt. Der Regierende Bürgermeister, Willy Brandt, und seine engsten Mitarbeiter, Heinrich Albertz, Klaus Schütz, Dietrich Spangenberg und Egon Bahr, hatten sich zum Ziel gesetzt, die Mauer wieder durchlässiger zu machen und einen innerstädtischen Besuchsverkehr zu ermöglichen. Um humanitäre Erleichterungen durchzusetzen, mußte man aber wohl oder übel mit den Behörden der DDR in Kontakt treten, womit die Nichtanerkennungspolitik der Bundesregierung tangiert wurde. Es bestand zudem die Gefahr, daß man dadurch die östliche These von der selbständigen politischen Einheit Berlin (West) bestätigte ${ }^{89}$. In seiner berühmt gewordenen Rede am 15. Juli 1963 in der Evangelischen Akademie Tutzing legte der damalige Leiter des Presse- und Informationsamts des Landes Berlin, Egon Bahr, die Notwendigkeit eines neuen Umgangs mit der DDR dar ${ }^{90}$. Er erklärte, daß humanitäre Erwägungen für die Berliner Verantwortlichen im Vordergrund stünden: „Uns hat es zunächst um die Menschen zu gehen und um die Ausschöpfung jedes denkbaren und verantwortlichen Versuchs, ihre Situation zu erleichtern." Den Bau der Mauer interpretierte Bahr als „ein Zeichen der Schwäche [...,] der Angst und des Selbsterhaltungstriebes des kommunistischen Regimes" und warf die Frage auf, „ob es nicht Möglichkeiten gibt, diese durchaus berechtigten Sorgen dem Regime graduell soweit zu nehmen, daß auch die Auflockerung der Grenzen und der Mauer praktikabel wird, weil das Risiko erträglich ist“. Eine derartige Politik bezeichnete er mit der doppeldeutigen, und deshalb oft mißverstandenen Formel „Wandel durch Annäherung"91.

87 KÖRNER, Wiedervereinigungspolitik, S. 606.

$88 \mathrm{Vgl}$. HaCKer, Deutsche Irrtümer, S. 127.

$89 \mathrm{Zu}$ den Überlegungen Brandts und seiner Mitarbeiter vgl. BENDER, Die „Neue Ostpolitik" und ihre Folgen, S. 126-131; BAHR, Zu meiner Zeit, S. 161 f.; SCHÜTZ, Logenplatz, S. 111 f.; AlberTZ, Blumen, S. 98 f. Zur Problematik einer ungewollten Bestätigung der These eines eigenständigen Völkerrechtssubjekts Berlin (West) vgl. auch BUCHHEIM, Deutschlandpolitik, S. 116.

90 Für den Wortlaut vgl. DzD IV/9, S. 572-575.

91 Ebenda, S. 575. Vgl. dazu auch die Rede Bahrs vom 11. 7.1973 in der Evangelischen Akademie Tutzing, in: DeUTSCHLAND-ARCHIV 1973, S. 865-873; sowie BAHR, Zu meiner Zeit, S. 152-159. 
Die erste Bewährungsprobe für diese neue Politik waren die Verhandlungen über eine Passierscheinvereinbarung im Winter 1963. Am 5. Dezember 1963 wandte sich der Stellvertretende Ministerpräsident der DDR, Alexander Abusch, in einem Schreiben an Brandt und schlug vor, Besprechungen über eine Regelung des innerstädtischen Verkehrs während der bevorstehenden Feiertage aufzunehmen $^{92}$. Auf eine solche Offerte war der Berliner Senat vorbereitet, da man sich seit knapp drei Monaten intensiv mit den juristischen Problemen und den Folgen für die Bonner Deutschland-Politik beschäftigt hatte, die etwaige Verhandlungen mit der DDR mit sich brächten ${ }^{93}$. Brandt ging daher, ohne zu zögern, auf das Angebot Ost-Berlins ein ${ }^{94}$. Es wäre aber wohl nicht zu Gesprächen gekommen, wenn nicht zu dem Zeitpunkt, als dieser Brief in der Senatskanzlei in Berlin-Schöneberg eintraf, ausschließlich Vizekanzler Mende in Bonn greifbar gewesen wäre. Der FDPVorsitzende, der sich schon seit längerem für eine Intensivierung der Kontakte mit der DDR ausgesprochen hatte, gab für Verhandlungen mit der DDR grünes Licht ${ }^{95}$. Kanzler Erhard, Bundestagspräsident Gerstenmaier, der CSU-Vorsitzende Strauß sowie der stellvertretende Vorsitzende der CDU/CSU-Fraktion, Rainer Barzel, kritisierten die Entscheidung des Ministers für gesamtdeutsche Fragen. Sie sahen in Kontakten zwischen Berlin (West) und der DDR eine indirekte Bestätigung der sowjetischen Drei-Staaten-Theorie ${ }^{96}$. Schröder befürchtete, daß die DDR mit den Verhandlungen eine Aufwertung zu erreichen suchte. Er erinnerte an Ulbrichts Ablehnung des Bonner Angebots, der DDR Kredite zu gewähren, falls sie für menschliche Erleichterungen sorgen würde. Damit, so der Außenminister, hätte der Staatsratsvorsitzende offenbart, daß er kein Interesse an Vereinbarungen mit dem Westen habe, selbst wenn diese wegen ihres humanitären Charakters das Ansehen seines Regimes unter der eigenen Bevölkerung vergrößerten. Inständig warnte er davor, die Bereitschaft der DDR zu Verhandlungen überzubewerten. Mit dem Passierscheinangebot sei mitnichten eine Abkehr OstBerlins von der bisherigen harten Linie verbunden ${ }^{97}$.

Zwischen dem 12. und 17. Dezember 1963 trafen sich die beiden Verhandlungsführer, der Staatssekretär im Ministerium für Kultur der DDR, Erich Wendt, und der Leiter der Politischen Abteilung der Senatskanzlei, Senatsrat Horst Korber, insgesamt siebenmal ${ }^{98}$. Sie konnten relativ rasch eine Vereinbarung zuwege bringen, indem sie sich auf die Anwendung des „uralten agree-to-disagree-Ausweg[s] der Diplomatie“ verständigten ${ }^{99}$. In das Protokoll wurde nämlich auf Anraten

92 Für den Wortlaut vgl. DzD IV/9, S. 982.

93 Vgl. BENDER, Die „Neue Ostpolitik“ und ihre Folgen, S. 130.

94 Vgl. BRANDT, Begegnungen, S. 103.

95 Vgl. Mende, Von Wende zu Wende, S. 118f.; AlberTZ, Blumen, S. 100.

$96 \mathrm{Vgl}$. MENDE, Von Wende zu Wende, S. 119. Vgl. ferner die Ausführungen Erhards vor dem CDU-Bundesvorstand am 17.1. 1964, in: Protokolle DEs CDU-BundesvorSTANDS, S. 563.

97 Vgl. das Gespräch des Bundesministers Schröder mit dem britischen Außenminister Butler am 9. 12. 1963, in: AAPD 1963, Dok. 459, S. 1585.

$98 \mathrm{Vgl}$. Protokoll der Passierscheinvereinbarung vom 17. 12. 1963, in: DzD IV/9, S. 1023. Zu den Verhandlungen vgl. BAHR, Zu meiner Zeit, S. 161-163.

99 BENDER, Die „Neue Ostpolitik“ und ihre Folgen, S. 131. 
Albertz' eine sogenannte salvatorische Klausel eingefügt ${ }^{100}$, die besagte, „daß eine Einigung über gemeinsame Orts-, Behörden- und Amtsbezeichnungen nicht erzielt werden konnte"101. Die Bundesregierung verlangte während der Verhandlungen nachdrücklich, deutschlandpolitisch gefährliche Formulierungen nicht in die Vereinbarung aufzunehmen. Doch die Antwort des Berliner Senats lautete, mehr sei bei der anderen Seite nicht durchzusetzen ${ }^{102}$. Auch der Plan, die Unterzeichnung des Protokolls in Bonn in Anwesenheit der Botschafter und der Berliner Stadtkommandanten der Drei Mächte sowie des Beauftragten des Bundes für Berlin durchzuführen, um wenigstens symbolisch die sowjetische Drei-StaatenTheorie zu widerlegen, scheiterte, da Frankreich, Großbritannien und die USA dazu nicht bereit waren ${ }^{103}$.

Schon am 17. Dezember sollte die Unterzeichnung des Protokolls über die Bühne gehen. Erst um 6 Uhr 30 morgens wurde die Bundesregierung vom Berliner Senat über den endgültigen Wortlaut in Kenntnis gesetzt ${ }^{104}$. In Bonn äußerte man vor allem Bedenken gegen die Unterzeichnungsformel: „Auf Weisung des Chefs der Staatskanzlei, die im Auftrage des Regierenden Bürgermeisters von Berlin gegeben wurde" 105 . Konnte die DDR dies nicht als Bestätigung des Standpunkts interpretieren, Berlin (West) sei ein eigenständiges Völkerrechtssubjekt? Schröder zufolge war der Senat bei der Formulierung der Vereinbarung auf „eine schiefe Ebene" geraten. Die Stellungnahmen und Warnungen von seiten der Bundesregierung seien in den Verhandlungen mit der DDR bewußt ignoriert worden: „Herr Brandt hat für mein Gefühl in der Sache [...] gegen das gehandelt, was wir gesagt haben. “106 Die Zustimmung der Bundesregierung hing „an einem seidenen Faden". Doch der Außenminister wie auch der Kanzler kamen zu dem Schluß, es sei für ein Veto zu spät: „Wir glaubten nun, unmittelbar vor Weihnachten es eben nicht verantworten zu können, zumal wir auch die internationale Stimmung dabei berücksichtigt haben, die Sache nun scheitern zu lassen." 107 Wie geplant, wurde das Protokoll von Korber und Wendt unterzeichnet. Gleichzeitig veröffentlichten die drei Stadtkommandanten der Westmächte eine Stellungnahmen, in der sie betonten, daß durch die Passierscheinvereinbarung der Rechtsstatus Berlins unberührt bleibe ${ }^{108}$. In einer gemeinsamen Erklärung bekräftigten die Bundesregierung und der Berliner Senat, daß mit dem Abkommen keine völkerrechtliche An-

100 Vgl. BAHR, Zu meiner Zeit, S. 163.

101 Protokoll der Passierscheinvereinbarung vom 17. 12. 1963, in: DzD IV/9, S. 1023.

102 Vgl. die Ausführungen Erhards vor dem CDU-Bundesvorstand am 17. 1. 1964, in: PROTOKOLLE DES CDU-BUNDESVORSTANDS, S. 581.

103 Vgl. die Ausführungen Schröders vor dem CDU-Bundesvorstand am 17.1. 1964, in: ebenda, S. 583.

104 Vgl. die Aufzeichnung des Staatssekretärs Carstens vom 18. 12. 1963, in: AAPD 1963, Dok. 477, S. 1656-1658.

105 Protokoll der Passierscheinvereinbarung vom 17. 12. 1963, in: DzD IV/9, S. 1023.

106 So Schröder vor dem CDU-Bundesvorstand am 17.1. 1964, in: PROTOKOLLE DES CDUBUNDESVORSTANDS, S. 583.

107 So Erhard vor dem CDU-Bundesvorstand am 17.1. 1964, in: ebenda, S. 581. Vgl. auch die Aufzeichnung des Staatssekretärs Carstens vom 18.12. 1963, in: AAPD 1963, Dok. 477, S. $1656 \mathrm{f}$.

108 Für den Wortlaut der Erklärung vom 17. 12. 1963 vgl. DZD IV/9, S. 1030. 
erkennung der DDR verbunden sei ${ }^{109}$. Aus Bonner Sicht handelte es sich bei dem Protokoll um eine Verwaltungsvereinbarung und nicht um einen völkerrechtlichen Vertrag 110 .

In der Zeit vom 19. Dezember 1963 bis zum 5. Januar 1964 konnten etwa 790000 Westberliner ihre Verwandten und Bekannten in Ost-Berlin besuchen ${ }^{111}$. Angestellte der Deutschen Post der DDR nahmen in Berlin (West) die Anträge entgegen. Damit in den westlichen Sektoren der Stadt kein Hoheitsakt der DDR stattfand, wurden sie in den Osten gebracht, um die Passierscheine auszustellen. Am nächsten Morgen brachte man die Scheine wieder zurück und händigte sie den Antragstellern aus ${ }^{112}$. Angesichts der Tatsache, daß es den Berlinern nach über zwei Jahren ermöglicht wurde, für einige Tage wieder zusammenzukommen, war diese Vereinbarung für Brandt sowohl politisch wie psychologisch ein „riesengroßer kleiner Erfolg"113. Am Rhein beurteilte man hingegen das Abkommen äußerst reserviert. Man sah vor allem den politischen Nutzen, den die DDR aus den Kontakten mit dem Berliner Senat ziehen konnte. Wurde trotz der salvatorischen Klausel der Alleinvertretungsanspruch der Bundesrepublik nicht beeinträchtigt, wenn ostdeutsche Funktionäre, die noch dazu in Wahrheit keine Postbeamte waren, sondern den Sicherheitsorganen der DDR angehörten, in Berlin (West) präsent waren ${ }^{114}$ ? Wurde aus dem von Brandt postulierten Drei-MächteStatus von Berlin (West) nicht ein Vier-Mächte-Status, wenn die UdSSR „durch ihre Agenten nach West-Berlin hineingewirkt hat mit der Peinlichkeit, daß der Staatssekretär Wendt nach West-Berlin kommt und dort unter westlichem Polizeischutz diese Dienststellen besichtigt" 115 ? Waren die Verhandlungen zwischen dem Berliner Senat und der Regierung der DDR nicht ein Beweis für die sowjetische Behauptung, der Westteil Berlins sei ein eigenständiges Völkerrechtssubjekt ${ }^{116}$ ?

Ende Dezember 1963 schüttete Schröder gegenüber Rusk sein Herz aus. Er erklärte, er hätte sich strikt gegen die Aufnahme von Verhandlungen ausgesprochen, wenn er nur rechtzeitig von Abuschs Brief vom 5. Dezember erfahren hätte. Zwar könne er für die "Weihnachtssentimentalität" Verständnis aufbringen; dennoch seien die Verhandlungen ein „Fehler“ gewesen, weil sie „zu früh" stattgefunden hätten ${ }^{117}$. Man sei zudem in eine schwierige Lage geraten, da die Öffentlichkeit einen Erfolg erwartet habe. Erneut beklagte er, daß der Berliner Senat seine Ver-

109 Für den Wortlaut der gemeinsamen Erklärung vom 17.12. 1963 vgl. ebenda, S. 1029.

110 Vgl. Osterheld, Außenpolitik, S. 43. Zur juristischen Problematik des Passierscheinabkommens vgl. BUCHHEIM, Deutschlandpolitik, S. 118-120.

111 Vgl. VeTTER, Passierscheine, S. 314.

112 Vgl. die Anlage zum Protokoll der Passierscheinvereinbarung vom 17.12. 1963, in: DzD IV/9, S. 1024-1027.

113 BAHR, Zu meiner Zeit, S. 164.

114 Vgl. VeTtER, Passierscheine, S. $315 \mathrm{f}$.

115 So der Vorsitzende des CDU-Landesverbandes von Berlin (West), Amrehn, vor dem CDU-Bundesvorstand am 17.1. 1964, in: ProtoKolle des CDU-Bundesvorstands, S. 576.

116 Vgl. VeTter, Passierscheine, S. $315 \mathrm{f}$.

117 Deutsch-amerikanische Regierungsbesprechung am 28.12. 1963 in Stonewall, Texas, in: AAPD 1963, Dok. 487, S. 1684. 
handlungsführung zu wenig mit der Bundesregierung abgestimmt habe ${ }^{118}$. Rusk hingegen konnte die Einwände seines Amtskollegen gegen das Passierscheinabkommen nicht nachvollziehen. Er bekannte, die amerikanische Regierung habe die Verhandlungen „ohne Sorge“ verfolgt, da sie davon überzeugt sei, „daß sich Kontakte mit dem Osten zugunsten des Westens auswirken müßten“. Die Bundesregierung habe unnötigerweise ihre "Anziehungskraft" auf die DDR in den vergangenen Jahren stets unterschätzt, bedauerte der Chef des State Department ${ }^{119}$. Sein Gesprächspartner teilte diese positive Beurteilung nicht. Schröder beklagte, die Vereinbarung habe dem Ulbricht-Regime dazu verholfen, den Eindruck zu erwecken, „menschlicher zu sein als es allgemein angenommen werde“. Die Öffentlichkeit könnte zu dem Schluß kommen, Verhandlungen mit der anderen Seite seien nicht nur möglich, sondern lohnten sich auch. Auf diese Weise würde aber „die Anziehungskraft unter Mißbrauch auf die andere Seite verlagert und von ihr zu ihrem Vorteil ausgenutzt". Schröder befürchtete darüber hinaus, daß Bahrs These Unterstützung finden könnte, man müsse die DDR anerkennen, um eine Möglichkeit der Einflußnahme auf Ost-Berlin zu erhalten und dadurch eine Änderung der Politik der SED herbeizuführen. Bahrs Konzept hielt er für „völlig falsch“, da auf diese Weise nur der sowjetische Standpunkt unterstützt würde, die Deutschen hätten die Probleme der Teilung unter sich zu lösen ${ }^{120}$. Schröder stellte klar, daß er Gespräche mit Ost-Berlin nicht prinzipiell ablehne. Dabei müßte aber die Absicht im Vordergrund stehen, humanitäre Erleichterungen auszuhandeln, und nicht, eine Änderung der Deutschland-Politik durchzusetzen. Niemand habe ihm bislang nämlich erklären können, „wie man durch diese Kontakte tatsächlich weiterkomme". Andererseits könnten diese aber zu einer „Quasi-Anerkennung“ der DDR und zu einer „Konsolidierung des SBZ-Regimes“ führen, was „das Ende der bisherigen Deutschlandpolitik und nicht der Anfang einer größeren Aktivität" wäre ${ }^{121}$ ! Entschlossen kündigte er an, er werde es nicht zulassen, daß der Berliner Senat eine gesamtdeutsche Politik betreibe, da dadurch die Vier-Mächte-Verantwortung untergraben würde: „Dies sei nicht nur eine Gefährdung für die Alliierten, sondern auch das Gegenteil der bisherigen Politik." 122

Ein Trost war für ihn nur das Verhalten der DDR während der Verhandlungen: Die Konzessionen, die Ost-Berlin bei der Formulierung des Abkommens gemacht hatte, wertete er als Bestätigung, daß seine Ostpolitik von den richtigen Annahmen ausging. Da West- und Ost-Berliner bislang bereits die Möglichkeit gehabt hätten, sich auf dem Territorium der osteuropäischen Staaten zu treffen, sei die DDR in Zugzwang geraten. Die anderen Warschauer-Pakt-Staaten hätten auf Ulbricht Druck ausgeübt, einer Besuchsregelung zuzustimmen ${ }^{123}$. Allerdings

118 Ebenda, S. 1680 f.

119 Ebenda, S. 1682.

120 Ebenda, S. 1683.

121 Ebenda, S. 1684.

122 Ebenda, S. 1686.

$123 \mathrm{Vgl}$. die deutsch-britische Regierungsbesprechung am 15.1.1964 in London, in: AAPD 1964, Dok. 13, S. 56; sowie den Drahterlaß des Staatssekretärs Carstens an die Botschaft in Washington vom 4.1.1964, PA/AA, B 150, Aktenkopien 1964. 
habe der Berliner Senat nicht das Bestmögliche bei den Verhandlungen herausgeholt und bedauerlicherweise gegenüber Ost-Berlin „viel zu früh nachgegeben“. Nach seiner Auffassung wäre es vorteilhafter gewesen, noch eine Steigerung des Drucks abzuwarten. So jedoch habe Ulbricht eine Vereinbarung erreicht, die er „als großen politischen Erfolg ausgeben habe können“124. Entrüstet zeigte er sich auch darüber, daß Brandt am Potomac großes Ansehen genoß. Mitte Januar 1964 äußerte er gegenüber seinem britischen Kollegen Butler, er habe die in Washington weitverbreitete Besorgnis nicht begreifen können, daß ein Scheitern der Verhandlungen dem Regierenden Bürgermeister hätte schaden können. Die amerikanische Regierung hätte doch die Sachfragen in den Vordergrund stellen müssen und sich nicht darüber Gedanken machen dürfen, welche Auswirkungen ein Abbruch der Gespräche auf das Renommee Brandts haben könnte ${ }^{125}$.

Bei der Bewertung des Passierscheinabkommens kamen die deutschlandpolitischen Gegensätze zwischen Washington und Bonn besonders deutlich zum Vorschein. Die amerikanische Regierung betrachtete die Kontaktaufnahme mit OstBerlin als eine konsequente Fortentwicklung der Osteuropa-Politik der Bundesregierung ${ }^{126}$, während diese darin eine Gefahr sah. Nach Schröders Einschätzung war die Politik Brandts ein Irrweg, weil sie Ulbricht die Gelegenheit bot, als humanitärer Wohltäter aufzutreten und sein Ansehen in der Bevölkerung zu steigern. Die Passierscheine trugen somit indirekt zu einer Stabilisierung des SEDRegimes bei und standen in Widerspruch zu der von ihm beabsichtigten Isolierung der DDR. Auf der Sitzung der CDU/CSU-Bundestagsfraktion am 10. März 1964 erklärte der Außenminister im Hinblick auf die Verhandlungen zwischen dem Berliner Senat und der DDR: „Es sei aber zu fragen, ob nicht das andere, was man betreibe, störe. Während man eine Art umfassende Bewegung zu machen suche, gebe es an der falschen Stelle einen Ausbruch" ${ }^{127}$. Vergeblich versuchte er, seinen amerikanischen Kollegen auf diesen Gesichtspunkt aufmerksam zu machen. Rusk, so berichtete er dem britischen Außenminister Butler enttäuscht, sehe hingegen bereits eine Art „De-facto-Wiedervereinigung“ am Horizont auftauchen, falls die Kontakte zwischen den beiden deutschen Staaten noch zunehmen würden und eine größere Reisefreiheit für die Bevölkerung der DDR ausgehandelt werden könnte ${ }^{128}$. In der Tat, ein innerdeutscher Dialog wäre ganz im Sinne

124 Gespräch des Bundesministers Schröder mit dem britischen Außenminister Butler am 16. 1. 1964 in London, in: ebenda, Dok. 15, S. 76.

$125 \mathrm{Vgl}$. ebenda. Vgl. auch die Ausführungen Schröders vor dem CDU-Bundesvorstand am 17. 1. 1964, in: PROTOKOLLE DES CDU-BundesvorSTANDS, S. $584 \mathrm{f}$.

$126 \mathrm{Vgl}$. die deutsch-amerikanische Regierungsbesprechung am 28.12. 1963 in Stonewall, Texas, in: AAPD 1963, Dok. 487, S. $1684 \mathrm{f}$.

127 Zitiert nach HildebraND, Von Erhard zur Großen Koalition, S. 92. Vgl. auch das Gespräch des Bundesministers Schröder mit dem britischen Außenminister Butler am 16. 1. 1964 in London, in: AAPD 1964, Dok. 15, S. 76; und das Gespräch des Bundeskanzlers Erhard mit dem Regierenden Bürgermeister Brandt am 6.3. 1964, in: ebenda, Dok. 64, S. 308.

128 Gespräch des Bundesministers Schröder mit dem britischen Außenminister Butler am 16. 1.1964 in London, in: ebenda, Dok. 15, S. 76. Vgl. auch die Ausführungen Schröders vor dem CDU-Bundesvorstand am 17.1.1964, in: PROTOKOLLE DES CDU-BundesvorSTANDS, S. 585. 
der amerikanischen Entspannungspolitik gewesen. Mit dem Passierscheinabkommen hatte der Berliner Senat ein erstes, schwerwiegendes Problem in Angriff genommen, das aus der Teilung Deutschlands entstanden war. Das Abkommen gab am Potomac Anlaß zu der Hoffnung, daß ähnliche Vereinbarungen, die für menschliche Erleichterungen sorgen könnten, auch auf anderen Gebieten möglich seien, solange man pragmatisch vorginge und nicht sogleich auf einer Änderung des politischen Status quo bestünde. Würde man den eingeschlagenen Weg Schritt für Schritt weitergehen, könnte die Teilung humaner gestaltet und gleichzeitig das Verhältnis zum Ostblock entkrampft werden. Eine Veränderung der bestehenden politischen Verhältnisse, wie sie die Bundesregierung mit ihrem Deutschland-Plan anstrebte, sorgte dagegen nach Ansicht der Amerikaner für Spannungen und erschwerte die Aussichten, weitere Vereinbarungen mit der anderen Seite zu treffen. Hingegen hielt Schröder an dem Gedanken fest, die Änderung des Status quo müßte das vorrangige Ziel des Westens bleiben: „Es handle sich nicht darum, die Bevölkerung zu gewinnen, vielmehr müsse die kommunistische Führungsschicht weggebracht werden." 129

Für die Bundesregierung wurde es indes immer schwieriger, ihre DeutschlandPolitik der Öffentlichkeit verständlich zu machen. Während sie sich bemühte, die deutschlandpolitischen Rechtspositionen zu wahren, sah sie sich immer öfter mit der Frage konfrontiert, welche konkreten Erfolge damit bislang erreicht worden seien. Die juristischen Feinheiten, die im Gespräch mit Ost-Berlin gemäß der vertretenen Rechtsposition beachtet werden mußten, waren kaum mehr vermittelbar: Was war der Unterschied zwischen deutschlandpolitisch gefährlichen ,Kontakten mit der Regierung der DDR und den erlaubten ,technischen Kontakten'? Schröder gab zu, dies werde man „Lieschen Müller nie klarmachen können“130. Die „mobile Deutschlandpolitik“ der SPD stieß dagegen auf breite Resonanz ${ }^{131}$. Unter dem Strich brachten die Passierschein-Verhandlungen das für viele Deutsche entscheidende Ergebnis, daß die Mauer, die Deutschland teilte, für mehr als zwei Wochen zumindest in eine Richtung etwas durchlässiger geworden war. Brandt strebte deshalb eine Wiederholung der Passierscheinvereinbarung an den Osterund Pfingstfeiertagen 1964 an $^{132}$. Die Bundesregierung forderte für diesen Fall eine bessere Berücksichtigung der bestehenden deutschlandpolitischen Grundsätze. Erhard stellte die Bedingung, im Gegensatz zu der Passierscheinregelung vom Dezember dürfe eine neue Vereinbarung absolut nichts enthalten, was als Bestätigung der sowjetischen Drei-Staaten-Theorie interpretiert werden könnte ${ }^{133}$. Damit riskierte er ein Scheitern der Gespräche, denn es war ziemlich unwahrscheinlich, daß die DDR eine Revision des Abkommens zu ihren Ungunsten hinnehmen würde. Doch im Grunde wünschte der Kanzler auch gar keine Neuauf-

129 Gespräch des Bundesministers Schröder mit dem britischen Außenminister Butler am 16. 1. 1964 in London, in: ebenda, Dok. 15, S. 76.

130 So Schröder vor dem CDU-Bundesvorstand am 17.1. 1964, in: PROTOKOLLE DES CDUBUNDESVORSTANDS, S. 599.

131 Vgl. Hildebrand, Von Erhard zur Großen Koalition, S. 193.

132 Vgl. das Gespräch des Bundeskanzlers Erhard mit dem Regierenden Bürgermeister Brandt am 6. 3. 1964, in: AAPD 1964, Dok. 66, S. 315.

$133 \mathrm{Vgl}$. ebenda, S. 307. 
lage der Passierscheinvereinbarung, da er darin ein "Trojanisches Pferd“ des Ostens sah. Seiner Ansicht nach beabsichtigte die DDR auf diesem Weg, die Bindungen zwischen Berlin (West) und der Bundesrepublik zu lockern, um letztendlich die Dreiteilung Deutschlands durchzusetzen ${ }^{134}$. Außerdem wollte Erhard verhindern, daß die DDR durch derartige Vereinbarungen "weiter hoffähig“ würde ${ }^{135}$.

Obwohl Schröder Anfang März 1964 das Passierscheinabkommen positiver beurteilte als noch zwei Monate zuvor und nun mehr Vor- als Nachteile darin sah, warnte er Brandt ebenfalls vor einer Wiederholung der Vereinbarung, "da sie die Argumentation Pankows, das ein Interesse daran habe, die Unabhängigkeit Berlins vom Bund zu demonstrieren, erleichtert"136. Die Bundesregierung habe dem Abkommen im Dezember „ausschließlich aus humanitären Gesichtspunkten“ zugestimmt, machte der Minister deutlich, das Ulbricht-Regime habe es jedoch „zu politischen Zwecken mißbraucht“. Er schloß sich deshalb dem Standpunkt des Bundeskanzlers an und verlangte ebenfalls eine deutliche Verbesserung der Vereinbarung 137. Vor allem die Ausgabe der Passierscheine durch eine ostdeutsche Behörde auf dem Hoheitsgebiet der Bundesrepublik war ihm ein Dorn im Auge. Er wollte es nicht hinnehmen, daß ein weiteres Mal Postbeamte der DDR, die in Wirklichkeit mehrheitlich dem Staatssicherheitsdienst angehörten, in Berlin (West) tätig und dort den Eindruck einer staatlichen Aktivität der DDR erwecken würden ${ }^{138}$. Unmißverständlich machte er auf die "Quasi-Fakten“ zu Lasten der Bundesrepublik aufmerksam, die dadurch geschaffen würden ${ }^{139}$. Bleibe das Abkommen ein Einzelfall, dann könnte es angesichts seiner humanitären Zielsetzung sogar als positiv beurteilt werden, meinte Schröder. Eine Erneuerung der Vereinbarung habe aber zur Folge, „daß der Wiederholungseffekt die menschliche Seite stark herunterschneidet, aber die politische Seite vergrößert" 140 .

Brandt hingegen protestierte entschieden gegen den Beschluß des Bundeskabinetts, eine erneute Präsenz von DDR-Beamten nicht mehr zu erlauben. Er hielt es für falsch, im nachhinein neue Forderungen zu stellen ${ }^{141}$. Einer über den Rundfunk verbreiteten Erklärung war zu entnehmen, daß der Regierende Bürgermei-

134 OSTERHELD, Außenpolitik, S. 55.

135 Gespräch des Bundeskanzlers Erhard mit Ministerpräsident Erlander am 9.3. 1964, in: AAPD 1964, Dok. 67, S. 327.

136 So Schröder in dem Gespräch des Bundeskanzlers Erhard mit dem Regierenden Bürgermeister Brandt am 6. 3. 1964, in: ebenda, Dok. 64, S. 308.

137 So Schröder in dem Gespräch des Bundeskanzlers Erhard mit Ministerpräsident Erlander am 9. 3. 1964, in: ebenda, Dok. 67, S. 327. Vgl. auch das Gespräch des Bundesministers Schröder mit dem indischen Botschafter Menon am 6.3. 1964, in: ebenda, Dok. 66, S. $314 \mathrm{f}$.

138 Vgl. ebenda, S. 315.

139 Rede Schröders auf dem 12. Bundesparteitag der CDU am 16. 3. 1964 in Hannover, in: DzD IV/10, S. 424.

140 So Schröder auf der CDU/CSU-Fraktionssitzung am 10.3. 1964. Zitiert nach HILDEBRAND, Von Erhard zur Großen Koalition, S. 94.

$141 \mathrm{Vgl}$. das Gespräch des Bundeskanzlers Erhard mit dem Regierenden Bürgermeister Brandt am 6. 3. 1964, in: AAPD 1964, Dok. 64, S. 306. 
ster die Berlin-Politik der Bundesregierung für konzeptionslos hielt ${ }^{142}$. Ferner gab er zu verstehen, daß er nicht gewillt war, sich den Anweisungen aus Bonn zu beugen: Er, Brandt, sei „kein französischer Präfekt, kein Untergebener des Bundeskanzlers"143. Durch solche Äußerungen brachte er wiederum die Bundesregierung gegen sich auf, weil sie ihre politische Verantwortung für Berlin in Frage gestellt sah ${ }^{144}$. Bonn verlangte, unmißverständlich herauszustellen, daß die Gespräche zwischen Wendt und Korber einen unpolitischen Charakter hätten. Die DDR dürfe durch die Verhandlungen nicht aufgewertet und der Drei-Staaten-Theorie müsse eine deutliche Absage erteilt werden ${ }^{145}$.

Das Ziel der Bundesregierung, ein günstigeres Abkommen zu erreichen, konnte jedoch nicht erreicht werden. Ulbricht war nicht bereit, hinter die Vereinbarung von Weihnachten 1963 zurückzugehen, sondern verlangte sogar zusätzliche Zugeständnisse, die Ost-Berlin der De-facto-Anerkennung näher gebracht hätten ${ }^{146}$. So kam es nicht zu einer Wiederholung der Passierscheinregelung an Ostern 1964. Erst am 24. September 1964 gelang es, eine neue Vereinbarung zu schließen ${ }^{147}$. Die Bundesregierung bestand diesmal nicht ultimativ auf einer Revision. Schröder wies aber den Berliner Senat an, er müsse „zäh um Verbesserungen gegenüber dem Abkommen vom 17. Dezember 1963 ringen, das eine Minimallösung darstellte" 148 . In der Tat gelang es Korber diesmal, zumindest einige Erleichterungen durchzusetzen. Unter anderem wurde das Verfahren der Antragstellung vereinfacht; auch eine paritätische Präsenz von westlichen und östlichen Beamten in den Passierscheinstellen war jetzt vorgeschrieben. Die Regelung sollte zudem nicht nur an Allerheiligen 1964, sondern auch an den folgenden Feiertagen, also Weihnachten und Neujahr 1964/65 sowie Ostern und Pfingsten 1965, gelten ${ }^{149}$. Damit, so konstatierte das Auswärtige Amt befriedigt, sei es gelungen, „ein rechtliches und materielles Minus zuungunsten der Zone zu erzielen "150. Die massive Kritik, die in Bonn noch ein Jahr zuvor laut geworden war, war nun nicht mehr zu hören. Schröder wertete die Passierscheinvereinbarung jetzt als „per Saldo nützlich“, weil sie das Zusammengehörigkeitsgefühl der Deutschen stärke. Auch konnte er nun keine negativen Wirkungen auf den Rechtsstatus Berlins mehr erkennen: "Politisch und rechtlich bleibt es neutral und ohne Folgen."151

142 Vgl. die Rundfunk- und Fernseherklärung des Regierenden Bürgermeisters von Berlin, Brandt, am 28. 2. 1964, in: DzD IV/10, S. $282 \mathrm{f}$.

143 Zitiert nach dem Artikel „Geständnis im Äther", in: Der SPIEGEL vom 11. 3. 1964, S. 21.

$144 \mathrm{Vgl}$. das Gespräch des Bundeskanzlers Erhard mit dem Regierenden Bürgermeister Brandt am 6. 3. 1964, in: AAPD 1964, Dok. 64, S. 306 f.

145 Vgl. die Aufzeichnung des Referats II 1 vom 10. 4. 1964, in: ebenda, Dok. 92, S. 408-410.

146 Vgl. OSTERHELD, Außenpolitik, S. 73.

147 Für den Wortlaut der Passierscheinvereinbarung vom 24. 9. 1964 vgl. DzD IV/10, S. 987990.

148 Interview Schröders mit der dpa am 1. 9. 1964, in: Bulletin 1964, S. 1270.

149 Vgl. das Protokoll der Passierscheinvereinbarung vom 24. 9. 1964, in: DzD IV/10, S. 987990.

150 Runderlaß des Ministerialdirektors Krapf vom 24. 9. 1964, in: AAPD 1964, Dok. 258, S. 1068.

151 Gespräch des Bundesministers Schröder mit dem britischen Außenminister Gordon Walker am 15. 11. 1964, in: ebenda, Dok. 336, S. 1318. 
Das zweite Passierscheinabkommen vom September 1964 enthielt eine Option, die Regelung im Sommer 1965 um ein Jahr zu verlängern, sobald man sich auf weitere Besuchszeiträume verständigt hätte ${ }^{152}$. Als Korber zu diesem Zweck mit Ost-Berlin wieder Kontakt aufnahm, war die DDR plötzlich nicht mehr bereit, das Abkommen unverändert in Kraft zu lassen. Sie bestand auf Nachbesserungen. Nach zähen Verhandlungen konnte am 25. November 1965 eine neue Übereinkunft für Weihnachten und Neujahr 1965/66 geschlossen werden ${ }^{153}$. Am 7. März 1966 gelang es schließlich, noch ein Abkommen für Ostern und Pfingsten $1966 \mathrm{zu}$ unterzeichnen ${ }^{154}$. Im Dezember 1966 scheiterten jedoch die Bemühungen, ein neues Protokoll auszuhandeln, da Ost-Berlin die salvatorische Klausel im Protokoll nicht länger akzeptieren wollte. Ulbricht verlangte jetzt die völkerrechtliche Anerkennung durch den Senat von Berlin (West) ${ }^{155}$. Drei Jahre, nachdem zum ersten Mal die Berliner wieder den Ostteil der Stadt besuchen konnten, war die Mauer wieder so undurchlässig wie in den Tagen nach dem 13. August 1961.

\section{Die „deutsche Nabostkrise“}

Die dramatischen Ereignisse zu Beginn des Jahres 1965, die zum Austausch von Botschaftern mit Israel und dem Abbruch der diplomatischen Beziehungen mehrerer arabischer Staaten mit der Bundesrepublik führten, hatten ihre Wurzeln in den Anfangsjahren der Bundesrepublik. Um die Ereignisse richtig einordnen zu können, ist zumindest ein kurzer Rückblick auf die Entwicklung des Verhältnisses zwischen Bonn und dem 1947 gegründeten israelischen Staat notwendig: Am 27. September 1951 nahm die Bundesregierung erstmals in einer Regierungserklärung zur jüdischen Frage und dem Problem der Wiedergutmachung Stellung. Kanzler Adenauer kündigte an, „mit Vertretern des Judentums und des Staates Israel, der so viele heimatlose jüdische Flüchtlinge aufgenommen hat, eine Lösung der materiellen Wiedergutmachungsprobleme herbeizuführen, um damit den Weg zur seelischen Bereinigung unendlichen Leides zu erleichtern" ${ }^{156}$. Bonn erklärte sich bereit, mit offiziellen Vertretern Israels über die Wiedergutmachungsfrage zu verhandeln, nachdem sich zuvor die Kontakte auf den Jüdischen Weltkongreß und dessen Vorsitzenden, Nahum Goldmann, beschränkt hatten. Fast genau ein Jahr später, am 10. September 1952, unterzeichneten Adenauer und der israelische Außenminister Moshe Sharett in Luxemburg ein Wiedergutmachungsabkommen

152 Vgl. das Protokoll der Passierscheinvereinbarung vom 24. 9. 1964, in: DzD IV/10, S. 989; sowie die Denkschrift „Die Passierscheinvereinbarungen“ des Abgeordneten Lummer (CDU) vom 12.1. 1966, in: DzD IV/12, S. $66 \mathrm{f}$.

153 Für den Wortlaut der Passierscheinvereinbarung vom 25.11. 1965 vgl. DzD IV/11, S. 953-955.

154 Für den Wortlaut der Passierscheinvereinbarung vom 7. 3. 1966 vgl. DzD IV/12, S. 291294. Es wurden also insgesamt vier Vereinbarungen geschlossen, die für acht Besuchszeiträume galten. HildEBRAND, Von Erhard zur Großen Koalition, S. 94, spricht dagegen irrtümlich von acht Vereinbarungen.

155 Vgl. BrandT, Begegnungen, S. 106; Hildebrand, Von Erhard zur Großen Koalition, S. 196.

156 Der Deutsch-Israelische Dialog, Teil I, Bd. 1, S. 47. 
über 3 Milliarden DM, die Bonn bis 1966 an Israel zu zahlen hatte ${ }^{157}$. Zur Abwicklung des Abkommens wurde in der Bundesrepublik die sogenannte Israel-Mission unter der Leitung von Felix E. Shinnar eingerichtet. Es handelte sich dabei nicht um eine diplomatische Vertretung, sondern um eine halbamtliche israelische Regierungsagentur, die nur für die Dauer des Abkommens, also bis zum 31. März 1966, bestehen sollte ${ }^{158}$. Bei seiner berühmten Unterredung mit David Ben Gurion im Waldorf Astoria Hotel am 14. März 1960 in New York bot Adenauer dem um deutsche Kredite bittenden israelischen Ministerpräsidenten zusätzliche finanzielle Unterstützung an, nannte aber keine Einzelheiten. Dennoch legte die israelische Regierung das Angebot des Kanzlers so aus, daß die Bundesrepublik Israel über zehn Jahre eine Entwicklungshilfe in Form eines Darlehens von jährlich 200 Millionen DM gewähren würde ${ }^{159}$. Tatsächlich überwies Bonn im Rahmen der intern als Aktion Geschäftsfreund bezeichneten Absprache zwischen 1961 und 1965 insgesamt 629,4 Millionen DM an Tel Aviv ${ }^{160}$. Bereits im Dezember 1957 hatte Verteidigungsminister Strauß mit dem Generalsekretär im israelischen Verteidigungsministerium, Shimon Peres, militärische Hilfen für Israel vereinbart. Nur ein enger Kreis von Eingeweihten wußte, daß die Bundesrepublik seit 1958 unter dem Decknamen Frank[reich]/Kol[onien] heimlich Waffen an Israel lieferte ${ }^{161}$. Selbst das Auswärtige Amt war darüber nicht informiert ${ }^{162}$. Der Umfang der Lieferungen nahm im Laufe der Zeit immer mehr zu. Bis 1961 erhielt der jüdische Staat Waffen im Wert von 20 Millionen DM. 1962 wurde eine weitere Absprache über die Abgabe von Militärmaterial in Höhe von 239 Millionen DM getroffen ${ }^{163}$.

Obwohl also zwischen Tel Aviv und Bonn zahlreiche Kontakte bestanden, unterhielten die beiden Staaten keine diplomatischen Beziehungen. Zunächst war es die israelische Regierung, die eine Aufnahme diplomatischer Beziehungen mit einem deutschen Staat nicht in Betracht zog, da angesichts des Holocaust ein derartiger Schritt sowohl bei der israelischen Öffentlichkeit wie bei den Juden in aller Welt auf Unverständnis gestoßen wäre ${ }^{164}$. Zu Beginn der sechziger Jahre änderte Israel jedoch seine Meinung. Immer intensiver drängte man die Bundesregierung,

157 Für den Wortlaut des Abkommens vom 10. 9. 1952 zwischen der Bundesrepublik und Israel über die Wiedergutmachung (Luxemburger Abkommen) vgl. ebenda, S. 75-91.

158 Vgl. dazu Artikel 12 des Luxemburger Abkommens vom 10. 9. 1952, in: ebenda, S. 84-86.

159 Vgl. JELINEK/BLASIUS, Ben Gurion und Adenauer im Waldorf Astoria, S. 330-334; sowie den Drahtbericht des Botschafters Pauls, Tel Aviv, an Bundesminister Schröder vom 24. 4. 1966, in: AAPD 1966, Dok. 120, S. 528-531.

160 Vgl. BLASIUS, Die schwierige Interpretation der Patriarchen.

161 Vgl. STRauss, Erinnerungen, S. 341-346; SHINNAR, Bericht eines Beauftragten, S. 136143; HÜNSELER, Die außenpolitischen Beziehungen der Bundesrepublik zu den arabischen Staaten, S. 142-144, HANSEN, Geheimvorhaben, S. 230-244.

162 Strauß versicherte Carstens noch am 10.6. 1961, es würden keine Waffen an Israel geliefert. Vgl. die Aufzeichnung des Staatssekretärs Carstens vom 4. 1. 1965, in: AAPD 1965, Dok. 2, S. 6 f.

163 Vgl. ebenda, S. 9 f.; sowie den Drahterlaß des Staatssekretärs Carstens an Botschafter Federer, Kairo, vom 27. 1. 1965, in: ebenda, Dok. 39, S. 195. Einen Überblick über Umfang und Art der Lieferungen findet sich in der Aufzeichnung des Ministerialdirektors Pauls vom 21. 10. 1964, in: AAPD 1964, Dok. 289, S. 1164-1167.

164 Vgl. Deutschkron, Israel, S. 86; Ben NATAN, Brücken, S. 79. 
den Austausch von Botschaftern einzuleiten. Adenauer hatte für diesen Wunsch Verständnis. Im Februar 1963 teilte er dem Auswärtigen Amt mit, er „halte den Zeitpunkt für gekommen, diplomatische Beziehungen zu Israel aufzunehmen"165. Schröder sprach sich jedoch dagegen aus, da er befürchtete, ein derartiger Schritt könnte die arabischen Staaten veranlassen, entweder die Beziehungen zur Bundesrepublik abzubrechen oder die DDR völkerrechtlich anzuerkennen. Er prophezeite eine weitere Aushöhlung der westlichen Position im Nahen Osten, die seit der Suez-Krise im Jahr 1956 auf schwachen Beinen stand. Davon, so argumentierte der Außenminister, profitiere allein die UdSSR, die die Möglichkeit erhielte, ihre Stellung in der Krisenregion weiter auszubauen, wodurch aber auch die Bedrohung Israels weiter zunehmen würde. Er kam deshalb zu dem Schluß, der Austausch von Botschaftern sei im Grunde nicht im israelischen Interesse ${ }^{166}$.

Weder Adenauer noch Shinnar stimmten mit der Analyse des Außenministers überein. In einem Gespräch am 5. April 1963 versuchte der Leiter der Israel-Mission Schröder davon zu überzeugen, daß die Deutschland-Politik der Bundesrepublik durch die Aufnahme diplomatischer Beziehungen mit Israel nicht beeinträchtigt werde ${ }^{167}$. Schröder ging auf die Argumente Shinnars nicht ein. Er erwiderte ausweichend, die Zeit für einen derartigen Schritt sei noch nicht reif ${ }^{168}$. Der Außenminister nahm aber trotzdem in den nächsten Monaten Sondierungen auf, wie die arabischen Staaten auf ein solches Vorhaben reagieren würden. Anfang August 1963 führte er dem ägyptischen Botschafter in Bonn, Ibrahim Sabri, vor Augen, daß die Aufnahme diplomatischer Beziehungen zwischen Bonn und Tel Aviv sogar Vorteile für die arabische Welt mit sich brächte, „da dann die Bundesrepublik vielleicht unbefangener mit Israel sprechen könnte“. Im Augenblick sei die Bundesregierung bekanntermaßen gegenüber Israel "anfälliger"169. Diese Argumentation war nicht nur Taktik. Schröder war in der Tat über das Auftreten der israelischen Regierung verärgert: Israel, so beklagte er sich einmal bei Couve de Murville, verlange einerseits finanzielle Hilfe, stelle aber andererseits die Bundesrepublik immer wieder öffentlich an den Pranger, obwohl Bonn sich nicht auf die gleiche Weise verteidigen könne ${ }^{170}$. Nach einer Normalisierung der Beziehungen, führte er am 22. September 1963 gegenüber dem Staatssekretär im amerikanischen Außenministerium, Ball, aus, könnten sich die Israelis jedoch nicht länger ein Verhalten erlauben, welches an „Erpressung“ grenze ${ }^{171}$. Gegenüber dem ägyptischen Botschafter wies er auch auf den Druck der Öffentlichkeit in der Bundesrepublik

165 Schreiben Adenauers an Schröder vom 15.2. 1963, PA/AA, B 150, Aktenkopien 1963. Vgl. auch AAPD 1963, S. 404, Anm. 2.

166 Vgl. das Schreiben des Bundesministers Schröder an Bundeskanzler Adenauer vom 13. 3. 1963, in: AAPD 1963, Dok. 121, S. 404.

167 Vgl. das Gespräch des Bundesministers Schröder mit dem Leiter der Israel-Mission, Shinnar, am 5. 4. 1963, in: ebenda, Dok. 142, S. 464-466.

168 Vgl. ebenda, S. 466.

169 Gespräch des Bundesministers Schröder mit dem ägyptischen Botschafter Sabri am 9. 8. 1963, in: ebenda, Dok. 289, S. 963.

170 Vgl. das Gespräch des Bundesministers Schröder mit dem französischen Außenminister Couve de Murville am 3. 7. 1964, in: AAPD 1964, Dok. 181, S. $734 \mathrm{f}$.

171 Diese Äußerung wurde von Schröder nachträglich aus der Gesprächsaufzeichnung gestrichen. Vgl. AAPD 1963, S. 1211 Anm. 10. 
hin, dem sich die Bundesregierung in dieser Frage ausgesetzt sehe. Ihr werde vorgeworfen, sie zögere aus Angst vor einer heftigen Reaktion der arabischen Staaten, diplomatische Beziehungen zu Israel aufzunehmen. Die Bundesregierung befinde sich folglich „zwischen zwei Feuern"; der einzige Ausweg sei der Austausch von Botschaftern mit Israel. Doch alle Argumente Schröders blieben wirkungslos. Sabri ließ keinen Zweifel daran, daß die arabischen Staaten dies nicht hinnehmen würden ${ }^{172}$.

Aufgrund der starren Haltung der arabischen Staaten ist es nicht erstaunlich, daß das von Adenauer gegenüber Shinnar am 16. August 1963 abgegebene Versprechen, bis zum Ende seiner Amtszeit, also bis zum Oktober, die Aufnahme diplomatischer Beziehungen mit Israel zu vereinbaren ${ }^{173}$, im Auswärtigen Amt für höchste Aufregung sorgte. Eindringlich warnte Carstens, die Risiken eines solchen Beschlusses stünden „, in keinem Verhältnis zu den möglichen Vorteilen"174. Schröder sah katastrophale Folgen für die Nichtanerkennungspolitik Bonns voraus: „Hätten aber erst einmal die 12 arabischen Staaten mehr oder weniger vollzählig die sogenannte DDR und ihre Regierung anerkannt, wäre die Hallstein-Doktrin nicht mehr zu halten und Kettenreaktionen mindestens in der neutralen Welt nicht mehr zu vermeiden." 175 Außerdem, so erläuterte er dem Kanzler, stünde Bonn bei den Arabern im Wort. Ihnen sei wiederholt zugesichert worden, der Status quo würde beibehalten werden. Sollte sich die Bundesregierung nun anders entscheiden, würde sie ihre Glaubwürdigkeit verlieren ${ }^{176}$. Angesichts des Widerstands des Auswärtigen Amts gab Adenauer sein Vorhaben auf. Am 16. September 1963 bestätigte er seinem Außenminister schriftlich, die Aufnahme diplomatischer Beziehungen mit Israel sei „zur Zeit nicht möglich“177. Da aber abzusehen war, daß sich die israelische Regierung auf Dauer nicht mit dem momentanen unbefriedigenden Zustand begnügen würde, stellte Schröder Über-

172 Gespräch des Bundesministers Schröder mit dem ägyptischen Botschafter Sabri am 9. 8. 1963, in: ebenda, Dok. 289, S. 963.

173 Vgl. das Schreiben des Bundeskanzlers Adenauer an Bundesminister Schröder vom 17. 8. 1963, in: ebenda, Dok. 307, S. 1038.

174 Aufzeichnung des Staatssekretärs Carstens vom 17.8. 1963, in: ebenda, Dok. 310, S. 1043.

175 Schreiben des Bundesministers Schröder an Bundeskanzler Adenauer vom 27. 8. 1963, in: ebenda, Dok. 318, S. 1064.

176 Vgl. ebenda, S. 1063 f. Erst am 13. 3. 1963 hatte das Auswärtige Amt in einer Note die arabischen Staaten informiert, eine Änderung der Haltung der Bundesregierung in der Frage einer Aufnahme diplomatischer Beziehungen zu Israel sei „nicht eingetreten“. Vgl. PA/ AA, Referat I B 4, Bd. 43. Regierungssprecher von Hase bekräftigte dies erneut auf einer Pressekonferenz Ende Mai 1963. Vgl. den Artikel „Strauß besucht Kibbuz-Siedlungen in Galiläa“, in: FrankfURTER Allgemeine ZEITUNG vom 30. 5. 1963, S. 3.

177 Schreiben des Bundeskanzlers Adenauer an Bundesminister Schröder vom 16. 9. 1963, in: AAPD 1963, Dok. 341, S. 1132. Bereits am 1.9. 1963 hatte der Kanzler in einem Schreiben an Schröder bestritten, Shinnar die Aufnahme diplomatischer Beziehungen zugesichert zu haben. Er, Adenauer, habe lediglich erklärt, daß er einem solchen Schritt „positiv gegenüberstünde“, aber zuvor „Erkundungen über diese Frage einziehen würde“. Vgl. ebenda, Dok. 324, S. 1079. Diese Behauptung steht aber im Widerspruch zu seiner eindeutigen Weisung an den Außenminister in seinem Schreiben vom 17.8. 1963. Vgl. ebenda, Dok. 307, S. 1038. 
legungen an, Tel Aviv Beziehungen unterhalb der diplomatischen Ebene anzubieten, etwa in Form von Handelsvertretungen ${ }^{178}$. Die Idee wurde aber nicht weiter verfolgt, da die Experten des Auswärtigen Amts zu der Auffassung gelangten, die Reaktion der arabischen Staaten würde darauf nicht günstiger ausfallen als bei der Aufnahme voller diplomatischer Beziehungen ${ }^{179}$.

Die Hallstein-Doktrin, die entwickelt worden war, um andere Staaten von einer völkerrechtlichen Anerkennung Ost-Berlins abzuhalten, schien sich nun gegen ihre Schöpfer zu richten. Mit der Drohung, die DDR völkerrechtlich anzuerkennen, hatten die arabischen Staaten ein Mittel in der Hand, um Einfluß auf die Nahostpolitik der Bundesrepublik zu nehmen und Bonn von der Aufnahme diplomatischer Beziehungen mit Israel abzuhalten. Die Bundesregierung hatte kaum Zweifel, daß die Araber tatsächlich entschlossen waren, im Ernstfall mit Bonn zu brechen. Man rechnete im schlimmsten Fall mit einer „Kettenreaktion in der neutralistischen Welt" ${ }^{180}$. Schon jetzt konstatierte das Auswärtige Amt an vielen Orten Rückschläge für den Alleinvertretungsanspruch der Bundesrepublik ${ }^{181}$. Sollte im Nahen Osten die DDR von einer Reihe von Staaten völkerrechtlich anerkannt werden, könnte dies das entscheidende Signal für andere Regierungen sein, die bereits mehr oder weniger verdeckt Kontakte zu Ost-Berlin unterhielten, nun ebenfalls diplomatische Beziehungen aufzunehmen. Ein Durchbruch durch die Nichtanerkennungspolitik Bonns auf breiter Front hätte aber das unweigerliche Ende der bisherigen Deutschland-Politik bedeutet.

Angesichts der überaus prekären Situation im Nahen Osten war die Bundesrepublik mit dem Beschluß, Waffen an Israel zu liefern, ein großes Risiko eingegangen. Damit gab Bonn den arabischen Staaten ein weiteres Druckmittel in die Hand, denn diesen blieben die Lieferungen nicht lange verborgen. Zunächst hielten sie sich aus eigenem Interesse mit Kritik daran zurück. Ägypten hatte nämlich in der Bundesrepublik Wissenschaftler und Techniker für Rüstungsprojekte angeworben und fürchtete, die Bundesregierung könnte dagegen Maßnahmen ergreifen ${ }^{182}$. Doch wenn es nötig sein sollte, konnte die ägyptische Regierung jederzeit die deutsch-israelischen Waffengeschäfte publik machen und die Bundesregierung damit in schwerste Bedrängnis bringen, da sie mehrmals erklärt hatte, sie würde keine Waffen in Spannungsgebiete liefern. Die geheimen Vereinbarungen hingen somit "wie ein Damokles-Schwert über der westdeutschen Nahostpolitik"183. Daher protestierte das Auswärtige Amt, als es von der Militärhilfe an Israel erfuhr, sogleich energisch beim Verteidigungsministerium. Staatssekretär Carstens, der am 11. Juli 1962 an einer Besprechung zwischen Peres und Strauß teilnahm, sprach sich entschieden gegen die Lieferung von Waffen aus und wollte nur die

178 Vgl. den Vermerk des Staatssekretärs Carstens vom 16. 10. 1963, in: ebenda, Dok. 390, S. 1327.

179 Vgl. die Botschafterkonferenz vom 21. 4. 1964, in: AAPD 1964, Dok. 105, S. 459.

180 Ebenda.

181 Vgl. dazu die Aufzeichnung des Ministerialdirektors Krapf vom 2. 2. 1965, in: AAPD 1965, Dok. 53, S. 244.

182 Vgl. die Aufzeichnung des Ministerialdirektors Jansen vom 16.6. 1964, in: AAPD 1964, Dok. 164, S. 669-671.

183 BERGGÖTZ, Nahostpolitik, S. 438. 
Übergabe von Ausrüstungsmaterial bewilligen ${ }^{184}$. Als Adenauer zwei Wochen später die Verschickung von Panzern an Israel genehmigte, erklärte Schröder unmißverständlich: „Ganz falsch. Ich übernehme keine Verantwortung dafür.“ Er appellierte an den Kanzler, weder mit Ägypten noch mit Israel irgendwelche Rüstungsgeschäfte zu tätigen ${ }^{185}$. Auch als im Juni 1964 die Vereinigten Staaten Bonn baten, dem israelischen Staat weitere 150 Panzer vom Typ M 48 zur Verfügung zu stellen, machte der Außenminister die „allerschwersten Bedenken“ gegen eine solche Vereinbarung geltend ${ }^{186}$. Erhard billigte jedoch unter der Bedingung, daß die Panzer zunächst ohne Geschütz und Motor nach Italien gebracht, dort umgerüstet und erst dann nach Israel verschifft würden, diese Transaktion im Wert von circa 30 Millionen $\mathrm{DM}^{187}$.

Ende Oktober 1964 berichteten die Frankfurter Rundschau und die Londoner Times über Waffenlieferungen der Bundesrepublik an Israel ${ }^{188}$ und zündeten damit die von Adenauer und Strauß der Regierung Erhard hinterlassene „Zeitbombe" 189 . Die Artikel waren derart fundiert, daß die Bundesregierung ein Dementi für sinnlos erachtete ${ }^{190}$. Regierungssprecher von Hase gab am 30 . Oktober $1964 \mathrm{zu}, \mathrm{daß}$ die Bundesrepublik den Israelis militärische Hilfe geleistet hatte, machte aber keine Aussagen über den Umfang der Lieferungen ${ }^{191}$. Es ist noch nicht geklärt, wer der Presse die Informationen in die Hände spielte. Michael Wolffsohn hält es sogar für möglich, daß das Auswärtige Amt die Informationen weitergab, um die Geschäfte auf diese Weise zu unterbinden ${ }^{192}$. Erwartungsgemäß reagierte die arabische Öffentlichkeit auf die Meldungen mit großer Empörung. Man bezichtigte die Bundesregierung, ein doppeltes Spiel zu treiben. Hatte sie nicht beteuert, keine Lieferung von Rüstungsgütern in Krisenregionen durchzuführen? Die arabische Presse rief ihre Regierungen dazu auf, nun den bisherigen Standpunkt in der Deutschland-Frage zu überdenken ${ }^{193}$.

Zusätzlich wurden die deutsch-arabischen Beziehungen durch eine Initiative des Bundestags belastet, der Tätigkeit von deutschen Staatsbürgern in der Rüstungsproduktion ausländischer Staaten einen Riegel vorzuschieben. Hinter die-

184 Vgl. die Aufzeichnung des Staatssekretärs Carstens vom 4. 1. 1965, in: AAPD 1965, Dok. 2, S. 9 f.; CARSTENS, Erinnerungen, S. 307.

185 Aufzeichnung des Staatssekretärs Carstens vom 4. 1. 1965, in: AAPD 1965, Dok. 2, S. 11.

186 Schreiben des Bundesministers Schröder an Bundeskanzler Erhard vom 5.6. 1964, in: AAPD 1964, Dok. 151, S. 604.

187 Vgl. das Gespräch des Bundeskanzlers Erhard mit Präsident Johnson in Washington am 12. 6. 1964, in: ebenda, Dok. 161, S. 653. Vgl. auch BLASIUS, Überfälliges Bekenntnis zum Staat Israel.

188 Vgl. AAPD 1964, S. 1215, Anm. 2; HANSEN, Geheimvorhaben, S. 250.

189 SCHWARZ, Adenauer II, S. 544.

190 Vgl. die Aufzeichnung des Staatssekretärs von Hase, Bundespresseamt, vom 2. 11. 1964, in: AAPD 1964, Dok. 306, S. 1215-1217; sowie den Runderlaß des Staatssekretärs Carstens vom 3. 11. 1964, in: ebenda, Dok. 308, S. 1227-1229.

$191 \mathrm{Vgl}$. HÜNSELER, Die außenpolitischen Beziehungen der Bundesrepublik zu den arabischen Staaten, S. 145.

192 Vgl. WOLFFSOHN, Der schwierige Anfang nach der „Endlösung“, S. 12.

193 Vgl. dazu die Aufzeichnung des Ministerialdirektors Jansen vom 3.11. 1964, PA/AA, B 150, Aktenkopien 1964. 
sem Ansinnen steckte natürlich die Absicht, der Arbeit der Rüstungsexperten aus der Bundesrepublik in Ägypten ein Ende zu setzen, die in der Öffentlichkeit heftigst kritisiert wurde ${ }^{194}$. Außerdem wurde der Druck auf die Verantwortlichen in Bonn immer stärker, die Aufnahme diplomatischer Beziehungen mit Israel nicht länger hinauszuschieben. Am 26. Oktober 1964 bat der Vorsitzende des Rats der Evangelischen Kirche in Deutschland, Kurt Scharf, Bundespräsident Lübke sowie die Bundesregierung Schritte für einen baldigen Botschafteraustausch in die Wege zu leiten ${ }^{195}$. Der DGB startete sogar eine Unterschriftenaktion ${ }^{196}$. Schließlich brachte Altbundeskanzler Adenauer die Bundesregierung weiter in Bedrängnis, indem er behauptete, im Auswärtigen Amt existierten Strömungen, die gegen Israel gerichtet seien ${ }^{197}$. Schröder wies diese Unterstellung umgehend zurück ${ }^{198}$, doch der Vorwurf des Antisemitismus stand nun im Raum.

Die Nahostpolitik der Bundesregierung geriet also im Spätherbst 1964 ins Kreuzfeuer der Kritik von In- und Ausland. Dies veranlaßte Schröder zu einem warnenden Brief an den Kanzler. Darin führte er aus, er verfolge die Entwicklung des deutsch-arabischen Verhältnisses mit „sehr großer Sorge“199. Es müßten schleunigst Gegenmaßnahmen ergriffen werden, da der Bundesrepublik ansonsten „schwerer Schaden“ drohe ${ }^{200}$. An erster Stelle sei die Militärhilfe für Israel einzustellen, die er „von Anfang an [...] für falsch gehalten“ habe. Erneut verwies der Außenminister auf die Undankbarkeit der israelischen Regierung: „Die Israelis honorieren unsere Großzügigkeit nicht, sondern setzen uns in anderen Fragen unter sehr starken Druck, wohl wissend, daß wir von der Tatsache unserer Waffenlieferungen an sie nicht sprechen und ihnen daher dieses Argument nicht entgegenhalten können. "201 Lediglich die finanzielle Hilfe sollte fortgesetzt werden. Die Aufnahme diplomatischer Beziehungen lehnte Schröder hingegen immer

194 Für den Wortlaut des von der SPD-Fraktion am 25.6. 1964 eingebrachten Antrags vgl. BT ANLAGEN, Bd. 91, Drucksache IV/2355.Vgl. auch das Schreiben Schröders an Erhard vom 9. 11. 1964, in: AAPD 1964, Dok. 315, S. 1244.

195 Für den Wortlaut der Schreiben vgl. PA/AA, Büro Staatssekretär, Bd. 138. Dagegen bekräftigte Carstens am 4. 11. 1964 im Bundestag nochmals, die Bundesregierung denke im Moment nicht daran, mit Israel diplomatische Beziehungen aufzunehmen. Vgl. BT STENOGRAPHISCHE BERICHTE, Bd. 56, S. 7095.

196 Vgl. dazu ebenda, S. 7271.

197 Vgl. den Artikel „Schröder über Verhältnis zu Israel“, in: SÜDDEUTSCHE ZEITUNG vom 4. 12. 1964, S. 4.

198 Vgl. Schröders Ausführungen im Bundestag am 3. 12. 1964: BT STENOGRAPHISCHE BERICHTE, Bd. 56, S. 7361.

199 Schreiben des Bundesministers Schröder an Bundeskanzler Erhard vom 9.11. 1964, in: AAPD 1964, Dok. 315, S. 1244. Obwohl mit dem Geheimhaltungsgrad streng gebeim gekennzeichnet, wurde das Schreiben Ende März 1965 in der Presse inhaltlich wiedergegeben. Vgl. ebenda, S. 1244, Anm. 1. Osterheld behauptet, Schröder hätte die Weitergabe veranlaßt, um der Öffentlichkeit rückwirkend zu zeigen, er sei nicht für die negative Entwicklung der Beziehungen zu den arabischen Staaten in den vorausgangenen Monate verantwortlich, sondern habe die Krise vorausgesehen und rechtzeitig vor den Konsequenzen einer Fortsetzung der Waffenlieferungen an Israel gewarnt. Vgl. OSTERHELD, Außenpolitik, S. 182.

200 Schreiben des Bundesministers Schröder an Bundeskanzler Erhard vom 9. 11. 1964, in: AAPD 1964, Dok. 316, S. 1245.

201 Ebenda, S. 1246. 
noch $a b$, da sie „einen schweren Einbruch in wichtigste Positionen unserer Deutschland-Politik“ mit sich brächte ${ }^{202}$. Statt dessen empfahl er die Errichtung von Handelsmissionen, denen konsularische Rechte übertragen werden sollten. Im Gegenzug sollte die Entwicklungshilfe für die arabischen Staaten erhöht werden, um sie dadurch zu besänftigen. Außerdem legte er dem Kanzler nahe, den ägyptischen Präsidenten, Gamal Abdel Nasser, zu einem Staatsbesuch in die Bundesrepublik einzuladen. Schröder verlangte ferner, das geplante Gesetz, das die Aktivitäten von Deutschen in der Rüstungsindustrie ausländischer Staaten verbieten sollte, derart zu formulieren, daß die Experten in Ägypten nicht davon betroffen wären ${ }^{203}$. Dem Außenminister kam es somit vor allem darauf an, einen Bruch mit Ägypten zu vermeiden. Diese Konzentration der Nahostpolitik auf die VAR ${ }^{204}$ erklärt sich aus der Schlüsselstellung, die Nasser sowohl in der arabischen Welt als auch im Lager der Blockfreien einnahm. Auf der Konferenz der blockfreien Staaten vom 5. bis 10. Oktober 1964 in Kairo hatte die VAR beispielsweise den Alleinvertretungsanspruch Bonns unterstützt und dadurch die Haltung der anderen Konferenzteilnehmer entscheidend zugunsten der Bundesrepublik beeinflußt ${ }^{205}$.

Mit seiner Hauptforderung - der Einstellung der Waffenlieferungen - konnte sich Schröder nicht durchsetzen. Zumindest einige der Anregungen seines Außenministers griff Erhard aber auf: Am 15. Dezember 1964 erklärte der Kanzler öffentlich, er beabsichtige als ersten Schritt zur Aufnahme diplomatischer Beziehungen, Israel die Eröffnung von Handelsmissionen anzubieten ${ }^{206}$. Bereits vier Wochen zuvor, am 12. November, hatte er Nasser mitgeteilt, er werde in Kürze eine offizielle Einladung zu einem Staatsbesuch erhalten ${ }^{207}$. Bundestagspräsident Gerstenmaier, der sich vom 20. bis 23. November in Ägypten aufhielt, versuchte ebenfalls auf die Verantwortlichen in Kairo einzuwirken. ${ }^{208}$ Nach seiner Rückkehr sprach auch er sich dafür aus, die Waffenlieferungen an Israel zu stoppen, plädierte aber zugleich dafür, zu eruieren, inwieweit das Verhältnis zu Tel Aviv normalisiert werden könnte, ohne die Deutschland-Politik der Bundesrepublik zu gefährden ${ }^{209}$. Im Auswärtige Amt erachtete man ohnehin die umgehende Beendigung der militärischen Zusammenarbeit mit Israel für unausweichlich. Mini-

\footnotetext{
202 Ebenda, S. 1247.

203 Vgl. ebenda, S. $1246 \mathrm{f}$.

204 Trotz des Austritts Syriens aus der Föderation mit Ägypten im Jahr 1961 bezeichnete sich der ägyptische Staat auch weiterhin als Vereinigte Arabische Republik (VAR).

205 Vgl. die Kabinettsvorlage des Auswärtigen Amts vom 4. 1. 1965, in: AAPD 1965, Dok. 1, S. 3; sowie den Drahtbericht des Botschafters Federer, Kairo, an das Auswärtige Amt vom 14. 10. 1964, PA/AA, B 150, Aktenkopien 1964.

206 Vgl. den Artikel „Bundeskanzler Erhard lehnt eine Große Koalition ab“, in: DIE WeLT vom 16. 12. 1964, S. 2.

207 Vgl. das Schreiben des Bundeskanzlers Erhard an Präsident Nasser vom 12. 11. 1964, in: AAPD 1964, Dok. 326, S. $1284 \mathrm{f}$.

$208 \mathrm{Zu}$ den Gesprächen Gerstenmaiers in Kairo vgl. den Drahtbericht des Botschafters Federer, Kairo, an Staatssekretär Carstens vom 23.11. 1964, in: ebenda, Dok. 352, S. 1374 1379; sowie GERSTENMAIER, Streit, S. 499-501.

209 Vgl. die Aufzeichnung des Ministerialdirektors Jansen vom 11. 12. 1964, in: AAPD 1964, Dok. 385, S. 1515-1517.
} 
sterialdirektor Meyer-Lindenberg, der Leiter der Politischen Abteilung I, machte Schröder darauf aufmerksam, das Waffengeschäft würde ebenso wie die Bemühungen um die Herstellung voller diplomatischer Beziehungen von den Arabern „als Beweis dafür gewertet, daß die Bundesregierung [...] einseitig für Israel Partei nimmt“210. An der Koblenzer Straße befürchtete man einen deutschlandpolitischen Seitenwechsel Nassers, dem sich in einem Domino-Effekt die anderen arabischen Staaten anschließen könnten. Die Nahost-Experten des Amts rechneten damit, daß bereits auf der Tagung der Staats- und Regierungschefs der Arabischen Liga im Januar 1965 eine Resolution verabschiedet werden würde, derzufolge man die DDR völkerrechtlich anerkennen werde, falls Bonn die Lieferung von Rüstungsgütern an Israel nicht einstellte ${ }^{211}$. Schröder drängte darauf, daß das Bundeskabinett deshalb den bisherigen Grundsatz der Bundesregierung, keine Waffen in Spannungsgebiete zu liefern, nochmals offiziell bekräftigte. Die militärische Zusammenarbeit mit Israel sollte beendet, die eingegangenen Verpflichtungen aber noch erfüllt werden ${ }^{212}$. Da bis Ende Januar 1965 den Israelis Waffen im Wert von 161 Millionen DM übergeben worden waren, stand folglich noch die Lieferung von Rüstungsgütern in Höhe von 78 Millionen DM aus. Von den 150 Panzern, die zusätzlich zu diesen Verpflichtungen Israel ausgehändigt werden sollten, waren inzwischen 60 Stück verschickt worden ${ }^{213}$. Das Auswärtige Amt nahm auch von dem Angebot, über die Errichtung von Handelsvertretungen zu verhandeln, wieder Abstand, da sich inzwischen herausgestellt hatte, daß die israelische Regierung daran nicht interessiert war. Sie bevorzugte volle diplomatische Beziehungen und wollte sich nicht mit halben Lösungen zufriedengeben ${ }^{214}$. Der diplomatische Status einer Handelsvertretung wäre zudem niedriger gewesen als derjenige der Israel-Mission. Diese wurde nämlich, ebenso wie die finnische Handelsvertretung, vom Auswärtigen Amt im diplomatischen Verkehr unter die Rubrik „Andere Vertretungen“ eingestuft, was ihrem Leiter - im Gegensatz zu den Chefs der osteuropäischen Handelsvertretungen - unter anderem das Recht gab, an Empfängen des Bundespräsidenten teilzunehmen ${ }^{215}$. Schröder überlegte deshalb, den Israelis anzubieten, das Aufenthaltsrecht der Israel-Mission über die Laufzeit des Wiedergutmachungsabkommens hinaus zu verlängern. Zwar hätte dies zur Folge gehabt, daß die Bundesrepublik weiterhin keine offizielle Vertretung in Israel besaß, doch hätte man auf diese Weise das bei der Errichtung von Handelsvertretungen entstehende Risiko vermieden, daß die arabischen

210 Aufzeichnung des Ministerialdirektors Meyer-Lindenberg vom 11. 1. 1965, in: AAPD 1965, Dok. 9, S. 45.

211 Vgl. die Kabinettsvorlage des Auswärtigen Amts vom 4. 1. 1965, in: ebenda, Dok. 1, S. 4.

212 Vgl. ebenda, S. 3-5.

213 Vgl. den Drahterlaß des Staatssekretärs Carstens an Botschafter Federer, Kairo, vom 27. 1. 1965, in: ebenda, Dok. 39, S. 196.

214 So der israelische Ministerpräsident Eshkol in einem Interview am 5.1. 1965 mit dem ZDF. Vgl. dazu die Aufzeichnung des Ministerialdirektors Meyer-Lindenberg vom 25. 1. 1965, PA/AA, B 150, Aktenkopien 1965.

215 Aufzeichnung des Staatssekretärs Carstens vom 25. 1. 1965, in: AAPD 1965, Dok. 33, S. 177. 
Staaten mit dem Austausch von Handelsvertretungen mit der DDR antworteten $^{216}$.

Während sich in Bonn der Entscheidungsfindungsprozeß hinzog, spitzte sich die Krise weiter zu. Bis Mitte Januar 1965 war Präsident Nasser immer noch keine offizielle Einladung zu einem Staatsbesuch übergeben worden. Schröder machte Terminprobleme dafür verantwortlich. Erst wenn diese mit dem ägyptischen $\mathrm{Au}$ ßenministerium geklärt seien, könnte Nasser förmlich eingeladen werden, teilte er Gerstenmaier mit ${ }^{217}$. Der Bundestagspräsident warf dem Auswärtigen Amt dagegen Untätigkeit vor. Er befürchtete, die Bemühungen Bonns, Nasser zu besänftigen, könnten schließlich wegen der eigenen Nachlässigkeit vergeblich gewesen sein $^{218}$. Für große Verwirrung in Bonn sorgte eine Meldung des amerikanischen Fernsehsenders CBS am 20. Januar 1965, derzufolge sich die zwischen der Bundesrepublik und Israel vereinbarte Rüstungshilfe auf insgesamt 320 Millionen DM belief. Als das Auswärtige Amt deswegen von der Presse zur Rede gestellt wurde, lehnte es eine Stellungnahme ab und verwies auf das Verteidigungsministerium. Die Hardthöhe wiederum erklärte den Journalisten, sie müßten sich an das Außenministerium wenden. Schließlich nahm die Bundesregierung Stellung und bezeichnete eine derartige Summe als reine Spekulation 219 . Dieses halbherzige Dementi wurde aber von der Weltöffentlichkeit nicht mehr zur Kenntnis genommen. Eine Woche, nachdem der CBS-Bericht über den Äther gegangen war, bewahrheitete sich die Prognose des Bundestagspräsidenten: Nasser wandte sich von der Bundesrepublik ab und verkündete, er werde zur Unterzeichnung eines Kreditabkommens über 78 Millionen US-Dollar den Staatsratsvorsitzenden der DDR, Walter Ulbricht, in der VAR empfangen 220.

Dem Botschafter der Bundesrepublik in Kairo, Georg Federer, wurde umgehend die Weisung erteilt, die Reise Ulbrichts „unter allen Umständen zu verhindern" und deswegen so schnell wie möglich das Gespräch mit dem ägyptischen Präsidenten zu suchen ${ }^{221}$. Federer sollte Nasser versprechen, die Bundesregierung würde keine neuen Rüstungsvereinbarungen mit der israelischen Regierung

$216 \mathrm{Vgl}$. ebenda, S. $176 \mathrm{f}$.

217 Vgl. das Schreiben des Bundesministers Schröder an Bundestagspräsident Gerstenmaier vom 18. 1. 1965, PA/AA, B 150, Aktenkopien 1965.

$218 \mathrm{Vgl}$. das Schreiben des Bundestagspräsidenten Gerstenmaier an Bundesminister Schröder vom 11. 1. 1965, in: AAPD 1965, Dok. 10, S. 49-52. Zwei Tage später wandte sich Gerstenmaier erneut an den Außenminister und warnte nochmals vor den Konsequenzen, wenn die Absprachen mit Nasser nicht eingehalten würden. Für den Wortlaut des Schreibens vom 13. 1. 1965 vgl. PA/AA, B 150, Aktenkopien 1965. Vgl. auch GERSTENMAIER, Streit, S. 502.

219 Vgl. DEUTSCHKRON, Israel, S. 263.

220 Vgl. HiLDEBRAND, Von Erhard zur Großen Koalition, S. 114. Klaus Hildebrand vermutet, wegen der starken Abhängigkeit von der UdSSR, in die die VAR geraten war, habe Nasser derart heftig auf das Bekanntwerden der deutschen Militärhilfe reagierte. Er erinnert in diesem Zusammenhang unter anderem auf das militärische und wirtschaftliche Hilfsabkommen, das anläßlich des Besuchs des sowjetischen Stellvertretenden Ministerpräsidenten, Alexander Schelepin, im Dezember 1964 zwischen der VAR und der Sowjetunion geschlossen wurde. Vgl. ebenda, S. $113 \mathrm{f}$.

221 Drahterlaß des Staatssekretärs Carstens an Botschafter Federer, Kairo, vom 27. 1. 1965, in: AAPD 1965, Dok. 39, S. 196. 
schließen, falls die Einladung zurückgezogen werde. Auch eine Reduzierung der noch ausstehenden Lieferungen werde in Bonn erwogen. Mindestens 50 der noch ausstehenden 60 Panzer sowie sechs zugesagte Schnellboote würden nicht übergeben werden ${ }^{222}$. Außerdem sollte Federer eine "namhafte Wirtschaftshilfe" in Aussicht stellen ${ }^{223}$. Schröder gab dem Botschafter des weiteren den Auftrag, Nasser zu garantieren, Bonn werde "sicher nicht bis zu den Wahlen in Deutschland diplomatische Beziehungen mit Israel aufnehmen"224. Dies hatte Erhard am 28. Januar 1965 dem Außenminister in Anwesenheit von Carstens zugesichert ${ }^{225}$.

Einen Tag zuvor hatte sich das Kabinett mit der Lage im Nahen Osten befaßt. Schröder hatte den Antrag gestellt, die Militärhilfe an Israel einzustellen, jedoch mit der Finanzhilfe fortzufahren. Als Ausgleich sollte den arabischen Staaten jährlich der dreifache Betrag dieser Hilfe, also 500 Millionen DM, zur Verfügung gestellt werden. Die Frage nach der künftigen Form der amtlichen Beziehungen zu Tel Aviv ließ der Außenminister offen. Er stellte drei Optionen zur Diskussion: Den Austausch von Handelsvertretungen, die Verlängerung der Israel-Mission sowie die Eröffnung einer eigenen Mission in Israel. Außerdem empfahl er nachdrücklich, den Präsidenten der VAR offiziell in die Bundesrepublik einzuladen ${ }^{226}$. Doch das Kabinett weigerte sich, Nasser als Staatsgast zu empfangen, denn „die unverschämte Einladung Nassers an Ulbricht dürfe nicht auch noch prämiert werden“227. Ebenso wollte man sich noch nicht auf die Art der Beziehungen zu Israel festlegen. Es wurde sogar beschlossen, die Waffenlieferungen an Israel fortzusetzen. Den Abschluß neuer Rüstungsgeschäfte mit Israel wollte Erhard vom weiteren Verhalten Nassers abhängig machen. Auch eine Gesetzesinitiative, die der Bundesrepublik nur noch den Waffenhandel mit NATO-Staaten erlaubt hätte, wurde abgelehnt ${ }^{228}$. Erhard schlug also einen "Zick-Zack-Kurs“ ein ${ }^{229}$ : Einerseits schreckte er davor zurück, hinsichtlich der Gestaltung der Beziehungen zu Israel eine Entscheidung zu treffen, andererseits kam er auch den Arabern in der Frage der Waffenlieferungen nicht entgegen.

Es gab also für Nasser keinen Anlaß, die Einladung an Ulbricht aufzuheben. Im übrigen ist es mehr als zweifelhaft, ob wirklich eine Chance vorhanden war, den ägyptischen Präsidenten zum Einlenken zu bewegen. Botschafter Federer berichtete am 1. Februar 1965 nach Bonn, seiner Einschätzung nach sei die Einladung an den Staatsratsvorsitzenden eine „völlig entschiedene Sache“. Nasser ziehe sogar

222 Vgl. ebenda, S. 196.

223 Ebenda, S. 197.

224 Drahterlaß des Bundesministers Schröder an Botschafter Federer, Kairo, vom 29. 1. 1965, PA/AA, B 150, Aktenkopien 1965.

225 Vgl. die Aufzeichnung des Staatssekretärs Carstens vom 18. 5. 1965, PA/AA, B 150, Aktenkopien 1965.

226 Vgl. die Aufzeichnung des Staatssekretärs Carstens vom 27. 1. 1965, in: AAPD 1965, Dok. 40, S. 199; sowie OSTERHELD, Außenpolitik, S. $152 \mathrm{f}$.

227 OSTERHELD, Außenpolitik, S. 152.

228 Vgl. die Aufzeichnung des Staatssekretärs Carstens vom 27.1. 1965, in: AAPD 1965, Dok. 40, S. $199 \mathrm{f}$.

229 WOLfFSOHN, Der schwierige Anfang nach der „Endlösung“, S. 12. 
die völkerrechtliche Anerkennung der DDR in Erwägung 230 . Angesichts dieser alarmierenden Nachricht glaubte Erhard, in der Frage der Rüstungsgeschäfte nachgeben zu müssen. Am 3. Februar rief er eine Besprechung auf höchster Ebene ein. Dort legte der Kanzler fest, die Bundesrepublik werde sich künftig wieder an den Grundsatz halten, keine Waffen in Spannungsgebiete zu liefern. Da der Nahe Osten als ein solches Gebiet anzusehen sei, erteilte er dem Auswärtigen Amt die Weisung, Verhandlungen mit dem Ziel aufzunehmen, eine Ablösung der noch ausstehenden Lieferungen zu erreichen ${ }^{231}$. Israel sollte fortan Geld anstelle von Waffen erhalten. Der Hintergedanke dieses Beschlusses war, die Front der Araber aufzubrechen und zu verhindern, daß sich die anderen arabischen Staaten mit Nasser solidarisch erklärten, falls im Zuge des Ulbricht-Besuchs die Spannungen weiter zunehmen würden. Während sich die Araber in ihrer Entrüstung über den Waffenhandel der Bundesrepublik einig waren, war nämlich auch in ihren Reihen der Flirt des ägyptischen Präsidenten mit dem ersten Mann der DDR umstritten ${ }^{232}$. Nach außen wirkte die Entscheidung Erhards aber „wie eine Kapitulation Bonns vor Nasser". Man fragte sich, ob allein die Drohung, die Nichtanerkennungspolitik der Bundesrepublik nicht länger zu respektieren, genügte, um Bonn zum Nachgeben zu bringen ${ }^{233}$.

Das Auswärtige Amt suchte nun, Rückendeckung in Washington zu erlangen. Carstens bat die amerikanische Regierung, ihren Einfluß in Tel Aviv geltend zu machen, damit Israel einer Beendigung des Waffengeschäfts gegen Zahlung einer Entschädigungssumme zustimme ${ }^{234}$. Aus Washington kam jedoch die Antwort, die Bundesrepublik solle die vereinbarte Lieferung von Rüstungsgütern fortsetzen. Angesichts der Tatsache, daß die vereinbarte Geheimhaltung nicht mehr gewährleistet war, hielt Schröder dies für "unmöglich“235. Am 12. Februar sprach Botschafter Knappstein im State Department vor. Gegenüber Averell Harriman wiederholte er die Bitte Bonns, die amerikanische Regierung möge auf Israel einwirken. Der Abteilungsleiter im State Department entgegnete indes, die Bundesrepublik habe kein Recht, die Hilfe zu stoppen. Beim Abschluß des Geschäfts sei vereinbart worden, daß sie nur dann die Lieferung von Panzern einstellen dürfte, wenn durch ein Verschulden der israelischen Seite die Transaktion der Öffentlichkeit bekannt würde. Die Pressemeldungen, so Harriman, würden aber eindeutig aus einer Bonner Quelle stammen ${ }^{236}$. Am folgenden Tag lehnten die USA das Ersuchen der

230 Drahtbericht des Botschafters Federer, Kairo, an das Auswärtige Amt vom 1. 2. 1965, in: AAPD 1965, Dok. 48, S. 230.

231 Vgl. die Aufzeichnung des Staatssekretär Carstens vom 3. 2. 1965, PA/AA, B 150, Aktenkopien 1965; OSTERHELD, Außenpolitik, S. $154 \mathrm{f}$.

232 Vgl. den Drahterlaß des Staatssekretärs Carstens an die Botschafter von Etzdorf (London), Klaiber (Paris) und Knappstein (Washington) vom 17.2. 1965, in: AAPD 1965, Dok. 84, S. 347.

233 Hildebrand, Von Erhard zur Großen Koalition, S. 115.

234 Vgl. den Drahterlaß des Staatssekretärs Carstens an die Botschaft in Washington vom 6. 2. 1965, in: AAPD 1965, Dok. 57, S. 260.

235 Gespräch des Bundesministers Schröder mit dem amerikanischen Botschafter McGhee am 11. 2. 1965, in: ebenda, Dok. 70, S. 296.

236 Vgl. den Drahtbericht des Botschafters Knappstein, Washington, an Staatssekretär Carstens vom 12. 2. 1965, in: ebenda, Dok. 74, S. 313-316. 
Bundesregierung „endgültig“ $a b^{237}$. Obwohl McGhee zwar am 22. Februar Schröder bestätigte, daß lediglich eine Geheimhaltungspflicht vereinbart worden war und Harrimans Interpretation der Geschäftsbedingungen völlig aus der Luft gegriffen sei, wollte sich die amerikanische Regierung nicht in den Streit verwickeln lassen. Washington, so deutete der amerikanische Botschafter an, beabsichtige im arabischen-israelischen Konflikt nicht, einseitig Partei zu ergreifen ${ }^{238}$.

Einen Tag, nachdem Erhard den Beschluß gefaßt hatte, die Waffenlieferungen einzustellen, am 4. Februar, wurde Shinnar darüber informiert. Staatssekretär Lahr erinnerte den Leiter der Israel-Mission an die Absprache, die Diskretion zu wahren. Obwohl der Handel nun aufgeflogen sei, sei die Bundesregierung dennoch bereit, Israel für die noch ausstehenden Güter finanziell zu entschädigen, erklärte Lahr ${ }^{239}$. Sechs Tage später teilte Shinnar Carstens jedoch mit, seine Regierung bestehe auf der vollständigen Abwicklung des Geschäfts. Die Panzerlieferungen könnten aber, wenn von Bonn erwünscht, rascher als vorgesehen durchgezogen werden ${ }^{240}$. Der Staatssekretär zeigte sich „tief enttäuscht" über diese Antwort und wies sie als inakzeptabel zurück. Auch er wies Shinnar auf die Geheimhaltungsklausel hin. Durch das Bekanntwerden der Transaktion sei zweifelsohne eine Änderung der Geschäftsgrundlage eingetreten ${ }^{241}$. Hinsichtlich der Frage der Aufnahme diplomatischer Beziehungen hatte der israelische Missionsleiter bereits am 29. Januar das Bundeskanzleramt darüber in Kenntnis gesetzt, daß seine Regierung immer noch auf den Austausch von Botschaftern bestehe ${ }^{242}$. Shinnar entsann sich, daß Bonn 1959 die Errichtung eines Generalkonsulats der DDR in der VAR nicht als völkerrechtliche Anerkennung der DDR interpretiert habe ${ }^{243}$. Sollte also die Bundesrepublik ein Konsulat in Israel eröffnen, würde sie damit indirekt die These Nassers, Israel sei kein Staat, unterstützen, folgerte der Diplomat ${ }^{244}$.

Am 11. Februar erläuterte der Chef des Bundeskanzleramts, Westrick, Shinnar nochmals die Entscheidung Erhards, keine Waffen mehr in sogenannte Spannungsgebiete zu liefern. Anschließend bekundete der Kanzler seinen Willen, Israel angemessen zu entschädigen. Mit der Ankündigung, sich für eine Verlängerung der Verjährungsfristen für Verbrechen aus der NS-Zeit einzusetzen, unterbreitete Er-

237 Drahtbericht des Botschafters Knappstein, Washington, an das Auswärtige Amt vom 13. 2. 1965, PA/AA, B 150, Aktenkopien 1965.

238 Vgl. das Gespräch des Bundesministers Schröder mit dem amerikanischen Botschafter McGhee am 22. 2. 1965, in: AAPD 1965, Dok. 89, S. 370.

239 Vgl. den Drahterlaß des Staatssekretärs Carstens an die Botschaft in Washington vom 6. 2. 1965 , in: ebenda, Dok. 58 , S. 259 f.

240 Vgl. die Aufzeichnung des Staatssekretärs Carstens vom 10. 2. 1965, in: ebenda, Dok. 65, S. $286 \mathrm{f}$.

241 Ebenda, S. 287.

242 Vgl. das Gespräch des Bundesministers Westrick mit dem Leiter der Israel-Mission, Shinnar, am 29. 1. 1965, PA/AA, B 150, Aktenkopien 1965.

243 Bereits am 22.9. 1959 eröffnete die DDR ein Generalkonsulat in Kairo. In der eingeschränkten Exequatur, die die ägyptische Regierung erteilte, wurde jedoch ausdrücklich betont, daß dadurch "weder eine de-jure- noch eine de-facto-Anerkennung der DDR durch die VAR verbunden sei“. Vgl. Blasius, „Völkerfreundschaft“ am Nil, S. 749.

244 Vgl. das Gespräch des Bundesministers Westrick mit dem Leiter der Israel-Mission, Shinnar, am 29. 1. 1965, PA/AA, B 150, Aktenkopien 1965. 
hard ein weiteres Angebot, das die israelische Regierung zum Einlenken bewegen sollte ${ }^{245}$. Der Leiter der Israel-Mission wurde auch über den fehlgeschlagenen spanischen Vermittlungsversuch in Kairo aufgeklärt ${ }^{246}$. Die spanische Regierung war Anfang Februar von Bonn gebeten worden, in dem Konflikt zwischen der Bundesrepublik und Ägypten zu vermitteln ${ }^{247}$. Daraufhin entsandte Madrid den Generaldirektor im spanischen Außenministerium, Francisco Elorza y Echaniz Marques de Nerva, nach Kairo. Dieser hielt sich jedoch nicht an seine Instruktionen. Obwohl er nicht dazu ermächtigt war, sicherte er der ägyptischen Regierung zu, die Bundesrepublik werde die militärischen Lieferungen an Israel einstellen. Ebenso gab er Kairo fälschlicherweise zu verstehen, Bonn sei bereit, den Besuch Ulbrichts zu tolerieren, falls Ägypten auf eine völkerrechtliche Anerkennung der DDR verzichte und den Staatsratsvorsitzenden nicht wie einen offiziellen Staatsgast empfange. Des weiteren soll er trotz eindeutiger Weisung, diesen Punkt nicht anzusprechen, den Eindruck erweckt haben, Bonn werde keine diplomatische Beziehungen mit Israel aufnehmen ${ }^{248}$. Der ägyptische Präsident versprach ihm im Gegenzug, an seiner Politik der Nichtanerkennung der DDR festzuhalten ${ }^{249}$. Im Auswärtigen Amt fürchtete man, falls die Bundesregierung Israel weiterhin mit Waffen beliefere, werde Nasser zu dem Schluß kommen, er sei von Marques de Nerva bewußt irregeführt worden. Dies könnte für ihn dann der Anstoß sein, die DDR doch noch völkerrechtlich anzuerkennen ${ }^{250}$.

In der Tat klangen die Berichte, die die Botschaft der Bundesrepublik aus Kairo nach Bonn telegraphierte, von Tag zu Tag bedrohlicher. Inzwischen wurde sogar schon verbreitet, Ägypten werde die Beziehungen zur Bundesrepublik abbrechen, falls Israel weiter Rüstungsgüter zur Verfügung gestellt würden ${ }^{251}$. Nasser drehte also den Spieß um und setzte nun seinerseits die Bundesregierung unter Zug-

245 Vgl. das Gespräch des Bundeskanzlers Erhard und des Bundesministers Westrick mit dem Leiter der Israel-Mission, Shinnar, am 11. 2. 1965, in: AAPD 1965, Dok. 70, S. 297301. Die Verjährungsfrist lief in der früheren britischen und französischen Besatzungszone am 8. 5. 1965, in der ehemaligen amerikanischen Zone am 1.7.1965 ab. Vgl. dazu Bulletin 1964, S. 1552f. Bereits am 2. 2. 1965 hatte Ministerialdirektor Krapf Schröder darauf hingewiesen, daß eine Nichtverlängerung der Bundesrepublik im Ausland schweren Schaden zufügen könnte. Krapf befürchtete Einbrüche in die Nichtanerkennungspolitik Bonns. Vgl. die Aufzeichnung des Ministerialdirektors Krapf vom 2. 2. 1965, in: AAPD 1965, Dok. 53, S. $244 \mathrm{f}$.

$246 \mathrm{Vgl}$. das Gespräch des Bundeskanzlers Erhard und des Bundesministers Westrick mit dem Leiter der Israel-Mission, Shinnar, am 11. 2. 1965, in: ebenda, Dok. 70, S. 297-301.

$247 \mathrm{Vgl}$. den Drahterlaß des Staatssekretärs Carstens an Botschafter Allardt, Madrid, vom 2. 2. 1965, PA/AA, B 150, Aktenkopien 1965.

248 Vgl. den Drahterlaß des Staatssekretärs Carstens an Botschafter Knappstein, Washington, vom 12. 2. 1965 sowie die Aufzeichnung von Carstens vom 17. 2. 1965, PA/AA, B 150, Aktenkopien 1965. Vgl. ferner das Gespräch des Staatssekretärs Carstens mit dem Abteilungsleiter im spanischen Außenministerium, Marques de Nerva, am 12.2. 1965, in: AAPD 1965, Dok. 73, S. 307-312.

249 Vgl. das Protokoll der CDU/CSU-Fraktionssitzung am 16. 2. 1965, ACDP VIII-0011010/1.

250 Vgl. die Aufzeichnung des Ministerialdirektors Meyer-Lindenberg vom 15. 5. 1965, in: AAPD 1965, Dok. 77, S. $324 \mathrm{f}$.

251 Vgl. den Drahtbericht des Botschaftsrats I. Klasse Müller, Kairo, an Staatssekretär Carstens vom 8. 2. 1965, in: ebenda, Dok. 61, S. 275 f. 
zwang. In Bonn wurde deshalb der Ruf immer lauter, die ägyptischen Provokationen nicht tatenlos hinzunehmen. Strauß verlangte die Anwendung der HallsteinDoktrin, also den Abbruch der diplomatischen Beziehungen zu Kairo, sobald Ulbricht in der VAR eintreffe. Entweder werde sie angewendet oder man gebe sie auf, meinte der CSU-Vorsitzende ${ }^{252}$. Gerstenmaier forderte ebenfalls die Schließung der Botschaft, da andernfalls die Doktrin ihre Wirkung verliere ${ }^{253}$. Obwohl Ägypten die DDR völkerrechtlich nicht anerkannt hatte und der Besuch Ulbrichts überhaupt nicht mit den beiden Präzedenzfällen Jugoslawien und Kuba ${ }^{254}$ verglichen werden konnte, war er der Ansicht: „Dieser Vorgang sei geradezu der klassische Fall der Hallstein-Doktrin. "255 Schröder hingegen plädierte dafür, die Beziehungen nicht abzubrechen. Er verwies auf Nassers Zusage, trotz der Einladung an Ulbricht auf eine völkerrechtliche Anerkennung Ost-Berlins verzichten zu wollen. Sollte sich die Bundesrepublik voreilig aus Ägypten zurückziehen, dann werde die DDR in die Bresche springen, warnte der Außenminister am 9. Februar 1965 die CDU/CSU-Fraktion. Dies würde aber ohne Zweifel dem Alleinvertretungsanspruch Bonns schweren Schaden zufügen, denn jeder Ort, „den die Bundesrepublik freimache, werde von Pankow eingenommen und es werde eine deutsche Flagge aufgezogen, sicher eine Spalterflagge, aber in den Augen der Leute eine deutsche Fahne". Im übrigen führe an der Einstellung der Waffenlieferungen kein Weg vorbei, da sich ansonsten alle arabischen Staaten gegen die Bundesrepublik stellen würden 256 .

Auch auf die ägyptische Regierung versuchte der Außenminister noch einmal persönlich einzuwirken. Am 13. Februar empfing er den Botschafter der VAR in Bonn, Gamal Mansour. Mit drastischen Worten führte er ihm die Wirkung des Ulbricht-Besuchs auf die deutsche Bevölkerung vor Augen. Ägypten habe innerhalb der neutralen Welt bedauerlicherweise auch in der Vergangenheit bereits eine Vorreiterrolle bei der Aufwertung Ost-Berlins gespielt, erklärte Schröder: So existiere bereits seit 1957 in Kairo eine Handelsmission der DDR, die 1959 in ein Generalkonsulat umgewandelt worden sei; im gleichen Jahr sei der Vorsitzende des Ministerrats der DDR, Otto Grotewohl, Gast der ägyptischen Regierung gewesen $^{257}$. Der Empfang Ulbrichts müsse folglich als „Höhepunkt einer Kette von

252 Vgl. das Protokoll der CDU/CSU-Fraktionssitzung am 9. 2. 1965, ACDP VIII-001$1010 / 1$.

253 Vgl. das Protokoll der CDU/CSU-Fraktionssitzung am 16. 2. 1965, ACDP VIII-0011010/1.

254 Am 19. 10. 1957 brach die Bundesrepublik die Beziehungen zu Jugoslawien ab, weil Belgrad die DDR völkerrechtlich anerkannte. Vgl. ADG 1957, S. 6698-6700. Am 14. 1. 1963 rief Bonn aus demselben Grund seinen Botschafter aus Kuba zurück. Vgl. den Drahtbericht des Botschafters Graf von Spreti, Havanna, an das Auswärtige Amt vom 14. 1. 1963, in: AAPD 1963, Dok. 19, S. 61-63. Auch in der Forschung wird noch heute zuweilen, so z. B. von Volker Hentschel, die Ansicht vertreten, die Entscheidung, die Beziehungen zu Kairo aufrechtzuerhalten, „bedeutete die Aufgabe der Hallstein-Doktrin“. Vgl. HeNTSCHEL, Ludwig Erhard, S. 557.

255 Protokoll der CDU/CSU-Fraktionssitzung am 16. 2. 1965, ACDP VIII-001-1010/1.

256 Protokoll der CDU/CSU-Fraktionssitzung am 9. 2. 1965, ACDP VIII-001-1010-1.

257 Vgl. das Gespräch des Bundesministers Schröder mit dem ägyptischen Botschafter Mansour am 13. 2. 1965, in: AAPD 1965, Dok. 77, S. 316-321. Zu der Handelsmission der 
Ereignissen“ gewertet werden, durch die "die Axt an die Wurzel der deutschen Politik" gelegt werde. Ausdrücklich warnte er die Machthaber in Kairo, auf das kommunistische Pferd zu setzen, „da die deutsche Frage niemals im Ulbrichtschen Sinne entschieden werde“258. Mansour verteidigte freilich das Verhalten seiner Regierung. Die Waffenlieferungen der Bundesrepublik an Israel seien für sein Land „eine Frage auf Leben und Tod“, führte der Botschafter aus. Nur aus „Enttäuschung “ über das Verhalten der Bundesregierung sei Ulbricht eingeladen worden ${ }^{259}$. Schröder wiederum kündigte an, Bonn werde den Besuch nicht widerspruchslos hinnehmen, da dadurch der Alleinvertretungsanspruch der Bundesrepublik „schwerwiegend beeinträchtigt" würde 260 .

Zwei Tage später gab die Bundesregierung bekannt, sie werde die wirtschaftliche Hilfe für Ägypten stoppen, falls Ulbricht in Kairo empfangen würde. Dies gelte auch für den Fall, daß es sich nicht um einen offiziellen Staatsbesuch handeln würde, wie die ägyptische Regierung gegenüber Marques de Nerva angedeutet hatte ${ }^{261}$. Bonn denke jedoch nicht an einen Abbruch der diplomatischen Beziehungen, klärte Carstens in einem Runderlaß die diplomatischen Vertretungen auf ${ }^{262}$. Schröder hielt im Grunde schon den jetzt getroffenen Entschluß für überzogen. Vor der FDP-Fraktion erklärte er am 16. Februar: „Ich bin keineswegs entzückt, daß wir durch das Überziehen irgendeiner Position unseren Platz aufgeben." Er sah die Gefahr, daß Bonn sich durch seine Deutschland-Politik auf der internationalen Bühne allmählich selbst blockierte 263 .

Ebenso wie die Spannungen mit der VAR zunahmen, verschlechterte sich auch das Klima zwischen Bonn und Tel Aviv. Vorläufiger Höhepunkt war am 15. Februar eine Rede des israelischen Ministerpräsidenten vor der Knesseth. Levi Eshkol attackierte die Bundesregierung scharf wegen ihrer Entscheidung, die Waffenlieferungen einzustellen. Er sah darin eine Kapitulation vor den arabischen Staaten. „Israel ist kein Spannungsgebiet“, verkündete der Ministerpräsident und erklärte, seine Regierung werde weder eine finanzielle Entschädigung noch einen materiellen Ersatz für die versprochenen Waffen akzeptieren ${ }^{264}$. Schröder warf daraufhin der israelischen Regierung vor, sie nehme keine Rücksicht darauf, daß Bonn auch an guten Beziehungen zu den arabischen Staaten interessiert sei, son-

DDR und dem Besuch Grotewohls in der VAR BLASIUS, „Völkerfreundschaft“ am Nil, S. 747-749; BERGGÖTZ, Nahostpolitik, S. $425 \mathrm{f}$.

258 Gespräch des Bundesministers Schröder mit dem ägyptischen Botschafter Mansour am 13. 2. 1965, in: AAPD 1965, Dok. 77, S. 317.

259 Ebenda, S. 319.

260 Ebenda, S. 321.

261 Vgl. die Presseerklärung des Staatssekretärs von Hase vom 15. 2. 1965, in: BULLETIN 1965, S. 225; Gespräch des Staatssekretärs Carstens mit dem Abteilungsleiter im spanischen Außenministerium, Marques de Nerva, am 12. 2. 1965, in: AAPD 1965, Dok. 73, S. 308; Drahterlaß des Staatssekretärs Carstens an die Botschafter von Etzdorf (London), Klaiber (Paris) und Knappstein (Washington) vom 17. 2. 1965, in: ebenda, Dok. 84, S. 347.

262 Vgl. ebenda, S. 345 f.

263 Zitiert nach SCHOLLWER, FDP im Wandel, Eintrag vom 16. 2. 1965, S. 246.

264 Vgl. ADG 1965, S. $11697 \mathrm{f}$. 
dern wolle den „totalen Bruch“ der Bundesrepublik mit den Arabern herbeiführen ${ }^{265}$.

Am 20. Februar wurde im Bundeskanzleramt über einen Ausweg aus der verfahrenen Situation diskutiert ${ }^{266}$. Regierungssprecher von Hase meinte, die Bundesrepublik stünde vor der "schwersten Krise“ ihrer Geschichte ${ }^{267}$. Eine „Kampagne des Weltjudentums" sei gegen Bonn im Gange, behauptete er erregt ${ }^{268}$. Nachdem sich Schröder noch einmal für ein bedachtsames Vorgehen gegenüber Ägypten ausgesprochen hatte, um zu verhindern, daß „die schwachen Sicherungen" in Kairo gegen eine Anerkennung der DDR nicht durchbrannten ${ }^{269}$, wurde der Beschluß, die Wirtschaftshilfe einzustellen, bestätigt und präzisiert ${ }^{270}$. Bezüglich der Waffengeschäfte mit Israel erklärte der Bundesminister für wirtschaftliche Zusammenarbeit, Walter Scheel, daß er diese nicht länger decken werde. Er verlangte, die Lieferungen unverzüglich zu stoppen: „Keine Schraube dürfe mehr versandt werden. "271 Schröder setzte sich hingegen dafür ein, gemeinsam mit der israelischen Regierung nach einer Lösung suchen. Falls Tel Aviv eine Ablösung der Lieferungen nicht akzeptiere, sollten alle Absprachen den arabischen Staaten offengelegt werden. Erhard pflichtete in diesem Punkt seinem Außenminister ausdrücklich bei. Ferner trug Schröder erneut seine Idee vor, konsularische Beziehungen mit Israel aufzunehmen und diesen Schritt in der arabischen Welt durch die Vergabe zusätzlicher Kredite abzusichern. Die Anwesenden beschlossen, der CDU-Abgeordnete Erik Blumenfeld solle mit einem engen Vertrauten Eshkols in Verbindung treten und eruieren, welche Verständigungsmöglichkeiten bestünden $^{272}$. Schon zwei Tage später traf Blumenfeld mit dem Kontaktmann des israelischen Ministerpräsidenten, dem Industriellen Xaver Federmann, in Rom zusammen. Dieser berichtete, der Regierungschef Israels sei bereit, einen Gesandten des Bundeskanzlers zu empfangen. Eshkol, so die hoffnungsvolle Botschaft Federmanns, betrachte die Abwicklung der Waffenhilfe inzwischen nur noch als „technisches Problem“, bestehe aber auf der Aufnahme voller diplomatischer Beziehungen ${ }^{273}$.

Zur gleichen Zeit bedrängte Schröder noch einmal die amerikanische Regierung. Das Verhalten Washingtons belaste die bilateralen Beziehungen enorm, betonte Schröder am 22. Februar gegenüber McGhee. In Bonn mache sich das Gefühl breit, „daß die Amerikaner die Deutschen in eine sehr schwierige Situation

265 Zitiert nach SCHOLLWER, FDP im Wandel, Eintrag vom 16. 2. 1965, S. 245.

266 Vgl. dazu die Aufzeichnung des Staatssekretärs Carstens vom 22. 2. 1965, in: AAPD 1965, Dok. 88, S. 363-366; OSTERHELD, Außenpolitik, S. 158.

267 Zitiert nach OSTERHELD, Außenpolitik, S. 158.

268 Aufzeichnung des Staatssekretärs Carstens vom 22.2. 1965, in: AAPD 1965, Dok. 88, S. 365.

269 Ebenda, S. 366.

270 Vgl. ebenda, S. $364 \mathrm{f}$.

271 Ebenda, S. 366.

272 Vgl. ebenda, S. 364-366.

273 Vgl. die Aufzeichnung des Staatssekretärs Carstens vom 23. 2. 1965, PA/AA, B 150, Aktenkopien 1965. 
gebracht hätten und jetzt entweder nicht willens oder nicht fähig seien, der Bundesrepublik in dieser Situation zu helfen". Nochmals beschwor er die USA, der Bundesrepublik gegenüber Israel beizustehen ${ }^{274}$. Im Anschluß an diese Unterredung appellierte auch der Kanzler an den Botschafter, seine Regierung müßte auf Israel einwirken, damit diese eine Ablösung der Waffenlieferungen akzeptierte ${ }^{275}$. Zumindest nahm Washington jetzt in dieser Angelegenheit mit Tel Aviv Kontakt auf. Am 2. März überbrachte McGhee jedoch die Nachricht, die israelische Regierung bestehe auf der Fortführung der Militärhilfe durch die Bundesrepublik ${ }^{276}$. Schröder äußerte sich „sehr enttäuscht“, daß Israel nicht auf das Angebot einging, die Waffenlieferungen abzulösen. Im Grunde, so stellte der Außenminister fest, sei die Bundesregierung nämlich nicht dazu verpflichtet, da es sich bei dem $\mathrm{Ge}$ schäft in Wahrheit um ein "Geschenk" handle ${ }^{277}$. Auch auf die Beziehungen zwischen der Bundesrepublik und der VAR ging der amerikanische Botschafter ein. Inzwischen war nämlich der Besuch Ulbrichts am Nil zu Ende gegangen. Von der ägyptischen Regierung war der Staatsratsvorsitzende am 24. Februar mit allen Ehren empfangen und während seines ganzen Aufenthalts, der bis zum 2. März dauerte, wie ein Staatsgast behandelt worden ${ }^{278}$. Aufgrund der deutlichen Aufwertung der DDR meinte Giselher Wirsing in der Wochenzeitung Christ $\mathcal{E}$ Welt, die Bundesrepublik habe nun ihr „Stalingrad am Nil“ erlebt ${ }^{279}$. Dies war sicherlich übertrieben, denn Kairo war letztendlich davor zurückgeschreckt, die DDR völkerrechtlich anzuerkennen. Die privilegierte Behandlung Ulbrichts mußte jedoch in Bonn als Affront empfunden werden. Die USA fürchteten deshalb, ihr Verbündeter könnte sich nun doch genötigt sehen, darauf mit dem Abbruch der Beziehungen zu reagieren. Einen solchen Schritt halte seine Regierung aber für falsch, teilte McGhee am letzten Tag von Ulbrichts Aufenthalt in der VAR Schröder mit. Die Konsequenz wäre nämlich, daß die arabischen Staaten ihrerseits ihre Botschafter aus Bonn abziehen würden. Wenn die Bundesrepublik aber über keine diplomatischen Vertretungen mehr im Nahen Osten verfügen würde, wäre dort "der Damm gegen den Kommunismus irreparabel durchbrochen“. Der UdSSR böte sich dann genügend Freiraum für eine kommunistische Infiltration, und auch die DDR würde in die von der Bundesrepublik freigemachte Lücke stoßen. Das State Department, so McGhee, betrachte die Lage deshalb als „sehr ernst“. Dieser Beschreibung der Situation pflichtete Schröder ausdrücklich bei, betonte dabei

274 Gespräch des Bundesministers Schröder mit dem amerikanischen Botschafter McGhee am 22. 2. 1965, in: AAPD 1965, Dok. 89, S. 370 f.

$275 \mathrm{Vgl}$. das Gespräch des Bundeskanzlers Erhard mit dem amerikanischen Botschafter McGhee am 22. 2. 1965, in: ebenda, Dok. 90, S. 372-376.

276 Vgl. das Gespräch des Bundesministers Schröder mit dem amerikanischen Botschafter McGhee am 2. 3. 1965, in: ebenda, Dok. 100, S. 415-421.

277 Ebenda, S. 416.

278 Vgl. dazu Osterheld, Außenpolitik, S. 159f. Zu den Gesprächen mit der ägyptischen Regierung vgl. BLASIUS, „Völkerfreundschaft“ am Nil, S. 775-805.

279 Vgl. den Artikel von Giselher Wirsing: „Ein Stalingrad am Nil“, in: CHRIST \& WELT vom 5. 2. 1965, S. 1 . 
aber nochmals, daß gerade deswegen die USA die Bundesrepublik gegenüber Israel nicht im Stich lassen dürften ${ }^{280}$.

Am selben Tag kam das Kabinett zu einer Sitzung zusammen, die angesichts der dramatischen Entwicklung ganz im Zeichen der Krise im Nahen Osten stand. Erhard stellte den Abbruch der Beziehungen zur VAR zur Diskussion, machte dabei aber darauf aufmerksam, daß die "Gefahr einer Kettenreaktion “ in den arabischen Staaten bestehe, solange das Problem der Waffenlieferungen an Israel noch nicht gelöst sei. Auch Schröder warnte vor einer unbedachten Aktion. Bei einer Entscheidung, so der Außenminister, müsse berücksichtigt werden, daß die USA "größten Wert" auf eine Fortführung der diplomatischen Beziehungen zwischen Bonn und Kairo legten. Da es sich offiziell bei dem Aufenthalt Ulbrichts in der VAR um keinen Staatsbesuch gehandelt habe, empfahl er, wie im Vorfeld des Besuchs angekündigt, lediglich mit wirtschaftlichen Sanktionen $\mathrm{zu}$ antworten. Scheel vertrat dieselbe Meinung und selbst Krone sprach sich gegen einen Abbruch aus. Hinsichtlich Israel regte Schröder an, ebenfalls die vereinbarte Linie beizubehalten, also die Waffenlieferungen einzustellen und Tel Aviv eine finanzielle Entschädigung anzubieten. Außerdem sollte entweder die Eröffnung von Handelsvertretungen oder der Austausch von Generalkonsulaten vereinbart werden. Die anschließende Diskussion zeigte jedoch, daß es innerhalb der Regierung immer noch kein einheitliches Meinungsbild gab281.

Zwei Tage später, am 4. März, wurde die Debatte fortgesetzt. Schröder sprach sich wiederum vehement gegen einen Abbruch der Beziehungen zu Ägypten aus: Nasser habe die DDR nicht völkerrechtlich anerkannt; auch die USA rieten dringend davon ab. Mende führte dem Kabinett die Folgen einer derartigen Entscheidung vor Augen. Kairo, so der FDP-Vorsitzende, werde dann endgültig das deutschlandpolitische Lager wechseln. Es dürfe aber nicht geschehen, daß die Bundesrepublik einen Alleinvertretungsanspruch erhebe, aber in Wirklichkeit die DDR über die einzige deutsche diplomatische Vertretung in Ägypten verfüge. Dagegen war Erhard überraschenderweise jetzt der Meinung, der Beschluß, die Wirtschaftshilfe einzustellen, reiche nicht aus. Er trat dafür ein, den Bruch mit der VAR zu vollziehen, selbst wenn damit gerechnet werden müsse, daß Nasser mit der völkerrechtlichen Anerkennung der DDR antworten werde. Wenn gleichzeitig die Waffenlieferungen an Israel gestoppt würden, dann sei nicht damit zu rechnen, daß sich die anderen arabischen Staaten der Entscheidung des ägyptischen Präsidenten anschließen würden, argumentierte der Kanzler. Viele Minister pflichteten ihm bei. Hätte Erhard an diesem Tag abstimmen lassen, hätte die Mehrheit des Kabinetts wohl für den Abbruch der Beziehungen gestimmt, glaubt Osterheld ${ }^{282}$. Nasser hatte es nämlich in der Zwischenzeit geschafft, die Bundesregierung noch mehr gegen sich aufzubringen. Er nahm die Einladung Ulbrichts zu einem Gegenbesuch an und verkündete, in Ost-Berlin werde in Kürze ein

280 Gespräch des Bundesministers Schröder mit dem amerikanischen Botschafter McGhee am 2. 3. 1965, in: AAPD 1965, Dok. 100, S. 415-421 (418).

281 Aufzeichnung des Staatssekretärs Carstens vom 2. 3. 1965, in: ebenda, Dok. 101, S. 422425 (422). Vgl. auch OSTERHELD, Außenpolitik, S. $161 \mathrm{f}$.

282 Vgl. ebenda, S. $164 \mathrm{f}$. 
ägyptisches Generalkonsulat eröffnet werden. Nach dem Urteil des Bundeskanzlers war die VAR damit nur noch „hauchdünn“ von einer völkerrechtlichen Anerkennung der DDR entfernt ${ }^{283}$.

Am 5. März empfing Erhard die Botschafter der Drei Mächte, um ihnen die Nahostpolitik der Bundesrepublik darzulegen. Bonn sehe sich konfrontiert mit einer "großangelegte[n] Offensive der Sowjetunion, wobei Ulbricht die Speerspitze sei", erläuterte der Kanzler und bekräftigte seinen Willen, darauf mit dem Abbruch der Beziehungen zur VAR zu antworten. Dies sei unvermeidlich, wenn die Bundesregierung am Alleinvertretungsrecht festhalten wolle ${ }^{284}$. McGhee widersprach dem Kanzler in einer ungehörigen Weise ${ }^{285}$. Er verlangte von der Bundesregierung beinahe ultimativ, die diplomatischen Beziehungen aufrechtzuerhalten. Der Westen könne auf die Präsenz und den Einfluß Bonns in Ägypten nicht verzichten, behauptete er. Der britische Botschafter Roberts stimmte den Ausführungen seines amerikanischen Kollegen $\mathrm{zu}^{286}$. Selbst die französische Regierung sprach sich gegen den Abbruch der Beziehungen aus, da allein die DDR davon profitiere ${ }^{287}$. McGhee, Roberts und Seydoux nahmen auch an der anschließenden Kabinettssitzung teil, in der Schröder nochmals vor einer überzogenen Reaktion warnte. Erneut plädierte er dafür, nicht mit der VAR zu brechen ${ }^{288}$. Wieder kam es zu einer stundenlangen Debatte, ohne daß am Ende eine Entscheidung getroffen wurde. Diesmal tendierte die Stimmung jedoch wieder zugunsten einer Fortführung der diplomatischen Beziehungen ${ }^{289}$.

Genauso gespalten wie das Kabinett war auch die Union. Adenauer und Strauß forderten den Abbruch der Beziehungen ${ }^{290}$. Strauß verlangte zudem öffentlich den Rücktritt Schröders ${ }^{291}$. Viele Abgeordnete folgten dagegen der Linie des Außenministers, die auch von der FDP unterstützt wurde. Als Barzel am 6. März

283 Gespräch des Bundeskanzlers Erhard mit den Botschaftern der Drei Mächte am 5. 3. 1965, in: AAPD 1965, Dok. 112, S. 458. Am 14. 7. 1965 wurde das ägyptische Generalkonsulat in Ost-Berlin eröffnet. Schröder schlug daraufhin vor, die Generalkonsulate der VAR in Hamburg und Frankfurt/Main zu schließen. Vgl. das Schreiben des Bundesministers Schröder an Bundeskanzler Erhard vom 17. 7. 1965, in: ebenda, Dok. 284, S. 11841187. Erhard zögerte jedoch eine Entscheidung hinaus, da er befürchtete, daß Ägypten dann die DDR völkerrechtlich anerkennen würde. Vgl. die Aufzeichnung des Staatssekretärs Carstens vom 25. 8. 1965, in: ebenda, Dok. 333, S. 1378f. Am 11.11. 1965 teilte Schröder dem Kanzler mit, eine Schließung sei nun nicht mehr angebracht, da inzwischen zu viel Zeit vergangen sei. Es könne nicht mehr plausibel gemacht werden, daß ein solcher Schritt eine Reaktion auf die Eröffnung des ägyptischen Generalkonsulats in der DDR sei. Vgl. PA/AA, B 150, Aktenkopien 1965.

284 Gespräch des Bundeskanzlers Erhard mit den Botschaftern der Drei Mächte am 5.3. 1965, in: AAPD 1965, Dok. 112, S. $457 \mathrm{f}$.

285 Osterheld berichtet, McGhee habe sich gegenüber Erhard fast wie ein „Politruk“ verhalten. Vgl. OSTERHEI.D, Außenpolitik, S. 166.

286 Vgl. das Gespräch des Bundeskanzlers Erhard mit den Botschaftern der Drei Mächte am 5. 3. 1965, in: AAPD 1965, Dok. 112, S. 459-461.

287 OSTERHELD, Außenpolitik, S. 167.

288 Vgl. MENDE, Von Wende zu Wende, S. 172.

289 Vgl. OSTERHELD, Außenpolitik, S. 166.

290 Vgl. ebenda, S. 168.

291 Vgl. BARZEL, Auf dem Drahtseil, S. 41. 
von einer USA-Reise zurückkehrte, schlug er als Ausweg aus dem Dilemma vor, nicht die Beziehungen zur VAR abzubrechen, sondern den Austausch von Botschaftern mit Israel in die Wege zu leiten. Seine Gespräche mit amerikanischen Politikern, darunter Präsident Johnson, sowie mit dem israelischen Botschafter bei der UNO, Avraham Harman, hatten den Fraktionsvorsitzenden der CDU/ CSU zu der Überzeugung gebracht, nicht auf die übliche Weise zu reagieren, sondern durch die Aufnahme diplomatischer Beziehungen zu Israel eine völlig neue Konstellation zu schaffen ${ }^{292}$. Schröder konnte einen solchen Beschluß zunächst noch verhindern. Erhard erteilte dem Abgeordneten Birrenbach, der als Sonderemissär nach Tel Aviv geschickt werden sollte, lediglich den Auftrag, über die Eröffnung von Generalkonsulaten zu verhandeln ${ }^{293}$.

Die Beschlußlage war also am Samstag, den 6. März, folgendermaßen: Die Beziehungen zu Ägypten sollten nicht abgebrochen, dafür aber die Wirtschaftshilfe eingestellt werden. Über die Frage einer Aufnahme diplomatischer Beziehungen $\mathrm{zu}$ Israel sollte in der kommenden Woche im Kabinett erneut beraten werden ${ }^{294}$. Barzel, Strauß, der geschäftsführende Vorsitzende der CDU, Dufhues, sowie weitere Unionspolitiker verlangten dagegen umgehend eine öffentliche Erklärung, daß Bonn den Austausch von Botschaftern mit Israel anstrebe. Sie sollen dem Kanzler sogar mit einem Mißtrauensvotum auf der am Montag stattfindenden CDU/CSU-Fraktionssitzung gedroht haben ${ }^{295}$. Auf einem Spaziergang am Sonntagnachmittag „mit Barzel, aber ohne Außenminister“ entschloß sich der Kanzler, Israel die Aufnahme von diplomatischen Beziehungen anzubieten ${ }^{296}$. Birrenbach erhielt eine entsprechende Weisung. Auch heftige Proteste Osterhelds, der voraussagte, daß dies alle arabischen Staaten dazu bringen würde, sich wieder hinter Nasser zu stellen, halfen nicht. Erhard ließ sich nicht mehr umstimmen ${ }^{297}$. Schröder wurde von dem Beschluß „total überrascht" ${ }^{298}$. Es war das erste und einzige Mal in seiner Amtszeit, daß Erhard eine außenpolitische Entscheidung in eigener Verantwortung getroffen hatte. Das bisher gute Verhältnis der beiden Männer bekam dadurch Risse. Schröder war über Erhards eigenmächtiges Handeln in einer derart bedeutenden Angelegenheit überaus verärgert ${ }^{299}$.

Noch am 7. März wurde der Beschluß des Kanzlers in einer Fünf-Punkte-Erklärung der Bundesregierung bekanntgegeben. Die Entscheidung, die Wirtschaftshilfe an die VAR einzustellen, wurde darin bestätigt. Gleichzeitig erklärte die Bundesrepublik ihren Willen, diplomatische Beziehungen mit Israel herzustellen. Des weiteren enthielt die Erklärung die Versicherung, künftig keine Waffen mehr in Spannungsgebiete zu liefern. Deshalb werde man Verhandlungen mit Tel

292 Vgl. ebenda, S. 42-47; BARZEL, Deutschland und Israel, S. 13-19.

293 Vgl. OSTERHELD, Außenpolitik, S. 168.

294 Vgl. MENDE, Von Wende zu Wende, S. 173.

$295 \mathrm{Vgl}$. Osterheld, Außenpolitik, S. 168; ZeITZeugenbefragung Stercken.

296 LAHR, Zeuge, S. 419.

297 Vgl. OSTERHELD, Außenpolitik, S. 168; MENDE, Von Wende zu Wende, S. 175.

298 SCHOLLWER, FDP im Wandel, Eintrag vom 16.3.65, S. 251.

299 ZEITZEUGENBEFRAGUNG von Hase. 
Aviv zwecks Umwandlung der noch ausstehenden Lieferungen aufnehmen ${ }^{300}$. Die Außenminister der Arabischen Liga reagierten tief empört. Am 14. März kündigten sie an, ihre Staaten würden die diplomatischen Beziehungen zur Bundesrepublik abbrechen, sobald Bonn und Tel Aviv den Austausch von Botschaftern vereinbart hätten ${ }^{301}$. Auch wenn die Entscheidung Erhards die arabischen Staaten vor den Kopf stieß, trug sie doch wesentlich zur Entkrampfung des Verhältnisses zu Israel bei. Bezüglich des Problems einer Ablösung der Waffenlieferungen zeichnete sich bei Eshkol ein langsames Umdenken ab. Bereits am 11. März konnte McGhee Schröder einen Kompromißvorschlag des israelischen Ministerpräsidenten unterbreiten. Nach dessen Vorstellungen sollte die Bundesrepublik die noch ausstehenden 90 Panzer an die USA liefern, die sie wiederum an Israel weitergeben würden. Außerdem wurde Bonn nahegelegt, auf ein mit Washington vereinbartes Waffengeschäft zugunsten Israels zu verzichten, was konkret bedeutete, daß Israel von den Vereinigten Staaten zusätzliche Panzer erhalten sollte, für die die Bundesrepublik die Kosten zu tragen hatte. Der Außenminister machte indessen den Gegenvorschlag, daß Israel die Panzer aus eigenen Mitteln bezahlte, dafür aber von der Bundesrepublik nichtgebundene finanzielle Hilfe erhalten werde. Erneut rief er die USA dazu auf, ihren Einfluß in Tel Aviv geltend zu machen, da Bonn durch amerikanische Schuld, in die übelste Patsche der Nachkriegszeit" geraten sei ${ }^{302}$.

In zähen Verhandlungen gelang es Birrenbach, bis Mitte April eine Übereinkunft mit der israelischen Regierung zu treffen. Gegen die Zahlung einer Abstandssumme von 140 Millionen DM wurde die Bundesrepublik aus ihren Verpflichtungen entlassen. Die noch ausstehenden Lieferungen übernahmen die USA und Frankreich. Washington sollte die fehlenden 90 Panzer liefern, Paris die versprochenen sechs Schnellboote. Gleichzeitig vereinbarte man die Aufnahme diplomatischer Beziehungen ${ }^{303}$. Am 12. Mai 1965 gaben in einem Briefwechsel die beiden Regierungschefs, Erhard und Eshkol, bekannt, sie seien übereingekommen, Botschafter auszutauschen ${ }^{304}$. Neun arabische Länder setzten daraufhin die Resolution der Arabischen Liga vom 14. März um. Noch am selben Tag brach der Irak die Beziehungen zur Bundesrepublik ab. In den folgenden Tagen schlossen sich Algerien, der Jemen, Jordanien, Libanon, Saudi-Arabien, Syrien, der Sudan und die VAR dem Schritt Bagdads an. Kuwait erklärte die kürzlich getroffene Vereinbarung mit der Bundesrepublik, diplomatische Beziehungen aufzunehmen,

300 Für den Wortlaut der Erklärung der Bundesregierung zur Lage im Nahen Osten vom 7. 3. $1965 \mathrm{vgl}$. DzD IV/11, S. $263 \mathrm{f}$.

$301 \mathrm{Vgl}$. das Kommuniqué des Rats der Außenminister der arabischen Staaten vom 15.3. 1965, in: DzD IV/11, S. 279 f.

302 Gespräch des Bundesministers Schröder mit dem amerikanischen Botschafter McGhee am 11. 3. 1965, in: AAPD 1965, Dok. 125, S. 501-507 (505).

303 Vgl. das Schreiben des Abgeordneten Birrenbach (CDU), z.Z. Badenweiler, an Bundeskanzler Erhard vom 16. 4. 1965, in: ebenda, Dok. 185, S. 740-744; sowie den Runderlaß des Staatssekretärs Carstens vom 10. 5. 1965, in: ebenda, Dok. 203, S. 812-815.

304 Für den Wortlaut des Briefwechsels sowie der am gleichen Tage veröffentlichten Erklärung der Bundesregierung zur Aufnahme der diplomatischen Beziehungen vgl. BulLETIN 1965, S. $665 \mathrm{f}$. 
für nichtig ${ }^{305}$. Die Nahostpolitik der Bundesregierung stand somit vor einem Scherbenhaufen. Das Ganze sei „ein totales Fiasko der Hallstein-Politik“, notierte Wolfgang Schollwer in sein Tagebuch ${ }^{306}$. Doch in Wahrheit kam Bonn noch mit einem blauen Auge davon, da sich die arabischen Staaten hüteten, ganz mit der Bundesrepublik zu brechen. Keiner der zehn Staaten nahm in der Folgezeit diplomatische Beziehungen zur DDR auf. Lediglich in Syrien wurde am 16. September 1965 ein Generalkonsulat der DDR eröffnet ${ }^{307}$. Der befürchtete Zusammenbruch der Nichtanerkennungspolitik der Bundesregierung fand also nicht statt: „Der Schaden blieb insgesamt begrenzt ", lautet dementsprechend das Fazit Christian Hackes ${ }^{308}$.

\section{Ist eine Änderung der Deutschland-Politik unumgänglich?}

Die Nahost-Krise hatte nicht nur der Öffentlichkeit vor Augen geführt, daß die Hallstein-Doktrin, die die völkerrechtliche Anerkennung der DDR auf internationaler Ebene verhindern und den Alleinvertretungsanspruch der Bundesrepublik durchsetzen sollte, den Handlungsspielraum Bonns auf dem diplomatischen Parkett einzuengen drohte. Schröder stellte vor der CDU/CSU-Bundestagsfraktion am 2. Februar 1965 fest, die Bundesrepublik sei durch ihre DeutschlandPolitik „erpreßbar“ geworden ${ }^{309}$. Die Drohung, die Beziehungen zu einem Staat abzubrechen, der die DDR völkerrechtlich anerkannte, schien die Isolierung OstBerlins auf der internationalen Bühne nicht länger verhindern zu können. Die blockfreien Staaten der Dritten Welt erkannten, daß sie damit ein Mittel in der Hand hatten, mit dem sie die Bundesregierung unter Druck setzen konnten. Da zunehmend denjenigen Staaten größere finanzielle Hilfen gewährt wurden, die nicht fest hinter dem Alleinvertretungsanspruch standen, schien es lukrativer zu sein, die Grundsätze der Bonner Deutschland-Politik in Frage zu stellen, als diese vorbehaltlos zu unterstützen.

An vielen Orten befanden sich die Diplomaten der Bundesrepublik in einem ständigen politischen Kampf, ein weiteres Vordringen der Konkurrenz aus OstBerlin zu verhindern. Dennoch gelang es der DDR, immer mehr Fuß zu fassen. Im Januar und Februar 1964 wurde der Stellvertretende Vorsitzende des Ministerrats, Bruno Leuschner, in Indonesien, Kambodscha, Birma, Ceylon und Indien empfangen ${ }^{310}$. Zum Abschluß seines Besuches in Ceylon kündigte die dortige Regierung am 14. Februar 1964 an, die Handelsmission der DDR in Colombo werde in ein Generalkonsulat umgewandelt ${ }^{311}$. Die Bundesrepublik antwortete darauf

305 Vgl. AAPD 1965, S. 814, Anm. 20.

306 SCHOLLWER, FDP im Wandel, Eintrag vom 15. 5. 1965, S. 259.

307 Vgl. ADG 1965, S. 12064.

308 HACKE, Weltmacht, S. 132. Hacke schloß sich damit dem Urteil Klaus Hildebrands an. Vgl. HildEBRAND, Von Erhard zur Großen Koalition, S. 116.

309 Protokoll der CDU/CSU-Fraktionssitzung am 9. 2. 1965, ACDP VIII-001-1010/1.

310 Vgl. dazu das Interview Leuschners für die Zeitung Neues Deutschland am 22. 2. 1964, in: DzD IV/10, S. 267-269.

311 Für den Wortlaut der Presseerklärung vgl. DzD IV/10, S. $248 \mathrm{f}$. 
mit der Einstellung der Entwicklungshilfe ${ }^{312}$. In algerischen Regierungskreisen gab es ebenfalls nicht zu unterschätzende Strömungen, die eine Aufwertung der DDR anvisierten ${ }^{313}$. Auch in Indonesien spielte man mit dem Gedanken, diplomatische Beziehungen zu Ost-Berlin herzustellen. Am 29. Juli 1964 teilte der indonesische Gesandte in Bonn, Burhanuddin Malaju, dem Auswärtigen Amt mit, die Ostblock-Staaten sowie die Kommunistische Partei Indonesiens drängten Sukarno, die DDR völkerrechtlich anzuerkennen. Es sei nur eine Frage der Zeit, bis der indonesische Präsident diesem Druck nachgeben müßte ${ }^{314}$. In Afrika befand sich die DDR ebenfalls auf dem Vormarsch. Bereits seit dem Sommer 1963 existierte eine Handelsvertretung Ghanas in Ost-Berlin ${ }^{315}$. Ende Juli 1964 gab der ghanaische Außenminister Kojo Botsio bekannt, er werde die DDR besuchen ${ }^{316}$. Die neu gegründete Republik Sansibar sprach am 29. Januar 1964 die völkerrechtliche Anerkennung der DDR aus. Wenige Tage später eröffnete Ost-Berlin eine Botschaft auf der ostafrikanischen Insel ${ }^{317}$. Durch die Vereinigung Tanganijkas und Sansibars am 27. April des gleichen Jahres übernahm der neue Staat die diplomatische Vertretung der DDR. Die Bundesregierung forderte daraufhin von Präsident Nyerere die Schließung der Botschaft auf Sansibar ${ }^{318}$. Dieser schob jedoch eine Entscheidung auf. Im Februar 1965 wurde bekannt, er wolle der DDR als Ersatz mindestens ein Generalkonsulat in Daressalam zugestehen ${ }^{319}$. Auch in internationalen Organisationen versuchte Ost-Berlin Fuß zu fassen. Die Aufnahme der DDR in die Weltgesundheitsorganisation (WHO) und die Internationale Fernmeldeunion (ITU) konnte von der Bundesrepublik zwar verhindert wer$\operatorname{den}^{320}$. Eine Niederlage mußte Bonn jedoch auf sportpolitischem Gebiet hinnehmen. Das Internationale Olympische Komitee (IOC) beschloß am 8. Oktober 1965 die Zulassung zweier deutscher Mannschaften für die Olympischen Spiele

312 Für den Wortlaut der Erklärung der Bundesregierung vom 19.2. 1964 vgl. BULLETIN 1964, S. 288.

313 Vgl. die Aufzeichnungen des Staatssekretärs Lahr vom 31.7. und 6. 10. 1964, in: AAPD 1964, Dok. 215, S. 908-910, bzw. Dok. 273, S. 1122; sowie das Gespräch des Bundesministers Schröder mit dem französischen Außenminister Couve de Murville am 3.7. 1964, in: ebenda, Dok. 181, S. $732 \mathrm{f}$.

314 Vgl. das Gespräch des indonesischen Gesandten Malaju mit Ministerialdirigent Böker am 29. 7. 1964, PA/AA, B 150, Aktenkopien 1964.

315 Vgl. dazu die Aufzeichnung der Politischen Abteilung I vom 19. 9. 1963, in: AAPD 1963, Dok. 347, S. 1146-1149.

316 Vgl. die Aufzeichnung des Staatssekretärs Lahr vom 15.8. 1964, in: AAPD 1964, Dok. 233, S. $971 \mathrm{f}$.

317 Vgl. dazu die Aufzeichnung des Ministerialdirektors Jansen vom 11. 2. 1964, in: ebenda, Dok. 40, S. 188f. Da die Bundesrepublik zu Sansibar keine amtlichen Beziehungen unterhielt, hatte die Bundesregierung kein Mittel in der Hand, um darauf zu reagieren.

318 Vgl. die Aufzeichnung des Staatssekretärs Carstens vom 11. 8. 1964, in: AAPD 1964, Dok. 228, S. $957 \mathrm{f}$.

319 Vgl. den Drahterlaß des Staatssekretärs Carstens an die Botschafter von Etzdorf (London), Klaiber (Paris) und Knappstein (Washington) vom 17. 2. 1965, in: AAPD 1965, Dok. 84, S. $348 \mathrm{f}$.

320 Vgl. die Aufzeichnung des Staatssekretärs Carstens vom 2. 3. 1965, in: ebenda, Dok. 101, S. 423; die Aufzeichnung des Legationsrats Dröge vom 25. 3. 1965, in: ebenda, Dok. 151, S. 619-621, sowie AAPD 1966, S. 81, Anm. 20. 
1968, die aber unter einer gemeinsamen Flagge und einem gemeinsamen Emblem auftreten sollten ${ }^{321}$.

Die Abschreckungswirkung der Hallstein-Doktrin war also fragwürdig geworden. Darüber hinaus stand sie einer Intensivierung der Ostpolitik im Wege. Durch die Errichtung von Handelsvertretungen hatte Bonn zwar einen amtlichen Kontakt zu den osteuropäischen Staaten unterhalb der diplomatischen Ebene hergestellt, doch einer völligen Normalisierung der Beziehungen stand die Maxime entgegen, daß Bonn keine Botschaft in einem Land, zu dem Ost-Berlin bereits Beziehungen unterhielt, eröffnen könnte, da dies eine De-facto-Anerkennung der DDR zu Folge hätte. Schröder verlor trotz des Widerstands aus den eigenen Reihen gegen die sogenannte Geburtsfeblertheorie, derzufolge die kommunistischen Staaten Osteuropas in ihrer Entscheidung, die DDR völkerrechtlich anzuerkennen, nicht frei gewesen seien, sein Ziel nicht aus den Augen, zu den Staaten Ostmittel- und Südosteuropas diplomatische Beziehungen aufzunehmen. Die schweren Spannungen im Verhältnis zu den arabischen Staaten zu Beginn des Jahres 1965 wertete er als eine günstige Gelegenheit, dieses Vorhaben in die Tat umzusetzen. Er wies seine Beamten an, ein entsprechendes Schreiben an den Kanzler vorzubereiten ${ }^{322}$. Darin trat er dafür ein, nun „selbst zur Aktion über[zu]gehen“, um aus der negativen Entwicklung im Nahen Osten doch noch „politischen Gewinn zu ziehen“323. Als Befreiungsschlag wollte Schröder „das unsere Bewegungsfreiheit in der Deutschlandfrage einengende Problem unserer Beziehungen zu den osteuropäischen Staaten in Angriff nehmen“. Früher oder später müsse sich die Bundesregierung ohnehin damit auseinandersetzen, argumentierte der Außenminister. Zum jetzigen Zeitpunkt sei aber die Gefahr geringer, daß andere Staaten im Gegenzug die DDR völkerrechtlich anerkannten, da sich der Austausch von Botschaftern mit den osteuropäischen Staaten quasi „im Schatten der Vorgänge um die Nahost-Krise" vollzöge. Ihm schwebte vor, zunächst zu Rumänien diplomatische Beziehungen aufzunehmen, dann sollten Ungarn und Bulgarien folgen. Eine indirekte Anerkennung der DDR beabsichtigte Schröder durch einen Vorbehalt auszuschließen, wie ihn die Bundesrepublik 1955 anläßlich der Aufnahme diplomatischer Beziehungen mit der UdSSR formuliert hatte. Zwar rechnete er nicht damit, daß „der Austausch von Botschaften mit einigen osteuropäischen Staaten in absehbarer Zeit zu sichtbaren Erfolgen, insbesondere auf dem Gebiet der Einstellung dieser Staaten zur Deutschlandfrage führen wird“, doch war er davon überzeugt, daß die Vorteile eines solchen Schritts überwogen: Die Aufnahme diplomatischer Beziehungen würde nämlich sowohl von der Öffentlichkeit als auch von den Westmächten begrüßt werden, die die Bundesregierung schon seit einiger Zeit dazu ermuntert hätten. Vor allem aber könnte dadurch den Aktivitäten der DDR in Osteuropa entgegengewirkt werden: „In einem Zeit-

321 Für den Wortlaut des Beschlusses vgl. DzD IV/11, S. 867 f. Vgl. auch die Aufzeichnung des Legationsrats I. Klasse Klingeberg, Washington, vom 24.7. 1965, in: AAPD 1965, Dok. 302, S. 1260-1268.

322 Vgl. das Schreiben des Bundesministers Schröder an Bundeskanzler Erhard (Entwurf) vom 22. 3. 1965, in: AAPD 1965, Dok. 140, S. 574-577.

323 Ebenda, S. 576. 
punkt, wo Ulbricht unsere Position in der nichtgebundenen Welt auszuhöhlen versucht, gehen wir dazu über, ihm in seinem eigenen Bereich, dem kommunistischen Lager, die Stellung streitig zu machen." Außerdem erwartete Schröder, den negativen Auswirkungen der Hallstein-Doktrin damit ein Ende setzen zu können: „Wir würden [...] endlich aus der Erpressungssituation hinausgelangen, in der sich die Bundesrepublik Deutschland in letzter Zeit ständig befunden hat. “324

Auf die Pläne seines Außenministers reagierte der Bundeskanzler zunächst positiv $^{325}$, zumindest aber nicht eindeutig ablehnend ${ }^{326}$. Schröder wagte sich deshalb an die Öffentlichkeit. In einem Interview mit der amerikanischen Nachrichtenagentur Associated Press deutete er Anfang Mai 1965 an, die Bundesregierung überlege, diplomatische Beziehungen zu den osteuropäischen Staaten aufzunehmen. Einschränkend fügte er aber hinzu, die Realisierung dieses Vorhabens werde noch einige Zeit auf sich warten lassen ${ }^{327}$. Im Gegensatz dazu erklärte der FDPVorsitzende Mende, Bonn wolle schon „bald“ diplomatische Vertretungen in den Staaten Ostmittel- und Südosteuropas eröffnen. Auf diese Ankündigung am 14. Mai im Bundestag angesprochen, blieb Schröder eine Antwort schuldig328. Auch zu der Ansicht Mendes, die Hallstein-Doktrin sei „kein geeignetes Instrument mehr [...], um den Alleinvertretungsanspruch der Bundesrepublik Deutschland zu wahren und die Wege zu einer friedlichen und freiheitlichen Lösung der deutschen Frage offenzuhalten" ${ }^{329}$, wollte er sich nicht äußern, meinte aber vieldeutig: „Für nichts passen doktrinäre Sätze schlechter als für die auswärtige Politik. "330 In einem Interview mit dem ZDF bekräftigte er am 21. Mai 1965 allerdings seinen Standpunkt, die Hallstein-Doktrin sei kein Hindernis für die Eröffnung diplomatischer Vertretungen der Bundesrepublik in den osteuropäischen Staaten: „Wir könnten solche Beziehungen, ungehindert durch irgendeine theoretische Auffassung, ebensogut aufnehmen wie das gegenüber der Sowjetunion war. “331

Bei der FDP fand dieser Standpunkt erwartungsgemäß Zustimmung, die große Mehrheit der Union äußerte jedoch heftige Kritik. Regierungssprecher von Hase brachte das Interview vier Tage später im Rahmen einer Besprechung beim Kanzler, an der neben Schröder und Mende unter anderem auch Krone, Westrick sowie Finanzminister Dahlgrün teilnahmen, zur Sprache. Der Außenminister mußte sich vorwerfen lassen, er habe durch seine Äußerungen die Lage der Bundesrepublik in denjenigen Ländern erschwert, in denen Bonn sich verzweifelt bemühe, ein weiteres Vordringen der DDR zu verhindern. Erhard verlangte von Schröder, die Frage der Normalisierung der Beziehungen zu den osteuropäischen Staaten nicht mehr in der Öffentlichkeit zu thematisieren. Dieser verteidigte sich, er stelle den Alleinvertretungsanspruch überhaupt nicht in Frage, plädierte aber nochmals für

324 Ebenda, S. $575 f$.

325 ZeITZEUGENBEFRAGUNG Krapf.

326 ZEITZEUGENBEFRAGUNG Osterheld.

327 Für den Wortlaut des Interviews vom 3. 5. 1965 vgl. BuLleTIN 1965, S. 620.

328 BT STENOGRAPHISCHE BERICHTE, Bd. 58, S. 9164.

329 Rede des FDP-Vorsitzenden Mende auf dem 16. Bundesparteitag der FDP am 23. 3. 1965 in Frankfurt/Main, in: DzD IV/11, S. 312.

330 BT STENOGRAPHISCHE BERICHTE, Bd. 58, S. 9164.

331 DzD IV/11, S. 610. 
den Austausch von Botschaftern mit den osteuropäischen Staaten, um mehr außenpolitischen Spielraum zu gewinnen. Das wollte der Kanzler jedoch nicht mittragen. Die Diskussion wurde schließlich dadurch beendet, daß von Hase einen Zeitungsartikel Grewes zitierte, in dem der Botschafter das Interview als erhebliche Schwächung der Hallstein-Doktrin bezeichnet hatte ${ }^{332}$. Daraufhin korrigierte Schröder öffentlich seine Aussage ${ }^{333}$.

Die Aufnahme diplomatischer Beziehungen zu den Ostblock-Staaten war innerhalb der Union nicht durchzusetzen. Die meisten Abgeordneten von CDU und CSU lehnten die Geburtsfehlertheorie ab und waren gegen eine Uminterpretation der Hallstein-Doktrin 334 . Gradl beispielsweise argumentierte, den neutralen und blockfreien Staaten könnte nicht begreiflich gemacht werden, wenn bei der Anerkennungsfrage zwischen ihnen und den osteuropäischen Staaten differenziert würde. Die Glaubwürdigkeit des Alleinvertretungsanspruchs wäre dadurch gefährdet. Deswegen sei „noch nicht einmal der Zeitpunkt für ernsthafte Erwägungen" gekommen, den Austausch von Botschaftern einzuleiten ${ }^{335}$. Der wesentliche Einwand gegen eine Normalisierung der Beziehungen lautete also, daß Bonn in Erklärungsnotstand geriete, wenn ein Botschafter der Bundesrepublik in einen Staat entsandt würde, der die DDR bereits völkerrechtlich anerkannt hatte, während allen übrigen Staaten im Falle der Aufnahme diplomatischer Beziehungen zu Ost-Berlin weiterhin mit dem Abbruch der Beziehungen gedroht wurde. Erhard wurde auf diesen Widerspruch aufmerksam gemacht und darüber aufgeklärt, daß „die Aufnahme diplomatischer Beziehungen zu den osteuropäischen Ländern als Durchlöcherung der Hallstein-Doktrin und Abweichen von unserer bisherigen Deutschlandpolitik angesehen werde“336. Hätte sich der Kanzler in dieser Frage Schröders Standpunkt zu eigen gemacht, wäre ihm wohl die parlamentarische Unterstützung entzogen worden ${ }^{337}$. Am 9. Juli 1965 ließ er deshalb dem Persönlichen Referenten des Außenministers, Klaus Simon, mitteilen, er teile die Bedenken gegen eine Modifikation der Hallstein-Doktrin ${ }^{338}$. Nur wenige Tage darauf erklärte er auch öffentlich, die Frage der Aufnahme diplomatischer Beziehungen mit den osteuropäischen Staaten stünde gegenwärtig "nicht zur Diskussion“339.

Unmittelbar nach den Bundestagswahlen am 19. September 1965 lebte die Diskussion jedoch erneut auf. In einem Aufsatz für die amerikanische Zeitschrift Foreign Affairs bezeichnete Schröder die Argumente gegen die Einleitung diplomatischer Beziehungen mit Ostmittel- und Südosteuropa als „nicht stichhaltig“,

332 Vgl. OSTERHELD, Außenpolitik, S. $192 \mathrm{f}$.

333 Vgl. ebenda, S. 193.

334 ZEITZEUGENBEFRAGUNG Osterheld.

335 Protokoll der CDU/CSU-Fraktionssitzung am 24. 3. 1965, ACDP-001-1010/1.

336 Vgl. das Schreiben des Ministerialdirigenten Osterheld, Bundeskanzleramt, an Ministerialdirigent Simon vom 9. 7. 1965, PA/AA, B 150, Aktenkopien 1965.

337 ZEITZEUGENBEFRAGUNG Osterheld.

338 Vgl. das Schreiben des Ministerialdirigenten Osterheld, Bundeskanzleramt, an Ministerialdirigent Simon vom 9. 7. 1965, PA/AA, B 150, Aktenkopien 1965.

339 Interview des Bundeskanzlers Erhard mit dem Münchner Merkur am 14. 7. 1965, in: DzD IV/11, S. 734 . 
da sich mit Hilfe einer Vorbehaltsklausel alle Zweifel ausräumen ließen, die Bundesrepublik gäbe damit ihren Alleinvertretungsanspruch auf ${ }^{340}$. Hingegen betonte Erhard am 18. Oktober vor der CDU/CSU-Bundestagsfraktion erneut, es sei im Moment "völlig unmöglich", in diesen Staaten eine diplomatische Vertretung zu eröffnen. Eine Ausnahmeregelung könne nicht plausibel nach außen vertreten werden. Die Aufnahme diplomatischer Beziehungen war seines Erachtens nur möglich, nachdem eine deutliche Liberalisierung in Osteuropa stattgefunden hatte; vielleicht sogar erst im Rahmen der Wiedervereinigung ${ }^{341}$. Trotz dieser eindeutigen Aussagen warb Schröder kurz darauf vor dem Evangelischen Arbeitskreis wiederum um Unterstützung für sein Vorhaben. Strauß richtete deswegen am 27. Oktober ein Schreiben an den Kanzler, indem er sich über die Pläne des Außenministers beschwerte. Erhard setzte schließlich der Debatte ein Ende, indem er schriftlich seine Auffassung bekräftigte, er lehne Schröders Vorhaben $a b^{342}$. Damit hatte er sich endgültig festgelegt, die amtlichen Beziehungen zu den osteuropäischen Staaten vorerst auf der Ebene von Handelsvertretungen einzufrieren.

In der Öffentlichkeit wurde hingegen immer häufiger der Wunsch geäußert, Bonn sollte sich bemühen, das Verhältnis zu Osteuropa, insbesondere zu Polen, zu normalisieren. Eine "Zäsur in der Meinungsentwicklung “343 stellte dabei die sogenannte Ost-Denkschrift der Evangelischen Kirche in Deutschland vom 15. Oktober 1965 dar. Ihr offizieller Titel lautete: „Die Lage der Vertriebenen und das Verhältnis des deutschen Volkes zu seinen östlichen Nachbarn“. Das Memorandum ist deshalb bemerkenswert, weil mit ihm ein erster Schritt zur Aussöhnung zwischen Deutschen und den Völkern Osteuropas gemacht wurde. Die EKD sprach das Schicksal der aus ihrer Heimat vertriebenen Menschen ebenso an, wie das Leid, das den Polen und anderen Völkern während des Zweiten Weltkrieges durch Deutsche zugefügt wurde. Auch zeigten die Autoren der Denkschrift Verständnis für die Befürchtung der Polen, sie könnten ihre neue Heimat in den früheren Ostgebieten des Deutschen Reiches wieder verlieren. Die Verfasser bezeichneten die ungelöste Grenzfrage als einen fortdauernden Unruheherd im Verhältnis zu Polen und als ein Hindernis für eine wirkliche Entspannung ${ }^{344}$. Die katholische Kirche schloß sich ebenfalls dem Bemühen an, eine Verbesserung der Beziehungen zu Polen in die Wege zu leiten. Ein Briefwechsel zwischen dem polnischen und dem deutschen Episkopat im Spätherbst 1965 stand ganz im Zeichen der Versöhnung ${ }^{345}$. Beide Initiativen fanden Schröders prinzipielle Zustim-

340 Aufsatz des Bundesministers Schröder „Deutschland schaut nach Osteuropa“, in: DzD IV/11, S. 857.

341 Vgl. das Protokoll der CDU/CSU-Fraktionssitzung am 18. 10. 1965, ACDP VIII-0011010/1.

342 Vgl. OSTERHELD, Außenpolitik, S. 259.

343 BENDER, Die „Neue Ostpolitik“" und ihre Folgen, S. 124.

344 Für den Wortlaut der Denkschrift der EKD vom 15. 10. 1965 vgl. DzD IV/11, S. 869897.

345 Für den Wortlaut der Botschaft der katholischen Bischöfe Polens an die katholischen Bischöfe Deutschlands vom 18.11. 1965 und der Botschaft der katholischen Bischöfe 
mung, weil sie zu einer Verbesserung der Atmosphäre zwischen Bonn und Warschau beitrugen ${ }^{346}$. Mit dem Inhalt der Denkschrift der EKD war er gleichwohl nicht einverstanden. Er kritisierte, daß darin die Grenzfrage nicht im Zusammenhang mit dem Deutschland-Problem erörtert wurde. Die Autoren verkannten nach Ansicht des Außenministers, daß nicht die Oder-Neiße-Linie, sondern die Teilung Deutschlands der „Unruheherd und ein Element der Spannung in Mitteleuropa" sei. Eine Konzession wie die Anerkennung der polnischen Westgrenze sollte erst in einem Friedensvertrag mit einer gesamtdeutschen Regierung erfolgen, damit eine Wiedervereinigung Deutschlands für die Osteuropäer „erstrebenswert" bleibe ${ }^{347}$.

Die Frage der innerdeutschen Beziehungen wurde auch in der öffentlichen Diskussion verstärkt thematisiert. Immer häufiger wurde die Nichtanerkennungspolitik gegenüber der DDR kritisiert und ihr Nutzen in Frage gestellt. Angesehene Professoren wie Karl Jaspers und Theodor Eschenburg, einflußreiche Journalisten wie Rudolf Augstein und Peter Bender sprachen sich für die Anerkennung der DDR, zumindest aber für die Respektierung Ost-Berlins aus ${ }^{348}$. Bender zum Beispiel glaubte, durch verstärkte Kontakte könnte langfristig die Teilung Deutschlands überwunden werden ${ }^{349}$. Allgemein wurde die Frage des künftigen deutschdeutschen Verhältnisses Mitte der sechziger Jahre von Wissenschaftlern und Publizisten leidenschaftlich diskutiert ${ }^{350}$. Die Parteienlandschaft der Bundesrepublik reagierte darauf mit Korrekturen an den deutschlandpolitischen Positionen. Die radikalste Kehrtwende vollzog wohl der Parteivorsitzende der CSU, Franz Josef Strauß. Er erklärte am 8. April 1966 in einem Interview mit der Hamburger Wochenzeitung Die Zeit, er "glaube nicht an die Wiederherstellung eines deutschen Nationalstaates, auch nicht innerhalb der Grenzen der vier Besatzungszonen “351. Dagegen hielten die Freien Demokraten am Ziel der Wiedervereinigung fest. In der FDP wurde aber schon seit längerem nachgedacht, wie die Bonner Deutschland-Politik an die veränderte internationale Großwetterlage angepaßt werden konnte. Eine Vorreiterrolle in der parteiinternen Diskussion spielte dabei der Chefredakteur der Parteizeitschrift $f d k$ und Referent für Außen- und Deutschland-Politik, Wolfgang Schollwer. Wie bereits in einem der ersten Kapitel kurz erwähnt wurde, hatte er lange vor dem Amtsantritt Erhards, am 9. April 1962, der Parteiführung ein Thesenpapier vorgelegt ${ }^{352}$, in dem er forderte: „Der

Deutschlands an die katholischen Bischöfe Polens vom 5.12. 1965 vgl. ebenda, S. 940947 bzw. S. 973-976. Vgl. dazu auch Heller, Macht, S. 89-202.

346 Vgl. das Gespräch des Bundesministers Schröder mit dem amerikanischen Botschafter McGhee am 9. 12. 1965, in: AAPD 1965, Dok. 452, S. $1868 \mathrm{f}$.

347 Interview Schröders mit der Welt am Sonntag am 14.11. 1965, in: BulletiN 1965, S. 1471.

348 Vgl. dazu Hildebrand, Von Erhard zur Großen Koalition, S. 195.

349 Vgl. BENDER, Offensive Entspannung.

350 Vgl. dazu die Literaturangaben bei HAFTENDORN, Sicherheit, S. 280 Anm. 31.

351 Interview des CSU-Vorsitzenden Strauß für Die Zeit vom 8. 4. 1966, in: DzD IV/12, S. 439. Zur Entwicklung von Strauß' deutschlandpolitischen Vorstellungen vgl. HACKER, Deutsche Irrtümer, S. 232-236.

352 Für den Wortlaut der Denkschrift „Verklammerung und Wiedervereinigung“ vom 9. 4. 1962 vgl. DzD IV/8, S. 376-389. Vgl. auch SCHOLlWER, FDP im Wandel, S. 44-47; 
Westen muß die Zweistaatlichkeit Deutschlands anerkennen und die Souveränität der DDR bis zur Wiedervereinigung respektieren." ${ }^{353}$ Des weiteren verlangte er die Akzeptierung der Oder-Neiße-Linie sowie die Aufgabe der Hallstein-Doktrin gegenüber den osteuropäischen Staaten. Im Gegenzug sollte Ulbricht abgelöst sowie eine Entstalinisierung der DDR eingeleitet werden. Auch sei die Freizügigkeit zwischen den beiden deutschen Staaten wiederherzustellen. Schollwers Abkehr von den bisherigen deutschlandpolitischen Grundsätzen war aber nicht als Verzicht auf die Wiederherstellung der staatlichen Einheit aufzufassen. Im Gegenteil, nach seiner Ansicht würde erst die von ihm skizzierte Politik die „Wiedervereinigung, wenn auch zu einem vielleicht noch fernen Zeitpunkt, überhaupt möglich [...] machen" 354 . In der Führungsriege der FDP waren die Thesen Schollwers umstritten $^{355}$. Als die Denkschrift Anfang September 1964 von der Illustrierten Quick publiziert wurde 356 , distanzierte sich die Parteispitze von den Überlegungen ihres Referenten ${ }^{357}$. Die Freien Demokraten wollten keine radikale Abkehr, sondern eine behutsame Anpassung des bisherigen Kurses an die internationalen Veränderungen der letzten Jahre. In Außenminister Schröder sahen sie den „wichtigsten Verbündeten für eine realistische Ost- und Deutschlandpolitik“358. Die Errichtung von Handelsmissionen in Osteuropa fand die Zustimmung der FDP; Schröders Isolierungskonzept der DDR stieß hingegen auf Widerspruch ${ }^{359}$. Während die „Öffnung nach Osten“ innerhalb der Union kritisiert wurde, ging sie dem Koalitionspartner nicht weit genug 360 .

Ab 1965 scheuten sich die Liberalen nicht mehr, die Deutschland-Politik der Bundesregierung in Frage zu stellen. Auf dem Bundesparteitag der Liberalen im März 1965 in Frankfurt verlangte Mende neben der Aufnahme diplomatischer Beziehungen mit den osteuropäischen Staaten eine Intensivierung der innerdeutschen Kontakte. Bonn sollte dabei versuchen, menschliche Erleichterungen für die ostdeutsche Bevölkerung auszuhandeln. Der Parteivorsitzende wollte damit auch die Auseinanderentwicklung der beiden deutschen Staaten bremsen, weil sie eine spätere Wiedervereinigung erschweren könnte ${ }^{361}$. Mit einer „Politik der klei-

EngelmanN, Brüchige Verbindungen, S. 100f.; ERHARD, Die Schollwer-Papiere von 1962 und 1967, S. 238.

353 DzD IV/8, S. 384.

354 Ebenda, S. 386.

355 Vgl. MOERSCH, Kurs-Revision, S. 48 f. und S. 64; SCHOLLWER, FDP im Wandel, Eintrag vom 9. 4. 1962, S. 46 f.; ENGELMANN, Brüchige Verbindungen, S. 101 f.; sowie die rückblickende Stellungnahme Erich Mendes in HüBSCH/FRÖLICH (Hrsg.), Deutsch-deutscher Liberalismus im Kalten Krieg, S. 145.

356 Vgl. den Artikel „Geheimes Dokument über gefährliche Deutschlandpläne ... und der Kanzler weiß von nichts“, in: QuICK vom 6. 9. 1964, S. 12-14 und S. 104-109. Die Denkschrift wurde von dem Fotohändler und FDP-Kreisvorsitzenden Hannsheinz Porst dem Staatssicherheitsdienst der DDR übergeben, der sie dann der Presse zuspielte. Vgl. dazu ENGELMANN, Brüchige Verbindungen, S. 102.

357 Vgl. MENDE, Von Wende zu Wende, S. 34.

358 MOERSCH, Kurs-Revision, S. 73.

359 Vgl. ebenda, S. $77 \mathrm{f}$.

360 HANRIEDER, Deutschland, S. 401.

361 Für einen Auszug aus der Rede Mendes auf dem 16. Bundesparteitag der FDP am 22. 3. 1965 in Frankfurt/Main vgl. DzD IV/11, S. 307-316. 
nen Schritte“ 362 , wie sie sich bei den Passierscheinabkommen bewährt hatte, strebte er eine "allmähliche Wieder-Verklammerung "363 der beiden Teile Deutschlands an. Mende orientierte sich offensichtlich an Bahrs Konzept vom Wandel durch Annäberung. Dieser wollte bekanntlich ebenfalls mittels einer $\mathrm{Zu}$ nahme der innerdeutschen Kontakte die Gegensätze abbauen, um die Aussichten auf eine Überwindung der Zweistaatlichkeit Deutschlands zu vergrößern. Der FDP-Vorsitzende und Minister für gesamtdeutsche Fragen stellte sich mit seiner Frankfurter Rede aber in Gegensatz zur Deutschland-Politik des Außenministers, der glaubte, daß eine Fortsetzung der „Politik der kleinen Schritte“- so wie es bei den Passierschein-Verhandlungen geschehen war - die von ihm beabsichtigte Isolierung der DDR erschwere ${ }^{364}$.

Innerhalb des Kabinetts konnte Mende seine Vorstellungen nicht durchsetzen. Zumindest in seiner Funktion als Vorsitzender der FDP war es ihm aber möglich, den Dialog mit der DDR zu suchen. Eine Gelegenheit bot der „Offene Brief“ des ZK der SED vom 7. Februar 1966 an die Delegierten des Bundesparteitags der SPD in Dortmund, in dem ein Redneraustausch zwischen den Parteien und Massenorganisationenen der Bundesrepublik und der DDR vorgeschlagen wurde ${ }^{365}$. Der stellvertretende FDP-Bundesvorsitzende, Wolfgang Mischnick, griff innerhalb der Freien Demokraten diese an die SPD gerichtete Anregung als erster auf. Er entschloß sich kurzfristig, an einer seit längerem von den hessischen Jungdemokraten geplanten Podiumsdiskussion mit Vertretern der LDPD am 31. März 1966 in Bad Homburg teilzunehmen, und hob die Veranstaltung dadurch „auf ein völlig anderes Niveau"366. Erstaunlicherweise sah Schröder in dem Redneraustausch keine Gefährdung seines Isolierungsplans. Die „einzigartige Möglichkeit, die Stimme der Freiheit in der Zone selbst zu erheben", wollte er nicht ungenutzt lassen. Der Außenminister sprach sich dafür aus, auf das Angebot einzugehen, da auf diese Weise einem Auseinanderleben der beiden Teile Deutschlands entgegengewirkt werden könne. Er verwies außerdem darauf, daß die ostdeutsche Bevölkerung dadurch die Gelegenheit erhalten würde, in direktem Kontakt mit Politikern aus der Bundesrepublik zu erfahren, daß dort unbeirrt an der Einheit Deutschlands festgehalten werde ${ }^{367}$. Damit SED-Politiker in der Bundesrepublik auftreten konnten, beschloß die Bundesregierung, den bestehenden Strafverfol-

362 Ebenda, S. 314.

363 Ebenda, S. 315.

364 Vgl. die Aufzeichnung des Staatssekretärs Carstens vom 2.3. 1965, in: AAPD 1965, Dok. 101, S. 423. Vgl. auch Booz, „Hallsteinzeit“, S. 99.

365 Für den Wortlaut des offenen Briefs des ZK der SED „an die Delegierten des Dortmunder Parteitages der SPD und an alle Mitglieder und Freunde der Sozialdemokratie in Westdeutschland“ vom 7.2. 1966 vgl. DzD IV/12, S. 175-183, besonders S. 182. Zu der Reaktion der Parteien der Bundesrepublik auf diesen Vorschlag vgl. BRANDT, Begegnungen, S. 125-129.

366 ENGELmanN, Brüchige Verbindungen, S. 125. Vgl. dazu auch Gerlach, Liberale in der DDR und Deutschlandpolitik der LDPD, S. 180-182; SIEKMEIER, Restauration oder Reform, $263 \mathrm{f}$. Für einen Auszug aus der Podiumsdiskussion vgl. DzD IV/12, S. 413-416.

367 Rede Schröders auf der 13. Bundestagung des Evangelischen Arbeitskreises am 20.5. 1966, in: Bulletin 1966, S. 546. Vgl. auch die Rede Schröders an der Universität Köln am 28. 4. 1966, in: ebenda, S. 466. 
gungszwang, das sogenannte „Handschellengesetz“ aufzuheben ${ }^{368}$. Doch zu weiteren Veranstaltungen kam es nicht mehr. Bereits der für Juli 1966 vereinbarte Redneraustausch zwischen SED und SPD wurde von der DDR abgesagt. Der sowjetische Botschafter in Ost-Berlin, Pjotr Andrejewitsch Abrassimow, intervenierte bei Ulbricht und legte im Namen Moskaus sein Veto ein. Der Kreml hielt einen Auftritt führender Sozialdemokraten vor der Bevölkerung der DDR für zu riskant ${ }^{369}$. Durch Vermittlung des schwedischen Generalkonsuls Sven Backlund kam es statt dessen zwischen dem 8. Mai und dem 22. November $1966 \mathrm{zu}$ insgesamt fünf Treffen Brandts mit Abrassimow, bevor dieser Kontakt wieder abriß. Der Regierende Bürgermeister hatte sowohl Schröder wie Carstens, als auch die Westmächte von dem Gesprächsangebot informiert. Weder das Auswärtige Amt noch die Alliierten hatten gegen die Begegnungen etwas einzuwenden ${ }^{370}$.

Ebenso wie die FDP stellte die SPD die bisherige Deutschland-Politik immer stärker in Frage. Den Sozialdemokraten erschien im Augenblick eine Erleichterung der Teilung dringlicher als ihre Überwindung. Anstatt das im Augenblick nicht zu realisierende Ziel der Wiedervereinigung monoton zu wiederholen, hielten sie es für wichtiger, im Interesse der Menschen die Lebensbedingungen in Ostdeutschland zu verbessern. Die SPD bewegte sich somit auf eine De-facto-Anerkennung der DDR zu. Auf dem Dortmunder Bundesparteitag Anfang Juni 1966 rief Brandt dazu auf, die Existenz der DDR nicht länger zu ignorieren ${ }^{371}$. Er verlangte, bis zur Wiedervereinigung ein "qualifiziertes, geregeltes und zeitlich begrenztes Nebeneinander" der beiden Teile Deutschlands zu vereinbaren ${ }^{372}$. Im Endeffekt forderte der SPD-Vorsitzende also, die Beziehungen zur DDR zu normalisieren, ohne sie aber völkerrechtlich anzuerkennen. Das Urteil Bessons, damit hätte die „Opposition das formuliert, was Schröder pragmatisch vorbereitet hatte " 373 , trifft aber nicht zu. Für den Außenminister kam die Aushandlung eines Modus vivendi mit Ost-Berlin und damit eine Hinnahme der Teilung Deutschlands nicht in Frage, selbst wenn sie - wie der Rede Brandts zu entnehmen war nur befristet sein sollte. Schröder suchte zwar die Hallstein-Doktrin zu modifizieren, die Aufgabe des Alleinvertretungsanspruches und eine De-facto-Anerkennung der DDR stand aber niemals auf seinem deutschlandpolitischen Programm. Auch im Rückblick bestritt er ausdrücklich die Behauptung, seine Politik sei von Brandt fortgesetzt worden ${ }^{374}$. Die Sozialdemokraten stellten auch den Rechts-

368 Protokoll der CDU/CSU-Fraktionssitzung am 3. 5. 1966, ACDP VIII-001-1010/2. Für den Wortlaut des Gesetzes vom 29. 7.1966 über befristete Freistellung von der deutschen Gerichtsbarkeit vgl. BUNDESGESETZBLATT 1966, Teil I, S. $453 \mathrm{f}$.

369 Vgl. BENDER, Die „Neue Ostpolitik“ und ihre Folgen, S. 100. Schon Brandt hatte den Eindruck, daß das Vorhaben letztendlich am Widerstand der sowjetischen Regierung scheiterte. Vgl. BRANDT, Begegnungen, S. 128.

370 Vgl. ebenda, S. 114-122.

371 Für einen Auszug aus der Rede des Regierenden Bürgermeisters von Berlin, Brandt, auf dem Parteitag der SPD am 1. 6. 1966 in Dortmund, in: DzD IV/12, S. 807-816. Zu seinen Motiven vgl. BRANDT, Begegnungen, S. $124 \mathrm{f}$.

372 Rede Brandts auf dem Parteitag der SPD am 1.6. 1966 in Dortmund, in: DzD IV/12, S. 812 .

373 BESSON, Außenpolitik, S. 358.

374 Vgl. SCHRÖDER, Im Gespräch mit Meinhold Krauss, S. $63 \mathrm{f}$. 
standpunkt in Frage, das Problem der deutschen Ostgrenze könne erst in einem Friedensvertrag von einer gesamtdeutschen Regierung endgültig geregelt werden. Auf dem IV. Deutschlandtreffen der SPD am 14. August 1965 in Dortmund wurde ein Wahlaufruf verabschiedet, dem zu entnehmen war, daß eine von den Sozialdemokraten gestellte Bundesregierung deutschlandpolitische Gespräche mit Moskau aufnehmen und die Grundelemente eines Friedensvertrages mit den Westmächten ausarbeiten wollte. Dabei sollte die Anerkennung der Oder-NeißeLinie sowie der deutsch-tschechoslowakischen Grenze festgeschrieben wer$\operatorname{den}^{375}$. Schröder erachtete es für völlig verkehrt, so weit vorzupreschen. Ihm war selbstverständlich klar, daß im Falle der Wiedervereinigung Konzessionen gemacht werden müßten, doch sollte die Bundesrepublik nicht einseitig dem Osten entgegenkommen, ohne dafür etwas zu erhalten ${ }^{376}$. Seines Erachtens konnte das Interesse an der Einheit Deutschlands bei den Ostblock-Staaten nur wachgehalten werden, wenn noch ungeklärte Punkte blieben: „Löse man alle Fragen durch Vorleistungen im Sinne der sowjetischen Politik, so habe man nichts mehr in der Hand um die Spaltung Deutschlands zu überwinden." 377

So hielt der Außenminister auch über den CDU/CSU-Fraktionsvorsitzenden Barzel ein "Scherbengericht" ab ${ }^{378}$, als dieser in einer Rede am 17. Juni 1966 in New York eine konkrete Summe für die finanziellen Leistungen nannte, die die Bundesrepublik im Falle der Einheit Deutschlands übernehmen würde und dem Kreml sogar die Stationierung sowjetischer Truppen in einem wiedervereinigten Deutschland in Aussicht stellte ${ }^{379}$. Kaum in die Bundesrepublik zurückgekehrt, wurde Barzel in der CDU/CSU-Fraktionssitzung am 21. Juni 1966 von Schröder an den Pranger gestellt, der dabei auch die Gelegenheit nutzte, einen innerparteilichen Rivalen zu stutzen. Schröder warnte die Union nachdrücklich vor einem "Wettlauf in Ausverkaufsangeboten“. Keinesfalls sollten öffentliche Angebote für die Einheit Deutschlands gemacht werden, da sich die UdSSR damit nicht zum Umdenken bringen lasse. Vielmehr würde dadurch die Bundesrepublik jeglichen Spielraum für etwaige Verhandlungen über die Wiedervereinigung verlieren: „Wenn wir das vier Wochen betrieben haben, gibt es überhaupt nur noch etwas abzugeben, nämlich das letzte Hemd auf dem nackten Leib. “380

Trotz seiner heftigen Reaktion auf derartige Vorschläge kann Schröder nicht deutschlandpolitische Unbeweglichkeit vorgeworfen werden. An der Spitze des Auswärtigen Amts hatte er sich der Erkenntnis nicht verschließen können, daß

375 Vgl. Hildebrand, Von Erhard zur Großen Koalition, S. 198; sowie den Artikel „SPD will Gespräch ohne Illusionen über Friedensvertrag“, in: DIE WELT vom 15. 8. 1965, S. $1 \mathrm{f}$.

376 Vgl. dazu den Artikel von Gerhard Schröder: „Naivität - Kein Beweis für Qualität“ in der Zeitschrift Deutsches Monatsblatt, Heft 9 (1965), ACDP Pressearchiv, Sammlung "Gerhard Schröder".

377 Gespräch des Bundesministers Schröder mit dem französischen Außenminister Couve de Murville am 12.11. 1965, in: AAPD 1965, Dok. 413, S. 1699.

378 BARZEL, Auf dem Drahtseil, S. 94.

379 Für den Wortlaut der Rede des CDU/CSU-Fraktionsvorsitzenden Barzel vor dem „Council on Germany“ am 17.6. 1966 in New York vgl. EurOPA-ARCHIV 1966, D 404412.

380 Protokoll der CDU/CSU-Fraktionssitzung am 21.6. 1966, ACDP VIII-001-1010/2. 
die bisherige Deutschland-Politik der Bundesregierung im Ausland an ihre Grenzen stieß. Er suchte sie deshalb im Rahmen des von Adenauer vorgegebenen Kurses an die veränderten internationalen Gegebenheiten anzupassen. Auf einer Botschafterkonferenz zur Deutschland-Frage Ende Dezember 1965 gab er den Anstoß, eine kritische Bestandsaufnahme vorzunehmen und Anregungen für eine von inneren Widersprüchen freie Wiedervereinigungspolitik zu machen ${ }^{381}$. Bereits im Januar 1966 legte Carstens eine umfangreiche Analyse mit dem Titel „60 Thesen zur Deutschlandpolitik“ vor, die Schröder an den Kanzler, Verteidigungsminister von Hassel, den Bundesminister für Vertriebene, Gradl, sowie an den stellvertretenden SPD-Fraktionsvorsitzenden Wehner weiterleitete ${ }^{382}$. Der Staatssekretär legte in der Denkschrift dar, daß das Ziel, die Einheit Deutschlands wiederherzustellen, von zwei Seiten bedroht war. So lasse zum einen sowohl das Zusammengehörigkeitsgefühl der Deutschen nach, zum anderen gebe es Probleme, die deutschlandpolitischen Positionen international durchzusetzen. Carstens zufolge galt dies insbesondere für das Prinzip der Vier-Mächte-Verantwortung für Gesamtdeutschland, den Alleinvertretungsanspruch sowie die These von der Fortexistenz des Deutschen Reiches in den Grenzen von 1937. Die Verantwortung für diese ungünstige Entwicklung lag für ihn jedoch nicht bei der Bundesregierung, sondern hatte ihre Ursache im Bereich der internationalen Politik: Einerseits dränge die UdSSR immer stärker, die internationale Anerkennung der Existenz zweier deutscher Staaten sowie von Berlin (West) als selbständige politische Einheit zu erreichen, andererseits sei das Interesse der Verbündeten der Bundesrepublik an der Lösung der deutschen Frage geschwunden. Beispielsweise konzentriere sich die USA darauf, eine Verständigung mit Moskau auf der Basis des Status quo zu erzielen. Hinzu komme, daß der Bau der Mauer zu einer Stabilisierung des Ulbricht-Regimes geführt habe. Alle diese Faktoren hätten zu einem Erosionsprozeß des Alleinvertretungsanspruchs der Bundesregierung auf internationaler Ebene geführt, resümierte Carstens ${ }^{383}$.

Damit charakterisierte er die prekäre deutschlandpolitische Lage zutreffend. Die Gegenmaßnahmen, die die Bundesregierung nach seiner Auffassung ergreifen sollte, lassen aber berechtigte Zweifel aufkommen, ob sie die Bundesrepublik aus der deutschlandpolitischen Defensive herausgeführt hätten. Seine Vorschläge liefen zwar auf eine Reform der Deutschland-Politik hinaus, im Prinzip hielt er aber an den bisherigen Grundsätzen fest: So sollte die Bundesregierung, wenn sie die Wiederherstellung der staatlichen Einheit Deutschlands über den Weg des Selbstbestimmungsrechts forderte, stärker betonen, daß es ihr vor allem darum gehe, den Menschen in der DDR dazu zu verhelfen, dieses Recht auszuüben. Ferner sollte Bonn erklären, in einem Friedensvertrag seien Konzessionen in der Grenzfrage und hinsichtlich des militärischen Status Deutschlands möglich. Carstens empfahl, die Grenze zur ČSSR als endgültig anzuerkennen und schon jetzt einen

381 Vgl. CARSTENS, Erinnerungen, S. 755.

382 Aufzeichnung des Staatssekretärs Carstens vom 27.1. 1966, in: AAPD 1966, Dok. 21, S. 76-102. Vgl. auch CARSTENS, Erinnerungen, S. 755.

383 Vgl. die Aufzeichnung des Staatssekretärs Carstens vom 27.1. 1966, in: AAPD 1966, Dok. 21, S. 76-83. 
Verzicht auf die ehemaligen deutschen Ostgebiete auszusprechen. Außerdem regte er an, den Willen hervorzuheben, die Bundesrepublik werde für die Wiedervereinigung große wirtschaftliche und finanzielle Leistungen auf sich nehmen, und die diesbezüglichen Vorstellungen öffentlich zu präzisieren. Auch gegenüber der DDR sprach er sich für eine flexiblere Haltung aus. Prinzipiell sollte zwar der Alleinvertretungsanspruch und die Nichtanerkennungspolitik nicht aufgegeben werden, doch wollte er eine Teilnahme Ost-Berlins an internationalen Konferenzen ermöglichen. Der Staatssekretär dachte auch an eine Ausweitung des Interzonenhandels und befürwortete direkte Verhandlungen mit der DDR, die zu mehr Freizügigkeit im innerdeutschen Verkehr und einem verstärkten Austausch von Wissenschaft, Kultur und Sport führen sollten. Um den Tendenzen in der Dritten Welt, die DDR aufzuwerten, einen Riegel vorzuschieben und die blockfreien Staaten auf der deutschlandpolitischen Linie Bonns zu halten, wollte er der Entwicklungshilfe künftig eine bewußt politische Ausrichtung geben. Außerdem hielt er es für dringend erforderlich, die Beziehungen zur Sowjetunion zu verbessern sowie diplomatische Beziehungen zu den osteuropäischen Staaten aufzunehmen $^{384}$.

Dies waren alles im Grunde keine revolutionären Ideen, sondern Maßnahmen, die entweder bereits diskutiert worden waren oder die die Bundesregierung bereits aufgegriffen hatte. In ihrer Gesamtheit mußten sie aber den Eindruck einer Abkehr von den bisherigen Prinzipien der Deutschland-Politik erwecken. Insbesondere der Verzicht auf die unter sowjetischer und polnischer Verwaltung befindlichen Gebiete des Deutschen Reiches wäre angesichts des starken Einflusses der Vertriebenenverbände aus innenpolitischer Sicht ein mutiger Schritt gewesen. Andererseits hätte sich die Bundesregierung damit aber nur der Realität gestellt, denn weder Paris noch London oder Washington hatten in der Vergangenheit gegenüber Bonn einen Zweifel daran gelassen, daß ein wiedervereinigtes Deutschland nur das Staatsgebiet der DDR und der Bundesrepublik (einschließlich Berlins) umfassen würde. Doch Carstens' Vorschläge gingen Gradl, von Hassel und Erhard bereits zu weit. In ihren Stellungnahmen erklärten sie sich zwar mit der Mehrzahl der Anregungen einverstanden, zu den bedeutsameren Punkten, wie die Aufnahme diplomatischer Beziehungen mit den osteuropäischen Staaten oder eine deutliche Modifikation der Nichtanerkennungspolitik, äußerten sie aber erhebliche Bedenken ${ }^{385}$.

Dennoch gab Schröder sein Vorhaben nicht auf, die Beziehungen zu Osteuropa zu normalisieren. Im Auswärtigen Amt traf er Vorbereitungen, die Aufnahme diplomatischer Beziehungen mit Rumänien in die Wege zu leiten ${ }^{386}$. Sondierungen in Bukarest im Sommer 1966 ergaben, daß die rumänische Regierung daran keine

384 Vgl. ebenda, S. 83-102.

385 Vgl. die Aufzeichnung des Staatssekretärs Carstens vom 12.4. 1966, in: ebenda, Dok. 103, S. 451-454.

386 Vgl. den Drahterlaß des Ministerialdirektors Werz vom 18. 7.1966 (Entwurf), in: ebenda, Dok. 226, S. 935-937. 
Bedingungen knüpfte ${ }^{387}$. Schröder bat deshalb am 11. Oktober den Kanzler, grünes Licht für die Aufnahme offizieller Verhandlungen zu geben ${ }^{388}$. Wegen der Regierungskrise im Herbst 1966 wurde die Angelegenheit jedoch nicht weiter verfolgt ${ }^{389}$. Es kann deshalb nur spekuliert werden, ob Erhard schließlich doch noch die Aufnahme diplomatischer Beziehungen mit den osteuropäischen Staaten genehmigt hätte. Erst die Große Koalition aus CDU/CSU und SPD unter Bundeskanzler Kiesinger nahm den Kontakt zu Bukarest wieder auf. Am 1. Februar 1967 vereinbarten die Bundesrepublik und Rumänien den Austausch von Botschaftern, wobei der Alleinvertretungsanspruch durch die Abgabe einer Vorbehaltserklärung gewahrt blieb ${ }^{390}$. Das eigentliche Verdienst für die - vom Sonderfall UdSSR abgesehen - erstmalige Aufnahme diplomatischer Beziehungen zu einem Ostblock-Staat gebührt jedoch Schröder. Er hatte mit seiner Ostpolitik den Grundstein gelegt und in Bukarest den Boden für eine Normalisierung der Beziehungen geebnet.

$387 \mathrm{Vgl}$. die Aufzeichnung des Ministerialdirektors Ruete vom 15. 9. 1966, in: ebenda, Dok. 289, S. 1208-1213.

388 Vgl. das Schreiben des Bundesministers Schröder an Bundeskanzler Erhard vom 11. 10. 1966, in: ebenda, Dok. 321, S. 1332 f.

389 Vgl. ebenda, S. 1333, Anm. 10.

390 Für den Wortlaut der Erklärung der Bundesregierung zur Wahrung des deutschen Rechtsstandpunktes bei der Aufnahme diplomatischer Beziehungen zu Rumänien, abgegeben von Bundeskanzler Kiesinger vor dem Bundestag am 1.2. 1967, vgl. DzD V/1, S. $439 f$. 


\title{
3. Krise im Bündnis, Krise der EWG
}

\author{
Schröders Kampf um die MLF und \\ ein französisches "Angebot " $z$ ur atomaren Zusammenarbeit
}

In ihrer Regierungserklärung vom 18. Oktober 1963 bekräftigte die neue Bundesregierung zwar ihren Willen, eine multilaterale nukleare Streitmacht im Rahmen der NATO aufzubauen ${ }^{1}$, doch die Bundestagsfraktion von CDU und CSU war in dieser Frage gespalten. Die sogenannten Gaullisten zogen die Schaffung einer europäischen Nuklearmacht dem MLF-Projekt vor. Außenminister Schröder drängte deshalb die Vereinigten Staaten, die Realisierung der MLF zu forcieren: "Je schneller die multilaterale Streitmacht aufgestellt werde, um so besser.“ Dem ehemaligen amerikanischen Außenminister Acheson versicherte er, daß die Bundesregierung ohne Wenn und Aber hinter der MLF stünde, da den französischen Vorstellungen einer europäischen Nuklearmacht kein integratives Konzept zugrundeliegen würde. Paris denke lediglich an die Zusammenlegung der französischen und der britischen Atomstreitkräfte, was aber „nur eine Kombination von Zwergen“ wäre. Die Gegner der MLF, so Schröder, befänden sich im Irrtum, wenn sie glaubten, eine Beteiligung an einer solchen Streitmacht würde sich für die Bundesrepublik mehr lohnen als die Teilnahme an der multilateralen Atomflotte. Das Kabinett Erhard werde daher „alles tun, um den Gedanken einer europäischen Streitmacht zu entlarven“, versprach er seinem Gesprächspartner ${ }^{2}$. Schröder befürchtete, daß sich die Europäer durch die Schaffung einer europäischen Atommacht verteidigungspolitisch von den USA abkoppeln würden. Da aber nach seiner festen Überzeugung Europa sich ohne die Hilfe der Vereinigten Staaten nicht wirksam gegen den Warschauer Pakt verteidigen könnte, bemühte er sich, die Amerikaner von der Dringlichkeit des MLF-Projekts zu überzeugen, indem er ihnen vor Augen führte, daß bei einem Scheitern des Vorhabens die Gaullisten in der Bundesrepublik die Oberhand gewinnen könnten. Sollte die MLF nicht zustande kommen, dann „werde de Gaulle vor der Tür stehen“, warnte er die amerikanische Regierung wiederholt. Bonn würde dann im nuklearen Bereich mit Frankreich zusammenarbeiten, obwohl de Gaulle nicht gewillt sei, die Kontrolle über die französischen Atomwaffen zu teilen ${ }^{3}$. Seine Haltung in dem innenpolitischen Streit war eindeutig. Er hielt es für „töricht“, die Ansicht zu vertreten, Bonn müsse sich in dieser Frage zwischen Paris und Washington entscheiden: „Wählen könne man nur, wenn einem etwas angeboten werde.“ Die französische Regierung hätte aber der Bundesrepublik nie ein Angebot zur nuklearen Zusammenarbeit gemacht ${ }^{4}$. Die Befürworter einer europäischen Nuklear-

BT STENOGRAPHISCHE BERICHTE, Bd. 53, S. 4196.

2 Gespräch des Bundesministers Schröder mit dem ehemaligen Außenminister Acheson am 19. 10. 1963, in: AAPD 1963, Dok. 394, S. 1343.

3 Gespräch des Bundesministers Schröder mit dem Sicherheitsberater des amerikanischen Präsidenten, Bundy, am 27.11. 1964 in Washington, in: AAPD 1964, Dok. 363, S. 14091411 (1411).

4 Gespräch des Bundesministers Schröder mit dem amerikanischen Außenminister Rusk am 26. 10. 1963, in: AAPD 1963, Dok. 403, S. 1395. 
macht verwiesen jedoch auf die bereits erwähnte Rede des französischen Staatssekretärs Habib-Deloncle am 23. September 1963 vor dem Europarat, in der er die Perspektive einer nuklearen Zusammenarbeit der Europäer entwickelt hatte. Wie geschildert, sah Schröder darin keine wirkliche Offerte. Daß er mit dieser Einschätzung richtig lag, bewies die Unterredung Erhards mit de Gaulle am 21. November 1963 in Paris. Dort stellte der französische Staatspräsident unmißverständlich fest: „Frankreich könne heute Europa noch keine atomare Verteidigung bieten. " 5 Er sagte dem Kanzler lediglich zu, daß im Ernstfall die französischen Atomwaffen auch die Bundesrepublik schützen würden ${ }^{6}$. Zudem betrachtete es Schröder als Zeitverschwendung, sich über eine Mitarbeit an der Force de frappe weiter Gedanken zu machen, nachdem die Bundesregierung im Januar 1963 eine klare Entscheidung getroffen hatte. Sie hätte damals für die Mitarbeit an der MLF optiert, weil es sich dabei um „ein aktuelles Angebot“ gehandelt hatte ${ }^{7}$. Schröder war sehr wohl bewußt, daß auch die Amerikaner die Entscheidungsbefugnis über den Einsatz ihrer Atomwaffen nicht aus der Hand geben würden. Sein Ziel war es aber, „möglichst nahe an [die] Verfügungsgewalt heran[zukommen]". Deshalb stand für ihn fest: „[Die] MLF-Karte muß gespielt werden."8

Mit dem Beginn der offiziellen Verhandlungen über die Schaffung einer multilateralen Atomflotte am 11. Oktober 1963 setzte eine diplomatische Offensive der UdSSR ein. Am 21. Oktober veröffentlichte die sowjetische Nachrichtenagentur TASS eine Erklärung, derzufolge die MLF mit dem Geist des Atomteststoppabkommens nicht vereinbar sei. Man warnte den Westen, dieses Projekt zu realisieren: Die „Bonner revanchistischen und militaristischen Kreise“ dürften keinen Zugang zu Atomwaffen erhalten. Sollten die Pläne weiter verfolgt werden, würde sich dies auf die Entspannungsbemühungen sehr schädlich auswirken, verkündete der Kreml' ${ }^{9}$. Zwei Monate später, im Dezember 1963, gab Gromyko zu verstehen, ein Abkommen über die Nichtverbreitung nuklearer Waffen werde nur zustande kommen, wenn der Westen auf die MLF verzichte ${ }^{10}$. Schröder war bewußt, daß die sowjetischen Proteste gegen eine Beteiligung der Bundesrepublik an der Atomflotte durchaus auf fruchtbaren Boden fallen konnten. Der Gedanke, Deutsche könnten Nuklearwaffen in ihre Hände bekommen, löste beinahe überall Unbehagen aus. Der Außenminister argumentierte deshalb stets dahingehend, daß die MLF die befürchtete Proliferation von Atomwaffen verhindern würde, weil sie einen integrativen Ansatz verfolge: Die Kontrolle über die Nuklearwaffen würde gemeinsam ausgeübt werden ${ }^{11}$. Die sowjetische Kritik interpretierte

\footnotetext{
5 Gespräch des Bundeskanzlers Erhard mit Staatspräsident de Gaulle am 21.11. 1963 in Paris, in: ebenda, Dok. 423, S. 1477.

6 Vgl. ebenda, S. 1474.

7 Interview Schröders mit dem DLF am 29. 10. 1963, in: BulleTIN 1963, S. 1703.

8 So Schröder am 21. 10. 1963 vor dem außenpolitischen Arbeitskreis der CDU/CSU-Bundestagsfraktion (Arbeitskreis V), zitiert nach MARCOWITZ, Option, S. 186.

9 Vgl. DzD IV/9, S. 800 f.

10 Vgl. das Gespräch des Bundesministers Schröder mit dem britischen Außenminister Butler am 9. 12. 1963, in: AAPD 1963, Dok. 459, S. 1578.

11 Interview Schröders mit der japanischen Zeitung Nibon Keizai Shimbun am 14. 11. 1963, in: BULLETIN 1963, S. 1846.
} 
Schröder als den Versuch, die MLF zu Fall zu bringen. Außerdem war sie für ihn ein Indiz, daß das Projekt tatsächlich in der Lage war, den Zusammenhalt in der Allianz zu fördern und die NATO zu stärken ${ }^{12}$.

Innerhalb des Bündnisses war es vor allem die französische Regierung, die die MLF überaus negativ beurteilte. Auf de Gaulles Fundamentalkritik an den amerikanischen Plänen wurde bereits ausführlich eingegangen. Den heftigsten öffentlichen Angriff gegen die multilaterale Atomflotte führte jedoch am 4. Dezember 1963 der Generalsekretär der gaullistischen Partei UNR/UDT, Jaques Baumel. Vor der parlamentarischen Versammlung der WEU bezeichnete er das Vorhaben als militärisch absurd und politisch unrealistisch. Den Vereinigten Staaten warf er vor, sie bezweckten auf diese Weise, ihr Atommonopol aufrechtzuerhalten ${ }^{13}$. Das vernichtende Urteil der französischen Regierung über die MLF deutete Schröder jedoch als weiteren „Hinweis, daß hier ein Projekt vorliege, das man intensiv weitertreiben sollte" ${ }^{14}$. Aus der Tatsache, daß „alle diejenigen, die gegen eine Integration seien, dagegen sprächen“, zog er den Schluß, die Atomflotte verfüge ohne Zweifel über "positive Elemente“ 15 .

Es muß an dieser Stelle noch einmal betont werden, daß Schröder kein blinder Befürworter der MLF war, sondern ihre Konzeptionsmängel durchaus erkannte. Stets hob er hervor, das Projekt sei keine Idealkonstruktion, doch enthalte es einen richtigen Ansatz zur Lösung des nuklearen Problems innerhalb der NATO. Der Außenminister bestritt nicht, daß auch andere Modelle einer nuklearen Kooperation der NATO-Mitgliedstaaten denkbar seien, doch hielt er es für müßig, sich darüber Gedanken zu machen, weil der MLF-Plan der einzige Vorschlag war, der wirklich Gestalt angenommen habe ${ }^{16}$. Die Befürworter einer europäischen Atomstreitmacht versuchte er mit dem Hinweis zu beruhigen, daß Aufbau und Konstruktion der MLF noch nicht festgelegt seien ${ }^{17}$. Auch bezüglich des im Brennpunkt der Kritik stehenden amerikanischen Vetos gegen den Einsatzbefehl der Nuklearwaffen war seiner Meinung nach noch nicht das letzte Wort gesprochen. Er erinnerte in diesem Zusammenhang an den italienischen Vorschlag einer Europäisierungsklausel, die seit Juli 1963 auf dem Tisch lag ${ }^{18}$. Sie sollte die Option offenhalten, daß bei einem weiteren Voranschreiten der europäischen Einigung eines Tages die Kontrollmechanismen überprüft und das amerikanische Veto durch die Einführung des Mehrheitsbeschlusses abgelöst werden könnte. Mit dieser Regelung waren auch die Amerikaner prinzipiell einverstanden ${ }^{19}$. Ohnehin war die

12 Vgl. das Gespräch des Bundesministers Schröder mit dem britischen Außenminister Butler am 9. 12. 1963, in: AAPD 1963, Dok. 459, S. 1580 und S. 1589 f.

13 Vgl. ebenda, S. 1590, Anm. 55.

14 Deutsch-amerikanische Regierungsbesprechung am 28.12. 1963 in Stonewall, Texas, in: ebenda, Dok. 488, S. 1697.

15 Gespräch des Bundesministers Schröder mit dem britischen Außenminister Butler am 9. 12. 1963, in: ebenda, Dok. 459, S. 1591.

16 Vgl. ebenda, S. 1590 und S. 1592.

17 Vgl. das Interview Schröders mit dem DLF am 29. 10. 1963, in: Bulletin 1963, S. 1703.

18 Vgl. den Runderlaß des Staatssekretärs Carstens vom 9.7. 1963, in: AAPD 1963, Dok. 222, S. 733.

19 Vgl. die Aufzeichnung des Ministerialdirektors Krapf vom 15.11. 1963, in: ebenda, Dok. 414, S. $1441 \mathrm{f}$. 
Bundesregierung der Überzeugung, daß der Einfluß der Europäer auf die Kontrolle der MLF-Atomwaffen im Laufe der Zeit automatisch wachsen würde ${ }^{20}$.

Auffallend ist, wie sich Schröders Argumentation für das MLF-Projekt im Lauf der Zeit wandelte. Nachdem die Washingtoner Arbeitsgruppe, die mit der Untersuchung der technischen und strategischen Aspekte beauftragt worden war, in ihrem Abschlußbericht vom Februar 1964 die Atomflotte als militärisch sinnvoll bewertet hatte, warb der Außenminister nicht mehr ausschließlich mit politischen Argumenten für das Projekt, sondern rückte zunehmend die militärischen Vorzüge in den Vordergrund ${ }^{21}$. Außerdem wies er nun verstärkt darauf hin, durch die MLF werde die Forderung des Oberbefehlshabers der NATO in Europa (SACEUR) nach einer Nachrüstung im Bereich der Mittelstreckenraketen erfüllt ${ }^{22}$. Auch die Prognose, mittels der neuen Flotte würden die transatlantischen Bindungen durch ein „ein unlösbares militärisches Engagement der Vereinigten Staaten in Europa" gestärkt werden, war jetzt vermehrt von ihm zu hören ${ }^{23}$. Seines Erachtens war sie ein unverzichtbarer Ersatz für den wegen der weltweiten Verpflichtungen der USA langfristig zu erwartenden Abzug von amerikanischen Soldaten aus der Bundesrepublik. Sobald die multilaterale Atomflotte die Verklammerung Europas mit den Vereinigten Staaten garantiere und „eine viel bedeutsamere Bindung zwischen Deutschland und Amerika" schaffe ${ }^{24}$, bräuchte eine Reduzierung der US-Streitkräfte nicht mehr als ein Sicherheitsrisiko empfunden zu werden ${ }^{25}$.

20 Vgl. die deutsch-britische Regierungsbesprechung am 16.1. 1964 in London, in: AAPD 1964, Dok. 14, S. 71, sowie ZEITZEUGENBEFRAGUNG Krapf.

21 Vgl. dazu z.B. das Vortragsexposé des Bundesministers Schröder vom 4. 8. 1964, in: AAPD 1964, Dok. 220, S. 937.

$22 \mathrm{Vgl}$. ebenda; sowie das Gespräch des Bundesministers Schröder mit dem amerikanischen Außenminister Rusk am 27.11. 1964 in Washington, in: ebenda, Dok. 360, S. 1400. Der Oberbefehlshaber der NATO-Streitkräfte in Europa, der amerikanische General Lemnitzer, hielt die Stationierung von 860 bis 870 landgestützten Mittelstreckenraketen in Europa für erforderlich. Vgl. dazu die Besprechung mit NATO-Generalsekretär Stikker am 31. 10. 1963, in: AAPD 1963, Dok. 406, S. 1406 f. Laut dem Urteil der militärischen Experten sollten bis 1970 die veralteten alliierten Strike-Verbände durch MRBMs ersetzt werden, da schon jetzt im Ernstfall damit gerechnet werden mußte, daß nur 30\% der Jagdbomber ihren Auftrag erfüllen konnten. Bei den Mittelstreckenraketen wurde dagegen die Wahrscheinlichkeit einer Auftragserfüllung auf $85 \%$ taxiert. Vgl. dazu die Aufzeichnung des Ministerialdirektors Krapf vom 4. 6. 1964, in: AAPD 1964, Dok. 149, S. 600-602.

23 Vortragsexposé des Bundesministers Schröder vom 4. 8. 1964, in: ebenda, Dok. 220, S. 937.

24 Gespräch des Bundesministers Schröder mit dem Sicherheitsberater des amerikanischen Präsidenten, Bundy, am 27. 11. 1964 in Washington, in: ebenda, Dok. 363, S. 1411.

25 Gespräch des Bundesministers Schröder mit dem britischen Außenminister Gordon Walker am 15. 11. 1964, in: ebenda, Dok. 334, S. 1305. In der Tat wurde am Potomac bezweifelt, ob in der Bundesrepublik wirklich eine derart große Zahl von amerikanischen Truppen stationiert bleiben müßte. Im Frühjahr 1964 wurden 7500 Soldaten, die im Zuge des Manövers Big Lift nach Deutschland verlegt worden waren, wieder abgezogen. Die amerikanische Regierung versicherte aber, Bonn könne der Zusage Präsident Johnsons vom Dezember 1963 vertrauen, sechs US-Divisionen würden auf Dauer in der Bundesrepublik bleiben. Vgl. dazu die Aufzeichnung des Staatssekretärs Carstens vom 17.3. 1964, in: ebenda, Dok. 72, S. 349f. Andererseits beklagte Johnson aber am 3. 5.1964 in einem Inter- 
Im Herbst 1963 war Schröder guter Dinge, daß die Briten ihre negative Beurteilung der MLF überdenken würden. Der Regierungswechsel in Großbritannien vom 18. Oktober 1963 stimmte ihn zuversichtlich. Er verwies darauf, daß der neue Premierminister Lord Home, der sich jetzt Sir Alec Douglas-Home nannte ${ }^{26}$, bislang gegenüber dem Projekt positiver eingestellt gewesen sei als Macmillan ${ }^{27}$. Tatsächlich teilte der britische Botschafter Roberts am 14. November dem Kanzler mit, die Aussichten auf eine Beteiligung Londons an dem Projekt seien nun gestiegen, deutete aber zugleich an, daß die neue Regierung vor den Unterhauswahlen im Herbst 1964 keine endgültige Entscheidung treffen wolle ${ }^{28}$. Selbst einen Wahlsieg der Labour Party empfand Schröder nicht als Bedrohung des Projekts, obwohl diese bislang gegen die multilaterale Atomflotte opponiert hatte. Er baute darauf, daß die britischen Sozialisten ihre Haltung früher oder später zwangsläufig ändern würden, weil sie auf der anderen Seite die Existenz von Atomstreitkräften in nationaler Verfügungsgewalt ablehnten ${ }^{29}$. Bei der ersten Unterredung mit dem neuen britischen Außenminister, Richard Butler, am 9. Dezember 1963, mußte Schröder jedoch erfahren, daß auch die Regierung DouglasHome die MLF-Pläne nicht wesentlich anders beurteilte als ihre Vorgängerin. Immer noch hielten die Briten die finanziellen Belastungen für zu hoch und lehnten das Konzept gemischter Besatzungen ab. Butler betonte, in der Downing Street hätte man sich lediglich „aus Rücksichtnahme“ auf die Bundesrepublik entschlossen, in offizielle Verhandlungen einzuwilligen. Die britische Regierung sei aber bereit, sich „als Zeichen ihres guten Willens“ an dem noch von Kennedy angeregten Versuchsschiff zu beteiligen ${ }^{30}$. Trotz dieser deutlichen Worte bewahrte Schröder seinen Optimismus, daß Großbritannien letztendlich an der MLF teilnehmen würde. Gegenüber Rusk behauptete er, Douglas-Home befürworte die Schaffung einer multilateralen Atomflotte, lediglich Verteidigungsminister Thorneycroft sei noch unentschlossen. Auch der Vorsitzende der Labour Party, Harold Wilson, würde sich privat "viel positiver" äußern als in seinen öffentlichen Stellungnahmen $^{31}$. Rusk war ebenfalls „ziemlich optimistisch“, daß die Briten mitmachen

$26 \mathrm{Da}$ im politischen System Großbritanniens der Premierminister über einen Sitz im Unterhaus verfügen muß, verzichtete Lord Home zunächst auf diejenigen Adelstitel, die ihm einen Sitz im Oberhaus garantierten und kandidierte anschließend in einer Nachwahl erfolgreich für das Unterhaus. Vgl. ADG 1966, S. $10868 \mathrm{f}$.

27 Vgl. die Gespräche des Bundesministers Schröder mit dem japanischen Außenminister Ohira am 7./8. 11. 1963 in Tokio, in: AAPD 1963, Dok. 410, S. 1423.

28 Vgl. das Gespräch des Bundeskanzlers Erhard mit dem britischen Botschafter Roberts am 18. 11. 1963, in: ebenda, Dok. 418, S. 1448.

29 Vgl. die Gespräche des Bundesministers Schröder mit dem japanischen Außenminister Ohira am 7./8.11. 1963 in Tokio, in: ebenda, Dok. 410, S. 1423.

30 Gespräch des Bundesministers Schröder mit dem britischen Außenminister Butler am 9. 12. 1963, in: ebenda, Dok. 459, S. 1591. Großbritannien gab seine Teilnahme an dem gemischt-bemannten Versuchsschiff allerdings erst am 8.1. 1964 offiziell bekannt. Vgl. AAPD 1964, S. 72, Anm. 41.

31 Deutsch-amerikanische Regierungsbesprechung am 28.12. 1963 in Stonewall, Texas, in: AAPD 1963, Dok. 488, S. 1697. 
würden. Er teilte Schröders Ansicht, die Tories könnten im Hinblick auf den Wahlkampf keine so positive Haltung einnehmen, wie sie eigentlich wollten ${ }^{32}$.

Nichts an Rusks Äußerungen deutete darauf hin, daß nach der Ermordung Kennedys das Projekt auch in Washington auf der Kippe stand, so daß Schröder den Eindruck gewann, der Wechsel im Weißen Haus habe keine Auswirkungen auf die MLF-Pläne. Doch der neue Präsident, Lyndon B. Johnson, zögerte lange, sich mit dem Projekt zu identifizieren ${ }^{33}$. So vermied er es auch, anläßlich der deutsch-amerikanischen Regierungsbesprechungen im Dezember 1963 persönlich zur MLF Stellung zu nehmen ${ }^{34}$. Erst fünf Monate später, am 16. April 1964, ließ er Bonn durch den amerikanische NATO-Botschafter Finletter die Botschaft übermitteln, die Vereinigten Staaten hätten weiterhin ein starkes Interesse an einer Realisierung der MLF. Johnson versprach, sich dafür einzusetzen, daß eine Vertragsunterzeichnung unmittelbar nach den amerikanischen Präsidentschaftswahlen im November 1964, spätestens aber im Januar 1965, erfolgen könnte. Finletter deutete zudem an, man ziehe im Weißen Haus notfalls auch einen Alleingang der Bundesrepublik und der USA in Erwägung. Seine Regierung hoffe, auf diese Weise andere Staaten wie Italien und Großbritannien, die bislang abwartend taktiert hatten, zu einer Teilnahme zu bewegen, erklärte der Botschafter und fügte hinzu, der Präsident sei der Ansicht, Bonn und Washington sollten abseits der offiziellen MLF-Arbeitsgruppe bilaterale Verhandlungen aufnehmen ${ }^{35}$.

Durch ein gemeinsames Vorgehen mit der Bundesrepublik beabsichtigte Johnson offensichtlich, die ins Stocken geratenen Beratungen über das Gründungsstatut der MLF wieder in Gang zu bringen. Im Gegensatz zur Washingtoner Arbeitsgruppe, die im Februar 1964 ihre Arbeit erfolgreich beendet hatte, kamen die politischen Beratungen in Paris nämlich nicht voran. Der einzige vorzeigbare Erfolg war die einstimmige Entscheidung, ab Ende des Jahres ein Versuchsschiff mit einer gemischten Besatzung für die Dauer von einem Jahr einzusetzen, um das Zusammenwirken von Soldaten verschiedener Nationalität auf engstem Raum in der Praxis zu erproben ${ }^{36}$. Weitere Verhandlungsfortschritte wurden von der britischen Regierung blockiert. Mehr als ein halbes Jahr nach der Aufnahme offizieller Verhandlungen stellte London plötzlich die gesamte Konzeption des Projekts in Frage. Die britische Delegation plädierte unter anderem für eine Verkleinerung der Flotte und dachte an eine Einbeziehung von Flugzeugen bzw. von landgestützten Mittelstreckenraketen. Außerdem strebten die Briten eine Verringerung ihres Kostenanteils an. Sie stellten zudem die Bedingung, daß sowohl ein britisches wie ein amerikanisches Vetorecht gegen den Einsatz der MLF-Kernwaffen fixiert werden müßte. Ihren Verhandlungspartnern blieb nicht verborgen, daß die Einwände hauptsächlich darauf abzielten, die Beratungen in die Länge zu ziehen.

32 Ebenda, S. 1696.

33 Vgl. dazu Hoppe, Zwischen Teilhabe und Mitsprache, S. 153.

34 Vgl. AAPD 1963, Dok. 486-492, S. 1672-1713.

35 Vgl. das Gespräch des Bundeskanzlers Erhard mit dem amerikanischen Botschafter Finletter am 16. 4. 1964, in: AAPD 1964, Dok. 98, S. 428-430; sowie die Aufzeichnung des Vortragenden Legationsrats I. Klasse Luedde-Neurath vom 21.4. 1964, in: ebenda, Dok. 104, S. $454 \mathrm{f}$.

36 Vgl. ebenda, S. 450. 
Man nahm aber nicht an, daß die britische Regierung damit die Absicht verfolgte, die MLF zu Fall zu bringen, sondern machte für ihr Verhalten den Wahlkampf in Großbritannien verantwortlich. Die britischen Stellungnahmen wurden so gedeutet, daß die Tories nach einem Sieg bei den Unterhauswahlen im Herbst 1964 ihre Vorbehalte zurückstellen würden ${ }^{37}$. Immerhin hatte bereits Premierminister Douglas-Home im Januar 1964 gegenüber Erhard zum Ausdruck gebracht, daß das Vorhaben erst nach den Unterhauswahlen verwirklicht werden könnte ${ }^{38}$.

Mit ihren Forderungen standen die Briten in der MLF-Arbeitsgruppe allerdings allein. Dennoch nahm das Auswärtige Amt an, das Argument Londons, die Atomflotte sei zu kostspielig, könnte bei den kleineren NATO-Staaten auf fruchtbaren Boden fallen. Zudem wurde die Befürchtung geäußert, durch die ständigen Verzögerungen werde in Washington die Neigung wachsen, auf die Vorschläge Großbritanniens einzugehen. Eine nach den britischen Vorstellungen geschaffene MLF hätte jedoch laut dem Urteil der deutschen Sachverständigen einen militärisch geringeren Stellenwert gehabt und die Nicht-Nuklearstaaten praktisch von der Mitsprache über die Nuklearstrategie und den Einsatz der Atomwaffen ausgeschlossen. Andererseits konnte aber auf die Mitarbeit der Briten nur schwerlich verzichtet werden. Italien hatte bereits deutlich gemacht, daß seine Mitwirkung von der Teilnahme Londons abhing. An der Koblenzer Straße wußte man, daß auch Holländer, Belgier, Griechen und Türken nur dann mitmachen würden, wenn die drei „Großen“, die Bundesrepublik, Großbritannien und die Vereinigten Staaten, sich über die Konzeption der MLF einigten ${ }^{39}$. Insofern bot der von Johnson angeregte deutsch-amerikanische Alleingang keine Lösung aus dem Dilemma. Bonn durfte die anderen an der MLF interessierten Staaten nicht verstimmen. Die Bundesregierung präferierte deshalb ein mit den Amerikanern koordiniertes Vorgehen innerhalb der Arbeitsgruppe $e^{40}$.

Mit den Vorstellungen der USA, wie die multilaterale Atomflotte im Detail konzipiert sein sollte, war man am Rhein allerdings höchst zufrieden. Als die amerikanische Regierung im Frühjahr 1964 in Bonn den Vertragsentwurf für eine MLF-Charta übergab, stellte die Bundesregierung erfreut fest, daß Washington ihre Anregung über die Kontrolle der Atomwaffen der MLF übernommen hatte. Bonn hatte vorgeschlagen, das Mitspracherecht eines Landes von seiner Beteiligung an den Kosten abhängig zu machen. Für die Freigabe der Nuklearwaffen sah man ein Quorum von 67,5\% der Anteile vor. Da die Amerikaner 35\% der finanziellen Belastungen übernehmen sollten, bedeutete dies, daß einerseits das Veto der USA gesichert war, andererseits die Amerikaner aber nicht alleine über den Einsatz der Atomwaffen entscheiden konnten ${ }^{41}$. Übereinstimmung bestand auch, daß die Verhandlungen in Paris zügig fortgesetzt werden müßten. Im Kommuni-

37 Vgl. ebenda, S. 451-454.

38 Vgl. das Gespräch des Bundeskanzlers Erhard mit Premierminister Douglas-Home am 15. 1. 1964 in London, in: ebenda, Dok. 12, S. 48.

$39 \mathrm{Vgl}$. die Aufzeichnung des Vortragenden Legationsrats I. Klasse Luedde-Neurath vom 21. 4. 1964, in: ebenda, Dok. 104, S. 453 f.

40 Vgl. ebenda, S. 455 f.

41 Vgl. ebenda, S. 454. 
qué über die Besprechungen, die Erhard und Schröder Mitte Juni 1964 in Washington führten, bekräftigten beide Seiten, daß „weiterhin alle Anstrengungen unternommen werden sollten, um zum Ende dieses Jahres ein Abkommen zur Unterzeichnung fertigzustellen" 42 .

Alles in allem waren also die Aussichten auf eine Verwirklichung des Projekts zur Jahresmitte 1964 nicht ungünstig. Den einzigen, aber bedeutsamen Unsicherheitsfaktor stellte noch Großbritannien dar; doch ließen die Äußerungen der britischen Regierung den Schluß zu, daß eine Beteiligung an der MLF nach den Unterhauswahlen in Erwägung gezogen wurde. De Gaulle, der das Projekt bislang als eine zu vernachlässigende Größe angesehen hatte, rechnete nun erstmals mit seiner Verwirklichung ${ }^{43}$. Die Neubeurteilung der MLF bewog ihn wohl dazu, anläßlich der deutsch-französischen Konsultationsgespräche Anfang Juli 1964 in Bonn die Möglichkeit einer bilateralen Zusammenarbeit im Bereich der nuklearen Verteidigung anzusprechen. Gegenüber Carstens, den er am Mittag des 4. Juli in der Bibliothek von Schloß Ernich, der Residenz des französischen Botschafters, zu einem Vieraugengespräch empfing, beklagte der Staatspräsident zunächst, er vermisse „eine gemeinsame und selbständige europäische Politik Deutschlands

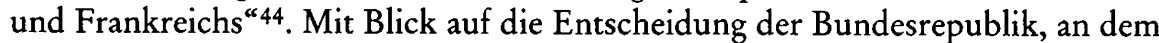
MLF-Projekt mitzuarbeiten, bemerkte er lapidar: „Die Bombe bekommen sie von den USA nie." Zur Überraschung des Staatssekretärs schlug er statt dessen eine Beteiligung an der Force de frappe vor: „Warum gehen Sie nicht mit uns zusammen? Wir haben die Bombe auch. Bei uns können Sie einen weit größeren Anteil erhalten." ${ }^{45}$ Carstens unterrichte umgehend den Kanzler und den Außenminister von dem Angebot ${ }^{46}$, fünf Tage später auch Osterheld ${ }^{47}$. Der Ministerialdirigent forderte sogleich Westrick, Schröder und Erhard auf, diese „Sternstunde“ nicht verstreichen zu lassen: „Wir müssen zugreifen!“ Er arbeitete eine Denkschrift aus, in der er dem Kanzler nachdrücklich empfahl, Sondierungen aufzunehmen, wie sich de Gaulle eine Beteiligung der Bundesrepublik konkret vorstelle. Etwaige sowjetischen Proteste sollte man einfach ignorieren, meinte Osterheld. Diese gebe es ja auch wegen dem Interesse Bonns an der MLF. Auch amerikanische Einwände wollte er in Kauf nehmen. Der Leiter des Außenpolitischen Büros im Bundeskanzleramt begründete dies damit, daß de Gaulles Standpunkt, die Europäer dürften nicht länger auf die Sicherheitsgarantie der USA bauen, nicht völlig von der Hand zu weisen sei. Zwar hatten auch für ihn die transatlantischen Beziehungen weiterhin Priorität, doch sollte sich Bonn deswegen nicht von einer Zusammenarbeit mit Paris abhalten lassen 48 .

Aber war die Offerte des Generals tatsächlich ernst gemeint? Carstens jeden-

\footnotetext{
42 DzD IV/10.2, S. 686.

43 Vgl. dazu Bozo, Deux stratégies pour l'Europe, S. 117.

44 Gespräche des Staatssekretärs Carstens mit Staatspräsident de Gaulle und dem französischen Außenminister Couve de Murville am 4. 7. 1964, in: ebenda, Dok. 186, S. 767.

45 Ebenda, S. 768. Vgl. auch CARSTENS, Erinnerungen, S. 255 und S. 272.

46 Vgl. ebenda, S. 272.

47 Vgl. OSTERHELD, Außenpolitik, S. 100.

48 Ebenda.
} 
falls war davon überzeugt ${ }^{49}$. Auch Kusterer war sich sicher, angesichts einer Sache von so enormer Bedeutung sei „bei einem Mann wie de Gaulle von vornherein auszuschließen, daß es ihm etwa nur entschlüpft wäre, es nur so dahingesagt gewesen sein könnte" 50 . Es stellt sich dann allerdings die Frage, was den Staatspräsidenten bewog, einem Staatssekretär - und damit jemandem, der nur sehr begrenzt auf den politischen Kurs der Bundesregierung Einfluß nehmen konnte - ein derart weitreichendes Angebot zu unterbreiten und gegenüber dem Kanzler, bei dem letztlich die Entscheidungsgewalt lag, nicht die geringste Andeutung zu machen, sondern sogar noch ausdrücklich zu betonen, daß Frankreich die Verfügungsgewalt über seine Nuklearwaffen nicht aufgeben würde. Als Erhard nämlich am Morgen des 4. Juli 1964, also wenige Stunden vor der Unterredung zwischen de Gaulle und Carstens, ein Vieraugengespräch mit dem Präsidenten führte ${ }^{51}$, fragte er ihn unter anderem zu seinen Plänen hinsichtlich der Force de frappe. In seiner Replik erklärte de Gaulle ausdrücklich, daß die französische Nuklearstreitmacht unter nationaler Kontrolle bleiben werde, solange weder ein europäischer Staat noch eine europäische Regierung existiere: „Bis zu dem Zeitpunkt, da Europa verteidigungsmäßig einmal selbst bestehen kann, und bis zu dem Zeitpunkt, da seine politische Organisation so weit gediehen sei, daß eine wirklich europäische Regierung möglich werde, bis zu diesem Zeitpunkt gebe es die getrennten nuklearen Waffen Großbritanniens und Frankreichs [...]. " Er versicherte dem Kanzler zwar anschließend erneut, daß das französische Potential im Falle eines Angriffs auf Europa „automatisch“ zum Einsatz kommen würde, da die Verteidigung Frankreichs mit der Verteidigung Europas identisch sei, doch mit keiner Silbe deutete er an, daß er in Betracht zog, irgend jemanden an der Kontrolle über die Force de frappe zu beteiligen ${ }^{52}$. Auch Carstens betont in seinen Erinnerungen, de Gaulle habe laut den Gesprächsprotokollen "nicht die leiseste Andeutung " gemacht ${ }^{53}$.

Handelte es sich also in Wahrheit nur um ein Lockangebot, das die Bundesrepublik von einer Teilnahme an der MLF und einer engen militärischen Zusammenarbeit mit den USA abhalten sollte? Erhard jedenfalls war nicht gewillt, über eine Partizipation an der französischen Atomstreitmacht auch nur nachzudenken. Am 6. Juli 1964 legte er McGhee dar, die auf einer Kooperation der Regierungen basierende europapolitische Konzeption de Gaulles ziele bekanntlich darauf ab, eine gesamteuropäische Regierung zu verhindern. Somit könnten die schon früher von französischer Seite genannten Voraussetzungen für eine Umwandlung der Force de frappe in eine gemeinsame, europäische Atomstreitmacht gar nicht erfüllt werden. Der Bundesrepublik bleibe damit nur die Wahl, sich verteidigungspolitisch entweder den Amerikanern oder den Franzosen anzuvertrauen. In Anbetracht der Größe des amerikanischen Potentials sei selbstverständlich der atomare

49 Vgl. CARSTENS, Erinnerungen, S. 272.

50 Vgl. KuSTERER, Der Kanzler und der General, S. 422.

51 Vgl. das Gespräch des Bundeskanzlers Erhard mit Staatspräsident de Gaulle am 4. 7. 1964, in: AAPD 1964, Dok. 187, S. 768-777.

52 Vgl. ebenda, S. 775.

53 CARstens, Erinnerungen, S. 272. 
Schutzschild der USA vorzuziehen ${ }^{54}$. Der Kanzler gab sich überzeugt, daß de Gaulle die Bundesrepublik nur ködern wollte, weil Frankreich Probleme hatte, sein ehrgeiziges Nuklearprogramm zu finanzieren. Er werde aber nicht zustimmen, deutsche Steuergelder in ein „Faß ohne Boden“ zu werfen, erklärte Erhard resolut ${ }^{55}$.

Angesichts von Erhards tiefem Mißtrauen gegenüber der französischen Politik, ist schwer nachzuvollziehen, warum de Gaulle sein Angebot ausschließlich Carstens vortrug. Osterheld vermutete, der französische Präsident habe sich an den Staatssekretär gewandt, weil er ihm gegenüber ein solch heikles Thema wie eine Beteiligung an der Force de frappe inoffiziell ansprechen und auf diese Weise erst einmal die deutsche Reaktion testen konnte. Außerdem war mit Carstens ein Gespräch ohne Dolmetscher möglich, da dieser fließend französisch sprach ${ }^{56}$. Kusterer wiederum nahm an, daß de Gaulle Erhard nicht die Entschlußkraft zutraute, auf eine derartige Offerte sogleich zu antworten. Er habe vermeiden wollen, sofort abgewiesen zu werden. Außerdem habe der General Carstens irrtümlich dem Lager Adenauers zugerechnet. Der frühere Chefdolmetscher spekulierte, de Gaulle habe mit seiner Vorgehensweise die Erwartung verbunden, der Staatssekretär könnte die Bundesregierung im Laufe der Zeit von ihrem antifranzösischen Kurs abbringen ${ }^{57}$. Sollten dies tatsächlich seine Motive gewesen sein, war es dennoch äußerst ungeschickt, gegenüber Erhard derart kategorisch auf die französische Souveränität über die Force de frappe zu pochen.

Die im Rahmen der Regierungsgespräche am 3./4. Juli 1964 gefallene Äußerung Couve de Murvilles, Nuklearwaffen hätten eine so grauenhafte Wirkung, „daß man sie mit niemandem teilen kann", bestärkte aber die Führungsspitze des Auswärtigen Amtes in ihrer Ansicht, de Gaulles Angebot sei nicht seriös. Man entschied sich deswegen, die Sache nicht weiter zu verfolgen ${ }^{58}$. Carstens regte zwar in einer für Schröder gefertigten Aufzeichnung vom 27. Juli $1964^{59}$ an, in Erfahrung zu bringen, was die Franzosen unter einer Europäisierung ihrer Atomwaffen verstanden, hielt es aber für "ganz unwahrscheinlich“, daß der französische Staatspräsident an eine "gleichberechtigte Partnerschaft" mit der Bundesrepublik im atomaren Bereich denke. Außerdem prophezeite er angesichts der negativen Erfahrungen, die man mit de Gaulle in bezug auf den Beitritt Großbritanniens zur

$54 \mathrm{Vgl}$. das Gespräch des Bundeskanzlers Erhard mit dem amerikanischen Botschafter McGhee am 6. 7. 1964, in: AAPD 1964, Dok. 189, S. 791. Erhard äußerte gegenüber dem Botschafter zudem, er hätte dies auch gegenüber de Gaulle zum Ausdruck gebracht. Das ist aber dem Gesprächsprotokoll nicht zu entnehmen. Vgl. das Gespräch des Bundeskanzlers Erhard mit Staatspräsident de Gaulle am 4. 7. 1964, in: ebenda, Dok. 187, S. 774-777. Nichtsdestotrotz wiederholte der Kanzler am 14. 7. 1964 in einer Unterredung mit Spaak seine Behauptung. Vgl. das Gespräch des Bundeskanzlers Erhard mit dem belgischen Außenminister Spaak am 14. 7. 1964, in: ebenda, Dok. 198, S. 834 f.

55 Ausführungen des Bundeskanzlers Erhard gegenüber dem amerikanischen Botschafter McGhee am 14. 12. 1964, in: ebenda, Dok. 380, S. 1487-1492 (1492).

56 Vgl. OSTERHELD, Außenpolitik, S. 102.

$57 \mathrm{Vgl}$. KUSTERER, Der Kanzler und der General, S. $422 \mathrm{f}$.

58 CARSTENS, Erinnerungen, S. 272.

59 Vgl. die Aufzeichnung des Staatssekretärs Carstens vom 27.7. 1964, in: AAPD 1964, Dok. 210, S. 888-893. 
EWG gemacht hatte, daß dieser im Falle eines deutsch-französischen Interessenkonflikts auf die Wünsche Bonns keine Rücksicht nehmen würde ${ }^{60}$. Der Staatssekretär kam daher zu dem Schluß, man müsse „das MLF-Projekt nachdrücklich weiterverfolgen" 61 .

Sein Chef mußte aber gar nicht erst davon überzeugt werden, daß die französische Atomstreitmacht für die Bundesrepublik keine Alternative war. Militärisch sah der Außenminister in der Force de frappe keinen ernstzunehmenden Faktor: „Das Sahara-Bömbchen“, war sein spöttischer Kommentar zu den nuklearen Ambitionen Frankreichs ${ }^{62}$. Den „wirksamste[n] Schutz" für die Bundesrepublik bildete nach seiner Einschätzung nach wie vor das atomare Arsenal der USA ${ }^{63}$. Wie bereits ausgeführt wurde, waren seine Vorstellungen bezüglich der Gestaltung der westlichen Verteidigungspolitik absolut konträr zu denen de Gaulles. So strebte der Außenminister einen Ausbau des integrativen Systems innerhalb der NATO an. Nur eine Verstärkung der transatlantischen Verteidigungskooperation konnte seines Erachtens die von den Vereinigten Staaten postulierte Unteilbarkeit der Verteidigung Europas und Amerikas auch in der Praxis sicherstellen. Das Konzept einer Verklammerung der Streitkräfte aller Mitgliedstaaten der Allianz lehnte de Gaulle wiederum strikt ab. Er betrieb eine Politik, die laut Schröder unter dem Motto "Ami go home“ stand 64 . Verteidigungsminister von Hassel teilte den Standpunkt seines Parteifreunds. Auch er war der Ansicht, „daß eine wie auch immer geartete Beteiligung an der Force de frappe nicht in Erwägung gezogen werden" dürfte65.

Nach dem Konsultationstreffen vom Juli 1964 kühlte sich das Verhältnis zwischen beiden Staaten merklich ab. Aus Enttäuschung, daß es nach Abschluß des Freundschaftsvertrages am 22. Januar 1963 weder zu einer engeren politischen Abstimmung noch zu einer verteidigungspolitischen Zusammenarbeit gekommen war, gab de Gaulle nach seiner Rückkehr an die Seine intern die Weisung, die Bundesrepublik nicht mehr über die nuklearen Vorhaben Frankreichs in Kenntnis zu setzen $^{66}$. Pressemeldungen, denen zufolge dem Kanzler eine Beteiligung an der Force de frappe offeriert worden wäre, was dieser aber zurückgewiesen habe, riefen in Paris tiefe Verärgerung hervor ${ }^{67}$. Die französische Regierung äußerte den Verdacht, die Indiskretion sei „von höchster Bonner Stelle“ ausgegangen. Von einer drohenden „Krise in den deutsch-französischen Beziehungen“ war die Rede $^{68}$. Um die Wogen zu glätten, dementierte die Bundesregierung am 28. Juli

60 Ebenda, S. 888 (Hervorhebung im Original).

61 Ebenda, S. 890.

62 Zitiert nach SCHWARZ, Adenauer II, S. 894.

63 Vortragsexposé des Bundesministers Schröder vom 4. 8. 1964, in: AAPD 1964, Dok. 220, S. 934.

64 Gespräch des Bundesministers Schröder mit dem Sicherheitsberater des amerikanischen Präsidenten, Bundy, am 27.11. 1964 in Washington, in: ebenda, Dok. 363, S. 1412.

65 Militärisches Tagebuch von Hassel, Eintrag vom 3. 10. 1964. Zitiert nach MARCOWITZ, Option, S. 197.

66 Vgl. DE GAULle, Lettres X, S. 79.

67 Vgl. AAPD 1964, S. 887, Anm. 11; Koopmann, Das schwierige Bündnis, S. 240.

68 Drahtbericht des Gesandten Knoke, Paris, an das Auswärtige Amt vom 30. 7. 1964, PA/ AA, B 150, Aktenkopien 1964. 
die Berichte, ihr sei eine Mitwirkung an der französischen Nuklearstreitmacht angetragen worden ${ }^{69}$. Doch die Beziehungen zwischen Bonn und Paris blieben weiterhin gespannt, denn Frankreich startete nun, wie von Schröder befürchtet ${ }^{70}$, einen Frontalangriff gegen die multilaterale Atomflotte. Bislang hatte man an der Seine das Projekt zwar kritisiert, aber nichts unternommen, um ihm Steine in den Weg zu legen. Auch an einer deutschen Beteiligung hatte Paris nichts auszusetzen gehabt. Noch am 15. Februar 1964 hatte de Gaulle in Bezug auf den Wunsch der Bundesrepublik nach nuklearer Teilhabe gegenüber Adenauer ausgeführt: „Sie suchen die Lösung durch eine Beteiligung an der MLF, durch die Sie einen Einfluß auf die Entscheidungen erlangen wollen. Wir wünschen Ihnen von Herzen Erfolg. “71 Nun kündigte die französische Regierung jedoch an, sie werde gegen die MLF opponieren, weil sie das politische Ziel Frankreichs, ein von Amerika politisch unabhängiges Europa mit einer eigenständigen Verteidigung zu schaffen, gefährde. Couve de Murville erklärte gegenüber Carstens am 24. Oktober 1964, eine Europäisierungsklausel, die im Falle der Vereinigung Europas eine Revision der MLF-Charta ermögliche, sei für Paris „kein Ausweg“72. Er verlangte von Bonn den Verzicht auf das MLF-Projekt, das die Europäer "vollständig abhängig“ von den Vereinigten Staaten machen würde ${ }^{73}$. Auf die völlig neue Position Frankreichs angesprochen, antwortete Couve de Murville lapidar, früher hätte man keine Einwände gegen die multilaterale Atomflotte erhoben, weil man einfach nicht damit gerechnet habe, daß sie konkrete Gestalt annehmen könnte ${ }^{74}$. Auch de Gaulle gab am 9. November 1964 gegenüber Adenauer zu, er habe das MLF-Projekt zunächst „nicht sehr ernstgenommen"75.

Es war aber nicht nur die Angst vor den negativen Auswirkungen der MLF auf die französische Europa-Politik, die de Gaulle auf die Barrikaden brachte, sondern auch die Enttäuschung über die seinem Empfinden nach völlig unzureichende Umsetzung des deutsch-französischen Freundschaftsvertrags. Im ElyséePalast stellte man sich auf den Standpunkt, „die MLF werde den Vertrag sprengen"76. Ministerpräsident Georges Pompidou drohte am 5. November 1964, sollte die Bundesregierung ihre Pläne weiterverfolgen, werde dies zu einer schweren Belastung der bilateralen Beziehungen führen. Die Atomflotte sei „zerstörend für Europa, provozierend für gewisse andere Länder und letzen Endes mehr oder

69 Vgl. den Drahterlaß des Legationsrats I. Klasse Kastl an die Botschaft in Paris vom 31. 7. 1964, PA/AA, Referat I A 1, Bd. 531.

70 Vgl. FRUS 1964-1968, XV, Dok. 64, S. 145.

71 Deutsch-französische Regierungsbesprechung am 15.2. 1964 in Paris, in: AAPD 1964, Dok. 50, S. 246.

72 Gespräch des Staatssekretärs Carstens mit dem französischen Außenminister Couve de Murville am 24. 10. 1964 in Paris, in: ebenda, Dok. 296, S. 1185. Vgl. auch GrEwE, Rückblenden, S. 620.

73 Gespräch des Staatssekretärs Carstens mit dem französischen Außenminister Couve de Murville am 24. 10. 1964 in Paris, in: AAPD 1964, Dok. 296, S. 1189.

74 Vgl. ebenda, S. 1185.

75 Gespräch des ehemaligen Bundeskanzlers Adenauer mit Staatspräsident de Gaulle am 9. 11. 1964 in Paris, in: ebenda, Dok. 318, S. 1258.

76 GREWE, Rückblenden, S. 619. 
weniger gegen Frankreich gerichtet" $" 77$. Während eines Empfangs in Bonn am 16. November 1964 bekräftigte der Vorsitzende des Auswärtigen Ausschusses der französischen Nationalversammlung, Maurice Schumann, die Kritik der französischen Regierung an der Atomflotte. Diese, so der gaullistische Abgeordnete, „zerstöre die europäische Zusammenarbeit“78. Im Verlauf der Unterhaltung erinnerte er den Staatssekretär zu dessen Überraschung an sein Gespräch mit de Gaulle auf Schloß Ernich am 4. Juli, wobei er hinzufügte, Paris wünsche immer noch über eine Europäisierung der Force de frappe zu sprechen. Carstens empfahl daraufhin Schröder nochmals, diesbezüglich Kontakt zum französischen Staatspräsidenten aufzunehmen ${ }^{79}$.

Der Außenminister wollte aber nicht von seiner bisherigen Linie abweichen: Die Franzosen könnten nicht erwarten, „daß wir zwei Jahre über [die] MLF bis zur Unterschriftsreife verhandeln und dann auf vage Andeutungen hin abspringen “, war seine Reaktion auf Carstens' Bericht ${ }^{80}$. Statt dessen bemühte er sich, die französische Regierung dazu zu bringen, ihren Widerstand gegen die multilaterale Atomflotte einzustellen. Gegenüber Couve de Murville argumentierte er am 9. Dezember 1964, man könne dem sowjetischen Potential, welches sich „von Wladiwostok bis Weimar" erstrecke, nicht eine Strategie entgegenstellen, „die nur in Kategorien Berlin/Bonn und Straßburg/Paris denke"81. Für eine glaubhafte Abschreckung sei es vielmehr erforderlich, ein System aufzubauen, das „von Berlin bis San Francisco" reiche. Die Bundesregierung erachte es deswegen für unverzichtbar, daß sich die "größte Macht der Welt an der vordersten Konfliktstelle engagiere" und sowohl in Berlin und der Bundesrepublik als auch in Westeuropa Truppen stationiert halte. Auch müßte Bonn auf der Integration der Truppen aller NATO-Mitgliedstaaten bestehen, damit der "größte Abschreckungsfaktor" gewahrt bleibe, nämlich der automatische und vollständige Einsatz der Streitkräfte der Allianz im Falle eines Angriffs. Die MLF würde alle diese Bedingungen erfüllen, erläuterte Schröder: Sie sei „die beste Antwort, da sie eine multilaterale Institution sei, die in ihrem Bestand integriert ist und möglichst nahe an der nuklearen Entscheidung stehe "82. Nachdrücklich beteuerte er, das Projekt sei nicht gegen Frankreich gerichtet, und unterstrich seinen Willen, die Rahmenbedingungen zu schaffen, daß eines Tages die MLF und die Force de frappe kombiniert werden könnten ${ }^{83}$.

Ein derartiges Vorhaben widersprach jedoch fundamental der französischen Verteidigungsphilosophie. Eine Aufgabe der Entscheidungsbefugnis über die Force de frappe war für de Gaulle schlicht unvorstellbar. Immerhin hatte er den Aufbau einer eigenen Atomstreitmacht initiiert, weil er angesichts des atomaren

77 Zitiert nach ADG 1964, S. 11517.

78 Aufzeichnung des Staatssekretärs Carstens vom 17.11. 1964, in: AAPD 1964, Dok. 343, S. 1343.

79 Vgl. ebenda, S. $1343 \mathrm{f}$.

80 AAPD 1964, S. 1344, Anm. 8.

81 Gespräch des Bundesministers Schröder mit dem französischen Außenminister Couve de Murville am 9. 12. 1964 in Paris, in: ebenda, Dok. 377, S. 1474.

82 Ebenda, S. 1475.

83 Vgl. ebenda, S. 1474. 
Patts die Existenz eines Abschreckungspotentials in nationaler Verfügungsgewalt für unerläßlich hielt, um die Sicherheit Frankreichs zu garantieren. Nur im Falle einer nach seinen Vorstellungen durchgeführten Vereinigung Europas wollte er eventuell die Kontrolle über die französischen Kernwaffen mit seinen europäischen Partnern teilen, niemals jedoch mit den Amerikanern ${ }^{84}$. Dies erläuterte Couve de Murville auch seinem deutschen Amtskollegen. Hinsichtlich der MLF wiederholte er die französische These, daß die USA mit ihr in Wirklichkeit beabsichtigten, einen größeren Einfluß auf die europäische Verteidigungspolitik zu bekommen. Das Ziel der Vereinigten Staaten sei es, Frankreich zu isolieren, damit es über kurz oder lang auf die Force de frappe verzichte. Gelinge dieser Plan, dann hätten sie endgültig ihr Konzept der „Unteilbarkeit der Verteidigung“ durchgesetzt, was jedoch nichts anderes bedeute als die Aufrechterhaltung des amerikanischen Monopols über die nuklearen Waffen der freien Welt! Frankreich könne eine derartige Entwicklung nicht zulassen, da dadurch die Entstehung eines unabhängigen Europas unmöglich werde. Seine Regierung, so der französische Außenminister, sei deshalb zu einer anderen Einschätzung gelangt und sehe in dem Projekt jetzt „eine große Gefahr" 85 .

Couve de Murville war aber nicht aufrichtig, denn nur gegenüber Bonn verteidigte er die ablehnende Haltung Frankreichs mit dem Argument, die Entstehung eines Europe européenne werde durch die MLF verhindert. Den anderen NATOPartnern gaben die Franzosen hingegen zu verstehen, eine Beteiligung der Bundesrepublik an der Kontrolle über Atomwaffen sei für sie nicht akzeptabel. Während die europapolitische Vision de Gaulles außerhalb Frankreichs kaum Zuspruch fand, konnte man an der Seine hingegen sicher sein, daß die Ablehnung einer nuklearen Teilhabe Bonns allenthalben auf Verständnis stieß. Nur fünf Tage nach seinem Gespräch mit Schröder eröffnete Couve de Murville dem italienischen Außenminister Guiseppe Saragat, Frankreich habe nichts dagegen einzuwenden, wenn Italien eigene Atomwaffen entwickle; Paris könne jedoch nicht zulassen, daß die Bundesrepublik Zugang zu Nuklearwaffen erhalte, da nicht auszuschließen sei, daß die Deutschen „in Zukunft noch einmal ihre territorialen An-

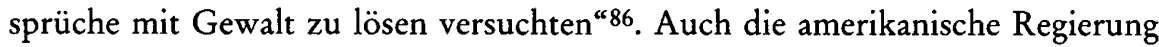
warnte er eindringlich, die Atomflotte werde den "nuklearen Appetit“ der Bundesrepublik wachsen lassen ${ }^{87}$.

Die radikale Opposition Frankreichs gegen den Plan einer multilateralen Atomflotte läßt vermuten, daß der französische Staatspräsident sein Angebot einer nuklearen Teilhabe vor allem mit dem Hintergedanken vorbrachte, eine Realisierung der MLF zu verhindern, die seinen europapolitischen Plänen im Weg stand, weil sie eine enge Verklammerung zwischen den Vereinigten Staaten und

\footnotetext{
$84 \mathrm{Vgl}$. dazu das Gespräch des ehemaligen Bundeskanzlers Adenauer mit Staatspräsident de Gaulle am 9. 11. 1964 in Paris, in: ebenda, Dok. 318, S. 1261.

85 Gespräch des Bundesministers Schröder mit dem französischen Außenminister Couve de Murville am 9. 12. 1964 in Paris, in: ebenda, Dok. 377, S. 1477.

86 Drahtbericht des Botschafters Blankenhorn, Rom, an das Auswärtige Amt vom 19.12. 1964, PA/AA, B 150, Aktenkopien 1964.

87 Zitiert nach BOzO, Deux stratégies pour l'Europe, S. 117.
} 
ihren europäischen Verbündeten geschaffen hätte. Die Bundesrepublik sollte mit einer vagen Offerte geködert werden, die mehr Teilhabe und Mitsprache in Aussicht stellte als eine Beteiligung an der Atomflotte. Falls der Lockruf de Gaulles in Bonn gehört worden wäre, hätte dies wohl das Ende des MLF-Projekts bedeutet, denn es war von den USA hauptsächlich zu dem Zweck konzipiert worden, dem Streben der Bundesrepublik nach Gleichberechtigung und Mitsprache im nuklearen Bereich Rechnung zu tragen. Auf das französische Pferd zu setzen, wäre für Bonn jedoch ein schlechter Tausch gewesen: Die Bundesregierung hätte die Beteiligung an der MLF verspielt, aber keine Garantie erhalten, daß sie am Ende nicht mit leeren Händen dastehen würde, auch wenn dies später oft bestritten wurde. So bestand zwar bei einer Diskussion von Zeitzeugen und Historikern Ende Januar 1995 im Institut de France in Paris weitgehend Übereinstimmung, daß der General der Bundesregierung damals weder den Mitbesitz noch ein Mitspracherecht an der Force de frappe angeboten habe, doch frühere Angehörige der Regierung de Gaulles äußerten sich davon überzeugt, daß ein Eingehen auf das Angebot eine Entwicklung eingeleitet hätte, an deren Ende die Gleichberechtigung der Bundesrepublik gestanden hätte ${ }^{88}$. Bereits im Juli 1965 hatte der stellvertretende Leiter des Generalsekretariats der nationalen Verteidigung Frankreichs, Pierre Maillard, gegenüber dem Botschafter der Bundesrepublik in Paris, Manfred Klaiber, das seltsame Vorgehen seines Präsidenten ein Jahr zuvor damit verteidigt, dieser habe Bonn verständlicherweise "nicht offen Atomwaffen anbieten können“. Hätte Erhard aber die verdeckte Einladung angenommen, wäre die Bundesrepublik dennoch "unausweichlich schrittweise in die atomare Verantwortung gerückt" ${ }^{\text {" } 9}$. Horst Osterheld kreidete daher der Regierung Erhard „das Ausschlagen einer historischen Chance" an 90 . Auch Hermann Kusterer beklagte, daß Bonn diese letzte Initiative de Gaulles für eine deutsch-französische „Union“ unbeantwortet ließ91. Von Zeithistorikern wird ebenfalls zuweilen die Ansicht vertreten, die Bundesrepublik habe damals die Möglichkeit einer nuklearen Teilhabe leichtfertig vertan. Reiner Marcowitz ist der Ansicht, die Bundesregierung hätte zumindest das Angebot vorurteilsfrei prüfen müssen. Aus Abneigung gegenüber dem General habe man sich statt dessen entschieden, „Bündnispolitik mit Scheuklappen“ zu betreiben $^{92}$. Für ihn ist der Vorfall ein eindrucksvolles Beispiel, „daß Vorurteile die schlimmste Sünde wider die außenpolitische Vernunft sind" "93. Doch was wäre passiert, wenn die Bundesrepublik - vorausgesetzt, es hätte sich tatsächlich um eine seriöse Offerte gehandelt - sich für eine Mitwirkung am Aufbau der Force de frappe entschieden hätte? Bonn hätte sich dadurch zweifellos von de Gaulle und der französischen Politik völlig abhängig gemacht und seine Außenpolitik einseitig auf Frankreich ausgerichtet, denn die bislang, trotz mancher Differenzen, alles

88 Vgl. Marcowitz, Eine Force de frappe für Europa, S. 19-22.

89 Drahtbericht des Botschafters Klaiber, Paris, an das Auswärtige Amt vom 13. 7. 1965, in:

AAPD 1965, Dok. 279, S. $1166 \mathrm{f}$.

90 OSTERHELd, Außenpolitik, S. 101.

91 KUSTERER, Der Kanzler und der General, S. 423.

92 MarcowITZ, Eine Force de frappe für Europa, S. 21.

93 Ebenda, S. 22. 
in allem stabilen Beziehungen zu den USA wären im Zuge einer solchen Entscheidung unwiderruflich in die Brüche gegangen. Washington war nicht bereit, eine enge militärische Zusammenarbeit zwischen Bonn und Paris zu tolerieren. Botschafter McGhee brachte am 15. Januar 1965 gegenüber Carstens unmißverständlich zum Ausdruck, daß ein derartiger Schritt eine radikale Änderung der amerikanischen Sicherheitspolitik nach sich ziehen würde. Unverhohlen drohte er damit, Bonn könne dann nicht damit rechnen, "daß die Amerikaner in diesem Fall ihre Truppen noch in Europa lassen werden, denn es bestünde die Gefahr, daß diese Truppen durch die force de frappe gegen den Willen der Vereinigten Staaten in einen Krieg verwickelt würden"94. Bei einem Eingehen auf de Gaulles Angebot hätte die Bundesrepublik das Zerwürfnis mit ihrem mächtigsten Verbündeten in Kauf nehmen müssen. Aus Sicherheitsgründen konnte es sich Bonn aber nicht leisten, einen Bruch mit den USA zu riskieren. Im Gegenteil, angesichts der Bedrohung durch den Warschauer Pakt mußte die Bundesregierung im ureigenen Interesse dafür sorgen, daß das amerikanische Engagement in Europa gerade im Zeitalter des atomaren Patts unverändert blieb. Wegen ihrer geringen Stärke konnte die Force de frappe keine echte Alternative zum nuklearen Schutzschild der USA sein. Es liegt folglich auf der Hand, warum Carstens zeit seines Lebens die Behauptung bestritt, Erhard und Schröder hätten gedankenlos eine Teilhabe der Bundesrepublik an nuklearen Waffen vergeben: „Ich zweifle auch heute noch, daß wir damals eine Chance versäumt haben." 95

\section{„Gespensterflotte“ MLF}

Ab dem Herbst 1964 bildeten Frankreich und die UdSSR praktisch eine Interessengemeinschaft gegen die MLF. Auch ihre Argumentation gegen das Projekt war nun weitgehend identisch. Während die sowjetische Regierung bislang hauptsächlich den Vorwurf erhoben hatte, durch die MLF käme es zu einer Proliferation von Atomwaffen, konzentrierte sie sich jetzt auf die Frage einer Beteiligung der Bundesrepublik. Am 11. Juli 1964 protestierte sie gegen die Mitwirkung von Soldaten der Bundeswehr an dem MLF-Versuchsschiff 96 . Anfang November warnte der sowjetische Botschafter in Bonn, Smirnow, das Auswärtige Amt, eine Teilnahme der Bundesrepublik an der MLF würde die bilateralen Beziehungen beeinträchtigen und eine Lösung der deutschen Frage erheblich erschweren ${ }^{97}$. Gromyko hieb am 7. Dezember vor der Generalversammlung der UNO in die gleiche Kerbe. Er erklärte, der Aufbau einer multilateralen Atomflotte und die Wiedervereinigung Deutschlands seien nicht miteinander vereinbar ${ }^{98}$. Andererseits gab

94 Aufzeichnung des Staatssekretärs Carstens vom 12.1. 1965, in: AAPD 1965, Dok. 275, S. 56.

95 CARSTENS, Erinnerungen, S. 272.

96 Für den Wortlaut der sowjetischen Note vom 11.7.1964 an die Bundesregierung vgl. DzD IV/10, S. 814-818.

97 Vgl. dazu die Aufzeichnung des Staatssekretärs Carstens vom 2. 11. 1964, in: AAPD 1964, Dok. 304, S. 1210-1212.

98 Für einen Auszug aus der Rede des sowjetischen Außenministers Gromyko am 7. 12. 1964 in New York vgl. DzD IV/10, S. 1210 f. 
er aber nur wenige Wochen später zu, daß selbst bei einem Verzicht auf die MLF der Kreml nicht in Verhandlungen über eine Lösung des Deutschland-Problems einwilligen werde 99 .

Aber sowohl in Moskau wie in Paris waren die Sorgen unnötig, daß eine Unterzeichnung der MLF-Charta in Kürze erfolgen würde. Zwar hatte am 2. Oktober 1964 Rusk gegenüber Grewe eine Unterzeichnung des Gründungsvertrags aller Voraussicht nach noch vor Jahresende angekündigt ${ }^{100}$, doch der Wahlsieg der britischen Labour Party am 15. Oktober 1964 schuf eine völlig neue Lage. Adenauer und Krone, die sich am 8. November mit de Gaulle in Paris trafen, überbrachten die Nachricht, die Konstitution der Atomflotte werde sich um unbestimmte Zeit verschieben, da die neue britische Regierung unter Harold Wilson angekündigt habe, sie wolle die Pläne zunächst einer genauen Prüfung unterziehen und dann mit neuen Vorschlägen an die NATO-Partner herantreten ${ }^{101}$. Ebenso wie die Konservativen mißbilligten die britischen Sozialisten das Konzept einer Flotte von Überwasserschiffen wie auch das Prinzip der gemischten Besatzungen, welches dabei Anwendung finden sollte. Nach der Machtübernahme erklärten sie daher, sie könnten sich an einer MLF in dieser Form nicht beteiligen ${ }^{102}$. Es sei unumgänglich, die „Schaffung einer integrierten westlichen Nuklearstreitmacht von Grund auf neu zu verhandeln" 103 .

Die Kritik an den konzeptionellen Mängeln der bisherigen Planung war indes nur ein Vorwand. Im Grunde beängstigte die Vorstellung, daß die Bundesrepublik mit Hilfe der MLF Zugang zu Atomwaffen erhalten würde, die politische Führung Großbritanniens in demselben Maße wie die Frankreichs oder der UdSSR. Bereits im Juni 1963 hatte Wilson dem sowjetischen Ministerpräsidenten Chruschtschow seine Ängste gestanden: „Die Perspektive, daß Westdeutschland Atommacht wird, läßt mir das Blut in den Adern gerinnen." 104 Von Anfang an befürchtete er, der Plan, das Streben der Bundesrepublik nach Kernwaffen durch eine physische Beteiligung an einer von mehreren Staaten gestellten Atomstreitmacht zu befriedigen, könnte sich als ein Schuß nach hinten erweisen: „If you have a boy and wish to sublimate his sex appetite it is unwise to take him to a striptease show. " 105 Nach der Regierungsübernahme wollten die Labour-Politiker daher zunächst herausfinden, wie groß die nuklearen Ambitionen in Bonn tatsächlich waren. Der neue britische Außenminister, Patrick Gordon Walker, ließ daher bei seiner ersten Unterredung mit Schröder am 15. November 1964 die Besorgnis

99 Vgl. den Drahtbericht des Botschafters Knappstein, Washington, an das Auswärtige Amt vom 8. 1. 1965, in: AAPD 1965, Dok. 8, S. 43 f.

100 Vgl. Grewe, Rückblenden, S. 620.

101 Vgl. den Drahtbericht des Botschafters Klaiber, Paris, an Bundesminister Schröder vom 9. 11. 1964, in: AAPD 1964, Dok. 316, S. 1249.

102 Vgl. dazu das Gespräch des Bundesministers Schröder mit dem britischen Außenminister Gordon Walker am 15.11. 1964, in: ebenda, Dok. 334, S. 1305 f.

103 Drahtbericht des Botschafters von Etzdorf, London, an das Auswärtige Amt vom 25. 11. 1964, PA/AA, B 150, Aktenkopien 1964.

104 Drahtbericht des Botschafters Groepper, Moskau, an das Auswärtige Amt vom 19.6. 1963, PA/AA, B 150, Aktenkopien 1963.

105 Zitiert nach BUNDY, Danger and Survival, S. 495. 
erkennen, nach Gründung der MLF könnten sich „bald in Deutschland Kräfte regen, die nach einem größeren Mitspracherecht drängten “. Gordon Walker warf nun den Köder aus: Seine Regierung trete deshalb dafür ein, der Bundesrepublik von Anfang an eine gleichberechtigte Rolle in dem Projekt einzuräumen ${ }^{106}$. Schröder ließ sich von dem Bekenntnis täuschen. Er gab zu, eine Aufrechterhaltung des amerikanischen Vetos wäre für Bonn in der Tat „auf die Dauer nicht ganz befriedigend " ${ }^{107}$. Nach diesem Bekenntnis mußte Wilson annehmen, die Bundesregierung trachte tatsächlich danach, Atomwaffen in ihre Verfügungsgewalt zu bekommen. Er wollte aber unter keinen Umständen einen „German finger on the trigger" ${ }^{108}$. Vor dem Unterhaus stellte er am 23. November 1964 unmißverständlich klar, daß die britische Regierung keinem Staat Mitentscheidungsrechte über den Einsatz der Atomwaffen der MLF einzuräumen beabsichtigte. Der Premierminister wies darauf hin, daß die sowjetischen Bedenken gegen die MLF im wesentlichen durch die Furcht motiviert seien, irgendwann könnte der Mehrheitsentscheid eingeführt und die multilaterale Atomflotte dann gegen den Willen Washingtons eingesetzt werden. Das amerikanische Veto dürfe deshalb nicht aufgeweicht werden ${ }^{109}$. Vergeblich dementierte Schröder in einem Vieraugengespräch mit Wilson am 11. Dezember, die Bundesrepublik strebe danach, eine Nuklearmacht zu werden. Das Ziel der Bundesregierung sei nicht, den Finger an den Abzugshahn zu bekommen, sondern „ein glaubwürdiges Abschreckungssystem zu schaffen“, versicherte der Außenminister. Die Behauptung des Premierministers sei "diskriminierend" 110 .

Schon das Bündnis zwischen Frankreich und der UdSSR gegen die MLF hatte Schröder als „erschütternd“ empfunden ${ }^{111}$. Doch nun wandte sich auch Großbritannien, mit dessen Beteiligung er fest gerechnet hatte, gegen die Atomflotte. Eine Mitwirkung Londons war aber die unabdingbare Voraussetzung für die Realisierung des Projekts. Neuverhandlungen kamen für Schröder nicht in Frage. Für ihn war die Sache „abschlußreif"112. Angesichts des bevorstehenden Wahlkampfs für die Bundestagswahlen im Herbst 1965 sah er zudem eine „gewisse Eilbedürftigkeit“, das Projekt rasch unter Dach und Fach zu bringen ${ }^{113}$. In der Tat hatte sich auch in der Bundesrepublik die Stimmung gegen die Atomflotte gedreht. Vor allem innerhalb von CDU und CSU kam es deswegen zu innerparteilichen Auseinandersetzungen. Die sogenannten Gaullisten zogen gegen die MLF mit dem Argument ins Felde, diese werde das bereits getrübte Verhältnis zu Frankreich end-

106 Gespräch des Bundesministers Schröder mit dem britischen Außenminister Gordon Walker am 15. 11. 1964, in: AAPD 1964, Dok. 334, S. 1306.

107 Ebenda, S. 1307.

108 So Wilson am 23. 11. 1964 vor dem Unterhaus. Zitiert nach ebenda, S. 1388, Anm. 4.

109 Vgl. die Rede Wilsons am 23.11. 1964 vor dem Unterhaus, in: EUROPA-ARCHIV 1964, D $624 \mathrm{f}$. (Auszug).

110 Gespräch des Bundesministers Schröder mit Premierminister Wilson am 11.12. 1964 in London, in: AAPD 1964, Dok. 383, S. 1511.

111 Gespräch des Bundesministers Schröder mit dem Sicherheitsberater des amerikanischen Präsidenten, Bundy, am 27.11. 1964 in Washington, in: ebenda, Dok. 363, S. 1412.

112 Gespräch des Bundesministers Schröder mit dem britischen Außenminister Gordon Walker am 15. 11. 1964, in: ebenda, Dok. 334, S. 1307.

113 Ebenda, S. 1308. 
gültig zerrütten. Insbesondere Adenauer, der während seiner Amtszeit als Bundeskanzler im Januar 1963 eine Beteiligung der Bundesrepublik an der Atomflotte beschlossen hatte, opponierte seit seinem Rücktritt gegen das Projekt ${ }^{114}$. Er prophezeite, daß die MLF „niemals tatsächlich zustande kommen werde“ ${ }^{115}$. Der CSU-Vorsitzende Strauß wandte sich ebenfalls gegen eine nukleare Zusammenarbeit mit den USA in Gestalt der multilateralen Atomflotte. Statt dessen regte er an, einen erneuten Versuch zur Gründung der zu Anfang der fünfziger Jahre gescheiterten Europäischen Verteidigungsgemeinschaft (EVG) zu unternehmen und die Force de frappe in dieser Gemeinschaft aufgehen zu lassen ${ }^{16}$. Angesichts von de Gaulles Ablehnung jeglicher integrativer Systeme und supranationaler Organisationen war dies ein vollkommen utopischer Vorschlag, doch erweckte er in der Öffentlichkeit den Anschein, als gäbe es noch Alternativen zur MLF. Aus Sorge um die deutsch-französischen Beziehungen sprach sich auch Krone gegen eine Teilnahme an der MLF aus ${ }^{117}$. Barzel kamen nun ebenfalls Bedenken, ob es angesichts der ablehnenden Haltung Frankreichs und Großbritanniens sinnvoll war, daß Bonn auf einer raschen Realisierung des Projekts bestand ${ }^{118}$. Er fand für seine Haltung Rückendeckung in der Fraktion. Am 11. November 1964 beschloß der Fraktionsvorstand der Union in Abwesenheit von Schröder, der erkrankt war ${ }^{119}$, der Bundesregierung nahezulegen, die Verhandlungen über die Schaffung der multilateralen Atomflotte im Moment nicht weiter zu forcieren ${ }^{120}$.

Schröder bekämpfte derartige Tendenzen in seiner Partei entschieden, doch mit der Dauer der Auseinandersetzung immer vergeblicher. Bei seinen Bemühungen erhielt er nach wie vor Unterstützung von Verteidigungsminister von Hassel, der weiterhin von der Notwendigkeit der Atomflotte überzeugt war ${ }^{121}$. Als am 2. Dezember 1964 im Kabinett die MLF-Frage debattiert wurde, warb der Außenminister nochmals eindringlich für eine Beteiligung. Die MLF, so erklärte er, komme "größte Bedeutung“ zu, da dadurch eine „zweite transatlantische Verbindung“ neben der NATO geschaffen würde. Nur die gemeinsame Atomflotte könne die Stellung der Bundesrepublik als einen wichtigen Faktor in der Weltpolitik sichern: „Wenn die MLF scheitert, werden wir international eineinhalb Stufen niedriger rangieren. Ohne sie haben wir keine Sicherheit und werden zum Spielball der Weltpolitik." 122 Viele Minister stellten hingegen die berechtigte Frage, ob die USA überhaupt noch hundertprozentig hinter dem Vorhaben standen. Trotz der allge-

114 Vgl. Carstens, Erinnerungen, S. 273.

115 Gespräch des ehemaligen Bundeskanzlers Adenauers mit Staatspräsident de Gaulle am 9. 11. 1964 in Paris, in: AAPD 1964, Dok. 318, S. 1260.

116 So äußerte sich Strauß am 5./6.12. 1964 in München. Vgl. den Artikel „Guttenberg für Atommacht Europa“, in: FrankfurTer Allgemeine ZeITUNG vom 7. 12. 1964, S. 5.

117 Vgl. den Drahtbericht des Bundesministers Krone, z.Z. Paris, an Bundeskanzler Erhard vom 9. 11. 1964, in: AAPD 1964, Dok. 319, S. 1265 f.

118 Vgl. die Ausführungen Barzels vor dem CDU-Bundesvorstand am 27.11. 1964, in: PROTOKOLLE DES CDU-BUNDESVORSTANDS, S. 753. Vgl. auch den Artikel „Barzel gegen Eile mit der MLF“, in: SÜDDEUTSCHE ZEITUNG vom 8. 1. 1965, S. 1 und S. 4.

119 Vgl. HOPPE, Zwischen Teilhabe und Mitsprache, S. 212.

$120 \mathrm{Vgl}$. ADG 1964, S. 11523.

121 Vgl. SCHRÖDER, Im Gespräch mit Meinhold Krauss, S. 50; GrEwE, Rückblenden, S. 618.

122 OSTERHELD, Außenpolitik, S. 123. 
meinen Zweifel gab Erhard jedoch die Parole aus, Bonn müsse auf das Projekt setzen, da es dazu keine Alternative gebe ${ }^{123}$.

Selbst im Bundeskanzleramt setzte sich allerdings die Überzeugung durch, das innerparteilich umstrittene Thema wegen den Bundestagswahlen bis zum Spätherbst 1965 zurückzustellen ${ }^{124}$. Erhard wollte dieses Problem aus dem Wahlkampf heraushalten, um der Öffentlichkeit nicht das Schauspiel einer in sich zerrissenen Regierungspartei zu bieten ${ }^{125}$. Von der militärischen Zweckdienlichkeit des Projekts war er jedoch voll und ganz überzeugt. Anders als de Gaulle vertrat der Kanzler die Meinung, daß die multilaterale Atomflotte die Sicherheit Europas erhöhen würde, da sie die UdSSR von einem auf Westeuropa begrenzten Angriff abschrecken könnte. Er verwies darauf, daß gegenwärtig die sowjetischen Machthaber noch die Hoffnung hegen konnten, die USA werden ihr Nuklearpotential nicht einsetzen, um einen Gegenschlag auf den amerikanischen Kontinent zu vermeiden. Wenn aber die Mittelstreckenraketen der multilateralen Atomflotte zur Verfügung stünden, könnte der Kreml „nie ganz sicher sein, ob nicht wenigstens diese eingesetzt würden“ 126 . Deshalb sei die MLF vonnöten - „nicht für den großen Weltbrand, sondern für einen Krieg im Umkreis von vielleicht $500 \mathrm{~km}$ “ 127 . Erhard hing indessen immer noch der Illusion an, de Gaulle könnte zu einer Teilnahme an dem Projekt überredet werden. Er baute darauf, der französische Präsident würde ebenso wie die politischen Verantwortlichen in Großbritannien irgendwann einsehen, daß er sein Land mit dem Aufbau einer eigenen Atomstreitmacht finanziell überfordere, und sich schließlich aus wirtschaftlichen Erwägungen für eine Mitarbeit an der MLF entscheiden ${ }^{128}$. Hier zeigt sich exemplarisch, daß Erhard in den Kategorien eines Ökonomen und nicht in denen eines Politikers dachte. Für ihn war nicht nachvollziehbar, daß de Gaulle sich ausschließlich aus politischen Gründen für die Force de frappe entschieden hatte. Die in der Tat immensen Kosten erachtete der General für zweitrangig. Der entscheidende Punkt war in seinen Augen die Sicherheit Frankreichs. Der Kanzler saß deshalb einem Trugschluß auf, wenn er darauf spekulierte, de Gaulle mit ökonomischen Argumenten zur Aufgabe seiner nuklearen Pläne bewegen zu können.

Sein Außenminister war sich hingegen bewußt, daß der französische Präsident seine Haltung gegenüber der MLF nicht ändern werde. Dies bewies seines Erachtens das französische Verteidigungsprogramm für die Jahre 1965 bis 1970, das explizit gegen die NATO und das Prinzip der Integration Stellung bezog. Da der

123 Vgl. ebenda, S. 124.

124 Vgl. die Aufzeichnung des Ministerialdirektors Jansen vom 24. 11. 1964, in: AAPD 1964, Dok. 355, S. 1390.

125 Vgl. die Ausführungen Erhards vor dem CDU-Bundesvorstand am 9. 2. 1965, in: PROTO KOLLE DES CDU-BUNDESVORSTANDS, S. 816.

126 Ausführungen des Bundeskanzlers Erhard gegenüber dem amerikanischen Botschafter McGhee am 11. 12. 1964, in: AAPD 1964, Dok. 380, S. 1489. Vgl. auch die Ausführungen Erhards vor dem CDU-Bundesvorstand am 9. 2. 1965, in: PROTOKOLLE DES CDU-BUNDESVORSTANDS, S. 815.

127 Ausführungen des Bundeskanzlers Erhard gegenüber dem amerikanischen Botschafter McGhee am 11. 12. 1964, in: AAPD 1964, Dok. 380, S. 1490.

128 Vgl. ebenda, S. 1487 und S. 1492. 
Standpunkt Frankreichs in der MLF-Frage somit eindeutig sei, beschwor er Anfang Dezember 1964 McGhee, die USA sollten nicht länger aus Rücksicht auf Frankreich die Gründung der MLF verzögern ${ }^{129}$. Gleichzeitig rief er die amerikanische Regierung dazu auf, in London zu intervenieren und den Briten nahezulegen, ihren Standpunkt zu überdenken. Die Bundesregierung sei zu einem Kompromiß bereit und würde auch eine Kombination von Schiffen und U-Booten akzeptieren, teilte er Ende November 1964 Rusk mit. Schröder regte an, die Vereinigten Staaten könnten dazu ebenso wie Großbritannien ihre drei der NATO assignierten Polaris-U-Boote einbringen. Zu einem späteren Zeitpunkt müßten aber auch diese eine gemischt-nationale Besatzung erhalten. Ferner brachte er unmißverständlich zum Ausdruck, daß die Bundesrepublik unter keinen Umständen auf die Überwasserflotte verzichten werde, da es nur auf Schiffen möglich sei, eine militärische Integration bis zu den untersten Stäben durchzuführen. Die Absicht Londons, die Diskussion wieder am Nullpunkt zu beginnen, bezeichnete er als „absolut unannehmbar" 130 . Nach seinen Vorstellungen sollten die Beratungen über die MLF-Charta bis zum März 1965 abgeschlossen werden, damit eine Ratifikation durch den Bundestag noch in der zu Ende gehenden Legislaturperiode möglich wäre ${ }^{131}$. Weitere Verzögerungen, so der Außenminister, könne man sich nicht erlauben: „Jemand, der die MLF zu Fall bringen wolle, werde sicherlich versuchen, Zeit zu gewinnen." Dies gäbe nämlich allen Gegnern der MLF die Gelegenheit, ihre Kräfte zu konzentrieren ${ }^{132}$. Die USA glaubten hingegen immer noch, daß mit der Labour-Regierung eine Verständigung möglich sei. Rusk versicherte seinem Amtskollegen: „Amerika werde es nicht so weit kommen lassen, daß Wilson nein sage." 133 Das State Department nahm an, der Premierminister schreckte lediglich vor den hohen Kosten beim Aufbau der MLF zurück. Im Falle einer Verkleinerung der Atomflotte, die auf 20 Schiffe angelegt war, rechnete man in Washington fest mit einer Beteiligung Großbritanniens ${ }^{134}$.

129 Vgl. das Gespräch des Bundesministers Schröder mit dem amerikanischen Botschafter McGhee am 4. 12. 1964, in: ebenda, Dok. 370, S. $1435 \mathrm{f}$.

130 Gespräch des Bundesministers Schröder mit dem amerikanischen Außenminister Rusk am 26. 11. 1964 in Washington, in: ebenda, Dok. 360, S. 1400. Vgl. auch das Gespräch des Bundesministers Schröder mit dem italienischen Außenminister Saragat am 8. 12. 1964 in Rom, in: ebenda, Dok. 375, S. 1454.

131 Vgl. das Gespräch des Bundesministers Schröder mit dem amerikanischen Außenminister Rusk am 26.11. 1964 in Washington, in: ebenda, Dok. 360, S. $1402 \mathrm{f}$.

132 Gespräch des Bundesministers Schröder mit dem Sicherheitsberater des amerikanischen Präsidenten, Bundy, am 27. 11. 1964 in Washington, in: ebenda, Dok. 363, S. 1409.

133 Gespräch des Bundesministers Schröder mit dem amerikanischen Außenminister Rusk am 26. 11. 1964 in Washington, in: ebenda, Dok. 360, S. 1402.

134 Vgl. das Gespräch des Bundesministers Schröder mit dem amerikanischen Botschafter McGhee am 4. 12. 1964, in: ebenda, Dok. 370, S. 1436. Auch die italienische Regierung sprach sich inzwischen aus Kostengründen für eine Reduzierung der MLF-Flotte aus. Sie war der Ansicht, zwölf Schiffe genügten. Schröder lehnte aber eine Reduzierung der vorgesehenen 20 Schiffe ab. Er verwies auf das Urteil der Experten, wonach die Überlebensgröße bei einem Angriff bei 17 Schiffen liege. Vgl. das Gespräch des Bundesministers Schröder mit dem italienischen Außenminister Saragat am 8.12.1964 in Rom, in: ebenda, Dok. 375, S. $1454 \mathrm{f}$. 
Doch von Kompromißbereitschaft war bei Wilson nichts zu bemerken. Im Dezember 1964 trat er mit einem eigenen Konzept über die Ausgestaltung der multilateralen NATO-Atomstreitmacht vor die Öffentlichkeit ${ }^{135}$. Definitiv lehnte er eine Flotte von Überwasserschiffen mit gemischt-nationalen Besatzungen ab. Großbritannien, so stellte der Premierminister klar, werde sich an einem derartigen Vorhaben niemals beteiligen. Die von ihm als Gegenmodell vorgeschlagene Atlantic Nuclear Force (ANF) sollte nur aus Flugzeugen und U-Booten bestehen. Der Premierminister schlug vor, daß die USA und Großbritannien jeweils drei bis vier Polaris-U-Boote der ANF zur Verfügung stellten, so daß Frankreich später zu den gleichen Bedingungen beitreten könnte. Wilson wollte das Prinzip der gemischten Besatzungen lediglich bei den teilnehmenden Flugzeugen anwenden. Zudem lehnte er eine Unterstellung der ANF unter den Befehl von SACEUR, wie sie das MLF-Projekt vorsah, ab. Er befürwortete ein an sich unabhängiges Oberkommando (SACSTRAT), das eng mit der NATO zusammenarbeiten sollte ${ }^{136 .}$ So wie es 1963 bei der Schaffung der IANF vorexerziert wurde, schwebte Wilson also nicht mehr als eine Umgruppierung der in der NATO vorhandenen Kernwaffen vor. Er hatte weder eine militärische Integration im Stile der MLF im Sinn, noch wollte er die ANF in die Befehlsstruktur der NATO eingliedern ${ }^{137}$.

In einer Analyse fällte das Auswärtige Amt daher ein vernichtendes Urteil über den Plan des Premierministers ${ }^{138}$. Man kam zu dem Schluß, daß die Bundesrepublik trotz aller gegenteiligen Behauptungen Londons ${ }^{139}$ in dem britischen Projekt nicht die von ihr angestrebte, gleichberechtigte Stellung erhalten würde: Die ANF schaffe „keine echte multilaterale politische Kontrolle, sondern eine Art angloamerikanisches Direktorium“. Sie würde eine Diskriminierung der Bundesrepublik im nuklearen Bereich mit sich bringen, „die mit der Stellung der Bundesrepublik als Faktor von europäischem und weltpolitischem Rang unvereinbar ist"140. Auch nach Grewes Einschätzung bot Wilsons Vorschlag keinen Ansatzpunkt für Verhandlungen: „Alles lief darauf hinaus, daß mit einem Minimum eigener Kostenbeteiligung ein Maximum britischer Einfluß- und Kontrollrechte erzielt und der deutsche Einfluß so weit wie möglich reduziert werden sollte."141 Für die Bundesregierung stand daher fest, der Vorschlag Wilsons sei „unter gar keinen

135 Vgl. dazu das Gespräch des Bundesministers Schröder mit dem britischen Außenminister Gordon Walker am 11. 12. 1964 in London, in: ebenda, Dok. 382, S. 1499-1501. Wilson hielt sich vom 7. bis 9.12. 1964 in den USA auf und unterbreitete dabei der amerikanischen Regierung seinen Plan. Vgl. ebenda. Am 16.12. 1964 präsentierte er ihn im Rahmen einer Rede vor dem Unterhaus erstmals der Öffentlichkeit. Vgl. ADG 1964, S. 11591.

136 Vgl. das Gespräch des Bundesministers Schröder mit dem britischen Außenminister Gordon Walker am 11. 12. 1964 in London, in: AAPD 1964, Dok. 382, S. 1499-1509.

137 Vgl. dazu die Stellungnahme der Bundesregierung vom 18.1. 1965, in: AAPD 1965, Dok. 20, S. 95-101.

138 Vgl. die Aufzeichnung des Botschaftsrats I. Klasse Hartlieb, Paris (NATO), vom 21. 12. 1964, in: AAPD 1964, Dok. 393, S. 1544-1555.

139 Vgl. dazu z. B. das Gespräch des Bundesministers Schröder mit dem britischen Außenminister Gordon Walker am 11. 12. 1964 in London, in: ebenda, Dok. 382, S. 1501.

140 Aufzeichnung des Botschaftsrats I. Klasse Hartlieb, Paris (NATO), vom 21. 12. 1964, in: ebenda, Dok. 393, S. 1555.

141 GREWE, Rückblenden, S. 621. 
Umständen annehmbar ${ }^{142}$. Schröder war allenfalls für eine Kombination zwischen ANF und MLF zu gewinnen. Wie schon der amerikanischen gab er auch der britischen Regierung zu verstehen, daß Bonn vom Konzept einer Überwasserflotte mit einem britischen Anteil nicht abrücken werde. Den britischen Plan wollte er außerdem nur als Diskussionsgrundlage akzeptieren, wenn langfristig auch auf den U-Booten gemischt-nationale Besatzungen eingeführt würden. $\mathrm{Zu}$ dem bestand er auf der Unterstellung der gemeinsamen Atomstreitmacht unter den Befehl von SACEUR. Nachdrücklich verlangte er von der politischen Führung Großbritannien, die Realisierung der multilateralen Atomstreitmacht nicht länger zu verzögern. Zwei Jahre Verhandlungen, so der Außenminister, seien mehr als genug 143 !

Eine rasche Einigung wäre nur möglich gewesen, wenn Washington die britische Regierung unter Druck gesetzt hätte. Zu Jahresende 1964 entschied sich Johnson jedoch, die ungeliebte, von Kennedy übernommene Idee einer multilateralen Atomstreitmacht nicht länger $z u$ forcieren. Bereits seit Ende November 1964 warnte Botschafter Knappstein seinen Minister, daß der Präsident seine Haltung zur MLF überprüfe. Doch Schröder wies Knappstein an, um so entschlossener die Realisierung des Projekts zu verlangen ${ }^{144}$. Am 17. Dezember erteilte Johnson intern die Weisung, nicht mehr auf einen Abschluß eines MLF-Abkommens zu drängen ${ }^{145}$. Wie McGhee zwei Tage später Schröder erläuterte, wollte der Präsident „dieses Projekt nicht erzwingen" 146 . Zwar bekundete die amerikanische Regierung auch weiterhin ihr Interesse an dem Zustandekommen einer multilateralen Atomstreitmacht, doch erklärte sie nun, es sei zunächst die Sache der Europäer, sich zu einigen ${ }^{147}$. Angesichts der konträren Vorstellungen Bonns und Londons war aber ohne amerikanische Vermittlung eine Verständigung auf ein gemeinsames Konzept nicht realistisch. Somit bedeutete die neue Haltung der USA nichts anderes als das „Zuschieben des Schwarzen Peters an die Europäer“, wie Knappstein am 30. Dezember zutreffend feststellte ${ }^{148}$. Grewe wies zu Recht darauf hin, daß der Widerstand Frankreichs und Großbritanniens zwar für Johnson

142 So Erhard vor dem CDU-Bundesvorstand am 9. 2. 1965, in: ProtoKOLLE DES CDUBUNDESVORSTANDS, S. 815.

$143 \mathrm{Vgl}$. das Gespräch des Bundesministers Schröder mit dem britischen Außenminister Gordon Walker am 11. 12. 1964 in London, in: AAPD 1964, Dok. 382, S. 1503 f.; sowie das Gespräch des Bundesministers Schröder mit Premierminister Wilson am 11. 12. 1964 in London, in: ebenda, Dok. 383, S. 1510-1513.

144 Vgl. Blasius, Heißer Draht nach Washington?, S. 59. Später warf Schröder Knappstein vor, er habe ihn „schlecht, verspätet oder überhaupt nicht“ über die Änderung der amerikanischen Haltung informiert. Zitiert nach ebenda.

145 Vgl. KoOPManN, Das schwierige Bündnis, S. 237.

146 Gespräch des Bundesministers Schröder mit dem amerikanischen Botschafter McGhee am 19. 12. 1964, in: AAPD 1964, Dok. 392, S. 1541.

147 Vgl. den Drahtbericht des Botschafters Knappstein, Washington, an das Auswärtige Amt vom 30. 12. 1964, in: ebenda, Dok. 401, S. 1572-1576; das Gespräch des Bundesministers Schröder mit dem amerikanischen Botschafter McGhee am 7.1. 1965, in: AAPD 1965, Dok. 3, S. 22; sowie GREWE, Rückblenden, S. 627.

148 Drahtbericht des Botschafters Knappstein, Washington, an das Auswärtige Amt vom 12. 1. 1965, PA/AA, B 150, Aktenkopien 1965. 
„ein willkommenes Argument" war, die MLF aufzugeben; er sei aber nicht "die entscheidende Ursache“ für das Scheitern des Projekts gewesen. Es darf nicht außer acht gelassen werden, daß es in den Vereinigten Staaten großen politischen Widerstand gegen die MLF gab. Der Kongreß war mehrheitlich gegen das Projekt, ebenso das Pentagon, vor allem Verteidigungsminister McNamara. Hinzu kam, daß sich die Prioritäten der Vereinigten Staaten verschoben hatten. Die Aufmerksamkeit der westlichen Weltmacht konzentrierte sich immer mehr auf den Vietnam-Krieg. Die finanziellen Belastungen, die das amerikanische Engagement in Südostasien verursachte, ließen Johnsons Interesse an einem kostspieligen Vorhaben wie der MLF schwinden ${ }^{149}$. Auch wurde nun die „Nichtweiterverbreitung von Atomwaffen [...] zum zentralen Ziel der USA“"150. Die MLF sei im wesentlichen nur zu dem Zweck konzipiert worden, um die nuklearen Ambitionen der Europäer, insbesondere der Bundesrepublik, zu befriedigen. Die Tatsache, daß die europäischen NATO-Mitgliedstaaten sich in endlosen Debatten über die konkrete Ausgestaltung der multilateralen Atomstreitmacht ergingen und dadurch den Eindruck erweckten, als hielten sie eine Realisierung für nicht besonders dringend, bot Johnson die Gelegenheit, sich aus dem Projekt zurückzuziehen, ohne daß er unmittelbar für das Scheitern verantwortlich gemacht werden konnte.

Im Rückblick zeigt sich, daß der Entschluß des amerikanischen Präsidenten vom Dezember 1964, nicht länger einen baldigen Abschluß der Verhandlungen anzustreben, letztendlich "der MLF das Lebenslicht ausblies"151. Ein ernsthafter Versuch, die Weichen für den Aufbau einer gemeinsamen Atomflotte zu stellen, wurde von der amerikanischen Regierung danach nicht mehr unternommen. Die multilaterale Atomseemacht war somit endgültig zur "Gespensterflotte“ geworden ${ }^{152}$. Für Grewe lag die eigentliche Ursache für das Scheitern jedoch in den konzeptionellen Mängeln des Vorhabens: „Die Schwäche des MLF- sowie des ANFProjekts bestand darin, daß sie in ihrem Kern Halbheiten blieben. Die Nichtnuklearen sollten an einem hochmodernen Waffensystem beteiligt werden, sie sollten Miteigentum daran erwerben, sie sollten die gemeinsame Flotte gemischt bemannen, sie sollten sie finanzieren und durch ein gemeinsames Organ verwalten und betreiben. Aber den Feuerbefehl sollten sie nicht geben dürfen: Die letzte und entscheidende Verfügungsgewalt über diese Waffen blieb dem Präsidenten der Vereinigten Staaten, die zentralisierte Lenkung aller Nuklearwaffen sollte nicht beeinträchtigt werden. Dieser inhärente Widerspruch forderte immer wieder Kritik heraus, die das Projekt als eine Scheinlösung angriff. Sie gab den nichtnuklearen Allianzpartnern soviel direkte Beteiligung, daß die Sowjetunion mit der Behauptung Alarm schlug, es handele sich um eine Proliferation von Nuklearwaffen; aber es gab ihnen nicht jenes Maß von Verfügungsgewalt, das für eine unabhän-

\footnotetext{
149 Vgl. dazu Grewe, Rückblenden, S. 622-626; sowie das Gespräch des Bundeskanzlers Erhard mit Präsident Johnson am 20.12. 1965 in Washington, in: AAPD 1965, Dok. 466, S. 1920-1928.

150 HACKE, Weltmacht, S. 115.

151 GREWE, Rückblenden, S. 627.

152 HuYN, Die Sackgasse, S. 225.
} 
gige Abschreckungsmacht notwendig gewesen wäre. An dieser Halbherzigkeit und Widersprüchlichkeit ist das Projekt schließlich gescheitert." 153

Warum aber sperrte sich ausgerechnet der Pragmatiker Gerhard Schröder gegen die Einsicht, daß ab dem Winter 1964/65 die Schaffung einer multilateralen Atomflotte mehr als unwahrscheinlich geworden war? Es schien, als ob er sich nicht mehr von dem Projekt lösen konnte, das er so lange beharrlich verfolgt hatte. Außenstehende gewannen den Eindruck, daß er die Realisierung der MLF „beinahe ins Zentrum seiner Überlegungen rückte" ${ }^{154}$. In der Tat war Schröder nicht entgangen, daß er auf der NATO-Ministerratstagung vom 15. bis 17. Dezember 1964 in Paris mit seinem Plädoyer für die Schaffung der MLF allein auf weiter Flur stand $^{155}$. Auch im Kabinett mußte er sich vorwerfen lassen, daß er weiterhin ein Projekt verfolgte, welches die Amerikaner längst aufgegeben hätten ${ }^{156}$. Doch für den Außenminister war die Atomflotte ein Symbol für die deutsch-amerikanische Zusammenarbeit. Sie sollte der Öffentlichkeit in der Bundesrepublik vor Augen führen, daß sich die enge Anbindung an die USA lohnte. Eine Beteiligung an der Kontrolle über atomare Waffen wäre der eindrucksvolle Beweis gewesen, daß er mit seinem außenpolitischen Kurs, den Beziehungen zu den Vereinigten Staaten Priorität zu geben und eine intensivere Zusammenarbeit mit Frankreich abzulehnen, die richtige Entscheidung getroffen hatte ${ }^{157}$. Zudem bemühten sich die Amerikaner zum Jahreswechsel 1964/65 erfolgreich, in Bonn nicht den Gedanken aufkommen zu lassen, sie hätten endgültig den Plan einer multilateralen Atomstreitmacht aufgegeben. Alle diesbezüglichen Gerüchte dementierten die USA entschieden. Am 11. Januar 1965 versicherte McGhee der Bundesregierung, die Vereinigten Staaten wünschten nach wie vor die Verwirklichung des Vorhabens ${ }^{158}$. Johnson verbreitete, er stünde „zur MLF genauso fest wie zur Wiedervereinigung "159. Und Rusk behauptete sogar, in Washington sei man nur deshalb untätig, weil man zu der Einschätzung gelangt sei, die Regierung Erhard sei nicht an einer Forcierung der MLF-Verhandlungen interessiert, um in der Zeit des Bundestagswahlkampfs eine Auseinandersetzung mit Adenauer und Strauß zu vermeiden ${ }^{160}$.

153 GREWE, Rückblenden, S. $628 \mathrm{f}$.

154 Schreiben Guttenbergs an Adenauer vom 26. 3. 1964. Zitiert nach MARCOwITZ, Option, S. 198. Es ist aufgrund der eindeutigen Quellenlage völlig unverständlich, wie Manfred Görtemaker zu dem Schluß kommt, Schröder hätte zum Jahreswechsel 1964/65 das Projekt „stillschweigend vom Tisch" genommen. Vgl. GÖRTEMAKER, Geschichte der Bundesrepublik Deutschland, S. 404.

$155 \mathrm{Vgl}$. das Gespräch des Bundesministers Schröder mit dem amerikanischen Außenminister Rusk am 13. 5. 1965 in London, in: AAPD 1965, Dok. 206, S. 828. Zur Diskussion über die MLF auf der NATO-Ministerratstagung, bei der sich unter anderem nun auch der belgische Außenminister Spaak sowie der norwegische Außenminister Halvard Lange gegen die Atomflotte ausspachen, vgl. GREwE, Rückblenden, S. $626 \mathrm{f}$.

156 Vgl. FRUS 1964-1968, XV, Dok. 80, S. 192.

157 ZEITZEUGENBEFRAGUNGEN Osterheld und Stercken.

158 Vgl. die Aufzeichnung des Staatssekretärs Carstens vom 12.1. 1965, in: AAPD 1965, Dok. 12, S. $54 \mathrm{f}$.

159 Drahtbericht des Botschafters Knappstein, Washington, an das Auswärtige Amt vom 25. 2. 1965 , in: ebenda, Dok. 96, S. 404.

160 Vgl. das Gespräch des Bundesministers Schröder mit dem amerikanischen Außenminister Rusk am 13. 5. 1965 in London, in: ebenda, Dok. 206, S. 827-829. 
Die USA, so der amerikanische Außenminister, wollten nicht „deutscher als die Deutschen" sein ${ }^{161}$. Angesichts einer derartigen "Vernebelungstaktik" 162 gab es für Schröder keinen Anlaß, an dem Engagement der USA für das MLF-Projekt zu zweifeln.

Die unrealistischen Forderungen, die die Amerikaner jetzt für ein Zustandekommen der MLF vorbrachten, hätten den Außenminister allerdings stutzig machen müssen. Sie waren ein deutliches Zeichen, daß die Vereinigten Staaten in Wahrheit die Atomflotte längst aufgegeben hatten: Johnson verlangte Ende Januar 1965, Großbritannien müsse sich an der MLF beteiligen und Frankreich seinen Widerstand einstellen ${ }^{163}$. Schröders Befürchtung, die Amerikaner könnten de Gaulle zum „Schiedsrichter über dieses Projekt" machen ${ }^{164}$, hatte sich bewahrheitet. Daß sie Frankreich sozusagen ein Vetorecht einräumten, war seines Erachtens „der größte Fehler der Welt “165. Die Chancen, ohne amerikanische Schützenhilfe die britische Regierung dazu bewegen zu können, ihre Haltung zu ändern, waren bereits äußerst gering. Wie aber sollte es Bonn gelingen, de Gaulle umzustimmen? Das Nein des französischen Präsidenten zu einer multilateralen Atomstreitmacht stand unwiderruflich fest. Am 20. Januar 1965 bekräftigte er gegenüber Erhard erneut, die MLF habe aufgrund des amerikanischen Vetos weder einen politischen noch einen militärischen Wert, riefe aber fatalerweise den Anschein hervor, als ob durch sie die Bundesrepublik "Zugang zu der atomaren Entscheidung erhalte“. Angesichts der deutschen Vergangenheit und der Tatsache, daß die Bundesrepublik "als einziges europäisches Land territoriale Forderungen habe", seien praktisch alle anderen europäischen Staaten dagegen ${ }^{166}$. Der General stellte unmißverständlich klar, daß für ihn die nuklearen Ambitionen Bonns und das Streben nach Wiedervereinigung unvereinbar waren ${ }^{167}$.

Auch mit London zeichnete sich keine Verständigung ab, obwohl Schröder schon Mitte Januar 1965 der britischen Regierung einen detaillierten Plan präsentierte, wie die ANF mit der MLF verknüpft werden konnte ${ }^{168}$, und in der Folgezeit weiterhin alle Anstrengungen unternahm, die Briten von dem Erfordernis eines integrativen Ansatzes im Bereich der nuklearen Verteidigung der NATO zu überzeugen ${ }^{169}$. Da Wilsons ANF-Vorschläge, lediglich „ein geschickter Schach-

161 Ebenda, S. 829.

162 KoOpmanN, Das schwierige Bündnis, S. 252.

163 Vgl. den Drahtbericht des Botschafters Knappstein, Washington, an Staatssekretär Carstens vom 1. 2. 1965, in: AAPD 1965, Dok. 49, S. 231-235.

164 Gespräch des Bundesministers Schröder mit dem amerikanischen Botschafter McGhee am 14. 1. 1965, in: ebenda, Dok. 15, S. 66.

165 Ebenda, S. 71.

166 Gespräch des Bundeskanzlers Erhard mit Staatspräsident de Gaulle am 20.1. 1965 in Rambouillet, in: ebenda, Dok. 26, S. 144.

167 Vgl. ebenda, S. 141; sowie das Gespräch des Bundeskanzlers Erhard mit Staatspräsident de Gaulle am 20.1.1965 in Rambouillet, in: ebenda, Dok. 27, S. 157.

168 Vgl. die Stellungnahme der Bundesregierung vom 18.1. 1965, in: ebenda, Dok. 21, S. 95101.

169 Vgl. z.B. das Gespräch des Bundesministers Schröder mit dem ehemaligen britischen Schatzkanzler Maudling am 18. 6. 1965, in: ebenda, Dok. 253, S. $1059 \mathrm{f}$. 
zug [waren], um die MLF ohne frontales Veto zu Fall zu bringen "170, mußten die Bemühungen des Außenministers zwangsläufig vergeblich bleiben. Warum sollte sich der Premierminister auf einen Kompromiß einlassen, wenn er sich mit seiner Strategie doch auf dem besten Weg befand, die gemeinsame Atomstreitmacht zu Fall zu bringen? Daß er niemals ernsthaft daran dachte, sein Alternativkonzept zu verwirklichen, zeigt sich daran, daß er seine Vorschläge umgehend zurückzog, als Anfang des Jahres 1966 feststand, daß das Projekt einer multilateralen Atomflotte endgültig gescheitert war ${ }^{171}$.

Trotz der von Anfang an auf der Hand liegenden eigentlichen Zielsetzung des ANF-Plans blieb Schröder nichts anderes übrig, als weiter an dem Vorhaben einer multilateralen Atomstreitmacht festzuhalten, wenn er der Bundesrepublik noch zu einer nuklearen Teilhabe verhelfen wollte. Andere Möglichkeiten bestanden nicht mehr, seitdem er eine Beteiligung an der Force de frappe ausgeschlossen hatte. War es doch ein Fehler gewesen, de Gaulles atomares Angebot vom Juli 1964 nicht näher zu prüfen? Die bereits erwähnten Äußerungen Maillards vom Juli 1965 gegenüber Botschafter Klaiber ließen den Schluß zu, daß die Offerte des Generals doch seriöser gewesen war, als das Auswärtige Amt damals angenommen hatte. Andererseits deutete der Vertraute de Gaulles mit keinem Wort an, daß Frankreich noch immer zu einer Zusammenarbeit im Bereich der nuklearen Verteidigung geneigt war ${ }^{172}$. Die letzte Chance für die Bundesrepublik bestand folglich darin, den Versuch zu unternehmen, die USA noch einmal für die Idee einer multilateralen Atomstreitmacht zu begeistern. Anläßlich eines Besuches Ende 1965 in Washington übergab Erhard ein Memorandum, in dem erneut das Erfordernis des Aufbaus einer SACEUR unterstellten, gemeinsam finanzierten und bemannten nuklearen Streitmacht bekräftigt wurde. Bonn forderte aber nicht länger die Schaffung einer Überwasserflotte, sondern ließ die praktische Umsetzung des Konzepts offen, das jetzt als Gemeinsame Nukleare Streitmacht (GNS) tituliert wurde ${ }^{173}$. Doch die USA waren an diesem Thema nicht mehr interessiert. Er verstünde nicht, „warum die Deutschen glaubten, überschüssiges Geld für eine nukleare Organisation loswerden zu müssen“, erklärte Johnson am 20. Dezember $1965^{174}$. Die USA hätten andere Prioritäten, stellte der Präsident gegenüber dem Kanzler klar: Die „Aufgabe Nummer 1“ der amerikanischen Politik sei der Vietnam-Krieg! Er verwies zudem auf die angespannte finanzielle Lage der Vereinigten Staaten. Johnson schlug als Ersatz eine verstärkte bilaterale Zusammenarbeit auf dem Gebiet der Weltraumforschung, der Raum- und Städteplanung sowie des Umweltschutzes vor: „Eine Zusammenarbeit auf all diesen Gebieten werde mehr

170 GrewE, Rückblenden, S. 621. Vgl. auch MAHNCKE, Nukleare Mitwirkung, S. 181.

171 Vgl. die Aufzeichnung des Ministerialdirigenten Ruete vom 25. 2. 1966, in: AAPD 1966, Dok. 46, S. 211-214.

172 Vgl. den Drahtbericht des Botschafters Klaiber, Paris, an das Auswärtige Amt vom 13. 7. 1965, in: AAPD 1965, Dok. 279, S. $1166 \mathrm{f}$.

173 Vgl. das Memorandum der Bundesregierung vom 20.12. 1965 mit dem Titel „Die nukleare Frage“, PA/AA, B 150, Aktenkopien 1965. Für die Übergabe vgl. das Gespräch des Bundeskanzlers Erhard mit Präsident Johnson am 20.12.1965 in Washington, in: AAPD 1965, Dok. 466, S. 1923.

174 Ebenda, S. 1922. 
dazu beitragen, eine unverbrüchliche Partnerschaft zu schaffen, und scheine ihm nützlicher als alles Gerede über Polaris-U-Boote." 175 Des weiteren erinnerte Johnson an die Erfüllung des deutsch-amerikanischen Devisenausgleichabkommens vom 11. Mai 1964, demzufolge die Bundesrepublik bis zum 30. Juni 1967 Rüstungskäufe im Wert von 1,35 Milliarden US-Dollar in den USA tätigen sollte ${ }^{176}$. Bis einschließlich November 1965 waren aber erst Aufträge in Höhe von knapp über einer halben Milliarde US-Dollar abgewickelt worden ${ }^{177}$. Beinahe ultimativ forderte der Präsident, Bonn müsse noch bis Jahresende 100 Millionen Dollar überweisen. Zusätzlich dazu sollte die Bundesrepublik zur Unterstützung des amerikanischen Engagements in Südostasien einen Beitrag in Höhe von 70 Millionen Dollar zum Aufbau der von den USA initiierten Asiatischen Entwicklungsbank leisten. Er ging mit seinen Forderungen sogar soweit, daß er in aggressivem Ton verlangte, Bonn müsse einen Beweis seiner Freundschaft erbringen, indem es den Vereinigten Staaten in Vietnam auch militärisch zur Seite stehe. Den Hinweis Erhards auf die schwierige Rechtslage in der Bundesrepublik hinsichtlich militärischer Auslandseinsätze wollte Johnson nicht hören ${ }^{178}$. Er meinte, "wenn er 200000 Mann auf die Beine stellen müsse, sollte es dem Bundeskanzler auch möglich sein, 2000 Mann zu finden"179. Derart unter Druck gesetzt, versprach Erhard trotz der sich abzeichnenden schwierigen Haushaltslage alles für eine fristgerechte Erfüllung des Offset-Abkommens zu tun ${ }^{180}$. Ferner sicherte er zu, auch die Zahlungen der Bundesrepublik an die Asiatische Entwicklungsbank in den nächsten Jahren auf 50 Millionen DM aufzustocken ${ }^{181}$.

Die Reaktion des Präsidenten ließ keinen Zweifel daran, daß alle Versuche vergeblich bleiben mußten, das Konzept einer multilateralen Atomstreitmacht wieder auf die Tagesordnung der westlichen Politik zu bringen. Ministerialdirektor Hans Ruete drückte sich noch optimistisch aus, wenn er in einer Aufzeichnung für Schröder zu dem Schluß kam: „Die gegenwärtige politische Konstellation ist für die Lösung der nuklearen Frage nicht günstig."182 Der Zeitpunkt, zu dem eventuell die Chance bestanden hatte, eine gemeinsame Atomstreitmacht innerhalb der NATO zu gründen, war spätestens im Dezember 1964 vorbei, als sich

175 Ebenda, S. 1927.

176 Für den Wortlaut des Protokolls vom 11. 5. 1964 zwischen dem Bundesministerium der Verteidigung und dem amerikanischen Verteidigungsministerium vgl. PA/AA, B 150, Aktenkopien 1964. Vgl. dazu auch die Aufzeichnung des Vortragenden Legationsrats I. Klasse Graf von Hardenberg vom 11. 5. 1964, in: AAPD 1964, Dok. 125, S. 526 f.; sowie RoSENBACH, Der Preis der Freiheit, S. 721-723.

177 Vgl. die Aufzeichnung des Vortragenden Legationsrats I. Klasse Middelmann vom 15. 11. 1965, PA/AA, B 150, Aktenkopien 1965.

178 Vgl. das Gespräch des Bundeskanzlers Erhard mit Präsident Johnson am 20.12.65 in Washington, in: AAPD 1965, Dok. 469, S. 1938-1942. Vgl. auch MCGHEE, Botschafter, S. 281-284.

179 Gespräch des Bundeskanzlers Erhard mit Präsident Johnson am 20.12. 65 in Washington, in: AAPD 1965, Dok. 469, S. 1941.

180 Vgl. ebenda, S. 1940-1942.

181 Vgl. ebenda, S. 1941, Anm. 15.

182 Aufzeichnung des Ministerialdirektors Ruete vom 25. 2. 1966, in: AAPD 1966, Dok. 46, S. 215. 
Johnson entschieden hatte, nicht mehr zugunsten des MLF-Projekts die Initiative $z u$ ergreifen. Als Ausgleich für die nicht zustande gekommene gemeinsame Atomstreitmacht wurde die Bundesrepublik in beschränktem Maße an der nuklearen Planung des Bündnisses beteiligt. Bereits am 31. Mai 1965 hatte der amerikanische Verteidigungsminister McNamara die Bildung eines aus vier oder fünf Staaten bestehenden select committee vorgeschlagen, das sich mit der Frage der nuklearen Zusammenarbeit in der NATO befassen sollte ${ }^{183}$. Schröder hatte von Anfang an in dem geplanten Ausschuß keinen Ersatz für die MLF gesehen, da es sich lediglich um eine Studiengruppe handelte, die nach den Vorstellungen des Pentagon keinen Einfluß auf die atomaren Entscheidungen der Allianz nehmen konnte ${ }^{184}$, doch die Bundesregierung mußte sich letztendlich mit diesem Trostpflaster zufriedengeben. Im September 1966 wurde die Initiative McNamaras in die Tat umgesetzt. Die am NATO-Verteidigungsprogramm beteiligten Staaten beschlossen, eine Arbeitsgruppe einzurichten, die sich mit den nuklearen Fragen des Bündnisses beschäftigen und allen interessierten Mitgliedstaaten offenstehen sollte. Eine zweite Gruppe, der vier ständige sowie zwei rotierende Mitglieder angehören sollten, wurde mit der Ausarbeitung der Detailplanungen betraut. Mit der Gründung der Nuklearen Planungsgruppe der NATO erachteten die USA das Problem der Zusammenarbeit in atomaren Fragen innerhalb der Allianz für endgültig gelöst ${ }^{185}$.

\section{Die Entwicklung der deutsch-französischen Beziehungen}

Der Wechsel im Bundeskanzleramt setzte der von Adenauer eingeleiteten Annäherung an Frankreich ein rapides Ende. Erhard ließ keinen Zweifel daran, daß er nicht daran dachte, die von seinem Vorgänger geknüpften engen Bande zum französischen Staatspräsidenten in gleichem Maße fortzuführen. Oberste Priorität hatten für ihn die Pflege und Intensivierung der Beziehungen zu den USA. Nur drei Tage nach seiner Wahl zum Kanzler, am 19. Oktober 1963, vertraute er dem gerade in Bonn befindlichen Dean Acheson an, seine erste Auslandsreise werde ihn zwar nach Paris führen, doch geschehe dies nur, „um die Politik Adenauers nicht in aller Öffentlichkeit zu desavouieren“. Das „eigentlich politische und für Deutschland bedeutsame Gespräch" sei für ihn jedoch das mit dem amerikanischen Präsidenten ${ }^{186}$. In das gleiche Horn blies auch Schröder. Er nutzte den Besuch Achesons in der Bundesrepublik, um erneut zu bekräftigen, daß es für die

183 Für einen Auszug aus der Rede McNamaras auf der Tagung der NATO-Verteidigungsminister am 31. 5. 1965 in Paris vgl. AAPD 1965, S. 918, Anm. 3.

184 Vgl. z.B. das Gespräch des Bundesministers Schröder mit dem ehemaligen britischen Schatzkanzler Maudling am 18. 6. 1965, in: ebenda, Dok. 253, S. 1059.

$185 \mathrm{Vgl}$. das Gespräch des Bundeskanzlers Erhard mit dem amerikanischen Außenminister Rusk am 26.9. 1966 in Wien, in: AAPD 1966, Dok. 297, S. 1240 f. Zu den Details der Gründung und der Arbeitsweise der beiden Planungsgruppen sowie ihre Bewertung vgl. u. a. HOPPE, Zwischen Teilhabe und Mitprache, S. 257-364, und HAFTENDORN, Kernwaffen, S. 166-180.

186 Gespräch des Bundeskanzlers Erhard mit dem ehemaligen amerikanischen Außenminister Acheson am 19. 10. 1963, in: AAPD 1963, Dok. 393, S. 1340. 
Bundesregierung keine Alternative zu einer Politik der engen Kooperation mit den USA gebe: „Von allen Verbündeten seien die Vereinigten Staaten nicht nur die stärksten, sondern auch die einzigen, mit denen das Problem der Wiedervereinigung gelöst werden könne." 187 Aufgrund des eindeutigen Kräfteverhältnisses hielt er die Ansicht, Bonn müsse sich zwischen Paris und Washington entscheiden, für „töricht“ ${ }^{188}$. Auch die Einschätzung Adenauers, die deutsch-amerikanischen Beziehungen seien in der Ära Eisenhower/Dulles deutlich besser gewesen, habe er nie geteilt, eröffnete er Acheson. Diese Auffassung des früheren Kanzlers sei nicht anderes als eine "Legende“, die „nicht den Realitäten entspreche“ 189 .

Im Gegensatz zu Erhard glaubte Schröder nicht daran, Adenauer habe tatsächlich die Intention verfolgt, der Zusammenarbeit mit Frankreich Vorrang vor den Beziehungen zu Washington einzuräumen. Die Schuld für die Probleme im deutsch-französischen Verhältnis trug seiner Ansicht nach nicht die deutsche, sondern die französische Seite, da sich de Gaulle ein vollkommen falsches Bild von Adenauers Politik gemacht habe. Er sei dem Trugschluß aufgesessen, daß der frühere Bundeskanzler ein Zusammengehen mit Frankreich, bei dem Paris die führende Rolle zugefallen wäre, angestrebt habe. Weil sich diese Hoffnung nicht erfüllt habe, sei der französische Staatspräsident nun mit der Bundesregierung unzufrieden ${ }^{190}$. Schröder warnte die Amerikaner, es komme letztlich auf ihre Politik an, ob de Gaulle für seine politischen Vorstellungen in der Bundesrepublik Unterstützung finden werde. Gegen die von Kennedy im Herbst 1963 erwogene Reduzierung der in Europa befindlichen Streitkräfte um 18000 Mann kämpfte er mit dem Argument, daß die Öffentlichkeit zu dem Urteil gelangen könnte, der französische Präsident habe mit seiner Prognose recht, die USA würden sich über kurz oder lang aus Europa zurückziehen ${ }^{191}$. Der Außenminister verstand zwar die Beweggründe Washingtons, die dem Reduzierungsplan zugrunde lagen, doch mahnte er die USA, die Glaubwürdigkeit der westlichen Abschreckung hinge nicht zuletzt von ihrer Präsenz auf dem europäischen Kontinent ab ${ }^{192}$.

Während er einerseits die amerikanische Regierung beschwor, ihr politisches und militärisches Engagement in Europa nicht zu reduzieren, damit die Anhänger de Gaulles keinen Auftrieb erhielten, bemühte er sich andererseits, den Vorwurf

187 Gespräch des Bundesministers Schröder mit dem ehemaligen amerikanischen Außenminister Acheson am 19. 10.1963, in: ebenda, Dok. 394, S. 1343.

188 Gespräch des Bundesministers Schröder mit dem amerikanischen Außenminister Rusk am 26. 10. 1963, in: ebenda, Dok. 403, S. 1395.

189 Gespräch des Bundesministers Schröder mit dem ehemaligen amerikanischen Außenminister Acheson am 19. 10. 1963, in: ebenda, Dok. 394, S. 1343. Zwei Tage nach diesem Gespräch führte Schröder vor dem außenpolitischen Arbeitskreis der CDU/CSU-Bundestagsfraktion (Arbeitskreis V) aus: „Unter Eisenhower-Dulles gab es zuletzt eine fallende Kurve für gesamtdeutsche Politik. Kennedy ist wieder härter. “Zitiert nach MARCOWITZ, Option, S. 182.

190 Gespräch des Bundesministers Schröder mit dem ehemaligen amerikanischen Außenminister Acheson am 19. 10. 1963, in: AAPD 1963, Dok. 394, S. 1343.

191 Vgl. das Gespräch des Bundesministers Schröder mit dem amerikanischen Außenminister Rusk am 26. 10. 1963, in: ebenda, Dok. 403, S. $1391 \mathrm{f}$.

192 Vgl. die Gespräche des Bundesministers Schröder mit dem japanischen Außenminister Ohira am 7./8. 11. 1963 in Tokio, in: ebenda, Dok. 410, S. $1422 \mathrm{f}$. 
$\mathrm{zu}$ entkräften, er betreibe eine gegen Frankreich gerichtete Politik. Schröder suchte die Öffentlichkeit in der Bundesrepublik zu überzeugen, daß der Aspekt einer Wahl zwischen Frankreich und den USA niemals für die Bundesregierung eine Rolle gespielt habe. Bei allen Fragen, die in der Vergangenheit von Bonn und Paris unterschiedlich beurteilt wurden, habe man „immer denjenigen Weg gewählt, der den deutschen Interessen und den Interessen des Bündnisses am besten zu dienen schien" ${ }^{193}$. Dies sei beim Beitritt zum Atomteststopp-Abkommen der Fall gewesen, wie auch bei dem Beschluß, am MLF-Projekt mitzuwirken. Auch das Aufnahmegesuch Großbritanniens in die europäischen Gemeinschaften habe die Bundesrepublik nicht deswegen unterstützt, weil die Amerikaner den Beitritt Londons wünschten, sondern allein aus eigenem Interesse ${ }^{194}$.

Am 21. November 1963 fand das erste deutsch-französische Konsultationstreffen nach dem Ende der Ära Adenauer statt. Zu Beginn der Gespräche unterstrich der neue Bundeskanzler gegenüber de Gaulle seinen Willen, die Freundschaft mit Frankreich zu wahren und "das reiche Erbe, das er aus den Händen seines Vorgängers Adenauer empfangen habe, weiterzuführen "195. Doch schon dieses erste Treffen brachte an den Tag, daß es zwischen den beiden Staatsmännern kaum politische Übereinstimmungen gab ${ }^{196}$. Erhard berichtete vier Wochen später Johnson, er habe ,in vielen wesentlichen Fragen keine gemeinsame Grundlage mit Frankreich gefunden“. Dies liege aber nicht daran, daß er sich zu wenig bemüht habe. Die Differenzen seien vielmehr bereits latent vorhanden gewesen, doch durch das „emotional[e]“ und „sentimental[e]“ Verhältnis zwischen Adenauer und de Gaulle verdeckt worden ${ }^{197}$. In der Tat ist die Verschlechterung des Verhältnisses zu Frankreich nach dem Rücktritt Adenauers auch darauf zurückzuführen, daß Erhard zu de Gaulle keinen Draht fand ${ }^{198}$. Er war von "tiefen Ressentiments “ ${ }^{199}$ gegen den General erfüllt und verhielt sich überaus abweisend und verletzend 200 . Der Kanzler bekannte offen, unter seiner Führung werde die Bundesrepublik nicht mehr „bedingungslos den französischen Kurs verfolge[n]“201. In Paris werde man bald den neuen Wind spüren, kündigte er an: „Wenn de Gaulle es nicht schon gelernt habe, so werde es sicher nicht lange dauern, bis er wissen werde, daß sich unter einem Bundeskanzler Erhard und einem Außenminister Schröder die Situation geändert habe." Die Freundschaft der beiden Staaten wollte er zwar weiter festigen, „aber unter Wahrung der deutschen eigenen Interessen und der deutschen Unabhängigkeit “202. Schröder pflegte ohnehin eine aus-

193 Interview Schröders mit dem DLF am 29. 10. 1963, in: Bulletin 1963, S. 1702.

194 Vgl. ebenda, S. 1701.

195 Gespräch des Bundeskanzlers Erhard mit Staatspräsident de Gaulle am 21.11. 1963 in Paris, in: AAPD 1963, Dok. 421, S. 1455.

196 Vgl. ebenda, Dok. 421-423, S. 1455-1478.

197 Gespräch des Bundeskanzlers Erhard mit Präsident Johnson am 28.12. 1963 in Stonewall, Texas, in: ebenda, Dok. 486, S. 1672.

198 Vgl. KUSTERER, Der Kanzler und der General, S. 347 und S. $398 \mathrm{f}$.

199 OSTERHELD, Außenpolitik, S. 311.

200 Vgl. ebenda, S. 388.

201 Gespräch des Bundeskanzlers Erhard mit Premierminister Douglas-Home am 15. 1. 1964 in London, in: AAPD 1964, Dok. 12, S. 46.

202 Ebenda, S. 47. 
geprägte Abneigung gegen de Gaulle. Er empfand sein Auftreten als „führerhaft" 203 und bezeichnete ihn abschätzig als „Präsidentenkaiser" 204 . Auch bestritt er dessen rhetorische Fähigkeiten und meinte, seine eigenen Reden hätten mehr Substanz und Qualität ${ }^{205}$. Nach der Einschätzung Kusterers sah der Außenminister in dem französischen Staatspräsidenten mehr einen "Schaumschläger" als einen ernstzunehmenden Politiker ${ }^{206}$.

Daß die Jahre 1964 bis 1966 den „Tiefpunkt in den deutsch-französischen Beziehungen" bildeten ${ }^{207}$, lag aber nicht in erster Linie an persönlichen Animositäten, sondern hauptsächlich an politischen Differenzen. Die Bundesregierung konnte und wollte de Gaulles Plan, ein "europäisches Europa“ zu schaffen, nicht unterstützen. Ein mit den USA verbündetes, aber ansonsten unabhängiges Europa lehnte Schröder kategorisch ab, da er die Anwesenheit der Amerikaner in Europa für die Sicherheit der Bundesrepublik als unerläßlich erachtete. Außerdem war er davon überzeugt, daß ohne die Hilfe der USA die Wiederherstellung der Einheit Deutschlands nicht zu erreichen sei208. Die Anhänger de Gaulles irrten ihm zufolge völlig, wenn sie glaubten, „Amerika könne Europa verlassen und dennoch die Wiedervereinigungspolitik fortsetzen"209. Darüber hinaus hielt er eine rein europäische Verteidigungspolitik für „unmöglich, unnützlich und unvernünftig“. Um eines Tages den Kreml dazu zu bringen, einem Ausgleich mit dem Westen zuzustimmen, sei es unbedingt erforderlich, daß das ,amerikanische Gewicht stark in der europäischen Waagschale gespürt werde“210. Deshalb gab es in seinen Augen für die amerikanische Präsenz in Europa keinerlei gleichwertigen Ersatz. Alle anderen Pläne waren seines Erachtens nur „Luftschlösser“211. Auch das integrative System der Allianz erachtete Schröder aus militärischen und politischen Gründen für unverzichtbar. Es sorgte nämlich zum einen für eine glaubhafte Abschreckung, da im Ernstfall die Streitkräfte sämtlicher Mitgliedstaaten geschlossen zum Einsatz kämen, und garantierte zum anderen die Gleichberechtigung der beteiligten Staaten, wodurch der Zusammenhalt des Bündnisses gefestigt würde. Konsequenterweise lehnte er deshalb die französischen Bestrebungen $a b$, die Souveränität Frankreichs im Bereich der Verteidigung wiederherzustellen und auf eine radikale Reform der NATO zu drängen ${ }^{212}$. Nach Schröders Auffassung war die französische Politik dafür verantwortlich, daß die Geschlossenheit der NATO nachgelassen habe. Frankreich habe hinsichtlich der Organisation und der

203 SCHRÖDER, Mit dem „Alten“ gebaut und gelitten.

204 SCHRÖDER, Im Gespräch mit Meinhold Krauss, S. 53.

205 Vgl. KUSTERER, Der Kanzler und der General, S. $199 \mathrm{f}$.

206 Ebenda, S. 202.

207 ZIEBURA, Die deutsch-französischen Beziehungen seit 1945, S. 189.

208 Gespräch des Bundesministers Schröder mit dem französischen Außenminister Couve de Murville am 4. 7. 1964, in: AAPD 1964, Dok. 185, S. 765.

209 Gespräch des Bundesministers Schröder mit dem Sicherheitsberater des amerikanischen Präsidenten, Bundy, am 27. 11. 1964 in Washington, in: ebenda, Dok. 363, S. 1410.

210 Gespräch des Bundesministers Schröder mit dem ehemaligen britischen Schatzkanzler Maudling am 18. 6. 1965, in: AAPD 1965, Dok. 253, S. 1059.

211 So Schröder am 17.5. 1966 im Bundestag: BT STENOGRAPHISCHE BERICHTE, Bd. 61, S. 1840.

212 Vgl. das Interview Schröders mit dem ZDF am 17. 4. 1966, in: BulletiN 1966, S. 406. 
Strategie der Allianz völlig konträre Vorstellungen zu denen der anderen Mitglieder der Allianz, stellte er im Dezember 1963 gegenüber dem britischen Außenminister Butler fest und beklagte sich, daß die französische Regierung ihre Vorstellungen nie konkretisiere: „Wenn man die Franzosen frage, was ihnen vorschwebe, so sagten sie, eine Neuorganisation der NATO. Danach näher befragt, erklärten sie, der europäische Einfluß müsse stärker werden. Auf die Frage, wie dies geschehen könne, sei die französische Antwort, Europa müsse besser organisiert werden, und die Antwort auf die Frage, wie dies geschehen solle, laute wahrscheinlich, indem man zunächst eine gemeinsame Landwirtschaftspolitik verabschiede. " 213

Erhard teilte Schröders Kritik der französischen Politik gegenüber dem Bündnis. Ein konstruktives Gespräch mit dem General sei nicht möglich, bemängelte er: „Man könne mit Präsident de Gaulle über die NATO einfach nicht diskutieren."214 Auch hinsichtlich der Durchführung der europäischen Vereinigung kam man sich nicht näher. Den europapolitischen Dialog zwischen Bonn und Paris hat Alfred Grosser treffend beschrieben: „Ich verstehe Sie nicht. Sie wollen, daß Europa mit lauter Stimme sprechen kann, aber sie wollen nicht, daß es einen Körper hat. - Ich verstehe Sie nicht. Sie wollen, daß Europa einen Körper hat, aber Sie lassen zu, daß seine Seele amerikanisch ist!" 215 Im Gegensatz zu Schröder, der nicht damit rechnete, daß de Gaulle ein Kursänderung an seiner Verteidigungspolitik vornehmen würde 216 , setzte Erhard auf die Flexibilität des Generals. Er prophezeite, daß dieser seine Pläne, mit Hilfe der Force de frappe eine „Hegemonie Frankreichs" zu errichten, aufgeben würde, wenn die Bundesrepublik sich ihm verweigere und die MLF Realität geworden sei: „Dann sei die Zeit gekommen, in der man wirksam mit de Gaulle sprechen könne." 217 Der Kanzler erinnerte in diesem Zusammenhang an die Kehrtwende des französischen Staatspräsidenten um $180 \mathrm{Grad}$ in der Algerien-Frage, wo er sich von einem Gegner plötzlich zu einem Befürworter der algerischen Unabhängigkeit gewandelt habe ${ }^{218}$.

Es waren aber nicht nur die Meinungsverschiedenheiten in den bedeutenden Fragen, die das bilaterale Verhältnis zunehmend belasteten. Auch abseits der Weltpolitik zeigte sich, daß von einer deutsch-französischen Freundschaft noch nicht gesprochen werden konnte. Ein exemplarisches Beispiel dafür sind die Ereignisse 1963/1964 um den in der Bundesrepublik sich aufhaltenden Oberst Antoine Argoud, einem Angehörigen der OAS. Bei dieser Organisation handelte es sich um eine terroristische Vereinigung französischer Militärs, die mit der Alge-

213 Gespräch des Bundesministers Schröder mit dem britischen Außenminister Butler am 9. 12. 1963, in: AAPD 1963, Dok. 459, S. 1588.

214 Deutsch-britische Regierungsbesprechung am 16. 1. 1964 in London, in: AAPD 1964, Dok. 14, S. $70 \mathrm{f}$.

215 Grosser, Das Bündnis, S. 267.

216 Vgl. das Gespräch des Bundesministers Schröder mit dem britischen Außenminister Butler am 9. 12. 1963, in: AAPD 1963, Dok. 459, S. 1589.

217 Gespräch des Bundeskanzlers Erhard mit Premierminister Douglas-Home am 15. 1.1964 in London, in: AAPD 1964, Dok. 12, S. 47.

$218 \mathrm{Vgl}$. die deutsch-britische Regierungsbesprechung am 16.1. 1964 in London, in: ebenda, Dok. 14, S. 71. 
rien-Politik de Gaulles nicht einverstanden waren und sich den Sturz des Generals auf ihre Fahnen geschrieben hatten. Mehrmals hatte die OAS schon Attentate auf den französischen Präsidenten verübt, jedoch ohne Erfolg219. Am 25. Februar 1963 wurde Argoud von französischen Geheimagenten aus einem Münchner Hotel entführt und nach Frankreich verschleppt ${ }^{220}$. Schröder vertrat die Ansicht, die Bundesrepublik dürfe sich die Verletzung der Souveränität der Bundesrepublik nicht gefallen lassen ${ }^{221}$. Da Paris nicht bereit war, sich zu entschuldigen ${ }^{222}$, protestierte die Bundesregierung am 30. Dezember 1963 und am 6. Januar 1964 gegen das französische Vorgehen und forderte die Rücküberstellung Argouds ${ }^{223}$. Die französische Regierung antwortete am 30. Januar 1964 jedoch, sie trage keine Verantwortung für den Vorfall, da sie keinen Befehl zur Verhaftung des Offiziers gegeben habe. Diese Stellungnahme stufte Schröder als "nicht zufriedenstellend“ ein: Paris, so erklärte er, müsse auch für Handlungen von untergeordneten Behörden haften, die diese ohne Befehl vornähmen, und bestand auf einer förmlichen Entschuldigung. Frankreich müsse ferner zusichern, daß die Verantwortlichen zur Rechenschaft gezogen würden, ansonsten würde im gegenseitigen Verhältnis „ein häßlicher Stachel bleiben“. Couve de Murville beabsichtigte indessen, die Angelegenheit unter den Tisch zu kehren. Er machte im Gegenzug den Behörden in der Bundesrepublik Vorwürfe, sie hätten wider besseren Wissens Argoud bei seinen gegen Frankreich gerichteten Tätigkeiten gewähren lassen ${ }^{224}$. Erst in einem Vieraugengespräch zwischen Erhard und de Gaulle gelang es, die Angelegenheit zu bereinigen. Man vereinbarte einen Briefwechsel, in dem der Staatspräsident sein Bedauern über die französische Vorgehensweise zum Ausdruck bringen sollte. Erhard wiederum hatte sich in seiner Antwort dafür zu entschuldigen, daß die Bundesrepublik gegen Argouds Aktivitäten nicht eingeschritten war ${ }^{225}$.

Für weitere Irritationen zwischen Bonn und Paris sorgte die Anerkennung der Volksrepublik China durch Frankreich am 27. Januar 1964. De Gaulle hatte es nicht für nötig gehalten, die Entscheidung mit der Bundesregierung abzuspre-

219 Zur OAS vgl. z. B. WEISENFELD, Frankreichs Geschichte seit dem Krieg, S. 148-154.

$220 \mathrm{Vgl}$. ADG 1963, S. $10435 \mathrm{f}$.

221 Vgl. Osterheld, Außenpolitik, S. 55.

222 Vgl. den Vermerk des Staatssekretärs Carstens vom 28.11. 1963, in: AAPD 1963, Dok. 436, S. $1511 \mathrm{f}$; sowie den Drahterlaß des Staatssekretärs Carstens an Botschafter Klaiber, Paris, vom 2. 12. 1963, in: ebenda, Dok. 441, S. 1522-1524.

223 Vgl. die Aufzeichnung des Ministerialdirigenten Meyer-Lindenberg vom 30. 12. 1963, PA/AA, B 150, Aktenkopien 1963; sowie den Drahterlaß des Staatssekretärs Carstens an die Botschaft in Paris vom 6. 1. 1964, PA/AA, B 150 Aktenkopien 1964.

224 Gespräch des Bundesministers Schröder mit dem französischen Außenminister Couve de Murville am 14. 2. 1964 in Paris, in: AAPD 1964, Dok. 45, S. 216-220 (217). Die Verhaftung Argouds folgte auf ausdrücklichen Befehl des französischen Verteidigungsministers Pierre Messmer, der aber de Gaulle nicht informiert hatte. Vgl. Linsel, Charles de Gaulle und Deutschland, S. 235.

225 Vgl. das Gespräch des Bundeskanzlers Erhard mit Staatspräsident de Gaulle am 15. 2. 1964 in Paris, in: ebenda, Dok. 49, S. 238-241. In seinem Schreiben an Erhard vom 19. 2. 1964 bedauerte de Gaulle zwar den Vorfall, warf der Bundesregierung aber zugleich erneut vor, sie sei gegen die Aktivitäten Argouds nicht eingeschritten. Für den Wortlaut vgl. DE GAulle, Lettres X, S. 37f. Für die Antwort Erhards an de Gaulle vom 8. 4. 1964 vgl. AAPD 1964, Dok. 87, S. 394 f. 
chen. Bonn war lediglich durch den französischen Botschafter de Margerie am 15. Januar 1964 vorab in Kenntnis gesetzt worden, daß Frankreich demnächst diplomatische Beziehungen zu Peking aufnehmen würde ${ }^{226}$. Zwar vertrat Schröder am 22. Januar vor dem Bundestag die Ansicht, es gebe laut Elysée-Vertrag keine Verpflichtung zur Konsultation ${ }^{227}$, doch gegenüber seinem französischen Amtskollegen kritisierte er den Pariser Alleingang vehement. Unmißverständlich bestand er darauf, die französische Regierung müsse mit Bonn in Kontakt treten, bevor sie eine Entscheidung treffe, da andernfalls die Bundesregierung ihre Auffassung nicht darlegen könnte. Schließlich sei es ja das Ziel beider Regierungen, zu einer gemeinsamen Haltung zu gelangen. Couve de Murville meinte dagegen, eine Unterrichtung der Bundesregierung sei nur bei Fragen von gemeinsamen Interesse nötig. Wäre dies nicht der Fall, könne Frankreich stets nach eigenem Ermessen handeln 228 .

In Bonn stieß man sich aber weniger an dem Punkt, daß keine Konsultation erfolgt war, sondern an der französischen Begründung für die Aufnahme diplomatischer Beziehungen mit dem kommunistischen China. Der französische Staatspräsident rechtfertigte seinen Beschluß nämlich mit der Notwendigkeit, die politischen Realitäten anzuerkennen ${ }^{229}$. Schröder nannte dies eine "gefährliche Formulierung“, weil die UdSSR mit dem gleichen Argument für die völkerrechtliche Anerkennung der DDR warb ${ }^{230}$. Da sich Frankreich mit der Aufnahme diplomatischer Beziehungen zu Peking eindeutig gegen die China-Politik der USA gestellt hatte, befürchtete er negative Auswirkungen auf die westliche Zusammenarbeit in der NATO. Er appellierte an Couve de Murville, künftig auch den Ministerrat der Allianz rechtzeitig zu konsultieren ${ }^{231}$. Trotz der heftigen Kritik verteidigte de Gaulle seine Maßnahme, die Beziehungen zu Peking zu normalisieren. Ihm schwebte vor, mittels einer Neutralisierung Vietnams, Kambodschas und Laos' den Frieden in Ostasien wiederherzustellen. Sein Plan habe aber nur unter Einbeziehung Pekings eine Chance, legte er dem Kanzler am 14. Februar 1964 dar 232. Erhard glaubte hingegen nicht an einen Erfolg der französischen Südostasien-Politik. Er prophezeite, eine Neutralisierung sei nur die Vorstufe für die endgültige kommunistische Machtergreifung in diesen Staaten ${ }^{233}$. Nach dem Willen Washingtons sollte die Bundesrepublik ihre Kritik auch öffentlich artikulieren. Schröder riet aber dringend davon ab, damit die Beziehungen zum westlichen

226 Vgl. die Aufzeichnung des Staatssekretärs Carstens vom 15. 1. 1964, in: ebenda, Dok. 11, S. 42-45.

227 BT STENOGRAPHISCHE BERICHTE, Bd. 54, S. 4916.

$228 \mathrm{Vgl}$. das Gespräch des Bundesministers Schröder mit dem französischen Außenminister Couve de Murville am 14. 2. 1964 in Paris, in: AAPD 1964, Dok. 46, S. 226.

229 Vgl. die Ausführungen de Gaulles auf einer Pressekonferenz am 31.1. 1964, in: DE GAULLE, Discours IV, S. 181.

230 Gespräch des Bundesministers Schröder mit dem französischen Außenminister Couve de Murville am 14.2. 1964 in Paris, in: AAPD 1964, Dok. 46, S. 223.

231 Vgl. ebenda, S. 224.

232 Vgl. das Gespräch des Bundeskanzlers Erhard mit Staatspräsident de Gaulle am 14. 2. 1964 in Paris, in: ebenda, Dok. 44, S. 210-212.

233 Vgl. Gespräch des Bundeskanzlers Erhard mit Ministerpräsident Erlander am 9. 3. 1964, in: ebenda, Dok. 67, S. 325. 
Nachbarn nicht noch stärker belastet würden. Er empfahl Erhard statt dessen, eine Erklärung zu veröffentlichen, daß Bonn den südvietnamesischen Abwehrkampf gegen den Kommunismus mit Sympathie verfolge. Auf diese Weise würde Bonn die amerikanische Position unterstützen, ohne direkt gegen Frankreich Stellung zu beziehen ${ }^{234}$. Beim Antrittsbesuch des neuen südvietnamesischen Botschafters in Bonn, Nguyen Qui Anh, am 18. Juni 1964, äußerte sich der Kanzler, der bereits im Rahmen seines Besuch in Washington, der wenige Tage zuvor zu Ende gegangen war, ausdrücklich zugunsten der amerikanischen Vorgehensweise in Vietnam Position bezogen hatte, in dem von Schröder gewünschten Sinn ${ }^{235}$. Einen entsprechenden Passus in dem nach seinen Besprechungen mit Johnson veröffentlichten Kommuniqué236 empfand de Gaulle als „Ohrfeige“ für seine Politik ${ }^{237}$.

Angesichts dieses Schauspiels ständiger politischer Differenzen zwischen Bonn und Paris reiste de Gaulle ziemlich verärgert zu den halbjährlichen Konsultationsgesprächen am 3./4. Juli 1964 nach Bonn. Bereits in seinem ersten Gespräch mit Erhard unter vier Augen, nur eine Dreiviertelstunde nach seiner Ankunft, warf er der Bundesregierung vor, sie wolle keine „wirklich europäische, d. h. eine von Amerika unabhängige Politik " betreiben. Da man in den wesentlichen politischen Fragen zumeist verschiedene Meinungen vertrete, sei eine wirklich bedeutsame Zusammenarbeit zwischen den beiden Staaten nicht möglich, bedauerte der General. Leider habe die Bundesrepublik nicht "gewählt" und sich nicht entschließen können, sich entweder für Frankreich oder die USA zu entscheiden ${ }^{238}$. Erhard ließ sich diesen Vorwurf nicht gefallen. Er entgegnete, der Bundesrepublik liege eine Wahl zwischen Frankreich und den Vereinigten Staaten fern: Seine Regierung wolle die Freundschaft zu beiden Staaten pflegen. Zwar wolle Bonn nicht von Amerika abhängig sein, doch könne man die Tatsache nicht außer acht lassen, daß die Bundesrepublik auf den amerikanischen Schutz angewiesen sei. De Gaulle beteuerte daraufhin erneut, er habe nicht vor, das Bündnis mit den USA aufzugeben. Die Allianz sollte aber künftig auf den Schultern zweier gleich starker und gleichberechtigter Partner beruhen ${ }^{239}$. Obwohl er erklärte, er respektiere die Gründe, warum sich die Bundesregierung nicht zwischen Paris und Washington entscheiden wolle, forderte er den Kanzler dennoch indirekt auf, endlich eine Wahl zugunsten Frankreichs zu treffen: „Wenn aber Deutschland sich nicht entscheide, dann werde es in der jetzigen Epoche der Geschichte nicht zu einer Einigung Europas kommen. " 240

234 Vgl. das Schreiben des Bundesministers Schröder an Bundeskanzler Erhard vom 17. 5. 1964, in: ebenda, Dok. 130, S. 541.

$235 \mathrm{Vgl}$. BuLLETIN 1964, S. 885.

236 Vgl. das Kommuniqué vom 12. 6. 1964, in: DzD IV/10, S. 685-687, besonders S. 686.

237 Drahtbericht des Botschafters Klaiber, Paris, an das Auswärtige Amt vom 10. 7. 1964, in: AAPD 1964, Dok. 195, S. 810.

$238 \mathrm{Vgl}$. das Gespräch des Bundeskanzlers Erhard mit Staatspräsident de Gaulle am 3.7. 1964, in: ebenda, Dok. 180, S. 714.

239 Vgl. ebenda, S. 715-718.

240 Ebenda, S. 722. Als Adenauer am 4. 7. 1964 Erhard wegen des mißlungenen Gipfels kritisierte, verteidigte sich dieser damit, de Gaulle hätte ihn vor die Wahl zwischen Frankreich und die USA gestellt. Der frühere Kanzler wollte dies nicht glauben. Auch vor dem Kabinett bekräftigte Erhard seine Darstellung. Barzel nahm daraufhin Einblick in die Ge- 
Auch Couve de Murville warf der Bundesregierung vor, sie habe bislang nicht nach dem Geist des deutsch-französischen Vertrags agiert ${ }^{241}$. Wie Schröder knapp zwei Wochen später gegenüber McGhee ausführte, war er überzeugt, daß Paris nur deshalb den Vorwurf der Nichterfüllung des Elysée-Vertrags erhob, weil Bonn die französischen Ziele nicht unterstützte. Die Forderung nach einer „europäischen Außenpolitik" bedeute nichts anderes, als daß sich die Bundesregierung mit der französischen Politik identifizieren solle242. Er wies daher den Vorwurf des französischen Außenministers entschieden zurück. Ausführlich erläuterte er ihm die Motive seiner Außenpolitik: Frankreich, so Schröder, müsse begreifen, daß Bonn nicht auf die britischen und amerikanischen Truppen verzichten könne. Die Präsenz der USA und Großbritanniens auf dem Territorium der Bundesrepublik sei auch im Hinblick auf die Wiedervereinigung Deutschlands unerläßlich ${ }^{243}$. Im übrigen habe er sich bis jetzt „auch nicht eine Sekunde lang als Satellit von irgend jemandem gefühlt“. Die Bundesrepublik verfolge nämlich eine Politik, die sich ausschließlich an ihren eigenen Interessen orientiere und nicht an denjenigen eines anderen Landes, machte Schröder deutlich ${ }^{244}$. In diesem Zusammenhang wies er erneut darauf hin, daß die Bundesrepublik wegen ihrer exponierten Lage auf den amerikanischen Schutz angewiesen sei. Desgleichen, so Schröder, müsse die Tatsache akzeptiert werden, daß sich Europa nicht ohne die Hilfe der Vereinigten Staaten gegen einen Angriff wehren könne. Aufgrund dieser beiden „lebenswichtigen Faktoren" widerspräche ein Rückzug der Vereinigten Staaten aus Europa den deutschen Interessen. Explizit bestritt er, daß dadurch ein „Abhängigkeitsverhältnis“ entstehen würde: „Deutschland wolle genauso unabhängig sein wie Frankreich und wünsche sich ein ebenso kräftiges Europa." 245 Anschließend versuchte er Couve de Murville zu überzeugen, daß es im Grunde keinen politischen Dissens zwischen Bonn und Paris gebe. So bestünden hinsichtlich der Auffassungen, wie ein vereintes Europa aussehen solle, keine Meinungsverschiedenheiten. Er habe sich immer mit den französischen Vorstellungen identifizieren können, wie seine Haltung zu den Fouchet-Plänen gezeigt habe. Selbst die Differenzen über die Gestaltung der europäischen Verteidigung waren seiner Meinung nach nicht unüberwindbar. Obwohl Frankreich das von der Bundesrepublik gewünschte Prinzip der Integration der Streitkräfte ablehnte und auf seine Souveränität pochte, erwartete er keine auseinanderlaufende Entwicklung, sondern rechnete vielmehr damit, daß sich in fünf bis zehn Jahren die Parameter geändert haben würden und eine Verschmelzung der MLF und der Force de frappe bzw. die Europäisierung der MLF denkbar wäre ${ }^{246}$. Diese Frage, so der Außenminister der

241 Vgl. das Gespräch des Bundesministers Schröder mit dem französischen Außenminister Couve de Murville am 4. 7. 1964, in: AAPD 1964, Dok. 185, S. 755-766.

$242 \mathrm{Vgl}$. das Gespräch des Bundesministers Schröder mit dem amerikanischen Botschafter McGhee am 14. 7. 1964, in: ebenda, Dok. 196, S. 820.

$243 \mathrm{Vgl}$. das Gespräch des Bundesministers Schröder mit dem französischen Außenminister Couve de Murville am 4. 7. 1964, in: ebenda, Dok. 185, S. 755-766.

244 Ebenda, S. 760.

245 Ebenda, S. 765.

246 Vgl. ebenda, S. 759-762. 
Bundesrepublik, sei somit kein „vitaler Gegensatz“247. Folglich existiere in Wahrheit „keine konkrete Sache, in der es echte Meinungsverschiedenheiten zwischen Frankreich und Deutschland gebe." Er bat Couve de Murville deshalb, sein negatives Urteil über die bilaterale Zusammenarbeit noch einmal zu überdenken ${ }^{248}$.

Am zweiten Tag der Konsultationsgespräche gab sich auch der französische Staatspräsident entschieden zugänglicher. In seiner Unterredung mit Erhard bemerkte er versöhnlich, „daß ja zwischen Deutschland und Frankreich keine Berge stünden“. Der bilaterale Dialog sei im Grunde völlig unproblematisch: „Schwierig sei nur das gemeinsame Handeln. "249 Dabei gab er seiner Überzeugung Ausdruck, daß sich Bonn im Laufe der Zeit „ganz automatisch“ der französischen $\mathrm{Li}_{\text {- }}$ nie annähern würde. Infolgedessen wollte er in Ruhe abwarten und sich bis dahin bemühen, die beiderseitigen Kontakte zu festigen und auszuweiten ${ }^{250}$. Ähnlich wohlwollend äußerte sich de Gaulle auch in seinem Schlußreferat bei der abschließenden gemeinsamen Regierungsbesprechung ${ }^{251}$. Seine „bewegenden Ausführungen “ 252 vor den versammelten Ministern der beiden Staaten beendete er mit einem flammenden Appell für eine enge und intensive Kooperation Frankreichs und der Bundesrepublik: „Es sei fast unglaubhaft und dennoch wahr, daß es für Frankreich heute keinen Staat auf der Welt gäbe, mit dem es aus Seelenneigung und natürlichen Gegebenheiten mehr zu einer Zusammenarbeit bereit sei als mit dem heutigen Deutschland." 253 Was sich nun ereignete, mußte de Gaulle allerdings als einen unerhörten Affront empfinden. Anstatt auf seine Rede zu antworten, verharrte der Kanzler in Schweigen. „Verwunderung, Beklommenheit breiteten sich aus, fast Lähmung", schilderte Osterheld die Szene ${ }^{254}$. Schließlich unterbrach Schröder "die peinliche Stille" und forderte die Dolmetscherin, Colette Bouverat, auf, mit der Übersetzung des Referats von Christian Fouchet - mittlerweile französischer Bildungsminister - fortzufahren, welche sie beim Eintreffen de Gaulles vor der Ministerrunde unterbrochen hatte. So mancher Besprechungsteilnehmer glaubte in diesem Moment, "Zeuge des Zerbrechens einer zukunftsträchtigen Freundschaft zu sein" 255 . Die Nichtbeachtung seines feierlichen Aufrufs traf de Gaulle schwer: „Je suis resté vierge“, bemerkte er frustriert gegenüber Adenauer. Dieser wiederum erzählte noch Jahre später, wie tief der französische Staatspräsident durch Erhards Verhalten verletzt worden sei: „Ich habe den Mann noch nie so aufgeregt gesehen, weil man ihm [...] nicht mit einer Silbe geantwortet hat. [...] Das war für ihn eine solche Blamage, eine solche Ablehnung!"256

\footnotetext{
247 Ebenda, S. 762.

248 Ebenda, S. 763.

249 Gespräch des Bundeskanzlers Erhard mit Staatspräsident de Gaulle am 4. 7. 1964, in: ebenda, Dok. 187, S. $784 \mathrm{f}$.

250 Ebenda, S. 776.

$251 \mathrm{Vgl}$. die deutsch-französische Regierungsbesprechung am 4.7. 1964, in: ebenda, Dok. 188, S. 784.

252 OSTERHELD, Außenpolitik, S. 99.

253 Deutsch-französische Regierungsbesprechung am 4. 7. 1964, in: AAPD 1964, Dok. 188, S. 785.

254 OSTERHELD, Außenpolitik, S. 99.

255 Ebenda. Vgl. auch KuSTERER, Der Kanzler und der General, S. 419.

256 Zitiert nach SCHWARZ, Adenauer II, S. 888.
} 
Schröder wurde später beschuldigt, er habe den französischen Staatspräsidenten durch seine Anordnung, zur Tagesordnung überzugehen, auf ungeheuerliche Weise brüskiert ${ }^{257}$. Man nannte ihn einen "homme fatale“, durch den eine "deutsch-französische Sternstunde" verhindert worden sei258. Auch Adenauer warf dem Außenminister die „Zerstörung des deutsch-französischen Verhältnisses" vor ${ }^{259}$. Sicherlich war Schröders Verhalten nicht besonders geschickt. Doch wäre es unfair, ihm die Verantwortung für die schlechte Behandlung des Generals zuzuschieben. Laut diplomatischem Protokoll stand es dem Außenminister nicht zu, im Namen der Bundesregierung einem Staatsoberhaupt zu antworten. Dies wäre die Aufgabe des Kanzlers gewesen. Nicht Schröder, sondern Erhard hätte also im Zentrum der Kritik stehen müssen. Dieser schwieg wohl ganz bewußt, um de Gaulle vor Augen zu führen, daß die Bundesrepublik an einer vertieften $\mathrm{Zu}$ sammenarbeit mit Frankreich nicht interessiert war. Ein Indiz dafür sind die abfälligen Äußerungen über den französischen Staatspräsidenten, die Erhard nach Beendigung der Konsultationsgespräche verbreitete. Die „Politik de Gaulles sei für ihn völlig unmöglich“ und ein „völliger Rückfall in die Vergangenheit“, sagte er beispielsweise dem belgischen Außenminister Spaak. Ginge die Bundesrepublik mit Frankreich zusammen, würde sie „auf jede Handlungsfreiheit verzichten und die Freundschaft der freien Welt verlieren “260. Auch gegenüber McGhee brüstete sich der Kanzler, daß er de Gaulles Pläne einer vertieften Kooperation zurückgewiesen habe 261 .

Während Schröder also die Konfrontation mit Paris zu vermeiden suchte und die Meinungsverschiedenheiten herunterspielte, schien Erhard nicht an einem einigermaßen verträglichen Verhältnis zu Paris interessiert. Er ließ keinen Zweifel daran, daß er völlig auf die amerikanische Karte setzte. Am 12. Februar 1964, nur einige Monate nach Übernahme des Kanzleramts, bekannte Erhard unmittelbar vor einer Reise an die Seine gegenüber dem amerikanischen Botschafter, er „würde fünfmal lieber in die Vereinigten Staaten gehen und sich dort mit dem Präsidenten unterhalten, als nunmehr nach Paris zu einer Begegnung mit de Gaulle“262. Osterheld sprach von einer „Amerikophilie“ des Kanzlers: Erhards Bestreben sei es gewesen, „der beste Freund Amerikas [zu] sein“263. Der Freundschaft Adenauers mit de Gaulle wollte er gleichwertiges entgegensetzen und suchte sich dafür den amerikanischen Präsidenten aus ${ }^{264}$. Dabei war er aber blind für die Tatsache, daß Johnson beispielsweise in der Frage der Devisenausgleichs-

257 Vgl. Strauss, Erinnerungen, S. 433; SEYdoux, Meine zweite Mission, S. 325; BRANDT, Begegnungen, S. 142.

258 Interview Schröders mit der Rhein-Zeitung am 26. 6. 1965, in: Bulletin 1965, S. 890.

259 Zitiert nach SCHWARZ, Adenauer II, S. 890.

260 Gespräch des Bundeskanzlers Erhard mit dem belgischen Außenminister Spaak am 14. 7. 1964, in: AAPD 1964, Dok. 198, S. 836.

261 Gespräch des Bundeskanzlers Erhard mit dem amerikanischen Botschafter McGhee am 6. 7. 1964, in: ebenda, Dok. 189, S. 788.

262 Gespräch des Bundeskanzlers Erhard mit dem amerikanischen Botschafter McGhee am 12. 2. 1964, in: ebenda, Dok. 42, S. 193.

263 OSTERHELD, Außenpolitik, S. 387.

264 Vgl. KuSTERER, Der Kanzler und der General, S. 397 f. 
zahlungen für die in der Bundesrepublik stationierten amerikanischen Truppen kompromißlos seine Forderungen vortrug und auf die innenpolitisch angeschlagene Position Erhards keine Rücksicht nahm ${ }^{265}$. Selbst noch im Sommer 1966 verkündete der Kanzler blauäugig: „Ich liebe den Präsidenten Johnson, und er liebt mich auch." 266 In allen Details setzte er McGhee über den Inhalt seiner Vieraugengespräche mit de Gaulle in Kenntnis und begründete diesen Vertrauensbruch gegenüber dem General damit, er wolle damit den „tiefste[n] Beweis der Freundschaft", die er für Präsident Johnson empfinde, erbringen ${ }^{267}$. Nachdem er im Juli 1964 dem französischen Staatspräsidenten vor Augen geführt hatte, „daß die Deutschen sein Spiel nicht mitmachten“, befürchtete der Kanzler jedoch, dieser könnte sich nun den Vereinigten Staaten zuwenden und sich mit den Amerikanern aussöhnen. Er ließ sich deshalb von McGhee versichern, daß sich Frankreich und die USA „niemals auf Kosten der Bundesrepublik arrangieren würden“268. Diese irrationale Angst vor einem Zusammengehen Frankreichs und der Vereinigten Staaten zeigt, daß Erhard die politischen Grundüberzeugungen de Gaulles offensichtlich nicht begriffen hatte und ihn als einen Machtpolitiker betrachtete, der seine Allianzen so schloß, wie sie ihm im Moment für günstig erschienen.

Wegen seiner antifranzösischen Haltung geriet Erhard innenpolitisch unter starken Druck. Die unterschiedliche Bewertung des deutsch-französischen Gipfeltreffens von Anfang Juli 1964 bildete nach der einhelligen Meinung Waldemar Bessons und Christian Hackes den "Höhepunkt" der Auseinandersetzung zwischen Gaullisten und Atlantikern ${ }^{269}$. Adenauer und Guttenberg kritisierten öffentlich den verheerenden Zustand der Beziehungen ${ }^{270}$. Strauß griff frontal den Kanzler an und mobilisierte zu diesem Zweck die CSU, auf deren Landesversammlung vom 10. bis 12. Juli 1964 in München es Erhard jedoch mit einer mutigen Rede gelang, die Fronde gegen ihn vorerst zu ersticken ${ }^{271}$. Er gab sich aber nicht der Illusion hin, daß er seine Gegner nun endgültig niedergerungen hätte. Er habe sie „zwar distanziert, doch wäre es irrig anzunehmen, daß sie nun wehrlos am Boden lägen“, bemerkte er am 13. Juli gegenüber McGhee ${ }^{272}$. Bezeichnend für das damalige schlechte Klima innerhalb der Union ist Erhards Vergleich der bayerischen Schwesterpartei mit dem amerikanischen Präsidentschaftskandidaten der Republikanischen Partei, Barry Goldwater, der durch seine ultrakonservativen und nationalistischen Aussagen von sich reden machte. Der Kanzler war der Auffassung, die geistige, moralische und politische Einstellung der CSU, die auf der

\footnotetext{
265 Vgl. HentsChel, Ludwig Erhard, S. 457.

266 Zitiert nach PrITTIE, Konrad Adenauer, S. 481. Vgl. dazu auch GörTEMAKER, Geschichte der Bundesrepublik Deutschland, S. 430.

267 Gespräch des Bundeskanzlers Erhard mit dem amerikanischen Botschafter McGhee am 6. 7. 1964, in: AAPD 1964, Dok. 189, S. 791.

268 Ebenda, S. 795.

269 HACKE, Weltmacht, S. 119; BESSON, Die Außenpolitik der Bundesrepublik, S. 324.

$270 \mathrm{Vgl}$. OSTERHELD, Außenpolitik, S. 102.

271 Für den Wortlaut der Rede Erhards vom 12. 7.1964 vgl. Bulletin 1964, S. 1061-1067.

272 Gespräch des Bundeskanzlers Erhard mit dem amerikanischen Botschafter McGhee am 13. 7. 1964, in: AAPD 1964, Dok. 195, S. 813.
} 
Landesversammlung offenbar geworden sei, entspräche den Ideen und Ansichten Goldwaters: „Beides speise sich aus der gleichen Wurzel.“273

Das Konsultationstreffen vom 3./4. Juli 1964 führte zu einer „erheblichen Verschlechterung " der beiderseitigen Beziehungen, wie Carstens Ende Juli in einer internen Analyse feststellte ${ }^{274}$. Daß de Gaulle auf einer Pressekonferenz am 23. Juli in Paris eine negative Bilanz der bilateralen Zusammenarbeit zog und sogar erstmals öffentlich die Bundesregierung kritisierte ${ }^{275}$, war nach der Meinung des Staatssekretärs dafür das herausragendste Indiz ${ }^{276}$. An der Koblenzer Straße stellte man sich deshalb die Frage, wie dieser Entwicklung entgegengewirkt werden konnte. Carstens kam in seiner Aufzeichnung zu dem Schluß, daß keinesfalls auf die französischen Offerten eingegangen werden dürfe: „Im Fall eines deutschfranzösischen Alleingangs, noch dazu mit einer deutlichen Frontstellung gegen die USA, würden die USA ihren Einfluß in Europa gegen uns mobilisieren." Außerdem sagte er voraus, daß die Bundesrepublik durch eine solche Politik in einen Gegensatz zu ihren europäischen Partnern geraten würde. Die „Entfremdung“, die dadurch entstünde, wäre von Bestand, warnte der Staatssekretär277. Ebenso sprach er sich auch gegen eine Unterstützung der französischen NATO-Politik aus, da sie einer Desintegration des Bündnisses Vorschub leiste. Carstens sah die Gefahr, daß die kleineren NATO-Staaten für eine Politik des Neutralismus anfällig werden könnten. Wie Schröder erachtete er die amerikanische Präsenz in der Bundesrepublik für unverzichtbar. Daher sah er keine Alternative zu dem von der Bundesregierung bislang verfolgten Kurs gegenüber dem westlichen Nachbarn: "Wir können die Wahl, die Frankreich uns aufzwingen will, nicht vollziehen." ${ }^{278}$ Carstens machte Schröder aber auf die Möglichkeit aufmerksam, daß Frankreich deswegen der Deutschland- und Berlin-Politik der Bundesregierung Schwierigkeiten bereiten könnte. Auch „partielle Verständigungen zwischen Frankreich und der Sowjetunion", wie sie sich in der gemeinsamen Opposition gegen die MLF abzeichneten, wären denkbar. Ein prinzipielles "renversement des alliances“ schloß er jedoch aus 279 . Um eine weitere Klimaverschlechterung zu verhindern, riet er dazu, öffentlich keinerlei Kritik an der französischen Politik zu äußern, sondern „größte Zurückhaltung" zu üben. Die Bundesregierung müsse den Willen zur Freundschaft mit Frankreich herausstreichen, selbst wenn der Ton de Gaulles an Schärfe zunehmen sollte 280 .

Schröder folgte in der nächsten Zeit den Empfehlungen seines Staatssekretärs. In Interviews bezeichnete er die deutsch-französische Freundschaft als „kostbares Gut", das durch die momentanen Differenzen nicht in Mitleidenschaft gezogen

273 Ebenda, S. 812.

274 Aufzeichnung des Staatssekretärs Carstens vom 27. 7. 1964, in: ebenda, Dok. 210, S. 884.

275 Vgl. DE GAULLE, Discours IV, S. 222-237.

276 Vgl. Aufzeichnung des Staatssekretärs Carstens vom 27.7. 1964, in: AAPD 1964, Dok. 210, S. 884-993.

277 Ebenda, S. 889.

278 Ebenda, S. 890.

279 Ebenda, S. 891 (Hervorhebung im Original).

280 Vgl. ebenda, S. 892. 
werden dürfe 281 . Ähnlich äußerte er sich auch vor dem Bundestag. Dort bekräftigte er am 13. November 1964 seine Absicht, diese Freundschaft noch weiter zu festigen ${ }^{282}$. In seinen Gesprächen mit französischen Politikern unterstrich er ebenfalls den Willen der Bundesregierung zur bilateralen Zusammenarbeit. Die Rüge der Franzosen, Bonn habe den gemeinsamen Vertrag nicht in die Praxis umgesetzt, wies er mit dem Hinweis zurück, er sei als Mitunterzeichner des ElyséeVertrags persönlich stark an einer erfolgreichen Zusammenarbeit interessiert ${ }^{283}$. Er gab zu, daß der „Idealzustand“ der Konsultation noch nicht erreicht sei, bat aber im gleichen Atemzug die französische Seite um mehr Geduld 284 .

Auf diese Weise wurden nach außen die Probleme zwischen den beiden Staaten beschönigt, während sich in Wirklichkeit die Atmosphäre zwischen Paris und Bonn seit dem Sommer 1964 immer stärker abkühlte. "Unsere Öffentlichkeit hat von den wirklichen Schwierigkeiten keine Ahnung“", bekannte Schröder Mitte November gegenüber dem britischen Außenminister Gordon Walker ${ }^{285}$. In fast allen wichtigen politischen Fragen bestanden zwischen der Bundesrepublik und Frankreich erhebliche Meinungsverschiedenheiten. Als sich im Mai 1965 Couve de Murville massiv über die stetige Verschlechterung der Beziehungen seit dem Kanzlerwechsel in der Bundesrepublik beklagte und meinte, der Elysée-Vertrag habe „überhaupt nicht funktioniert"286, warf Schröder wiederum den Franzosen vor, sie hätten nicht sehen wollen, daß die vom Bundestag eingefügte Präambel exakt die politische Linie Bonns widergespiegelt habe: Eine faire Beurteilung des Vertrages müsse auch die unterschiedliche Ausgangslage berücksichtigen ${ }^{287}$.

Innenpolitisch geriet der Außenminister wegen des schlechten Zustands der deutsch-französischen Beziehungen immer stärker ins Kreuzfeuer der Kritik. Noch Anfang August 1964 glaubte Schröder nach einer zweistündigen Aussprache mit Adenauer, er habe mit dem früheren Kanzler Frieden geschlossen ${ }^{288}$. Aber es handelte sich nur um einen trügerischen Waffenstillstand. Am 1. November 1964 griff Adenauer in einem Interview mit Bild am Sonntag die Bonner Außenpolitik scharf an, wobei er vor allem die schlechte Behandlung de Gaulles durch die Bundesregierung bemängelte 289 . Zwei Tage später kam es deswegen in der CDU/CSU-Fraktion zu einer erregten Aussprache, wobei Erhard sein Einvernehmen mit Schröders Politik herausstrich ${ }^{290}$. Schröder wiederum antwortete am 8. November 1964 in der Mainzer Allgemeinen Zeitung mit einer heftigen Kritik

281 Vgl. z. B. das Interview Schröders mit der dpa am 1. 9. 1964, in: BulletiN 1964, S. 1270. 282 Vgl. BT STENOGRAPHISCHE BERICHTE, Bd. 56, S. $7227 \mathrm{f}$.

283 Vgl. das Gespräch des Bundesministers Schröder mit dem Abteilungsleiter im französischen Außenministerium, Lucet, am 15. 9. 1964, in: AAPD 1964, Dok. 248, S. $1030 \mathrm{f}$.

284 Ebenda, S. 1031.

285 Gespräch des Bundesministers Schröder mit dem britischen Außenminister Gordon Walker am 15. 11. 1964, in: ebenda, Dok. 335, S. 1315.

286 Gespräch des Bundesministers Schröder mit dem französischen Außenminister Couve de Murville am 24. 5. 1965, in: AAPD 1965, Dok. 217, S. 870.

287 Vgl. ebenda, S. 871.

288 Vgl. FRUS 1964-1968, XV, Dok. 64, S. 145.

289 Vgl. OSTERHELD, Außenpolitik, S. 118; BARZEL, Im Streit und umstritten, S. 68 f.

290 Vgl. ebenda, S. 69 f. 
an dem früheren Kanzler ${ }^{291}$. Adenauer bezeichnete daraufhin vor dem CDUBundesvorstand das Verhalten des Außenministers als „unerhört" und gab offen $\mathrm{zu}$, er billige dessen Frankreich-Politik nicht ${ }^{292}$. Immer noch fürchtete er, Frankreich könnte von der Bundesrepublik in die Arme der Sowjetunion getrieben werden ${ }^{293}$. Unaufhörlich machte er daher innerhalb der Union Stimmung gegen Schröder. Er warf ihm sogar vor, er hintergehe den Kanzler: „Herr Schröder hat mich genauso beschwindelt, wie er Herrn Erhard beschwindelt. " $294 \mathrm{McCloy}$ bekam von ihm zu hören, der Außenminister sei ein „Dummkopf“295. Dieser wiederum beklagte sich bei McGhee, wie ihm der frühere Kanzler durch seine ständigen Attacken das Leben schwer mache. Es sei leider nicht mehr möglich, mit Adenauer ein ernsthaftes Gespräch zu führen ${ }^{296}$.

Obwohl ihm Erhard Rückendeckung gab, blieb Schröder im Mittelpunkt der parteiinternen Kritik. Ganze "Sündenregister" wurden erstellt. Neben seiner vermeintlichen antifranzösischen Einstellung konzentrierten sich die Vorwürfe auf seine Haltung im Streit um die Zugangsbehörde für Berlin, sein Verhalten auf der Ministerratssitzung der EWG am 29. Januar 1963, bei der er sich nicht an die mit de Gaulle getroffene Absprache gehalten habe, die Beitrittsverhandlungen mit Großbritannien zu vertagen, sowie auf seinen Versuch, sich der Mitverantwortung für den Bruch mit den arabischen Staaten zu entziehen, obwohl er versäumt habe, Nasser nach Bonn einzuladen ${ }^{297}$. Auch die Medien attackierten Schröder, hauptsächlich wegen seiner angeblich frankreichfeindlichen Politik. Die Kritik kam vor allem von der Bild-Zeitung und vom CSU-Parteiorgan Bayernkurier ${ }^{298}$. Ebenso stellte sich der Rheinische Merkur gegen ihn ${ }^{299}$. Nach der Bundestagswahl am 19. September 1965, die die Union überraschend klar mit 47,6\% der Stimmen gewann (die absolute Mehrheit wurde nur um vier Mandate verfehlt) ${ }^{300}$, sahen Schröders Gegner nun ihre Stunde gekommen. Adenauer, Gerstenmaier, Strauß und Guttenberg verlangten unisono, das Amt des Außenministers müsse neu besetzt werden. Ihre Forderung wurde von Bundespräsident Lübke unterstützt ${ }^{301}$,

291 Vgl. dazu AAPD 1964, S. 1255, Anm. 3. Schröder behauptete gegenüber McGhee, er hätte in dem Interview nicht beabsichtigt, Adenauer zu attackieren. Die Zeitung habe aber sich nicht an die Absprachen gehalten und auch nicht zur Veröffentlichung bestimmte Äußerungen zitiert. Vgl. FRUS 1964-1968, XV, Dok. 72, S. 169.

292 So Adenauer vor dem CDU-Bundesvorstand am 27.11. 1964. Vgl. ProtoKolle DES CDU-BUNDESVORSTANDS, S. 766.

293 Vgl. u. a. die Ausführungen Adenauers vor dem CDU-Bundesvorstand am 28. 3. 1965, in: ebenda, S. 899 und S. 905.

294 Ebenda, S. 904.

295 Vgl. FRUS 1964-1968, XV, Dok. 72, S. 170.

296 Vgl. ebenda, S. 169.

297 Vgl. OsTerHeLD, Außenpolitik, S. 244.

298 Vgl. MENDE, Von Wende zu Wende, S. 200.

299 Vgl. Hildebrand, Von Erhard zur Großen Koalition, S. 102.

300 Hanrieder führt den überraschend deutlichen Wahlsieg indirekt auf den Streit um die Außenpolitik zurück. Da die CDU/CSU teilweise gegen die eigene Regierung opponierte, die SPD mit ihr aber in vielen außenpolitischen Fragen übereinstimmte, verloren die Parteien an Profil, wovon aber allein die Union profitierte. Vgl. HANRIEDER, Deutschland, S. 401.

301 Vgl. Mende, Von Wende zu Wende, S. 200; MORSEY, Heinrich Lübke, S. 462. 
der von Guttenberg bearbeitet worden war. Der CSU-Abgeordnete behauptete, "größtenteils hinter dem Rücken des Bundeskanzlers“ betreibe Schröder ,in entscheidenden Fragen eine den Auffassungen des Bundeskanzlers und den Grundlinien der CDU entgegengesetzte Politik “302. Solche Unterstellungen fielen im Bundespräsidialamt auf fruchtbaren Boden. Bereits Ende März 1965 hatte Lübke angedeutet, er werde Schröder, dem er immer noch seinen pragmatischen Standpunkt in der Berlin- und Deutschland-Frage vorwarf, nicht mehr ernennen ${ }^{303}$. Zudem war er mit dessen Nahost-Politik nicht einverstanden ${ }^{304}$. Auch fühlte er sich vom Auswärtigen Amt unzureichend über die außenpolitische Entwicklung unterrichtet ${ }^{305}$. Um etwaige verfassungsrechtliche Bedenken zu zerstreuen, führte Adenauer in der Presse aus, der Bundespräsident müsse das Recht haben, die Ernennung eines ihm nicht genehmen Bundesministers zu verweigern ${ }^{306}$.

Obwohl sich die Mehrheit der führenden Unionspolitiker auf einer Sitzung am 6. Oktober 1965 gegen Schröder aussprach, stellte sich Erhard weiterhin hinter seinen Außenminister. Osterhelds Behauptung, daß der Kanzler an Schröder festhielt, weil dieser einerseits loyal war und andererseits seine innenpolitischen Gegner bekämpfte, erscheint plausibel. Erhard konnte sich in der Debatte gegen die Kritiker Schröders durchsetzen, weil diese sich nicht auf einen Gegenkandidaten einigen konnten ${ }^{307}$. Wie schon bei der Regierungsbildung 1961 kam es jetzt erneut auf die Haltung des Bundespräsidenten an. Nochmals intrigierte Guttenberg gegen den Außenminister. Einen Tag vor der Besprechung beim Kanzler am 6. Oktober übergab er Lübke eine Denkschrift mit dem Titel „Gerhard Schröder oder die Sicherheit Deutschlands“. In dieser Aufzeichnung legte der Abgeordnete dar, Schröder müsse sein Amt nicht nur wegen seiner politischen Ansichten verlieren, sondern auch wegen seiner privaten Verfehlungen. Er habe nämlich ein Verhältnis mit einer an der Botschaft der Bundesrepublik in Paris beschäftigten Sekretärin $^{308}$. Lübke zögerte jedoch, Schröder die Ernennungsurkunde zu verweigern. Der Bundespräsident glaubte, diese Entscheidung nicht aufrechterhalten zu können. Andererseits trug er sich mit dem Gedanken, eine richterliche Untersuchung gegen Schröder einzuleiten. Der Präsident des Bundesverfassungsgerichts, Gebhard Müller, hielt ihn aber davon ab. Seiner Ansicht nach gab es dafür keine verfassungsrechtliche Grundlage ${ }^{309}$. Am 18. Oktober beschworen auch Gerstenmaier, Krone und Dufhues den Bundespräsidenten, keinen Verfassungsstreit zu riskieren ${ }^{310}$. Wie schon vier Jahre zuvor, gab Lübke auch diesmal klein

302 Zitiert nach ebenda, S. 422.

303 Vgl. OSTERHELD, Außenpolitik, S. 182.

304 Vgl. MORSEY, Heinrich Lübke, S. 422 f.

305 Vgl. BLANKENHORN, Verständnis, S. 488; MORSEY, Heinrich Lübke, S. 421 f.

306 Vgl. ebenda, S. 463.

307 Vgl. OSTERHELD, Außenpolitik, S. $247 \mathrm{f}$.

308 Vgl. MORSEY, Heinrich Lübke, S. 463. Zu dieser Affäre, über die das französische Satireblatt Canard Enchainé am 31. 10. 1962 und 9. 1. 1963 berichtete, vgl. HuYN, Die Sackgasse, S. 370-373; WIRZ, Karl Theodor von und zu Guttenberg und das Zustandekommen der Großen Koalition, S. 376-379.

309 Vgl. MORSEY, Heinrich Lübke, S. $463 \mathrm{f}$.

310 Vgl. OSTERHELD, Außenpolitik, S. 247; GerSTENMAIER, Streit, S. 529f. Zur Regierungsbildung 1965 vgl. auch: KOERFER, Schwierige Geburten, S. 183-189; HENTSCHEL, Lud- 
bei ${ }^{311}$. Vergeblich unternahm Adenauer am folgenden Tag nochmals einen Vorstoß, seinen früheren Minister bei der Stange zu halten. In eindringlichen Worten mahnte er den Bundespräsidenten, fest zu bleiben: „Die neue Ernennung Schröders zum Außenminister wird de Gaulle als einen Faustschlag empfinden. Allein mit Frankreich können wir eine Zukunft haben. Diese Aussichten nimmt uns die Ernennung Schröders. Ich flehe Sie an: Verweigern Sie die Ernennung Schröders. Sie haben das Recht dazu. Machen Sie davon Gebrauch!“312

In letzter Minute wurde noch ein weiterer Versuch unternommen, Schröders Ernennung zu verhindern. Ausgangspunkt der Intrige war der als Legationsrat im Auswärtigen Amt tätige Hans Graf Huyn. Dieser informierte am 21. Oktober Guttenberg, in seinem Ministerium werde heimlich ein Konsultationspakt mit Großbritannien vorbereitet. Sein Vorgesetzter, Ministerialdirigent Paul Frank, habe dies heute in einer internen Besprechung bekanntgegeben ${ }^{313}$. Guttenberg wandte sich nun seinerseits an Adenauer, der wiederum bei Westrick vorstellig wurde und schwere Vorwürfe gegen die Bundesregierung erhob ${ }^{314}$. Wegen derselben Angelegenheit war Westrick bereits von Osterheld angesprochen worden. Dieser bekam routinemäßig Kopien der Botschaftsberichte und hatte einem Drahtbericht von Blankenhorn, der seit Anfang Mai die Botschaft der Bundesrepublik in London leitete, entnommen, daß Gespräche über eine Intensivierung der deutsch-britischen Konsultationen im Gang waren ${ }^{315}$. In der Tat gab es seit dem erfolgreichen Deutschland-Besuch von Königin Elisabeth II. im Mai 1965 im Auswärtigen Amt Überlegungen, regelmäßig Gespräche mit London zu vereinbaren ${ }^{316}$. Man beabsichtigte damit, ein „Gegengewicht gegen die Bemühungen um eine französische Vormachtstellung in Europa“ zu schaffen ${ }^{317}$, dachte aber nicht

wig Erhard, S. 579-588; SCHOllwer, FDP im Wandel, S. 281-291; MENDE, Von Wende zu Wende, S. 200-203.

311 Vgl. MORSEY, Heinrich Lübke, S. 465.

312 Schreiben Adenauers an Lübke vom 19. 10. 1965. Zitiert nach SCHWARZ, Adenauer II, S. 913.

313 Vgl. GutTenberg, Fußnoten, S. 117 f.; HuYn, Die Sackgasse, S. 400-402; Frank, Entschlüsselte Botschaft, S. 120-122; sowie die Aufzeichnung des Staatssekretärs Carstens vom 18. 11. 1965, in: AAPD 1965, Dok. 421, S. 1755-1758.

314 Vgl. CARSTENS, Erinnerungen, S. 259. Schröder ordnete umgehend eine amtsinterne Untersuchung an, wer Guttenberg informiert hatte. Als einziger Teilnehmer der Besprechung bei Frank weigerte sich Graf Huyn, eine Erklärung zu unterschreiben, daß er keine Indiskretion begangen hätte. Aus diesem Grund sollte ihm die Führung seiner Dienstgeschäfte untersagt werden. Huyn kam jedoch dem Beschluß zuvor und suchte um die Entlassung aus dem Beamtendienst nach, der sofort stattgegeben wurde. Guttenberg besorgte ihm als Ersatz die Stelle eines Referenten bei der CSU-Landesgruppe im Bundestag. Vgl. die Aufzeichnung des Staatssekretärs Carstens vom 18.11. 1965, in: AAPD 1965, Dok. 421, S. 1755-1758; CARSTENS, Erinnerungen, S. 259f.; HuYN, Die Sackgasse, S. 404-428; WIRZ, Karl Theodor Freiherr von und zu Guttenberg und das Zustandekommen der Großen Koalition, S. 390-404.

315 Vgl. OSTERHELD, Außenpolitik, S. 251.

316 Vgl. die Aufzeichnung des Vortragenden Legationsrats I. Klasse von Plehwe vom 23.6. 1965, in: AAPD 1965, Dok. 260, S. 1083-1090.

317 BLANKENHORN, Verständnis, S. 475. 
an eine vertragliche Fixierung ${ }^{318}$. Huyns Behauptung war also aus der Luft gegriffen ${ }^{319}$. Carstens konnte dann auch gegenüber Westrick die Beschuldigungen sogleich entkräften. Zudem wies Schröder schriftlich nach, daß Erhard dem Vorhaben zugestimmt hatte 320 . Dennoch gab es zwischen Adenauer, Strauß, Barzel und anderen Unionspolitikern sowie dem Bundeskanzler erneut heftige Auseinandersetzungen um die Wiederberufung Schröders. Erhard ließ sich aber nicht mehr umstimmen ${ }^{321}$.

Wie in den folgenden beiden Kapiteln noch ausführlich geschildert wird, nahmen die Spannungen zwischen Bonn und Paris immer mehr zu, bis die Beziehungen schließlich wegen der französische NATO-Politik am Ende der Regierungszeit Erhards ihren Tiefpunkt erreichten: „In der deutsch-französischen Ehe war 1965 ein schlechtes Jahr. 1966 war noch schlimmer. Es hätte leicht das Jahr der Ehescheidung sein können“, urteilt François Seydoux über die Entwicklung der bilateralen Beziehungen in den letzten beiden Jahren der Kanzlerschaft Erhards ${ }^{322}$. Im Bundeskanzleramt sorgte man sich zunehmend über die FrankreichPolitik des Kanzlers. Neben Osterheld versuchte nun auch Westrick den Kanzler von seinem antifranzösischen Kurs abzubringen. Der Chef des Bundeskanzleramts war zunächst probritisch eingestellt gewesen, die schlechten Erfahrungen mit der Regierung Wilson hatten ihn jedoch eines Besseren belehrt. Mit Hilfe des Leiters des Kanzlerbüros, Karl Hohmann, gelang es Schröder jedoch, Erhard auf seiner Linie zu halten ${ }^{323}$. Dies führte zu Auseinandersetzungen zwischen Schröder und Westrick, der es dem Außenminister übelnahm, daß dieser größeren Einfluß auf den Kanzler hatte als er selbst ${ }^{324}$.

Erstaunlicherweise beschuldigte Erhard am Ende seiner Kanzlerschaft sogar Schröder, dieser habe sich zu wenig um ein besseres Verhältnis mit Frankreich bemüht. In der Fraktionssitzung am 4. Oktober 1966 griff er seinen Außenminister scharf an: „Herr Schröder, sagen Sie doch einmal ein nettes Wort an die Adresse Frankreichs. Ich weiß, daß es Ihnen schwerfällt, aber sagen Sie es doch bitte mal. Die Psychologie ist nun mal ein Stück Politik, ob Sie das wahrhaben wollen oder nicht, aber als Diplomat sollten Sie das doch wissen, daß die Psychologie entschei-

318 Vgl. die Aufzeichnung des Vortragenden Legationsrats I. Klasse von Plehwe vom 23.6. 1965, in: AAPD 1965, Dok. 260, S. 1083-1090.

319 Auch Klaus Hildebrand kommt zu dem Urteil, der Vorwurf des Legationsrats sei „abwegig" gewesen. Vgl. Hildebrand, Von Erhard zur Großen Koalition, S. 184.

320 Vgl. CARSTENS, Erinnerungen, S. 259; OSTERHELD, Außenpolitik, S. 252. Am 19. 11. 1965 verabredeten Schröder und sein britischer Amtskollege Stewart eine Intensivierung der Konsultationen. Es sollten jährlich Begegnungen der Regierungschefs sowie alle sechs Monate Treffen der Außenminister stattfinden. Vgl. das Gespräch des Bundesministers Schröder mit dem britischen Außenminister Stewart am 19.11. 1965 in London, in: AAPD 1965, Dok. 424, S. 1770-1772. Erhard lehnte aber eine formelle Absprache über die Häufigkeit der Treffen ab, da dies im Widerspruch zu seinen während der Affäre Huyn abgegebenen Erklärungen gestanden hätte. Vgl. die Aufzeichnung des Staatssekretärs Carstens vom 1. 12. 1965, PA/AA, B 150, Aktenkopien 1965.

$321 \mathrm{Vgl}$. OSTERHELD, Außenpolitik, S. $252 \mathrm{f}$.

322 SEYdoux, Meine zweite Mission, S. 77.

323 ZeITZEUGENBEFRAgung Osterheld.

324 Vgl. OSTERHELD, Außenpolitik, S. 149. 
dend die politischen Dinge beeinflußt." Er kritisierte ferner, daß Schröder de Gaulle nicht gedankt hatte, als dieser anläßlich seiner Reise in die UdSSR Ende Juni 1966 die westliche Deutschland-Politik verteidigt hatte. Erhard meinte, „darüber ein nettes Wort zu sagen, wäre nicht nur Psychologie, das wäre Politik gewesen" ${ }^{325}$. Doch die Vorwürfe des Kanzlers waren absolut unberechtigt. Bis zu diesem Zeitpunkt war Erhard in allen Frankreich betreffenden Fragen mit Schröder nicht nur stets einer Meinung gewesen, sondern hatte die französische Regierung sogar viel härter attackiert als der Außenminister, der trotz der zahllosen Meinungsverschiedenheiten sich immer wieder bemüht hatte, in Paris um Verständnis für die Politik der Bundesregierung zu werben.

\section{Ökonomische und politische Differenzen in der europapolitischen Zusammenarbeit der "Sechs"}

Im Bereich der Europa-Politik verfolgte Schröder das Ziel, die ökonomische Kooperation der sechs EWG-Mitgliedstaaten um eine enge politische Zusammenarbeit zu ergänzen sowie die europäischen Gemeinschaften um Großbritannien und andere Staaten der EFTA-Zone zu erweitern. Dabei sollte aber die Kontrolle über die Entwicklung in der Hand der Regierungen bleiben. Auf die bestehenden Institutionen der Gemeinschaften wollte er keine politischen Kompetenzen übertragen, weil er eine zu starke Einschränkung der politischen Handlungsfreiheit der Bundesrepublik sowie eine Lockerung der Zusammenarbeit mit den USA und Großbritannien befürchtete ${ }^{326}$. Wie er in den Jahren 1963/63 erfahren mußte, stand seinen europapolitischen Zielen jedoch Frankreich im Wege. Die französische Regierung blockierte in Brüssel die Aufnahme Londons und wandte sich gegen die Abtretung souveräner Rechte an supranationale Institutionen. Schröder hielt es für aussichtslos, daß Fortschritte in die von ihm gewünschte Richtung erreicht werden könnten, solange de Gaulle regierte. Wie er gegenüber Acheson im Oktober 1963 bekannte, hatte er auch wenig Hoffnung, daß sich nach einem Rücktritt de Gaulles die französische Europa-Politik neu orientieren würde, da der General die Politik Frankreichs zu stark geprägt habe. Schröder sagte zutreffend voraus, daß deshalb „auf lange Sicht ein integriertes Europa mit einer gemeinsamen Außen- und Verteidigungspolitik noch unmöglich bliebe“327. Im Augenblick sah er allein die Möglichkeit, "Europa in einer relativ lockeren Weise“ zusammenzubringen. Angesichts dieser wenig aussichtsreichen Perspektive bestand er darauf, daß im Falle der Aufnahme von Verhandlungen über die Schaffung einer Politischen Union auch die britische Regierung an den Beratungen der Sechs teilnehmen müßte ${ }^{328}$. Diese Gespräche sollten nach seinen Vorstellungen jedoch erst nach den Unterhauswahlen in Großbritannien im Herbst 1964 wieder

325 Protokoll der CDU/CSU-Fraktionssitzung am 4. 10. 1966, ACDP VIII-001-1011/1.

326 Vgl. vON DER GROEBEN, Aufbaujahre, S. 347.

327 Gespräch des Bundesministers Schröder mit dem ehemaligen amerikanischen Außenminister Acheson am 19. 10. 1963, in: AAPD 1963, Dok. 394, S. 1342.

328 Gespräch des Bundesministers Schröder mit dem britischen Außenminister Butler am 10. 12. 1963, in: ebenda, Dok. 461, S. 1605. 
aufgenommen werden ${ }^{329}$. Zunächst stand die Angleichung der Landwirtschaftspolitik in der EWG sowie die Festlegung einer gemeinsamen Verhandlungsposition für die Beratungen mit den USA in der Kennedy-Runde auf dem Programm. Sollte man sich über diese beiden Punkte einig werden, dann war in seinen Augen auch das politische Klima wieder günstig genug, um das Problem der Politischen Union erneut aufzugreifen ${ }^{330}$.

Wie bereits erwähnt, war das Ziel der Kennedy-Runde die Vereinbarung einer globalen Zollsenkung. Wegen der großen Exportabhängigkeit ihrer Wirtschaft war die Bundesrepublik sehr stark an einem Erfolg der Verhandlungen interessiert. Schröder legte aber nicht nur aus handelspolitischen Gründen großen Wert auf diese Gespräche. Er war davon überzeugt, daß ein erfolgreicher Verlauf der Kennedy-Runde die „atlantische Partnerschaft“ festigen würde ${ }^{331}$. Im Kreise der Sechs war jedoch umstritten, wie die Verhandlungen in der Kennedy-Runde durchgeführt werden sollten. Frankreich beabsichtigte, vor der Erörterung der Zollsenkungen die Zolldisparitäten der Teilnehmer zu beseitigen. Mit dieser Vorgehensweise war die Bundesregierung prinzipiell einverstanden, doch wollte sie nicht über die circa 1200 Posten im einzelnen verhandeln, sondern präferierte eine Globallösung 332. Während die Verhandlungen im Rahmen des GATT für die Bundesrepublik oberste Priorität hatten, wünschte Paris vor allem rasche Fortschritte bei der Entwicklung eines gemeinsamen Agrarmarkts der EWG. Die Franzosen forderten bis zum Jahresende 1963 drei für die Preise und Produktionsquoten für Rindfleisch, Reis sowie Milch und Molkereierzeugnisse verbindliche Marktordnungen zu beschließen. Außerdem drängte die französische Regierung auf eine Vereinbarung über die Finanzierung der gemeinsamen Agrarpolitik $^{333}$. Am 21. November 1963 konfrontierte de Gaulle den neuen Bundeskanzler Erhard mit der Drohung, ein gemeinsames Vorgehen der Sechs in der KennedyRunde wäre nur möglich, wenn die Marktordnungen fristgerecht bis zum Ende des Jahres verabschiedet würden. Erhard hielt jedoch ein Durchpeitschen der schwierigen Materie in den wenigen verbleibenden Wochen bis zum Jahreswechsel nicht für möglich 334 .

Am Rhein ließ man sich durch die Drohung de Gaulles nicht einschüchtern. Schröder verwies auf sein im Frühjahr 1963 in Brüssel angenommenes „Pro-

329 Vgl. die Gespräche des Bundesministers Schröder mit dem japanischen Außenminister Ohira am 7./8. 11. 1963 in Tokio, in: ebenda, Dok. 410, S. 1419; sowie das Gespräch mit den Europa-Abgeordneten Battista und Furler am 4.12. 1963, in: ebenda, Dok. 448, S 1540.

330 Vgl. das Gespräch des Bundesministers Schröder mit dem britischen Außenminister Butler am 10.12. 1963, in: ebenda, Dok. 461, S. 1605 f.; das Gespräch mit dem amerikanischen Botschafter McGhee am 22.10. 1963, in: ebenda, Dok. 397, S. 1370; sowie die deutsch-amerikanische Regierungsbesprechung am 28.12. 1963 in Stonewall, Texas, in: ebenda, Dok. 488, S. 1695.

331 Gespräch des Bundesministers Schröder mit dem britischen Außenminister Butler am 10. 12. 1963 , in: ebenda, Dok. 461, S. 1594.

332 Vgl. ebenda, S. 1595.

333 Vgl. ebenda, S. 1596-1598; sowie das Gespräch des Bundeskanzlers Erhard mit Staatspräsident de Gaulle am 21. 11. 1963 in Paris, in: ebenda, Dok. 421, S. 1457-1459.

334 Vgl. ebenda, S. 1455-64. 
gramm des synchronisierten Fortschritts“, demzufolge die Fragen, deren Regelung einzelnen Mitgliederstaaten besonders am Herzen lagen, möglichst gleichzeitig in Angriff genommen werden sollten, um eine einseitige Entwicklung der EWG zu vermeiden. Wie dargestellt, bezweckte er mit dem Programm, Fortschritte bei der Schaffung eines gemeinsamen Agrarmarkts von der Einigung auf eine gemeinsame Haltung der Sechs in den Beratungen des GATT abhängig zu machen ${ }^{335}$. Problematisch war jedoch, daß die französische Regierung ihre agrarpolitischen Forderungen bis zum Jahresende erfüllt haben wollte, die KennedyRunde aber erst im Mai 1964 die Arbeit aufnahm. Somit verlangte die Bundesrepublik von ihren europäischen Partnern, sich bereits fünf Monate vor dem eigentlichen Termin verbindlich festzulegen. Trotz der zeitlichen Diskrepanz hielt Schröder an dem Junktim fest. Für die Zustimmung zu den drei Marktordnungen wünsche man Garantien für die Kennedy-Runde, erläuterte er Mitte Dezember seinem italienischen Amtskollegen Saragat die Position der Bundesregierung: „Hier bestehe eine absolute Klammer [...]. Eine platonische Liebeserklärung reiche hier nicht aus." Die Bundesrepublik, so der Außenminister, werde die von de Gaulle gesetzte Frist nicht akzeptieren, da der 31. Dezember 1963 kein „vom Himmel eingesetztes Datum" sei. Sollte bis zu diesem Tag keine Verständigung erreicht werden, müßte man eben weiter verhandeln. Bonn werde sich jedenfalls von Paris „nicht [...] unter künstlichen Druck setzen“ lassen ${ }^{336}$. Doch auch der französische Staatspräsident blieb hart. Noch am 21. Dezember bestätigte er Botschafter Klaiber, daß er auf der Einhaltung der im Frühjahr vereinbarten Frist bestehe ${ }^{337}$. Zwei Tage später polemisierte der französische Landwirtschaftsminister Edgar Pisani, die Bundesregierung kenne wohl ihr eigenes Synchronisierungsprogramm nicht. Dort sei nämlich eindeutig festgehalten, daß die Marktordnungen bis zum 31. Dezember 1963 zu verabschieden seien ${ }^{338}$. An Heiligabend gab de Gaulle jedoch überraschend seine Bereitschaft bekannt, nicht auf der Einhaltung der Frist zu bestehen, falls in Brüssel eine grundsätzliche Einigung erreicht würde. Nur einen Tag später gelang es dem Ministerrat der EWG, die drei Marktordnungen zu verabschieden sowie Maßnahmen zu beschließen, die zu einem gemeinsamen Getreidepreis führen sollten. Auch in Bonn konnte man zufrieden sein, da gleichzeitig Richtlinien für das Verhalten der EWG in der Kennedy-Runde vereinbart wurden 339 .

Das Brüsseler Ergebnis wertete Schröder als Bestätigung für die Richtigkeit seiner Verhandlungstaktik. Nach seiner Einschätzung war es letztendlich die feste Haltung Bonns gewesen, die de Gaulle zum Nachgeben gebracht habe. Der General, so die Interpretation des Außenministers, habe erkannt, daß die Bundesregierung auch das Scheitern der Verhandlungen in Kauf genommen und sich

335 Vgl. das Gespräch des Bundesministers Schröder mit dem britischen Außenminister Butler am 10. 12. 1963, in: ebenda, Dok. 461, S. 1596.

336 Gespräch des Bundesministers Schröder mit dem italienischen Außenminister Saragat am 15. 12. 1963, in: ebenda, Dok. 472, S. 1637.

337 Vgl. die Aufzeichnung des Ministerialdirektors Jansen vom 23.12. 1963, in: ebenda, Dok. 482, S. $1667 \mathrm{f}$.

338 Vgl. DEI, Bd. 2, Dok. 339, S. 463.

339 Vgl. ebenda, S. 463-465. 
deshalb zu einer positiveren Einstellung gegenüber der Kennedy-Runde durchgerungen hätte ${ }^{340}$. Erhard meinte sogar, es sei nun ein günstiger Zeitpunkt gekommen, um das lange verschobene Treffen der Staats- bzw. Regierungschefs der Sechs abzuhalten. Aufgrund der Art und Weise, wie die Brüsseler Beschlüsse zustande gekommen waren, sah hingegen Schröder keinen Anlaß von seinem Standpunkt abzuweichen, die Frage der Politischen Union bis zu den britischen Unterhauswahlen ruhen zu lassen. Vielmehr hatten ihn die letzten Ereignisse in seiner Ansicht bestärkt, daß europapolitische Fortschritte nur über das Prinzip des Gebens und Nehmens zu erreichen waren. Er ließ deshalb im Auswärtigen Amt einen Stufenplan zur europäischen Einigung ausarbeiten, der sich in seinem Aufbau an dem erfolgreichen Programm des synchronisierten Fortschritts orientierte $^{341}$.

Auch wenn der Plan niemals in dieser Form den anderen Mitgliedern der Europäischen Gemeinschaften vorgelegt wurde, soll doch näher auf ihn eingegangen werden, da er die europapolitischen Visionen Schröders prägnant zum Ausdruck bringt. Wie das Memorandum des Auswärtigen Amts zeigt, favorisierte der Außenminister eine fünfstufige Entwicklung, die letzten Endes zu einem europäischen Bundesstaat führen sollte: Für die erste Stufe, die bis zum Jahr 1965 abgeschlossen sein sollte, war eine Angleichung der Energie-, Verkehrs-, Sozial- und der Steuerpolitik der Sechs, die Einigung auf einen gemeinsamen Getreidepreis sowie ein gemeinsames Handeln in der Kennedy-Runde vorgesehen. Ebenso war die Fusion der Exekutiven der drei europäischen Gemeinschaften sowie eine Erweiterung der Kompetenzen des Europäischen Parlaments auf den Weg zu bringen. Außerdem plante man die Einrichtung einer NATO-Studiengruppe, die sich mit den Problemen der europäischen Verteidigung befassen sollte. Erst nach der Umsetzung all dieser Punkte sollte die zweite Stufe in Angriff genommen werden, nämlich die Aushandlung eines Vertrages über die Schaffung einer Politischen Union, in deren Zuständigkeitsbereich die Außen-, Kultur- und eine gemeinsame Verteidigungspolitik im Rahmen der NATO fiel. Zu diesem Zeitpunkt war auch die Aufnahme der beitrittswilligen Länder der EFTA-Zone in die Gemeinschaften vorgesehen, ebenso wie der Abschluß von Assoziationsabkommen mit neutralen Staaten wie Österreich und der Schweiz. Ferner sollten Verhandlungen mit den Vereinigten Staaten und Kanada über die Bildung einer Atlantischen Partnerschaft für die Bereiche der Wirtschafts- und Verteidigungspolitik aufgenommen werden. In der dritten Stufe würde dann die Politische Union ihre Arbeit aufnehmen, die Direktwahl des Europäischen Parlaments eingeführt und der Gemeinsame Markt der EWG Wirklichkeit werden. Anschließend, in der vierten Stufe, wäre über die Schaffung eines europäischen Bundesstaates zu verhandeln, der eine Zentralregierung sowie ein parlamentarisches Zwei-Kammer-System haben sollte, wobei die erste Kammer vom Volk gewählt werden, die zweite sich hingegen in Anlehnung

$340 \mathrm{Vgl}$. die deutsch-amerikanische Regierungsbesprechung am 28.12. 1963 in Stonewall, Texas, in: AAPD 1963, Dok. 488, S. $1689 \mathrm{f}$.

341 Vgl. das Gespräch des Bundesministers Schröder mit dem britischen Außenminister Butler am 16.1. 1964 in London, in: AAPD 1964, Dok. 15, S. 81 f.; sowie MüllerROSCHACH, Die deutsche Europapolitik, S. 147. 
an den Bundesrat aus Vertretern der nationalen Regierungen zusammensetzen würde. Auf diese Organe sollten die Mitgliedstaaten ihre Kompetenzen für die Außen-, Verteidigungs-, Wirtschafts- und Kulturpolitik übertragen. Die fünfte Stufe war dann gleichbedeutend mit der Gründung dieser „Europäischen Politischen Gemeinschaft" ${ }^{342}$. Schröder strebte also nicht wie de Gaulle ein vereintes Europa an, das auf einer politischen Zusammenarbeit der einzelnen Regierungen basierte. Nicht ein Staatenbund, sondern der europäische Bundesstaat war sein Ziel. Wie man dem Europa-Plan des Auswärtigen Amts entnehmen konnte, waren aber auf dem Weg dorthin supranationale Institutionen nicht zwingend vorgeschrieben. Trotz der unterschiedlichen Zielvorstellungen wäre also eine Einigung mit Frankreich zumindest bis zu der dritten Stufe des Plans, dem Inkrafttreten der Politischen Union, durchaus möglich gewesen.

Wie Schröder richtig vermutet hatte, war der Zeitpunkt für eine europapolitische Initiative nicht günstig. Dies mußte auch Erhard zu seinem Leidwesen erfahren. Am 27. Januar 1964 lehnte der italienische Ministerpräsident Aldo Moro das vom Kanzler vorgeschlagene Treffen der Staats- und Regierungschefs mit dem Argument ab, der europapolitische Dissens zwischen den Sechs sei zu groß ${ }^{343}$. In der Tat wäre eine Konferenz, wie Schröder bereits Mitte Januar gegenüber dem britischen Außenminister Butler prognostizierte ${ }^{344}$, wohl angesichts der Meinungsverschiedenheiten zwischen Frankreich und den fünf anderen EWG-Staaten hinsichtlich der Frage der Erweiterung der Gemeinschaften sowie der Gestaltung des vereinten Europas ergebnislos geblieben. Dennoch griff der Kanzler nur knapp zwei Wochen später gegenüber de Gaulle den Gedanken einer Gipfelkonferenz erneut auf. Der französische Präsident erklärte sich bereit, an einem solchen Treffen teilzunehmen, falls der Vorsitzende des EWG-Ministerrats, der noch bis zum 1. Juli 1964 von Belgien gestellt wurde, zu einer solchen Konferenz einladen würde. ${ }^{345}$ Am 24. März wiederholte die italienische Regierung jedoch ihre Absage, da ein Treffen auf höchster Ebene nur zu einer „Demonstration der derzeitigen Uneinigkeit“ der Sechs werden könne ${ }^{346}$. Trotz des nochmaligen Fehlschlags gab der Bundeskanzler sein Vorhaben nicht auf, Fortschritte im Bereich der politischen Integration auf den Weg zu bringen. Anläßlich des deutsch-französischen Konsultationstreffens Anfang Juli 1964 in Bonn suchte er de Gaulle dafür zu gewinnen, den anderen EWG-Partnern Vorschläge zur Verbesserung der

342 Vgl. den Entwurf für einen Stufenplan zur europäischen Einigung vom 23. 1. 1964, in: AAPD 1964, Dok. 22, S. 118-120.

343 Vgl. das Gespräch des Bundeskanzlers Erhard mit Ministerpräsident Moro am 27. 1. 1964 in Rom, in: ebenda, Dok. 27, S. 137f. Erhard hatte bereits am 21. 11. 1963 eruiert, wie de Gaulle einem Treffen der Staats- bzw. Regierungschefs der Sechs gegenüberstand. Dieser hatte keine Einwände, meinte aber, Italien müßte ebenfalls einverstanden sein. Vgl. das Gespräch des Bundeskanzlers Erhard mit Staatspräsident de Gaulle am 21.11. 1963 in Paris, in: AAPD 1963, Dok. 421, S. 1460-1464.

344 Gespräch des Bundesministers Schröder mit dem britischen Außenminister Butler am 16. 1. 1964 in London, in: AAPD 1964, Dok. 15, S. 81.

345 Vgl. das Gespräch des Bundeskanzlers Erhard mit Staatspräsident de Gaulle am 15. 2. 1964 in Paris, in: ebenda, Dok. 49, S. 237.

346 Vgl. die Aufzeichnung des Ministerialdirektors Jansen vom 24. 3. 1964, PA/AA, Referat I A 2, Bd. 1150. 
politischen Zusammenarbeit zu unterbreiten. Der französische Präsident hielt Erhards Idee angesichts der unverändert ablehnenden Haltung der Benelux-Staaten und Italiens für sinnlos. Außerdem war der General nicht geneigt, einer gemeinsamen Europa-Initiative zuzustimmen, solange Bonn sich nicht zu einer von Washington unabhängigen Politik durchringen würde ${ }^{347}$. Im Grunde wußten aber auch die Verantwortlichen in Bonn, daß die Rahmenbedingungen für die Schaffung einer Politischen Union im Moment nicht gegeben waren. Wie in der Unterredung zwischen Schröder und Couve de Murville am 3. Juli 1964 deutlich wurde, drängte die Bundesregierung aus innenpolitischen Gründen aber auf eine europapolitische Initiative. Schröder verwies auf die öffentliche Meinung in der Bundesrepublik, die von Bonn mehr europapolitisches Engagement erwarte. Er bat deshalb den französischen Außenminister um Zustimmung zu einer gemeinsamen Erklärung zur Europa-Politik ${ }^{348}$. Daß es sich dabei lediglich um eine Willenserklärung handeln würde, war Schröder bewußt. Gleichwohl stellte er Couve de Murville die Frage, „ob man nicht doch eine Geste machen könnte, die wenigstens den Anschein erwecke, daß etwas geschehe "349. Da die französische Regierung Bonn in diesem Punkt nicht entgegenkommen wollte, versuchte Adenauer sein freundschaftliches Verhältnis zu de Gaulle in die Waagschale zu werfen. Noch am gleichen Tag trug er dem General die Idee vor, die im Elysée-Vertrag erwähnten interministeriellen Kommissionen, welche die deutsch-französischen Aktivitäten koordinieren sollten, zu einer gemeinsamen Sitzung einzuberufen, um in diesem Gremium einen neuen Plan zur Schaffung der Politischen Union auszuarbeiten. Der General war zunächst damit einverstanden ${ }^{350}$. Am folgenden Tag, als er sich mit dem Kanzler zu einem weiteren Vieraugengespräch traf, nahm er seine Zusage jedoch wieder zurück. Er versprach Erhard zwar, er werde über den Vorschlag des Altbundeskanzlers nachdenken, doch verkündete er im gleichen Atemzug, er sehe „aber im Augenblick kaum die Möglichkeit dazu, da Deutschland und Frankreich ja nicht entschlossen schienen, eine gemeinsame Politik zu betreiben "351. Auch Couve de Murville lehnte den Vorschlag Adenauers ab - er jedoch mit dem Argument, daß eine Initiative im Sande verlaufen würde, weil die anderen vier EWGStaaten „nichts tun wollten“352. Selbst Schröder gab zu, daß er keinen Durchbruch in der Frage der Politischen Union erwartet habe, da es eben eine Tatsache sei, daß man im Moment lediglich die Weiterentwicklung der EWG vorantreiben könne. Trotzdem sollten nach seiner Auffassung die beiden Regierungen im Kommuniqué verkünden, daß „man bereit sei, alle Möglichkeiten zu prüfen und zu

347 Vgl. das Gespräch des Bundeskanzlers Erhard mit Staatspräsident de Gaulle am 3.7. 1964, in: AAPD 1964, Dok. 180, S. 713-715.

348 Gespräch des Bundesministers Schröder mit dem französischen Außenminister Couve de Murville am 3. 7. 1964, in: ebenda, Dok. 182, S. 735-737.

349 Ebenda, S. 737.

350 Vgl. das Gespräch des ehemaligen Bundeskanzlers Adenauer mit Staatspräsident de Gaulle am 4. 7. 1964, in: ebenda, Dok. 184, S. 749-755.

351 Gespräch des Bundeskanzlers Erhard mit Staatspräsident de Gaulle am 4. 7. 1964, in: ebenda, Dok. 187, S. 771.

352 Gespräch des Bundesministers Schröder mit dem französischen Außenminister Couve de Murville am 4. 7. 1964, in: ebenda, Dok. 185, S. 756. 
studieren, die zu Fortschritten in der europäischen Einigung führen können“. Doch selbst diese butterweiche Aussage wies der französische Außenminister mit der Begründung zurück, er könne keine Formulierung billigen, die nicht der Realität entspreche 353 . Damit war auch der Gedanke einer gemeinsamen Tagung der interministeriellen Kommissionen Frankreichs und der Bundesrepublik vom Tisch. Das Auswärtige Amt hielt es nicht für angebracht, Adenauers Vorschlag weiter zu verfolgen, da laut Carstens die Einrichtung neuer Gremien nicht ausreichen würde, um die zwischen Bonn und Paris bestehenden europapolitischen Differenzen auszuräumen ${ }^{354}$.

Nach dem Konsultationstreffen war auch bei Erhard der europapolitische Elan zunächst einmal verflogen. Die Besprechungen hatten bei ihm die Überzeugung gefestigt, eine Fortsetzung des europäischen Einigungswerks sei mit de Gaulle nicht durchzuführen, da dieser nur zu dem Zweck, eine Hegemonie in Europa zu errichten, mit der Bundesrepublik zusammenarbeiten wolle. Eine Realisierung der europapolitischen Pläne des französischen Staatspräsidenten wäre jedoch gleichbedeutend mit dem Ende des Traums der Einigung Europas: „Seine Vorstellungen von Europa würden aber Europa zerstören und nicht bauen. "355 $\mathrm{De}$ Gaulle, so der Kanzler, verfolge die Absicht, „die Deutschen von Amerika zu lösen und in ihrer Politik unselbständig zu machen" 356 . Nach dem Willen des Generals sollte die Bundesrepublik eine von den USA unabhängige Politik betreiben. Für Erhard stand jedoch fest: „Deutschland wolle keine deutsche Hegemonie, wolle aber auch an keiner französischen Hegemonie sich beteiligen. "357 Daher stellte er vorläufig seine Pläne zurück, die politische Integration der Sechs voranzubringen.

Hingegen rief der frankreichfreundliche Flügel von CDU und CSU weiterhin nach mehr europapolitischer Aktivität der Bundesregierung. Am 8. Juli verlangten Adenauer und Strauß öffentlich eine neue Europa-Initiative. Sollte diese nicht von allen EWG-Staaten positiv aufgenommen werden, dann müßten die Bundesrepublik und Frankreich eben allein handeln, meinten die beiden Politiker ${ }^{358}$. Diese Forderung wiederholte Strauß zwei Tage später auf der Landesversammlung der CSU in München ${ }^{359}$. Erhard widersetzte sich jedoch entschieden dem Ansinnen der beiden Vorsitzenden von CDU und CSU. Zu Recht sah er hinter diesem Vorstoß ein durchsichtiges Manöver: Da auch Adenauer und Strauß wüßten, daß weder Italien noch die Niederlande im Moment auf eine europapolitische

353 Ebenda, S. $756 f$.

354 Vgl. die Aufzeichnung des Staatssekretärs Carstens vom 10.7. 1964, in: ebenda, Dok. 193, S. 808.

355 Gespräch des Bundeskanzlers Erhard mit dem amerikanischen Botschafter McGhee am 6. 7. 1964, in: ebenda, Dok. 189, S. 791.

356 Gespräch des Bundeskanzlers Erhard mit dem amerikanischen Botschafter McGhee am 13. 7. 1964 , in: ebenda, Dok. 195, S. 814.

357 Gespräch des Bundeskanzlers Erhard mit dem belgischen Außenminister Spaak am 14. 7. 1964, in: ebenda, Dok. 198, S. 832.

358 Vgl. den Artikel „Adenauer und Strauß drängen auf Vorschläge an Frankreich“, in: FRANKFURTER AlLgEMEINE ZEITUNG vom 9. 7. 1964, S. 1.

359 Für einen Auszug aus der Rede des CSU-Vorsitzenden Strauß am 10. 7. 1964 vgl. EUROPÄISCHE POLITISCHE EINIGUNG, S. $262 \mathrm{f}$. 
Initiative eingehen würden, gehe es ihnen in Wahrheit nur darum, eine deutschfranzösische Zweier-Union ins Leben zu rufen, klärte er am 12. Juli McGhee auf ${ }^{360}$. Schröder stellte sich ebenfalls gegen Adenauer und Strauß. Er meinte, der von den beiden Politikern gewünschte deutsch-französische Alleingang sei bereits 1962 in die Tat umgesetzt worden, als Frankreich und die Bundesrepublik vereinbart hätten, den Fouchet-Plan in bilateralem Rahmen durchzuführen. Der ElyséeVertrag vom 22. Januar 1963 sei nämlich das „verkleinerte Abbild“ des Plans. Das Ziel der Bundesregierung sollte es daher nicht sein, die Zusammenarbeit zwischen Bonn und Paris zu intensivieren, sondern vielmehr auf die anderen europäischen Staaten auszudehnen ${ }^{361}$. Ebenso wie der Kanzler sah er in dem Ruf der Gaullisten nach einer europapolitischen Initiative nur einen Vorwand, der es ihnen ermöglichen sollte, nach einem Scheitern der Initiative um so nachdrücklicher ein Zusammengehen mit Frankreich verlangen zu können ${ }^{362}$. Die deutschen Anhänger de Gaulles würden bei ihren Forderungen die Augen davor verschließen, „daß die Zusammenarbeit mit Frankreich praktisch schon den Punkt erreicht habe, der angesichts der konkreten politischen Schwierigkeiten überhaupt denkbar sei“, beklagte er sich am 14. Juli bei Spaak ${ }^{363}$. Außerdem stünde die französische Regierung der Politischen Union heute noch skeptischer gegenüber als vor zwei Jahren. Somit wären die Aussichten, die Sechs auf einen gemeinsamen Nenner zu bringen, noch geringer als im April 1962, als Holländer und Belgier den Fouchet-Plan ablehnten ${ }^{364}$. Aufgrund des innenpolitischen Drucks war Schröder aber zum Nachgeben gezwungen. Er mußte sich bereit erklären, einen neuen Plan zur Schaffung einer Politischen Union vorzulegen ${ }^{365}$. Eine entscheidende Anregung für die neue Initiative gab Paul-Henri Spaak. Der belgische Außenminister hatte die Idee, auf den Fouchet-Plan zurückzugreifen, diesen aber zunächst nur für einen Zeitraum von drei Jahren in Kraft treten zu lassen. In der Zwischenzeit sollte ein endgültiger Vertrag zwischen den Sechs ausgehandelt werden. Das große Plus dieses Vorschlags war zum einen die Möglichkeit einer sofortigen Realisierung der Politischen Union, da auf einen fertigen Entwurf aufgebaut werden konnte, zum anderen die risikolose Beteiligung aller Staaten, da der Versuch zeitlich begrenzt war. Schröder empfand den Gedanken einer Politischen Union auf Probe „faszinierend", weil auf diese Weise die Chance bestand, auch diejenigen Länder, die noch skeptisch waren, zu einer Teilnahme zu bewegen. Er schlug vor, ein Konzept auf

360 Vgl. das Gespräch des Bundeskanzlers Erhard mit dem amerikanischen Botschafter McGhee am 13. 7. 1964, in: AAPD 1964, Dok. 195, S. 814.

361 So Schröder am 13.11. 1964 im Bundestag. Vgl. BT STENOGRAPHISCHE BerichTE, Bd. 56, S. 7230-7232 (7230).

362 Vgl. das Gespräch des Bundesministers Schröder mit dem amerikanischen Botschafter McGhee am 14. 7. 1964, in: AAPD 1964, Dok. 196, S. 819 f.

363 Gespräch des Bundesministers Schröder mit dem belgischen Außenminister Spaak am 14. 7. 1964, in: ebenda, Dok. 197, S. 823.

$364 \mathrm{Vgl}$. ebenda, S. $825 \mathrm{f}$.

365 Vgl. das Gespräch des Bundesministers Schröder mit dem amerikanischen Botschafter McGhee am 14. 7. 1964, in: ebenda, Dok. 196, S. 819. 
der Basis von Spaaks Vorschlag bis zum Herbst 1964 auszuarbeiten und es dann den Sechs sowie der neuen britischen Regierung zu präsentieren ${ }^{366}$.

Nach den Unterhauswahlen in Großbritannien im Oktober 1964 waren die EWG-Mitgliedstaaten aber bereits wieder voll und ganz mit der Agrarpolitik beschäftigt. Im Mittelpunkt stand jetzt die Festlegung eines gemeinsamen Getreidepreises. Laut den Römischen Verträgen mußte ein einheitliches Preisniveau spätestens bis zur Einführung des Gemeinsamen Markts am 1. Januar 1970 erreicht werden. Am 5. November 1963 hatte der Vizepräsident der EWG-Kommission und frühere niederländische Landwirtschaftsminister Sicco Mansholt ein Konzept zur Harmonisierung der Getreidepreise bis zum 1. Juli 1967 vorgelegt. Mansholt hatte vorgeschlagen, die belgischen Getreidepreise als Standard zu nehmen, was zur Folge gehabt hätte, daß in Frankreich und den Niederlanden die Preise erhöht, in Italien, Luxemburg und der Bundesrepublik dagegen gesenkt worden wären ${ }^{367}$. Trotz der vorgesehenen Brüsseler Ausgleichszahlungen rechneten die Behörden bei einer Umsetzung des Plans mit einem Einnahmeverlust von bis zu 900 Millionen DM für die Landwirtschaft in der Bundesrepublik ${ }^{368}$. Auf der Tagung des EWG-Ministerrats am 1./2. Juni 1964 konnten sich die Sechs jedoch nicht zur Annahme des Mansholt-Planes durchringen. Die Entscheidung wurde daraufhin auf den 15 . Dezember vertagt ${ }^{369}$. Nachdem die französische Regierung zunächst den Eindruck erweckt hatte, als ob eine Lösung dieser Frage keine besondere Eile habe, drohte de Gaulle am 21. Oktober plötzlich mit dem Austritt aus der Gemeinschaft. Paris verlangte die Einhaltung der getroffenen Vereinbarung. Sollte, so der General, im Dezember keine Einigung in der Getreidepreisfrage erzielt werden, werde Frankreich die Mitarbeit in der EWG einstellen ${ }^{370}$. Im Namen der Bundesregierung unterstrich Carstens in Paris jedoch, eine Einigung noch in diesem Jahr sei unrealistisch. Dies wollte wiederum die französische Regierung nicht akzeptieren ${ }^{371}$. Couve de Murville entgegnete erzürnt, Fortschritte innerhalb der EWG seien offenbar "nur durch Krisen“ möglich. Sollte es keinen gemeinsamen Agrarmarkt geben, würde „die EWG keinen Fortgang nehmen“. Desgleichen kündigte er eine Blockade der Kennedy-Runde an. Nachdrücklich appellierte er an Bonn, die Getreidepreisfrage nicht zu verzögern, „sonst nehme diese Sache eine böse Wendung “" ${ }^{372}$.

Um de Gaulle zu besänftigen, beabsichtigte Erhard, eine verbindliche Zusage abzugeben, daß die Bundesregierung in jedem Fall bis zum 1. Juli 1967 einer Vereinbarung über eine Harmonisierung der Agrarpreise in der Gemeinschaft zu-

366 Vgl. das Gespräch des Bundesministers Schröder mit dem belgischen Außenminister Spaak am 14. 7. 1964, in: ebenda, Dok. 197, S. 827-829 (827).

367 Für den Wortlaut des Mansholt-Plans vgl. BULLETIN DER EWG 12/1963 (Sonderbeilage), S. 2-12.

$368 \mathrm{Vgl}$. AAPD 1965, S. 102, Anm. 4.

369 Vgl. BulLETIN DER EWG 8/1964, S. 45 und S. 66.

370 Vgl. den Artikel „de Gaulle droht mit dem Austritt aus der Gemeinschaft“, in: FranKFURTER ALLGEMEINE ZEITUNG vom 22. 10.1964, S. 1.

371 Vgl. das Gespräch des Staatssekretärs Carstens mit dem französischen Außenminister Couve de Murville am 24. 10. 1964 in Paris, in: AAPD 1964, Dok. 297, S. 1187-1193.

372 Ebenda, S. 1188. 
stimmen werde. Westrick sollte als Sonderbotschafter nach Paris entsandt werden und dem französischen Präsidenten diese Nachricht überbringen. In diesem $\mathrm{Zu}$ sammenhang sollte er auch das Problem der Beteiligung der Bundesrepublik an der multilateralen Atomflotte ansprechen ${ }^{373}$. Dieser Plan fand jedoch Schröders Mißbilligung. Zwar begrüßte er die Grundsatzentscheidung des Kanzlers, da diese zur Entspannung des bilateralen Verhältnisses beitragen würde, doch war er dagegen, den Chef des Bundeskanzleramts auf eine Sondermission nach Paris zu schicken. De Gaulle sollte nicht annehmen, die Bundesregierung lasse sich von seinen Drohungen beeindrucken. Ebenso riet er explizit davon ab, die MLF-Frage in die Agrarproblematik einzubeziehen ${ }^{374}$. Vor dem Bundestag stellte der Außenminister am 13. November klar, Bonn werde sich von Paris nicht einschüchtern lassen. Einer Einigung in der Getreidepreisfrage werde die Bundesregierung nicht auf Biegen oder Brechen zustimmen: „Wir haben uns im Frühjahr verpflichtet, bis zum 15. Dezember etwas zu erklären. Wir haben uns nicht verpflichtet, etwas Bestimmtes zu erklären. " ${ }^{775}$ Schröder wurde sich allerdings sehr schnell gewahr, daß die Bundesrepublik einen derart harten Kurs nicht würde durchhalten können. Am 19. November legte er dem Kanzler dar, falls Bonn sich weiterhin weigere, die Getreidepreisfrage zu behandeln, werde die französische Regierung „jede Gelegenheit wahrnehmen, die Kennedy-Runde zu behindern oder zu blockieren“. Außerdem sagte er voraus, Paris werde auch der neuen europapolitischen Initiative der Bundesregierung Steine in den Weg legen ${ }^{376}$. Inzwischen war Bonn nämlich mit dem zwischen Spaak und Schröder besprochenen Konzept zur Gründung einer Politischen Union an die Öffentlichkeit getreten. Der am 13. November 1964 publizierte Plan sah die Einrichtung eines Beratenden Ausschusses von Regierungsvertretern der EWG-Staaten vor, dem es oblag, binnen drei Jahren einen Vertrag über die Schaffung der Politischen Union auszuarbeiten. Wie schon im Fouchet-Plan vorgesehen, sollten aber bereits während dieses Zeitraumes regelmäßige Treffen der Staats- bzw. Regierungschefs, sowie der Außen-, Verteidigungs-, Kultus- und Erziehungsminister stattfinden ${ }^{377}$.

Als Ausweg aus der Krise empfahl Schröder dem Kanzler, den Franzosen Gespräche über ein Verhandlungspaket anzubieten. Nach den Vorstellungen des Außenministers sollte die Bundesrepublik sich bereit erklären, den Mansholt-Plan zu akzeptieren, und dafür verbindliche Zusagen für die Kennedy-Runde verlangen. Im einzelnen dachte Schröder an eine Vereinbarung der Sechs, als gemeinsames Verhandlungsziel für die Kennedy-Runde eine generelle Zollsenkung um 50\% festzulegen und den Wegfall aller Zoll- und Steuerschranken im Binnenhandel der

373 Vgl. die Aufzeichnung des Staatssekretärs Carstens vom 30.10. 1964, in: ebenda, Dok. 301, S. 1199.

374 Vgl. ebenda; BT StenOgRaphische Berichte, Bd. 56, S. 7238, sowie das Interview Schröders mit der Allgemeinen Zeitung, Mainz, am 8.11. 1964, in: AAPD 1964, S. 1255, Anm. 3 (Auszug).

375 BT STENOGRAPHISCHE BERICHTE, Bd. 56, S. $7237 \mathrm{f}$.

376 Schreiben des Bundesministers Schröder an Bundeskanzler Erhard vom 19.11. 1964, in: AAPD 1964, Dok. 347, S. 1359.

377 Für den Wortlaut der Europa-Initiative der Bundesregierung vom 13.11. 1964 vgl. DER AufBAu EuROPAS, S. 387-394. 
Gemeinschaft zu beschließen. Schröder machte Erhard darauf aufmerksam, daß die Bundesregierung mit der Einwilligung in einen gemeinsamen Agrarmarkt den "letzten großen Trumpf" weggeben würde, den sie in der Europa-Politik noch ausspielen könnte. Infolgedessen müßte die Lösung der Getreidepreisfrage mit einem Junktim verbunden werden, wenn Bonn seine Interessen wahren wolle ${ }^{378}$. Der Kanzler scheute aber davor zurück, in Frontstellung gegen Paris zu gehen. Er wollte sich später nicht vorwerfen lassen, er habe Fortschritte bei der Einigung Europas blockiert ${ }^{379}$. Aber auch aus innenpolitischen Gründen wollte der Kanzler nicht den Konflikt mit de Gaulle schüren. Um „den Gaullisten in Deutschland nicht den Eindruck zu vermitteln, man sei gegen Frankreich eingestellt", entschloß er sich, Paris entgegenzukommen 380 . Am 24. November 1964 entschied der Kanzler im Kabinett, die Bundesrepublik werde den Mansholt-Plan akzeptieren ${ }^{381}$. Es war, wie Erhard den Bundestagsabgeordneten von CDU und CSU einige Wochen später erläuterte, eine rein „politische Entscheidung “382, da die Bundesregierung gezwungen war, die Einnahmeverluste der Bauern durch Bundesmittel auszugleichen ${ }^{383}$. Durch den Beschluß des Kabinetts wurde der Weg für eine Einigung der Sechs frei. Am 15. Dezember kam der EWG-Ministerrat ohne längere Debatten überein, bis zum 1. Juli 1967 ein einheitliches Preisniveau auf der Grundlage der Vorschläge Mansholts einzuführen ${ }^{384}$.

Nachdem dieses Problem gelöst war, wollte sich Schröder wieder der Frage der Politischen Union zuwenden ${ }^{385}$. Wie schon im Jahr zuvor hegte auch Erhard wieder die Hoffnung, die Einigung in Brüssel könnte als Impuls für Fortschritte bei der politischen Integration der Sechs genutzt werden. Bei den deutsch-französischen Konsultationsgesprächen am 19./20. Januar 1965 auf Schloß Rambouillet rief er dazu auf, neue Anstrengungen zur Verstärkung der politischen Zusammenarbeit zwischen den Sechs zu unternehmen. De Gaulle und er vereinbarten, im Kreis der Sechs ein Treffen der Außenminister der EWG-Staaten im Mai 1965 vorzuschlagen, um dort eine Konferenz der Staats- bzw. Regierungschefs vorzubereiten, die zwei Monate später stattfinden und den „Anfang einer organisierten Zusammenarbeit" in die Wege leiten sollte ${ }^{386}$. Der französische Staatspräsident er-

378 Schreiben des Bundesministers Schröder an Bundeskanzler Erhard vom 19. 11. 1964, in: AAPD 1964, Dok. 347, S. 1359-1362 (1361)

379 Vgl. die Ausführungen Erhards vor dem CDU-Bundesvorstand am 27. 11. 1964, in: ProTOKOLLE DES CDU-BUNDESVORSTANDS, S. 740.

380 Ausführungen des Bundeskanzlers Erhard gegenüber dem amerikanischen Botschafter McGhee am 11. 12. 1964, in: AAPD 1964, Dok. 380, S. 1490.

381 Vgl. den Drahterlaß des Staatssekretärs Lahr an Bundesminister Schröder, z.Z. Washington, vom 25. 11. 1964, in: ebenda, Dok. 358, S. 1394-1396.

382 Protokoll der CDU/CSU-Fraktionssitzung am 26.1. 1965, ACDP VIII-001-1010/1.

383 Vgl. den Drahterlaß des Staatssekretärs Lahr an Bundesminister Schröder, z.Z. Washington, vom 25. 11. 1964, in: AAPD 1964, Dok. 358, S. 1394-1396.

384 Vgl. ADG 1964, S. 11589-11591.

385 Vgl. das Gespräch des Bundesministers Schröder mit dem japanischen Botschafter Narita am 8. 1. 1965, in: AAPD 1965, Dok. 5, S. 30.

386 Vgl. das Gespräch des Bundeskanzlers Erhard mit Staatspräsident de Gaulle am 19.1. 1965 in Rambouillet, in: ebenda, Dok. 22, S. 104-109 (107); sowie das Gespräch am 20. 1. 1965, in: ebenda, Dok. 27, S. 152. 
klärte sich damit einverstanden, sofern die EWG ihren Zeitplan weiterhin einhalten und bis zum Juni die noch ungelösten Agrarfragen einvernehmlich regeln würde. Dabei handelte es sich um die Verabschiedung mehrerer Marktordnungen sowie die Festlegung einer Agrarfinanzordnung 387 . Nach seiner Rückkehr aus Frankreich sprach der Kanzler vor der CDU/CSU-Bundestagsfraktion euphorisch von einem „Durchbruch", den er in Rambouillet erreicht habe. Bonn und Paris seien nunmehr „auf einen gemeinsamen Weg gekommen “ ${ }^{388}$. Schröder hingegen teilte den Optimismus des Kanzlers nicht. Selbst wenn eine Gipfelkonferenz tatsächlich zustande kommen sollte, gestand er dem früheren britischen Commonwealth-Minister Duncan Sandys, sei es ausgeschlossen, daß dort konkrete Schritte hinsichtlich der politischen Integration der Gemeinschaft vereinbart werden könnten, da die europapolitischen Ziele de Gaulles unvereinbar mit den Vorstellungen der anderen Partner seien. Aufgrund der innenpolitischen Situation sei die Bundesregierung jedoch zu einem starken europapolitischen Engagement gezwungen. Erläuternd fügte er hinzu, daß die CDU von der Bundesregierung Fortschritte bei der politischen Einigung Europas fordere. Im Hinblick auf die bevorstehende Bundestagswahl, so der Außenminister, könne man sich einen innerparteilichen Streit nicht leisten ${ }^{389}$. Seine Skepsis äußerte er aber nicht öffentlich, wohl um nicht den Eindruck zu erwecken, er versuche eine europapolitische Einigung mit Frankreich zu verhindern. Adenauer machte bereits wieder Stimmung gegen ihn. Er warf Schröder vor, das von Erhard und de Gaulle initiierte Gipfeltreffen der Sechs werde von ihm „systematisch kaputtgemacht“390. Wie stark der Druck auf den Außenminister war, zeigt sich auch daran, daß er die Forderung nach einer Aufnahme Großbritanniens in die EWG, die er seit de Gaulles Veto vom Januar 1963 bei nahezu jeder Gelegenheit bekräftigt hatte, vorläufig mit keiner Silbe mehr erwähnte ${ }^{391}$. Weil es für einen harten Kurs gegen Frankreich in den Reihen von CDU und CSU keine Mehrheit gab, mußte sich Schröder in europapolitischen Fragen vorerst kompromißbereit zeigen.

Zu Beginn des Frühjahrs 1965 deutete vieles darauf hin, daß nach über vier Jahren wieder ein Gipfeltreffen der Sechs stattfinden könnte. Am 11. März 1965 lud der italienische Außenminister Fanfani seine Amtskollegen für den 10. Mai nach Venedig ein, um dort die Weichen für eine Konferenz der Staats- bzw. Regierungschefs zu stellen ${ }^{392}$. Vollkommen unvermittelt verlangte de Gaulle aber nun eine feste Tagesordnung für das vorbereitende Treffen der Außenminister, andernfalls, so drohte er, werde Couve de Murville nicht an der Konferenz teilnehmen. Der fran-

387 Vgl. die Gespräche des Bundeskanzlers Erhard mit Staatspräsident de Gaulle am 19. und 20. 1. 1965 in Rambouillet, in: ebenda, Dok. 22, S. 104, bzw. Dok. 27, S. 152.

388 Protokoll der CDU/CSU-Fraktionssitzung am 26. 1. 1965, ACDP VIII-001-1010/1.

$389 \mathrm{Vgl}$. das Gespräch des Bundesministers Schröder mit dem britischen Abgeordneten Sandys am 12.3. 1965, in: AAPD 1965, Dok. 126, S. 507-512.

390 So Adenauer vor dem CDU-Bundesvorstand am 28. 3. 1965, in: ProTOKOLLE DES CDUBUNDESVORSTANDS, S. 898.

391 Vgl. dazu z. B. das Gespräch des Bundesministers Schröder mit dem britischen Abgeordneten Sandys am 12.3.1965, in: AAPD 1965, Dok. 126, S. 507-512.

392 Für den Wortlaut des Schreibens Fanfanis vom 11.3. 1965 vgl. PA/AA, Referat I A 1, Bd. 522. 
zösische Staatspräsident bezweifelte lautstark, daß alle Teilnehmer ein wirkliches Interesse an einem erfolgreichen Treffen hätten. Dem niederländischen Außenminister Luns unterstellte er explizit, er würde mit der Absicht zu der Konferenz reisen, um sie „zu sabotieren“ ${ }^{393}$. Es müßte deshalb auf der Tagesordnung festgehalten werden, daß die sechs Außenminister in Venedig die Absicht verfolgten, eine enge Zusammenarbeit im Bereich der Außen-, Wirtschafts-, Verteidigungs- und Kulturpolitik zu vereinbaren und über die dafür geeignete Organisationsform diskutieren wollten ${ }^{394}$. Wie Botschafter Klaiber aus dem Quai d'Orsay erfuhr, war das Verhalten des französischen Staatspräsidenten von der Erkenntnis bestimmt, daß sein Konzept eines europäischen Europas in der Gemeinschaft keine Unterstützung fand ${ }^{395}$. De Gaulle wollte offensichtlich vermeiden, daß die politische Isolierung Frankreichs im Kreise der Sechs offenkundig würde. Er zog es aus diesem Grund vor, lieber das Treffen platzen zu lassen. Angesichts dieses Hintergrunds war auch einem Vermittlungsversuch Schröders bei Couve de Murville in letzter Minute kein Erfolg beschieden ${ }^{396}$.

Erhard fühlte sich von de Gaulle hintergangen. Er hatte fest darauf gesetzt, daß dieser die in Rambouillet getroffene Absprache einhalten würde. Andererseits profitierte der Kanzler aber auch vom Verhalten des Generals. Wie er Rusk am 4. Juni mitteilte, hielten sich die Gaullisten seit der Absage der Außenministerkonferenz zurück, da die Verantwortung für das Scheitern der europapolitischen Initiative diesmal eindeutig auf der französischen Seite lag. Fälschlicherweise nahm der Kanzler aber an, de Gaulle würde sich künftig konzilianter verhalten, weil ihn die harte Kritik an seiner Vorgehensweise zu der Einsicht führen müßte, $\mathrm{da}$ er „den Bogen in den letzten Monaten etwas überspannt“ habe ${ }^{397}$. Doch davon war im Handeln des französischen Staatspräsidenten nichts zu bemerken. Nur wenige Wochen später stürzte er die EWG in die schwerste Krise ihrer Geschichte.

\section{De Gaulles „Politik des leeren Stubls“}

Gemäß dem Beschluß des EWG-Ministerrats vom 14. Januar 1962 sollte bis zum 30. Juni 1965 eine Übereinkunft über die Finanzierung des gemeinsamen Agrarmarktes getroffen werden. Am 31. März 1965 legte die EWG-Kommission den Mitgliedstaaten ein Verhandlungspapier vor, das neben einem Stufenplan zur Agrarfinanzierung auch Vorschläge für eine Erweiterung der Kompetenzen des Europäischen Parlaments enthielt. Ferner sollte die Gemeinschaft künftig auch

393 Drahtbericht des Botschafters Klaiber, Paris, an das Auswärtige Amt vom 30. 3. 1965, in: AAPD 1965, Dok. 156, S. 638.

394 Vgl. die Drahtberichte des Botschafters Klaiber, Paris, an das Auswärtige Amt vom 30. 3. 1965, in: ebenda, Dok. 156, S. 636-638, bzw. Dok. 157, S. 639-642.

395 Vgl. den Drahtbericht des Botschafters Klaiber, Paris, an das Auswärtige Amt vom 31. 3. 1965, in: ebenda, Dok. 158, S. 642-644.

396 Vgl. das Gespräch des Bundesministers Schröder mit dem französischen Außenminister Couve de Murville am 24. 5. 1965, in: ebenda, Dok. 217, S. 865-867.

397 Gespräch des Bundeskanzlers Erhard mit dem amerikanischen Außenminister Rusk in Washington am 4. 6. 1965, in: ebenda, Dok. 253, S. 959. 
über eigene Einnahmen verfügen ${ }^{398}$. Noch unmittelbar vor der entscheidenden Sitzung des Ministerrats am 28. Juni 1965 gab es zwischen Frankreich und der Bundesrepublik erhebliche Differenzen über die praktische Ausgestaltung der Agrarpakets. Zwar hatte man sich bei den gemeinsamen Konsultationen am 11./ 12. Juni in Bonn darauf geeinigt, daß die Bundesrepublik einen Anteil von $31 \%$ am europäischen Agrarfonds übernehmen würde, doch war unter anderem noch die Laufzeit der Finanzordnung umstritten. Paris wünschte eine Regelung, die bis zum Beginn des Gemeinsamen Markts am 1. Januar 1970 Gültigkeit haben sollte. Die Bundesregierung war dagegen der Ansicht, daß eine Einigung auf eine dauerhafte Lösung in den wenigen verbleibenden Tagen bis zum 30. Juni 1965 nicht möglich sei. Falls die französische Regierung auf diesem Termin bestünde, war Bonn in Anbetracht der hohen Kosten, die die Finanzordnung der Bundesrepublik aufbürden würde, lediglich bereit, eine einjährige Übergangslösung zu akzeptieren ${ }^{399}$. Frankreich erklärte sich schließlich einverstanden, auf die Vorstellungen Bonns einzugehen, doch aufgrund mangelnder Koordination auf deutscher Seite stellte die Bundesregierung plötzlich Zusatzforderungen, die den Kompromiß zunichte machten ${ }^{400}$. De Gaulle war über die Haltung der Bundesregierung derart verärgert, daß er am Ende der Konsultationsbesprechungen alle getroffenen Absprachen, wie eine erneute Initiative zur Einberufung einer Konferenz der Staatsund Regierungschefs der Sechs, widerrief ${ }^{401}$.

Die Tagung des EWG-Ministerrats am 28. Juni 1965 begann daher unter denkbar schlechten Vorzeichen. Die französische Regierung bestand auf der sofortigen Verabschiedung einer Agrarfinanzordnung, die bis zum Ende der Übergangszeit, also bis zum 1. Januar 1970, in Kraft bleiben sollte. Da sich dies primär zugunsten Frankreichs ausgewirkt hätte - Paris hatte nach der bisherigen Regelung 1963/64 nur 25,6\% in den Europäischen Ausrichtungs- und Garantiefonds für die Landwirtschaft eingezahlt, aber $85,3 \%$ der Zuwendungen erhalten ${ }^{402}$ - waren die anderen fünf Staaten nicht gewillt, einem langfristigen Abkommen zuzustimmen ${ }^{403}$. Schröder ließ durch Staatssekretär Lahr Couve de Murville, der als Tagungspräsident die Sitzung leitete, die Bitte überbringen, die Angelegenheit zu vertagen. Doch das Ersuchen stieß auf „eisige Ablehnung “404. Der französische Außenminister hielt angesichts des unüberbrückbar erscheinenden Dissenses über die Laufzeit der Finanzordnung eine Einigung für ausgeschlossen und erklärte eigenmächtig die Verhandlungen für gescheitert ${ }^{405}$. Die Gemeinschaft erlitt dadurch

398 Für den Wortlaut der Vorschläge der EWG-Kommission vom 31. 3. 1965 vgl. EuROPAARCHIV 1965, D 404-417.

399 Vgl. die Aufzeichnung des Staatssekretärs Lahr vom 28. 7. 1965, PA/AA, B 150, Aktenkopien 1965. Für einen Auszug vgl. AAPD 1965, S. 1041, Anm. 3. Vgl. ferner HENTSCHEL, Ludwig Erhard, S. 568 f.

400 Vgl. OsterhelD, Außenpolitik, S. $206 \mathrm{f}$.

$401 \mathrm{Vgl}$. die Ausführungen des französischen Außenministers Couve de Murville und des Staatspräsidenten de Gaulle am 12. 6. 1965, in: AAPD 1965, Dok. 248, S. 1043.

402 Vgl. ebenda, S. 1101, Anm. 5.

403 Vgl. die Aufzeichnung des Staatssekretärs Lahr vom 3. 7. 1965, in: ebenda, Dok. 265, S. 1101 .

404 LAHR, Zeuge, S. 426.

405 Vgl. ebenda; sowie Europa-ArCHIV 1965, D $402 \mathrm{f}$. 
den „schwersten Rückschlag“ seit der Ablehnung des Fouchet-Plans am 17. April $1962^{406}$.

Schröder empfand das französische Verhalten als vollkommen unverständlich. Er war davon überzeugt, daß man im Falle einer Vertagung binnen 10 bis 14 Tagen eine für alle zufriedenstellende Lösung gefunden hätte, da sich bereits am Morgen des 1. Juli, als Couve de Murville die Sitzung platzen ließ, ein Erfolg der Verhandlungen abgezeichnet habe ${ }^{407}$. Auch jetzt hielt er einen Kompromiß immer noch für erreichbar ${ }^{408}$. Hingegen beurteilte die französische Regierung die Situation um einiges ernster. Couve de Murville warf Bonn vor, nichts unternommen zu haben, um den Bruch zu vermeiden 409 . Am 6. Juli 1965 zog Frankreich den Leiter seiner EWG-Vertretung aus Brüssel ab ${ }^{410}$. Z wei Tage später empfing Schröder den französischen Botschafter Seydoux. Dieser richtete dem Minister aus, in Paris sei man überaus enttäuscht, daß die Bundesregierung Frankreich bei den Verhandlungen keinerlei Unterstützung habe zukommen lassen. Die französische Regierung machte ihren europäischen Partnern den Vorwurf, sie hätten die Anfang 1962 eingegangene Selbstverpflichtung nicht eingehalten, die Agrarfinanzordnung bis zum Juli 1965 zu verabschieden. Nach französischer Auffassung war der Hauptverantwortliche für das Scheitern der Konferenz allerdings die Kommission der Gemeinschaft. Sie habe in ihrem Memorandum vom 31. März den Mitgliedstaaten Vorschläge unterbreitet, die ihr nicht zustünden, und dieses noch vor der Übermittlung an die sechs Regierungen publiziert. Die EWG-Kommission habe damit ihre Kompetenzen eindeutig überschritten ${ }^{411}$. Dadurch sei eine derart schwerwiegende "Vertrauenskrise" heraufbeschworen worden, daß nun nach Auffassung seiner Regierung „das Schicksal des Gemeinsamen Marktes selbst auf dem Spiele stünde“, erklärte Seydoux ${ }^{412}$. Um Frankreich entgegenzukommen, war Bonn inzwischen willens, eine Agrarfinanzordnung für den gesamten Zeitraum bis zum Ende der Übergangszeit abzuschließen, sofern eine Klausel eingefügt würde, derzufolge eine Revision der Vereinbarung nach zwei Jahren möglich sei. Im Gegenzug verlangte Bonn die Einführung einer Zollunion und die Abschaffung der Steuergrenzen zwischen den Sechs, die Festlegung einer gemeinsamen Außenhandelspolitik, sowie eine Ausweitung der Kompetenzen des Europäischen Parlaments: „Deutschland wolle nicht nur eine landwirtschaftliche Union, sondern eine gleichmäßige Entwicklung auf allen Gebieten“, bekräftigte Schröder die Position der Bundesregierung ${ }^{413}$. Seydoux vertraute dem Außenmi-

406 OSTERHELD, Außenpolitik, S. 209.

407 Vgl. das Gespräch des Bundesministers Schröder mit dem französischen Botschafter Seydoux am 3. 7. 1965, in: AAPD 1965, Dok. 266, S. 1109.

408 Vgl. den Artikel „Bonn fühlt in Paris vor“, in: FrANKFURTER Allgemeine Zeitung vom 5. 7. 1964, S. 4.

409 Vgl. Couve de Murville, Außenpolitik, S. 217.

410 Vgl. OSTERHELD, Außenpolitik, S. 210.

411 Vgl. das Gespräch des Bundesministers Schröder mit dem französischen Botschafter Seydoux am 8. 7. 1965, in: AAPD 1965, Dok. 270, S. 1130-1137.

412 Ebenda, S. 1132.

413 Gespräch des Bundesministers Schröder mit dem amerikanischen Botschafter McGhee am 9. 7. 1965, in: ebenda, Dok. 272, S. 1145. Vgl. auch die Rede Schröders vor dem Evangelischen Arbeitskreis im Juli 1965 in Lüdenscheid, in: BULLETIN 1965, S. 1020. 
nister jedoch an, derartige Bemühungen würden vergeblich bleiben, da Paris im Augenblick nicht an einem Arrangement interessiert sei ${ }^{414}$. De Gaulle war also nicht $\mathrm{zu}$ einem Kompromiß bereit. Seine Unterredung mit dem französischen Botschafter brachte Schröder zu der Erkenntnis, daß der General nicht nur eine Regelung des Agrarmarktes in seinem Sinn durchsetzen wollte, sondern nebenbei auch noch die Stellung der EWG-Kommission zu untergraben suchte. Dennoch setzte er darauf, daß die französische Regierung innerhalb der nächsten drei bis vier Monate klein beigeben würde 415 .

Am 22. Juli 1965 präsentierte die Kommission den Sechs ihre Vorstellungen zur Überwindung der Krise. Im Gegensatz zu den Vorschlägen vom März war nun nicht länger ein vorzeitiges Inkrafttreten des gemeinsamen Agrarmarkts zum 1. Juli 1967 vorgesehen. Bis zum Ende der Übergangszeit am 1. Januar 1970 sollte eine Übergangsregelung gelten. Die Kommission bestand auch nicht länger auf eigenen Haushaltsmitteln für die Gemeinschaft sowie einer Erweiterung der Befugnisse des Europäischen Parlaments ${ }^{416}$. Die französische Regierung war jedoch nicht einmal zu einer Diskussion über den Kompromißvorschlag bereit. De Gaulle entschloß sich zu einer „Politik des leeren Stuhls“ und ließ durch Ministerpräsident Pompidou bekanntgeben, daß Frankreich an der für den 26./27. Juli 1965 anberaumten Tagung des Ministerrats der EWG nicht teilnehmen werde ${ }^{417}$. Die anderen Mitgliedstaaten fühlten sich von der französischen Entscheidung vor den Kopf gestoßen. Der belgische Außenminister Spaak kam am 26. Juli nach Bonn und äußerte sich empört über das Verhalten de Gaulles. Der deutsch-französische Freundschaftsvertrag sei „ein großer Fehler“ gewesen, erklärte er. Obwohl Schröder stets hervorgehoben hatte, daß er den Elysée-Vertrag mitunterzeichnet hatte, meinte er jetzt, jeder Vorwurf sei „an den Urheber des deutschfranzösischen Vertrages" - also an Adenauer - zu richten ${ }^{418}$. Ebenso wie sein Amtskollege befürchtete auch Spaak, daß es dem französischen Staatspräsidenten vor allem darauf ankam, die Rechte der EWG-Kommission zu beschneiden. De Gaulle wollte seines Erachtens mit dieser Krise nachweisen, die Sechs könnten sich leichter einigen, wenn keine supranationale Institution an den Verhandlungen beteiligt wäre. Was aber konnte man tun, um Frankreich wieder an den Brüsseler Tisch zu bringen? Schröder war der Ansicht, das Ganze sei eine „Kraftprobe des Generals". Die Bundesrepublik, Italien und die Benelux-Staaten müßten deshalb unmißverständlich ihren Willen deutlich machen, notfalls die Gemeinschaft auch ohne Frankreich fortzusetzen. Nach den Erfahrungen, die man mit dem General in den vergangenen Jahren gemacht habe, sei zu erwarten, daß er nachgeben

\footnotetext{
414 Vgl. das Gespräch des Bundesministers Schröder mit dem französischen Botschafter Seydoux am 8. 7. 1965, in: AAPD 1965, Dok. 270, S. 1137.

415 Vgl. das Gespräch des Bundesministers Schröder mit dem amerikanischen Botschafter McGhee am 9. 7. 1965, in: ebenda, Dok. 272, S. $1146 \mathrm{f}$.

416 Für den Wortlaut des Memorandums der EWG-Kommission vom 22. 7. 1965 vgl. EuROPA-ARCHIV 1965, D 430-437.

417 Vgl. dazu das Rundfunkinterview des Ministerpräsidenten Pompidou vom 27. 7. 1965, in: ADG 1965, S. $11989 f$.

418 Vgl. das Gespräch des Bundesministers Schröder mit dem belgischen Außenminister Spaak am 26. 7. 1965, in: AAPD 1965, Dok. 303, S. 1270.
} 
werde, wenn die Fünf gemeinsam gegen ihn Front machten ${ }^{419}$. So dachten auch Italien und die Benelux-Staaten. Auf der Ministerratstagung am 26./27. Juli ließen die fünf Staaten keinen Zweifel daran, daß sie die Absicht hatten, die EWG am Leben zu halten ${ }^{420}$. Belgien und Luxemburg machten aber zugleich deutlich, daß sie in Abwesenheit Frankreichs keinen Entscheidungen des Ministerrats zustimmen würden ${ }^{421}$.

$\mathrm{Daß}$ der Streit um die Agrarfinanzierung nicht die Ursache für die Krise, sondern nur ein willkommener Anlaß für de Gaulle war, die Gemeinschaft in Frage zu stellen, bewiesen nicht nur nach Schröders Urteil die Ausführungen des Generals auf einer Pressekonferenz in Paris am 9. September 1965422. Der französische Staatspräsident stellte dort plötzlich den gesamten inneren Aufbau der EWG in Frage und erklärte, wegen der Konstruktionsmängel der Gemeinschaft sei ein Eklat mehr oder weniger unvermeidbar gewesen. Seine Kritik richtete sich in erster Linie gegen die Einführung des Mehrheitsbeschlusses im EWG-Ministerrat zum 1. Januar 1966. Er befürchtete, Frankreich drohe die Gefahr, in der Gemeinschaft majorisiert zu werden ${ }^{423}$. Außerdem verlangte die französische Regierung eine präzise Festlegung des Aufgabenbereichs und der Kompetenzen der Kommission, da man an der Seine das Gefühl hatte, als ob „die Regierungen nichts weiter zu tun hätten, als die Kommissionsmitglieder zu ernennen und dann für die vier Jahre ihrer Amtsdauer ihnen nichts mehr zu sagen hätten“424. Einerseits verurteilte Schröder das Vorgehen des französischen Staatspräsidenten sehr scharf („De Gaulle denke nicht in Kategorien wie Zusammenarbeit, Teamwork und Gleichberechtigung “425), andererseits hatte er sehr wohl Verständnis für die Bedenken des Generals hinsichtlich der Einführung des Mehrheitsbeschlusses. Auch er selbst war der Ansicht, daß bei Abstimmungen im Ministerrat weiterhin auf „vitale Interessen“ jedes einzelnen Mitgliedstaats Rücksicht genommen werden müßte ${ }^{426}$, denn man dürfe „souverän gebliebene Staaten durch eine Brüsseler Entscheidung gegen ihren Willen in essentiellen Fragen nicht binden“. Mit Blick auf die französische Kritik an der Kommission schlug er vor, eine Geschäftsordnung

419 Vgl. ebenda, S. $1270-1276$.

420 Vgl. den Drahtbericht des Botschafters Sachs, Brüssel (EWG/EAG), an das Auswärtige Amt vom 27. 7. 1965, in: ebenda, Dok. 307, S. 1286-1291.

421 Vgl. OSTERHELD, Außenpolitik, S. 212.

422 Vgl. den Runderlaß des Bundesministers Schröder vom 27. 9. 1965, in: AAPD 1965, Dok. 365, S. 1519.

423 Vgl. DE Gaulle, Discours IV, S. 372-392. Die Einführung des Mehrheitsbeschlusses schrieb Artikel 8 des EWG-Vertrags vom 25. 3. 1957 vor. Für den Wortlaut vgl. DEI, Bd. 1, S. 134 f. Am 14. Januar 1962 entschied der EWG-Ministerrat, am 1. Januar 1966 in die dritte Stufe der Vorbereitung für die Einführung des Gemeinsamen Markts am 1. Januar 1970 einzutreten. Entscheidungen über den Gemeinsamen Markt sollten dann per Mehrheitsbeschluß gefaßt werden. Vgl. BULLETIN DER EWG 1962, S. 12.

424 So der Geschäftsträger Frankreichs bei der EWG, Maurice Ulrich, Mitte September 1965 zum Leiter der Vertretung der Bundesrepublik bei der EWG, Hans-Georg Sachs. Vgl. den Drahtbericht des Botschafters Sachs, Brüssel (EWG/EAG), an das Auswärtige Amt vom 15. 9. 1965, PA/AA, B 150, Aktenkopien 1965.

425 Gespräch des Bundesministers Schröder mit dem amerikanischen Botschafter McGhee am 13. 9. 1965, in: AAPD 1965, Dok. 348, S. 1432.

426 Ebenda, S. 1429. 
auszuarbeiten, die künftig Eigenmächtigkeiten ausschließen sollte ${ }^{427}$. Entschieden wandte er sich jedoch gegen eine Änderung der Römischen Verträge, falls Frankreich dies fordern sollte. Auch eine Beschneidung der Kompetenzen der Kommission und eine einseitige Konzentration des Aufgabenbereichs der EWG auf die Entwicklung eines gemeinschaftlichen Agrarmarkts wollte er nicht zulassen ${ }^{428}$.

Am 25./26. Oktober 1965 regten die Bundesrepublik, Italien und die BeneluxStaaten im EWG-Ministerrat an, eine außerordentliche Sitzung unter Ausschluß der Brüsseler Kommission einzuberufen, auf der gemeinsam mit Frankreich, das darauf drängte, dort das Problem des Mehrheitsentscheids, die Rolle der Kommission und die Frage der Agrarfinanzierung zu erörtern, nach einem Ausweg aus der Krise gesucht werden sollte ${ }^{429}$. Couve de Murville stellte unmißverständlich fest, daß Frankreich seinen Platz erst wieder einnehmen werde, wenn für diese drei Punkte eine zufriedenstellende Regelung gefunden sei ${ }^{430}$. Auch eine Revision der Römischen Verträge sei in Erwägung zu ziehen ${ }^{431}$. Außerdem plante Paris im Zuge der am 8. April 1965 vereinbarten Fusion der Exekutiven von EURATOM, EGKS und EWG personelle Veränderungen bei der Besetzung der gemeinsamen Kommission durchzusetzen. Man dachte an der Seine unter anderem an eine Ablösung des Kommissionspräsidenten Walter Hallstein ${ }^{432}$.

Nachdem der Ministerrat am 30. November und am 20. Dezember seine Einladung an die französische Regierung wiederholt hatte, erklärte sich diese am 23. Dezember 1965 zur Teilnahme an einer Ratstagung bereit, sofern diese außerhalb von Brüssel abgehalten würde ${ }^{433}$. Am 17. und 18. Januar 1966 trafen sich die Sechs schließlich in Luxemburg zu einer außerordentlichen Sitzung. Das vorrangige Bestreben der Bundesregierung war dabei, Frankreich wieder zur Mitarbeit in der EWG zu bewegen. Schröder hielt dies vor allem im Hinblick auf einen erfolgreichen Verlauf der Kennedy-Runde für unerläßlich ${ }^{434}$. Auf diesem ersten Treffen aller sechs Mitgliedstaaten der Gemeinschaft nach über sieben Monaten

427 Ebenda, S. 1430.

428 Vgl. den Runderlaß des Bundesministers Schröder vom 27.9. 1965, in: AAPD 1965, Dok. 369, S. 1518-1522.

429 Für den Wortlaut der Erklärung des EWG-Ministerrats vom 26. 10. 1965 vgl. EuROPAARCHIV 1965, D $623 \mathrm{f}$.

430 Vgl. das Gespräch des Bundesministers Schröder mit dem französischen Außenminister Couve de Murville am 13. 11. 1965, in: AAPD 1965, Dok. 416, S. 1721 f. Zur französischen Reaktion vgl. auch die Aufzeichnung des Staatssekretärs Lahr vom 10. 11. 1965, in: ebenda, Dok. 412, S. 1689-1692.

431 Vgl. das Gespräch des Bundesministers Schröder mit dem französischen Außenminister Couve de Murville am 13. 11. 1965, in: ebenda, Dok. 416, S. 1729.

$432 \mathrm{Vgl}$. die Gespräche des Bundesministers Schröder mit dem britischen Außenminister Stewart am 19. 11. 1965, in: ebenda, Dok. 424, S. 1784, besonders Anm. 51. Für den Wortlaut des Vertrags vom 8. 4. 1965 über die Einsetzung eines gemeinsamen Rates und einer gemeinsamen Kommission der Europäischen Gemeinschaften (Fusion der Exekutiven) vgl. BUNDESGESETZBLATT 1965, Teil II, S. 1454-1497. Da sich die Ratifikation des Vertrages durch die Parlamente der Mitgliedstaaten verzögerte, trat der Fusionsvertrag erst am 1.7. 1967 in Kraft.

433 Vgl. BT STENOGRAPHISCHE BERICHTE, Bd. 60, S. 674.

434 Vgl. das Protokoll der CDU/CSU-Fraktionssitzung am 11.1. 1966, ACDP VIII-001$1010 / 2$. 
erläuterte die französische Regierung ihre Bedingungen für die Rückkehr nach Brüssel. Nach der Auffassung Frankreichs durfte der Mehrheitsentscheid nicht angewandt werden, falls ein Mitgliedstaat dies wünsche. Damit verlangte Paris praktisch die Beibehaltung des Vetorechts. Couve de Murville legte des weiteren ein Memorandum vor, das sich mit der politischen Stellung der Kommission befaßte. Die darin enthaltenen Forderungen liefen mehr oder weniger auf eine erhebliche Beschneidung ihrer Kompetenzen hinaus. Außerdem präsentierte der französische Außenminister einen Zeitplan zur Behebung der Krise. Dieser sah eine Einigung in der Frage des Mehrheitsentscheids und bezüglich der Stellung der Kommission bis Ende Januar vor. Einen Monat später sollte über die personelle Zusammensetzung der neuen Kommission entschieden und bis Ende März die umstrittene Agrarfinanzordnung verabschiedet werden. Nachdem die Sechs ihren jeweiligen Standpunkt dargelegt hatten, vertagten sie sich auf den 28. Januar 1966435 .

Schröder hatte ebenso wie der niederländische Außenminister Luns in Luxemburg eine harte Haltung eingenommen. Spaak sowie sein italienischer Kollege Colombo versuchten hingegen zu vermitteln. In den Verhandlungen zeigte sich jedoch, daß Frankreich nicht bereit war, von seinen Forderungen abzurücken ${ }^{436}$. Die Krise der Gemeinschaft hatten sich also trotz des Meinungsaustauschs „verschärft ${ }^{\star 437}$. Die Bundesregierung beanstandete vor allem das egoistische Verhalten Frankreichs. Wie Schröder am 27. Januar 1966, also unmittelbar vor der nächsten Ministerratstagung, vor dem Bundestag ausführte, lasse der von Frankreich in Luxemburg vorgelegte Forderungskatalog deutlich erkennen, daß Paris nur die Themenkreise besprechen wollte, auf deren Regelung es besonderen Wert lege. Der Grundsatz des gleichmäßigen Fortschritts sei von der französischen Regierung nicht beachtet worden. Zudem ließe sich der französische Zeitplan nicht einhalten, beklagte der Außenminister. Mit Blick auf das nächste Treffen machte Schröder deutlich, daß er weder ein generelles Vetorecht, noch eine Schwächung der Kommission akzeptieren werde ${ }^{438}$. In der Frage des Mehrheitsentscheids war er aber zu einem Kompromiß bereit. Ihm schwebte eine Vereinbarung vor, die die Majorisierung eines Landes ausschließen, aber nicht auf eine Beibehaltung des allgemeinen Vetorechts hinauslaufen sollte. Bereits in der Fraktionssitzung von CDU und CSU am 15. Januar hatte er den Abgeordneten versichert, daß er im Ministerrat auf eine Lösung in dem von ihm skizzierten Sinn hinarbeiten würde 439 .

In der Tat gelang es auf der zweiten außerordentlichen Ratstagung am 28./ 29. Januar 1966 in Luxemburg, das Problem des Mehrheitsentscheids zur Zufriedenheit aller zu regeln. Die Sechs legten fest, daß sich alle Partner um eine einver-

435 Vgl. die Aufzeichnung des Staatssekretärs Lahr vom 19.1. 1966, in: AAPD 1966, Dok. 12, S. 37-44. Vgl. ferner ADG 1966, S. 12284 f.

436 Vgl. Müller-RosChaCH, Die deutsche Europapolitik, S. 174.

437 Vgl. die Aufzeichnung des Staatssekretärs Lahr vom 19.1. 1966, in: AAPD 1966, Dok. 12, S. 37.

438 Vgl. BT STENOGRAPHISCHE BERICHTE, Bd. 60, S. 675 f. und S. 692.

439 Vgl. das Protokoll der CDU/CSU-Fraktionssitzung vom 25. 1. 1966, ACDP VIII-0001$1010 / 2$. 
nehmliche Lösung bemühen müßten, wenn bedeutsame Interessen eines Staates berührt würden. Allerdings wurde nicht definiert, welche Entscheidungen als bedeutsam anzusehen seien ${ }^{40}$. Schröder, der als Wortführer der Fünf auftrat ${ }^{441}$, konnte sich im Rat durchsetzen: Weder wurde eine Revision der Römischen Verträge noch eine Schwächung der Kommission beschlossen. Couve de Murville akzeptierte, das Memorandum vom 17./18. Januar 1966 dergestalt zu formulieren, daß die darin enthaltenen Forderungen Frankreichs den Charakter von Anregungen erhielten. Auch bestand die französische Regierung nicht mehr auf ihrem Zeitplan. Obwohl Paris im Endeffekt seine Intentionen nicht verwirklichen konnte, erklärte der französische Außenminister, sein Land werde den Boykott der Gemeinschaft beenden und den Platz im Ministerrat wieder einnehmen. Nach Überwindung der Krise würden die Sechs somit „dort die Arbeiten wieder aufnehmen, wo sie am 30. Juni [1965] unterbrochen worden sind“, bilanzierte Staatssekretär Lahr ${ }^{442}$. Frankreichs "Politik des leeren Stuhls" war beendet und die sechs Mitgliedstaaten der Gemeinschaft gingen wieder zur Tagesordnung über. Wenige Tage später versicherte de Gaulle dem Kanzler, Frankreich werde die in Luxemburg getroffenen Vereinbarungen nicht wieder in Frage stellen ${ }^{443}$.

Die Beschlüsse vom 29. Januar 1966 führten die EWG aus der schwersten Krise ihrer Geschichte. Der Preis, der dafür gezahlt werden mußte, war der Verzicht auf die Anwendung des Mehrheitsentscheids im Ministerrat. Im Rückblick sah der ehemalige französische Ministerpräsident und Präsident des Europäischen Parlaments, Pierre Pflimlin, darin einen folgenschwere Entscheidung für die weitere Entwicklung der Gemeinschaft. Die Lähmung der Europäischen Gemeinschaft in den siebziger und achtziger Jahren führte er auf den Luxemburger Beschluß zurück, das Vetorecht der Mitgliedstaaten praktisch ungeschmälert beizubehalten ${ }^{444}$. Es darf aber dabei nicht vergessen werden, daß 1966 sich sowohl Paris, als auch Bonn gegen die Einführung des Mehrheitsbeschlusses aussprachen. Ebenso wie de Gaulle stand auch Schröder dem Gedanken ablehnend gegenüber, daß künftig innerhalb der Gemeinschaft verbindliche Entscheidungen auch gegen den Willen eines souveränen Landes getroffen werden sollten. Da Frankreich und die Bundesrepublik sich dem Majoritätsprinzip nicht unterordnen wollten, bestand keine realistische Chance, den Grundsatz der Einstimmigkeit im Ministerrat abzuschaffen. Sicherlich wurde durch den Luxemburger Beschluß die Fortführung des europäischen Integrationsprozesses erschwert; andererseits wurden aber dadurch künftige Krisen verhindert, da keine Beschlüsse über den Kopf eines Mit-

440 Für den Wortlaut der Vereinbarung vom 29. 1. 1966 vgl. EUROPA-ARCHIV 1966, D 85 f. Vgl. auch den Runderlaß des Staatssekretärs Lahr vom 31.1. 1966, in: AAPD 1966, Dok. 25, S. 114-118.

441 Vgl. LAHR, Zeuge, S. 438.

442 Vgl. den Runderlaß des Staatssekretärs Lahr vom 31. 1. 1966, in: AAPD 1966, Dok. 25, S. 116.

443 Vgl. das Gespräch des Bundeskanzlers Erhard mit Staatspräsident de Gaulle in Paris am

7.2. 1966, in: ebenda, Dok. 34, S. 146.

444 Vgl. den Diskussionsbeitrag von Pierre Pflimlin in: Schwarz (Hrsg.), Adenauer und Frankreich, S. 31. 
gliedstaats hinweg gefaßt und Fortschritte somit nur noch im Konsens erzielt werden konnten.

\section{Frankreichs Austritt aus der militärischen Integration der NATO}

Nur wenige Wochen nach der Beilegung der Auseinandersetzungen in der EWG löste der französische Staatspräsident eine weitere Krise aus, diesmal innerhalb des Atlantischen Bündnisses. Auf einer Pressekonferenz am 21. Februar 1966 in Paris vertrat de Gaulle die Auffassung, die militärpolitische Lage in Europa habe sich seit der Gründung der NATO im Jahr 1949 erheblich verändert. Aufgrund des atomaren Gleichgewichts sei die Gefahr eines sowjetischen Angriffs wesentlich geringer als zu dem Zeitpunkt, da "das amerikanische Protektorat unter dem Deckmantel der NATO in Europa errichtet wurde“. Er äußerte jedoch die Befürchtung, die Europäer könnten durch einen amerikanisch-sowjetischen Konflikt in einem anderen Teil der Welt, beispielsweise in Vietnam, gegen ihren Willen in eine militärische Auseinandersetzung hineingezogen werden. Da die strategische Lage sich radikal verändert habe, kündigte er an, er werde für die Wiederherstellung der Souveränität Frankreichs sorgen. Zugleich versicherte er aber, Frankreich werde die Atlantische Allianz nicht verlassen ${ }^{445}$. Damit stand fest, daß er seine Politik fortsetzen wollte, die französischen Streitkräfte aus dem integrativen System der NATO herauszulösen. Nach dem fehlgeschlagenen Versuch im Jahr 1958, ein Dreier-Direktorium Frankreichs, Großbritanniens und der Vereinigten Staaten zur Lenkung des Bündnisses zu gründen ${ }^{446}$, hatte der General unter anderem am 11. März 1959 die französische Mittelmeerflotte und am 1. Januar 1964 die Atlantikflotte dem NATO-Befehl entzogen ${ }^{447}$. Jetzt beabsichtigte er, auch die übrigen, noch dem Bündnis unterstellten Truppenteile - es handelte sich dabei fast ausschließlich um die in der Bundesrepublik stationierten Streitkräfte - wieder unter französischen Oberbefehl zu stellen. Dies teilte der Quai d'Orsay am 25. Februar 1966 dem Gesandten der Bundesrepublik in Paris, Peter Limbourg, mit $^{448}$. Die offizielle Unterrichtung der NATO-Mitgliedstaaten erfolgte durch ein Aide-mémoire am 11. März. Die französische Regierung kündigte darin zudem an, daß sich Frankreich auch aus den integrierten NATO-Kommandobehörden, SHAPE und AFCENT, zurückziehen werde. Das Bündnis wurde aufgefordert, den Sitz dieser beiden auf französischem Territorium befindlichen Behörden zu verlegen. Gleichzeitig bekräftigte Paris aber noch einmal, es wolle weiterhin Mitglied der NATO bleiben ${ }^{449}$. Für die anderen 14 Mitgliedstaaten der Allianz waren

445 AdG 1966, S. 12346. Vgl. auch DE GAulle, Discours V, S. 6-23.

446 Vgl. dazu DE GaUlle, Mémoires d'espoir, S. 218f.; Grosser, Frankreich und seine Außenpolitik, S. $245 \mathrm{f}$.

447 Vgl. ADG 1959, S. 7603; ADG 1963, S. 10649; Aufzeichnung des Staatssekretärs Carstens vom 15.6. 1963, in: AAPD 1963, Dok. 194, S. 631 f.; DE GAUlle, Mémoires d'espoir, S. $219 \mathrm{f}$.

448 Vgl. den Drahtbericht des Gesandten Limbourg, Paris, an das Auswärtige Amt vom 25. 2. 1966, in: AAPD 1966, Dok. 47, S. 218-220.

449 Für den Wortlaut des französischen Aide-mémoires vom 11.3. 1966 vgl. EurOPAARCHIV 1966, D 229-231. 
die Ankündigungen „ein gewaltiger Schock“. Niemand hatte erwartet, daß de Gaulle derart drastische Schritte durchführen würde ${ }^{450}$. In einem zweiten Aidemémoire vom 29. März nannte die französische Regierung erstmals einen genauen Termin für die angekündigten Maßnahmen. Der Austritt aus dem integrativen System sollte bereits am 1. Juli 1966 über die Bühne gehen. Für die Verlegung der beiden NATO-Hauptquartiere sowie der NATO-Akademie wurde dem Bündnis eine Frist bis zum 1. Juli 1967 gewährt ${ }^{451}$.

Die Maßnahmen seiner Regierung verteidigte Couve de Murville damit, daß die von französischer Seite seit langem geforderte Reform der NATO nicht erfolgt sei ${ }^{452}$. Schröder hielt diesem Argument am 17. März im Bundestag entgegen, daß die französische Regierung zwar in den vergangenen Jahren eine Umstrukturierung der NATO verlangt, jedoch ihre Vorstellungen nie konkretisiert habe ${ }^{453}$. Das Auswärtige Amt nahm vielmehr an, de Gaulle plante in Wahrheit mit Blick auf seinen Besuch in der UdSSR vom 20. Juni bis 1. Juli 1966, den Spielraum der französischen Politik zu vergrößern ${ }^{454}$. Man verwies darauf, daß der General bereits anläßlich der deutsch-französischen Konsultationen im Februar 1966 erklärt hatte, es bestünde kein Anlaß mehr, die UdSSR „unter dem Gesichtspunkt des Kalten Krieges zu betrachten ${ }^{455}$, und sich auf den Standpunkt gestellt hatte, man müsse "den Russen neue Perspektiven eröffnen"456. Da de Gaulle schon seit längerem der Meinung war, um die Teilung Europas zu überwinden, müsse nach einer Phase der détente eine Politik der coopération mit dem Ostblock durchgeführt wer$\operatorname{den}^{457}$, vermuteten die Verantwortlichen in Bonn, daß der französische Staatspräsident jetzt den Zeitpunkt für gekommen sah, sein Konzept in die Tat umzusetzen.

Zusätzliche Unsicherheit im Kreis der NATO entstand dadurch, daß de Gaulle plötzlich den Begriff des unprovozierten Angriffs aufbrachte. Der NATO-Vertrag vom April 1949 unterschied bei der Definition des Bündnisfalls nicht zwischen einem provozierten oder einem unprovozierten Angriff, sondern machte den Mitgliedstaaten zur Auflage, "daß ein bewaffneter Angriff gegen eine oder mehrere von ihnen in Europa oder Nordamerika als ein Angriff gegen sie alle angesehen wird“. Jeder Mitgliedstaat war dann verpflichtet, dem Opfer militärischen Beistand zu leisten ${ }^{458}$. Da der französische Staatspräsident nun explizit betonte, im Falle einer „unprovozierten Aggression“ würde Frankreich dem angegriffenen

450 OSTERHELD, Außenpolitik, S. 289.

451 Für den Wortlaut des französischen Aide-mémoire vom 29. 3. 1966 vgl. EUROPA-ARCHIV 1966, D 241-243.

452 Vgl. den Drahtbericht des Botschafters Klaiber, Paris, an das Auswärtige Amt vom 10. 3. 1966, in: AAPD 1966, Dok. 66, S. $291 \mathrm{f}$.

453 Vgl. BT STENOGRAPHISCHE BERICHTE, Bd. 61, S. 1438.

454 Vgl. den Runderlaß des Staatssekretärs Carstens vom 25.4. 1966, in: AAPD 1966, Dok. 121, S. 532. Zur Reise de Gaulles in die UdSSR vgl. ADG 1966, S. 12575-12578.

455 Vgl. Gespräch des Bundeskanzlers Erhard mit Staatspräsident de Gaulle am 8. 2.1966 in Paris, in: AAPD 1966, Dok. 36, S. 177.

456 Vgl. die Aufzeichnung des Staatssekretärs Carstens vom 9. 2. 1966, in: ebenda, Dok. 38, S. 186.

457 Vgl. De Gaulle, Mémoires d'espoir, S. 186 und S. 218.

458 Artikel 5 des NATO-Vertrags vom 4.4. 1949, in: BundesgesetzBlatT 1955, Teil II, S. 290. 
Staat beistehen ${ }^{459}$, kamen Zweifel auf, ob er im Ernstfall seine Bündnispflichten erfüllen würde oder ob er sich mit dieser Differenzierung eine Hintertür offenlassen wollte ${ }^{460}$.

Die Entscheidung de Gaulles, das integrative System der NATO zu verlassen, wurde von Bonn mißbilligt, da dadurch die Sicherheit der Bundesrepublik beeinträchtigt wurde. Schröder konnte den Thesen des Generals hinsichtlich der veränderten militärstrategischen Lage in Europa in keinem Punkt folgen. Dessen Standpunkt, die Integration der NATO-Streitkräfte sei nicht mehr notwendig, da die Gefahr eines sowjetischen Angriffs gesunken sei, traf in seinen Augen überhaupt nicht zu: „Die Spannung werde in Europa so lange andauern, wie die russischen Divisionen in Deutschland stehen; solange diese Spannung andauere, sei auch die Notwendigkeit einer militärischen Verteidigung gegeben." Nicht durch einseitige Maßnahmen konnte seines Erachtens die Sicherheit in Europa erhöht werden, sondern nur durch die Beseitigung der Ursache der Spannungen, nämlich der Überwindung der Teilung Deutschlands ${ }^{461}$. Nach seiner Einschätzung täuschte sich de Gaulle, wenn er die Hoffnung hegte, ohne die USA ließen sich die europäischen Probleme leichter lösen. Er sah die Gefahr, daß der Abzug der Vereinigten Staaten aus Europa zu einer "Zementierung des Status quo" führen und das Gleichgewicht sich zugunsten der Sowjetunion verschieben würde ${ }^{462}$. Es genügte dem Außenminister nicht, wenn die Amerikaner nur atomar den Schutz Europas garantierten, sondern er legte genauso großen Wert auf ihre physische Präsenz auf dem Kontinent ${ }^{463}$. Auch die Differenzierung zwischen einem provozierten und einem nicht-provozierten Angriff wies Schröder zurück, da kein Zweifel bestehen dürfte, daß ein bewaffneter Angriff auf die Bundesrepublik „auch für die Franzosen den casus foederis darstellen müsse" ${ }^{464}$. Mit ihrer Kritik an der französischen Verteidigungspolitik stand die Bundesrepublik in einer Front mit den anderen 13 NATO-Mitgliedern, die Frankreichs Maßnahmen ebenfalls einmütig verurteilten. Primär kam es Bonn aber darauf an, ein Auseinanderfallen der Allianz zu verhindern: „Eine NATO ohne Frankreich sei immer noch besser als keine NATO“, erklärte Erhard vor der CDU/CSU-Bundestagsfraktion ${ }^{465}$. Schröder sprach sich dafür aus, die gleiche Taktik anzuwenden wie während der EWG-Krise: Die Betroffenen müßten eng zusammenstehen und ihren Willen zum Ausdruck bringen, daß sie die Allianz auch ohne Frankreich fortsetzen würden ${ }^{466}$. Gleichzeitig sei

459 Schreiben de Gaulle an Johnson vom 7. 3. 1966, in: EUROPA-ARCHIV 1966, D 228.

460 Vgl. dazu den Runderlaß des Staatssekretärs Carstens vom 25. 4. 1966, in: AAPD 1966, Dok. 121, S. 532.

461 Gespräch des Bundesministers Schröder mit dem portugiesischen Außenminister Nogueira am 24. 3. 1966 in Lissabon, in: ebenda, Dok. 81, S. 357.

462 Gespräch des Bundesministers Schröder mit Ministerpräsident Salazar am 25. 3. 1966 in Lissabon, in: ebenda, Dok. 83, S. $368 \mathrm{f}$.

463 Gespräch des Bundesministers Schröder mit dem spanischen Außenminister Castiella am 29. 3. 1966 in Madrid, in: ebenda, Dok. 87, S. 387.

464 Gespräch des Bundesministers Schröder mit den französischen Senatoren Lecanuet und Poher am 15. 6. 1966, PA/AA, Ministerbüro, Bd. 470.

465 Protokoll der CDU/CSU-Fraktionssitzung am 15. 3. 1966, ACDP VIII-001-1010/2.

466 Vgl. das Gespräch des Bundesministers Schröder mit dem amerikanischen Sonderbeauftragten McCloy am 15. 4. 1966, in: AAPD 1966, Dok. 110, S. 473. 
aber darauf hinzuwirken, daß Frankreich weiterhin „möglichst eng“ mit der NATO verbunden bleibe. Ansonsten, so Schröder, stünde das westliche Verteidigungsbündnis vor „einer langen Periode der Erosion“467.

Was aber sollte mit den rund 72000 in der Bundesrepublik stationierten französischen Soldaten nach ihrer Herauslösung aus der NATO-Integration geschehen? Die rechtliche Grundlage für ihre Stationierung bildeten Artikel 4, Absatz 2 des Deutschland-Vertrags sowie Artikel 1, Absatz 1 des Vertrages über den Aufenthalt ausländischer Streitkräfte in der Bundesrepublik vom 23. Oktober 1954. Dort wurde gleichlautend festgelegt, es dürften „Streitkräfte der gleichen Nationalität und Effektivstärke wie zur Zeit des Inkrafttretens dieser Abmachungen in der Bundesrepublik stationiert werden" 468 . Nach Ansicht der französischen Regierung tangierte der Austritt ihrer Truppen aus der NATO-Integration nicht das Stationierungsrecht Frankreichs in der Bundesrepublik. Couve de Murville hatte deshalb der Bundesregierung bereits am 10. März zugesagt, alle 72000 Soldaten würden in der Bundesrepublik verbleiben, sofern Bonn dies wünsche ${ }^{469}$. Das Auswärtige Amt vertrat hingegen den Standpunkt, nach dem 1. Juli 1966 müßte die Stationierung auf eine neue juristische Grundlage gestellt werden. Die von Schröder eingesetzte Arbeitsgruppe „Frankreich und NATO“, die sich mit diesem Problem eingehend beschäftigt hatte, verwies in ihrem Anfang April vorgelegten Bericht darauf, daß der Deutschland- und der Aufenthaltsvertrag Teil der Pariser Gesamtregelung vom Oktober 1954 seien, durch welche die Bundesrepublik die Souveränität erlangt hatte und als gleichberechtigtes Mitglied in NATO und WEU aufgenommen worden war. Nach der Interpretation der Experten des Auswärtigen Amts stellten die damaligen Verträge und Erklärungen eine „rechtliche und politische Einheit" dar. So hätten sich unter anderem alle Unterzeichnerstaaten verpflichtet, die eigenen Streitkräfte der NATO zu unterstellen. Demgemäß entfiele die Rechtsgrundlage für die Stationierung von Truppen auf dem Boden der Bundesrepublik, sobald diese dem Oberbefehl der NATO entzogen würden, da Frankreich nicht die Rechte des Vertragswerks in Anspruch nehmen, die daraus entstehenden Pflichten aber ignorieren könne. Folglich, so die Schlußfolgerung der Arbeitsgruppe, seien Verhandlungen über den Verbleib der französischen Truppen in der Bundesrepublik unausweichlich. Ziel der Gespräche sollte eine Regelung sein, derzufolge die französischen Soldaten im Ernstfall wieder unter NATO-Kommando gestellt würden. $\mathrm{Da}$ auch de Gaulle im Grunde einen Verbleib seiner Armee in Deutschland wünschte, empfahlen die Autoren, eine

467 Gespräch des Bundesministers Schröder mit dem portugiesischen Außenminister Nogueira am 24. 3. 1966 in Lissabon, in: ebenda, Dok. 81, S. 359.

468 Für den Wortlaut von Artikel 4, Absatz 2 des Vertrags über die Beziehungen zwischen der Bundesrepublik Deutschland und den Drei Mächten vom 26. 5. 1952 in der Fassung vom 23. 10. 1954 (General- bzw. Deutschland-Vertrag) und von Artikel 1, Absatz 1 des Vertrags über den Aufenthalt ausländischer Streitkräfte in der Bundesrepublik Deutschland (Aufenthaltsvertrag) vgl. DOKUMENTE DES GETEILTEN DEUTSCHLAND, Bd. 1, S. 231 und S. 271.

469 Vgl. den Drahtbericht des Botschafters Klaiber, Paris, an das Auswärtige Amt vom 10. 3. 1966, in: AAPD 1966, Dok. 66, S. 294. 
unnachgiebige Haltung einzunehmen: Frankreich würde nichts anderes übrig bleiben, als die Bedingungen Bonns zu akzeptieren 470 .

Während man sich amtsintern für eine harte Verhandlungsführung aussprach, aber zugleich das Interesse an einem Verbleib der französischen Truppen in der Bundesrepublik betonte, war Schröder durchaus bereit, ihren Abzug in Kauf zu nehmen. Für ihn hatte die Frage, ob Frankreich weiterhin Soldaten in der Bundesrepublik stationiert halte, nur eine "untergeordnete Bedeutung“. Der entscheidende Punkt war in seinen Augen die Sicherung des Zusammenhalts und der Funktionsfähigkeit der NATO ${ }^{471}$. Wie er am 25. März 1966 dem portugiesischen Ministerpräsidenten Antonió de Oliveira Salazar anvertraute, hielt er eine weitere Präsenz nur für sinnvoll, wenn die französischen Streitkräfte auch in Zukunft mit den übrigen in der Bundesrepublik befindlichen Truppen zusammenarbeiten würden. Andernfalls wäre die französische Armee „lediglich eine Belastung für die Bundesrepublik" 472. Am 15. April erläuterte er dem früheren amerikanischen Hochkommissar McCloy, man dürfe gegenüber de Gaulle keine Politik des „Appeasement" verfolgen, da sie ihn nur ermuntern würde, weiter daran zu arbeiten, "die Amerikaner aus Europa zu vertreiben" ${ }^{473}$. Er wolle deshalb darauf bestehen, $\mathrm{da} ß$ die in der Bundesrepublik stationierten französischen Soldaten solange unter dem Befehl der NATO zu bleiben hätten, bis eine zufriedenstellende Regelung gefunden sei - also, im Zweifelsfall auch über den Stichtag des 1. Juli hinaus. Könne de Gaulle dies nicht akzeptieren, müßten seine Truppen eben aus der Bundesrepublik abziehen ${ }^{474}$. Der Außenminister beabsichtigte, den Status und den Aufgabenkreis der französischen Truppen exakt festzulegen, um sicherzustellen, daß diese im Falle eines Angriffs auf die Bundesrepublik nicht nur an der Seite der NATO, sondern auch unter ihrem Kommando kämpfen würden ${ }^{475}$. Außerdem war aus seiner Sicht eine vertragliche Vereinbarung unbedingt erforderlich, damit die Souveränität der Bundesrepublik nicht verletzt würde ${ }^{476}$. Auch Erhard beabsichtigte nicht, einen Abzug der französischen Truppen um jeden Preis zu verhindern. Er hielt es für "unerträglich, wieder in eine Art Besatzungsstatut zurückzufallen“. Dies wäre nach seinem Empfinden der Fall gewesen, wenn ab dem 1. Juli 1966 keine Rechtsgrundlage für den Aufenthalt der französischen Streitkräfte mehr bestanden hätte. Ebenso wie Schröder war der Kanzler der Meinung, das Aufent-

470 Vgl. die Aufzeichnung der Arbeitsgruppe „Frankreich und NATO“ vom 4. 4. 1966, in: ebenda, Dok. 100, S. 437-446 (442).

471 Gespräch des Bundesministers Schröder mit dem britischen Außenminister Stewart am 16. 3. 1966 in London, in: ebenda, Dok. 71, S. 309.

472 Gespräch des Bundesministers Schröder mit Ministerpräsident Salazar am 25. 3. 1966 in Lissabon, in: ebenda, Dok. 83, S. 373.

473 Gespräch des Bundesministers Schröder mit dem amerikanischen Sonderbeauftragten McCloy am 15. 4. 1966, in: ebenda, Dok. 110, S. 472.

474 Vgl. ebenda, S. 472-475.

475 Vgl. das Protokoll der CDU/CSU-Fraktionssitzung am 14.6. 1966, ACDP VIII-0011010/2.

476 Vgl. den Runderlaß des Staatssekretärs Carstens vom 25.4. 1966, in: AAPD 1966, Dok. 121, S. 533. 
haltsrecht für die französische Armee sollte nur verlängert werden, wenn Frankreich bestimmte Bedingungen erfüllen würde ${ }^{477}$.

Ihre Haltung bekräftigten beide Politiker auf der Kabinettsitzung am 6. April nachdrücklich. Erhard äußerte, er könne nicht nachvollziehen, daß jedermann sich überlege, wie de Gaulle besänftigt werden könne, anstatt ihn einer peinlichen Befragung zu unterziehen. Schröder fügte hinzu, man dürfe es nicht durchgehen lassen, daß der französische Präsident einerseits seine Pflichten gegenüber dem Bündnis nicht mehr erfüllen, andererseits aber sein Land weiterhin von der NATO schützen lassen wolle ${ }^{478}$. Klipp und klar sprach er sich für einen Konfrontationskurs aus: De Gaulle sei „einer der härtesten, klarsten und kältesten Politiker, die es in der Welt gäbe. Ihm gegenüber müsse man genauso hart und kalt sein." 479 Daher sollte sich Bonn davor hüten, Frankreich förmlich um den Verbleib seiner Soldaten zu bitten. Um sich eine bessere Verhandlungsposition zu verschaffen, sollte die Bundesregierung vielmehr abwarten, bis Frankreich einen derartigen Antrag stellen würde ${ }^{480}$. Schröder war überzeugt, daß de Gaulle am Ende nachgeben würde. Es stand für ihn außer Frage, „daß Frankreich auf das äußerste daran interessiert ist, hierzubleiben“. Falls de Gaulle seine Truppen abziehen müßte, würden dies die Franzosen als „Niederlage“ empfinden. Für die Verhandlungen brauche man daher „Festigkeit, Geschick und Geduld“481. Nicht die Bundesregierung, sondern de Gaulle sollte also nach seiner Ansicht die Rolle des Bittstellers übernehmen.

Reiner Marcowitz gibt in seiner Studie Option für Paris? zu Recht zu bedenken, ob Schröder nicht einer Fehlkalkulation aufsaß. In Wirklichkeit gab es nämlich keine Garantie, daß de Gaulle sich nicht auch mit der Anwesenheit von französischen Truppen in Berlin (West) zufriedengeben würde, die bereits ausreichend den Anteil Frankreichs an der Vier-Mächte-Verantwortung für Deutschland symbolisierten. Marcowitz verneint eindeutig, daß sich Bonn einen Abzug der Franzosen hätte leisten können: Angesichts des Streits mit Großbritannien um die Devisenausgleichszahlungen für die britische Rhein-Armee ${ }^{482}$, des Teilrückzugs amerikanischer Truppen aus der Bundesrepublik im Rahmen der bereits erwähnten Big-Lift-Operation und der feindlichen Haltung der UdSSR hätte dies für die Bundesrepublik „katastrophale Folgen“ gehabt. Im Hinblick auf die unmittelbar bevorstehende Moskau-Reise de Gaulles sah er die Gefahr, daß sich der französi-

\footnotetext{
477 Protokoll der CDU/CSU-Fraktionssitzung am 15. 3. 1966, ACDP VIII-001-1010/2.

$478 \mathrm{Vgl}$. OsTERHELD, Außenpolitik, S. 310-312.

479 Ebenda, S. 312.

$480 \mathrm{Vgl}$. MENDE, Von Wende zu Wende, S. 218.

481 So Schröder am 5. 7. 1966 vor dem Kabinett. Zitiert nach Marcowitz, Option, S. 217.

482 Laut Rechnung des britischen Schatzkanzlers, James Callaghan, belief sich das Auftragsvolumen des deutsch-britischen Devisenausgleichsabkommens vom 26.7. 1964 auf 40 Millionen Pfund. Da die Devisenausgaben für die in der Bundesrepublik stationierten britischen Streitkräfte aber 90 Millionen Pfund betrugen, verlangte er im Mai 1966 von der Bundesregierung, den Differenzbetrag bar auszugleichen. Vgl. das Gespräch des Bundeskanzlers Erhard mit dem britischen Schatzkanzler Callaghan am 24. 5. 1966 in London, in: AAPD 1966, Dok. 162, S. 682-688. Daraufhin nahmen Großbritannien und die Bundesrepublik Verhandlungen auf. Vgl. dazu SCHMIDT, Die Labour-Regierung, die Bundesrepublik und Europa, S. 291-299.
} 
sche Staatspräsident entschließen hätte können, keine Rücksicht mehr auf die deutschlandpolitischen Rechtspositionen zu nehmen, um seine Ostpolitik voranzubringen ${ }^{43}$.

In einer Unterredung mit Schröder am 18. April 1966 bekräftigte Couve de Murville, daß Paris Verhandlungen über ein neues Truppenstatut für unnötig hielt. Angesichts der schwerwiegenden Differenzen fand der Meinungsaustausch, so der Eindruck Seydouxs, ,in winterlicher Atmosphäre“ statt ${ }^{484}$. Couve de Murville warf der Bundesregierung vor, sie habe den Standpunkt Frankreichs „überhaupt nicht verstanden“. Es gehe allein darum, ob sie den Verbleib der französischen Truppen wünsche. Sei dies der Fall, bräuchten auch keine Verhandlungen stattzufinden, da das Stationierungsrecht im Deutschland-Vertrag verankert sei. Sollte die deutsche Seite allerdings darauf bestehen, wäre die französische Regierung trotz der eindeutigen Rechtslage bereit, eine neue Vereinbarung zu schließen, konzedierte der französische Außenminister. Man würde sich dabei aber nicht von Bonn unter Druck setzen lassen: „Frankreich fordere aber keineswegs die Aufrechterhaltung seiner Truppen in Deutschland, und somit könne Deutschland auch keineswegs die Bedingungen für einen solchen Aufenthalt diktieren." 485

Die Bundesregierung war aber nicht willens, Paris in dieser Frage einen Freifahrtschein zu erteilen. Am 19. April informierte der Kanzler die Unionsabgeordneten, er werde von seinen Forderungen nicht abrücken. Die Vorgehensweise de Gaulles dürfe nicht hingenommen werden: „Man kann [...] nicht aus der Integration der NATO aussteigen, man kann nicht die Mitwirkung an einer Verteidigung mit einem Fragezeichen versehen, aber gleichzeitig das Recht behalten, auf deutschem Boden, kraft der NATO-Verträge und der NATO-Vereinbarungen dann noch Truppen zu unterhalten. " 486 Am Tag darauf unterstrich Schröder vor dem Kabinett noch einmal, die Franzosen müßten für ihren Verbleib in der Bundesrepublik „einen verläßlichen Preis zahlen“487. Auch gegenüber McGhee betonte er, de Gaulle dürfe für seine antiamerikanische Politik keine „Prämie“ erhalten. Wenn Frankreich seine Truppen in der Bundesrepublik belassen wollte, müßte es auch Verpflichtungen übernehmen ${ }^{488}$.

Der harte Kurs des Außenministers spiegelte sich in einer Note wider, die Bonn am 3. Mai 1966 an die französische Regierung richtete. Darin beharrte die Bundesregierung auf dem Standpunkt, das Stationierungsrecht sei untrennbar mit der

${ }^{483}$ MarcowITZ, Option, S. 217. Diese Befürchtungen waren aber grundlos. De Gaulle sprach sich gegenüber der sowjetischen Regierung für die Einheit Deutschlands aus und erklärte, es komme nicht in Frage, „daß Frankreich einen anderen deutschen Staat als die Bundesrepublik anerkenne“. Der französische Staatspräsident sah sich aber in seiner These bestätigt, daß die UdSSR nicht länger auf Expansion ausgerichtet, sondern an Kooperation mit dem Westen interessiert sei. Vgl. das Gespräch des Staatspräsidenten de Gaulle mit Bundespräsident Lübke am 21. 7. 1966, PA/AA, Ministerbüro, Bd. 460.

${ }^{484}$ SEYDOUX, Meine zweite Mission, S. 83.

485 Gespräch des Bundesministers Schröder mit dem französischen Außenminister Couve de Murville am 18. 4. 1966, in: AAPD 1966, Dok. 112, S. 494.

486 Protokoll der CDU/CSU-Fraktionssitzung am 19. 4. 1966, ACDP VIII-001-1010/2.

487 OSTERHELD, Außenpolitik, S. 313.

488 Gespräch des Bundesministers Schröder mit dem amerikanischen Botschafter McGhee am 29. 4. 1966, in: AAPD 1966, Dok. 125, S. 544-552 (550). 
militärischen Integration verbunden. Man verwies darauf, daß es einen „entscheidenden Unterschied" mache, ob die in der Bundesrepublik befindlichen ausländischen Streitkräfte „einem gemeinsamen Oberbefehl unterstellt sind, an dem die Bundesrepublik Deutschland in angemessener Weise beteiligt ist, oder ob diese Streitkräfte ausschließlich dem nationalen Oberbefehl ihres Heimatstaates unterstehen". Frankreich würde dementsprechend sein Stationierungsrecht verlieren, wenn es seine Streitkräfte aus dem integrativen System der NATO herauslöse ${ }^{489}$. Für Paris ging aus dem Aide-mémoire nicht hervor, daß Bonn auf einen Verbleib der französischen Soldaten besonderen Wert legte ${ }^{490}$. Die Replik, die der Bundesregierung am 18. Mai übergeben wurde, fiel deshalb ebenso scharf aus. Frankreich verlangte vor jeglichen weiteren bilateralen Gesprächen eine Grundsatzentscheidung der Bundesrepublik, daß sie die weitere Stationierung französischer Truppen auf ihrem Territorium wünsche. Sollte dies nicht der Fall sein, erklärte sich die französische Regierung bereit, ihre Streitkräfte ab dem 1. Juli 1966 abzuziehen. Der Rückzug könne binnen einen Jahres über die Bühne gehen, teilte man Bonn mit ${ }^{491}$. Wie Carstens aus französischen Quellen erfuhr, beabsichtigte man an der Seine, dann die Schuld für das Zerwürfnis der Bundesrepublik „in die Schuhe zu schieben" 492 .

In Anbetracht des Konfrontationskurses, auf dem sich Bonn und Paris im Mai 1966 befanden, kamen in der Bundesrepublik starke Zweifel an der Politik der Bundesregierung auf. Bereits am 5. April vermerkte Krone in seinem Tagebuch: „Schröder riskiert den totalen Bruch mit Frankreich. “493 Im Gegensatz zu Schröder und Erhard wollte die Mehrheit der Bundestagsabgeordneten von CDU/CSU in jedem Fall den Verbleib der französischen Streitkräfte in der Bundesrepublik. Strauß und Barzel empfanden das Aide-mémoire der Bundesregierung vom 3. Mai als zu hart und bedrängten den Kanzler, sich unter allen Umständen mit Paris zu einigen ${ }^{494}$. In den Fraktionssitzungen der Union schlug dem Außenminister scharfer Protest entgegen, wobei sich vor allem Guttenberg scharf gegen Schröders Kurs wandte 495 . Er war der Ansicht, ein Abzug sei „ein Schritt von geschichtlicher Tragweite“, der im Interesse der Bundesrepublik „beinahe um jeden Preis“ verhindert werden müsse. Der Abgeordnete befürchtete, Paris werde andernfalls seine Deutschland-Politik zum Nachteil Bonns revidieren ${ }^{496}$. Auch der außenpolitische Arbeitskreis der CDU/CSU-Fraktion hatte „schwerste Beden-

489 Note der Bundesregierung vom 3. 5. 1966 an Frankreich, in: EUROPA-ARCHIV 1966, D 255-257 (257).

$490 \mathrm{Vgl}$. SEYdOUX, Meine zweite Mission, S. 85.

491 Für den Wortlaut der französischen Note vom 18. 5. 1966 an die Bundesregierung vgl. EUROPA-ARCHIV 1966, D $335 \mathrm{f}$.

492 Aufzeichnung des Staatssekretärs Carstens vom 16. 5. 1966, in: AAPD 1966, Dok. 149, S. 634.

493 Zitiert nach HeNTSCHEL, Ludwig Erhard, S. 605.

494 Vgl. CARSTENS, Erinnerungen, S. 258; OSTERHELD, Außenpolitik, S. 313 f..

495 Vgl. CARSTENS, Erinnerungen, S. 258; WIRZ, Karl Theodor von und zu Guttenberg und das Zustandekommen der Großen Koalition, S. 419-424.

496 Schreiben Guttenbergs an Barzel vom 5.5. 1966. Zitiert nach MarcowITZ, Option, S. 218. 
ken gegen die derzeitige Außen- und Verteidigungspolitik“497. Seine Mitglieder warfen Schröder und von Hassel vor, sie wollten gegen den Willen der Parteimehrheit Frankreich aus der Bundesrepublik vertreiben ${ }^{498}$. Adenauer meldete sich ebenfalls zu Wort und forderte öffentlich den Verbleib der französischen Armee ${ }^{499}$. Der Vorsitzende des Auswärtigen Ausschusses des Bundestags, Hermann Kopf, warnte Schröder ebenfalls vor einem Abzug der französischen Soldaten. Dieser, so der CDU-Abgeordnete, würde sich für die Bundesrepublik „verhängnisvoll“" auswirken ${ }^{500}$. Selbst in London und Washington regte sich Kritik an der Haltung der Bundesregierung. Es wurde die Besorgnis laut, ob die Bundesrepublik durch ihr starrköpfiges Verhalten gegenüber de Gaulle nicht der NATO im ganzen und den westlichen Interessen im allgemeinen schade ${ }^{501}$. Die britische Regierung ließ der Bundesregierung ausrichten, sie teile deren Interpretation nicht, daß Frankreich mit dem Austritt aus der militärischen Integration sein Stationierungsrecht verliere ${ }^{502}$.

Schröder ließ sich von alldem nicht beirren. Er wies Botschafter Knappstein an, die amerikanische Regierung davor zu warnen, auf de Gaulles Seite zu schwenken. Der Diplomat sollte im State Department zum Ausdruck bringen, es würde das Vertrauen der Bundesrepublik in die USA „auf das schwerste erschüttern“, wenn Washington in dieser Frage Bonn in den Rücken falle ${ }^{503}$. Gegenüber McGhee bekräftigte er seine Position, daß die französischen Truppen die Bundesrepublik verlassen müßten, falls de Gaulle die Unterschrift unter die von Bonn vorgelegte Vereinbarung verweigern sollte ${ }^{504}$. Hermann Kopf bekam vom Außenminister zu hören, ein Abzug der französischen Streitkräfte sei zwar zu bedauern, doch „weit negativer" wären "die Wirkungen, die mit einem Verbleiben der französischen Truppen in Deutschland verbunden wären, wenn für ihren Rechtsstatus keine befriedigende Regelung gefunden würde". Dadurch würden nämlich sowohl die Sicherheit als auch die Souveränität der Bundesrepublik beeinträchtigt, was keinesfalls geduldet werden könne. ${ }^{505}$ Auch vor dem Bundestag sprach sich der Außenminister am 25. Mai dafür aus, nicht klein beizugeben. Die Kritik an dem harten und unfreundlichen Ton gegenüber Frankreich, der in der Note vom 3. Mai zum Ausdruck kam, wies er als unberechtigt zurück: „Nun, hart und unfreundlich sind doch bestenfalls oder schlimmstenfalls diejenigen, die eine solche Krise ausgelöst

497 Bericht über die Sitzung des Arbeitskreises V am 3. 5. 1966. Zitiert nach HENTSCHEL, Ludwig Erhard, S. 609.

498 Vgl. ebenda, S. 608.

499 Vgl. den Artikel „Erhard will unnötigen Streit mit Frankreich vermeiden“, in: DIE WELT vom 23. 5. 1966, S. 1.

500 Schreiben Kopfs an Schröder vom 6. 5. 1966, PA/AA, Ministerbüro, Bd. 335.

$501 \mathrm{Vgl}$. den Drahtbericht des Botschafters Knappstein, Washington, an Bundesminister Schröder vom 18. 5. 1966, in: AAPD 1966, Dok. 155, S. 650-652.

$502 \mathrm{Vgl}$. die Aufzeichnung des Vortragenden Legationsrats I. Klasse Blomeyer-Bartenstein vom 29. 4. 1966, PA/AA, B 150, Aktenkopien 1966.

503 Vgl. den Drahterlaß des Bundesministers Schröder an Botschafter Knappstein, Washington, vom 20. 5. 1966, PA/AA, B 150, Aktenkopien 1966.

504 Vgl. OSTERHELD, Außenpolitik, S. 314.

505 Schreiben des Bundesministers Schröder an den CDU-Abgeordneten Kopf vom 10. 10. 1966, in: AAPD 1966, Dok. 145, S. 621-624 (624). 
haben." 506 Auf der Bundestagung des Evangelischen Arbeitskreises unterstrich er nochmals, daß eine neue Vereinbarung unter Berücksichtigung der Prinzipien von Gleichberechtigung und Gegenseitigkeit geschlossen werden müßte: „Alles andere wäre ein Rückfall in besatzungsähnliche Zustände “507. Intern ließ er keinen Zweifel daran, daß ihn nichts davon abhalten konnte, den sogenannten Gaullisten "tödlich entschlossen entgegen[zu]treten" 508 . Erhard bewunderte seinen Außenminister zwar wegen seiner Standfestigkeit, doch warnte er ihn, den Einfluß seiner innerparteilichen Gegner, speziell in der Frage des Verbleibs der französischen Streitkräfte, nicht zu unterschätzen ${ }^{509}$. Der Kanzler wußte, daß es sich die Bundesregierung weder innen- noch außenpolitisch leisten konnte, den Bogen noch weiter zu überspannen. Am 25. Mai erklärte er deshalb vor dem Bundestag, die Bundesregierung wünsche den Verbleib der französischen Truppen in Deutschland 510 .

Damit war die Forderung der französischen Regierung nach einer Vorabentscheidung der Bundesregierung erfüllt. Paris erklärte sich nun auch zu Verhandlungen über den Rechtsstatus seiner Truppen sowie über die künftige Zusammenarbeit mit den anderen NATO-Verbänden bereit ${ }^{511}$. Der erste Problemkreis wurde ab dem 13. Juni 1966 in bilateralen Verhandlungen erörtert, der zweite im Rahmen der NATO512. Die Verhandlungen mit Frankreich gestalteten sich jedoch überaus schwierig. Schröder bekannte am 7. September gegenüber McGhee, die Gespräche verliefen „miserabel“513. Eine Annäherung der Standpunkte war nicht in Sicht. Das Auswärtige Amt machte dafür die zahlreichen öffentlichen Appelle von deutschen Politikern verantwortlich, die Bundesregierung dürfe die französischen Truppen nicht gehen lassen. Carstens beklagte, dadurch sei die eigentlich starke Verhandlungsposition der Bundesrepublik untergraben worden. Erneut sei das eingetreten, was schon seit einiger Zeit zu beobachten sei, nämlich, daß ausländische Regierungen die Erklärungen Bonns "nicht ernst“ nähmen, stellte der Staatssekretär bedauernd fest. Nicht Paris, wie man an der Koblenzer Straße beabsichtigt hatte, geriet schließlich unter Druck, sondern die Bundesregierung ${ }^{514}$.

506 BT STENOGRAPHISCHE BERICHTE, Bd. 61, S. 1839.

507 Rede Schröders vor der 13. Bundestagung des Evangelischen Arbeitskreises am 20. 5. 1966, in: BuLLETIN 1966, S. 545.

508 OSTERHELD, Außenpolitik, S. 319.

509 Vgl. ebenda.

510 Vgl. BT STENOGRAPHISCHE BERICHTE, Bd. 61, S. 2027.

511 Vgl. OsterhelD, Außenpolitik, S. 322. Vgl. auch den Runderlaß des Vortragenden Legationsrats I. Klasse Scheske vom 3. 6. 1966, PA/AA, B 150, Aktenkopien 1966.

$512 \mathrm{Zu}$ den Verhandlungen vgl. die Weisung des Bundesministers Schröder an Ministerialdirektor Meyer-Lindenberg vom 10. 6. 1966, in: AAPD 1966, Dok. 190, S. 809-812.

513 Gespräch des Bundesministers Schröder mit dem amerikanischen Botschafter McGhee am 7. 9. 1966, in: ebenda, Dok. 275, S. 1157.

514 Aufzeichnung des Staatssekretärs Carstens vom 3. 8. 1966, in: ebenda, Dok. 244, S. 10261029 (1028). So setzte beispielsweise Freiherr von und zu Guttenberg seinen Konfrontationskurs gegen Schröder fort und holte zusammen mit dem Landesvorsitzenden der CDU Rheinland-Pfalz, Helmut Kohl, am 25. 6. 1966 in Deidesheim „zu einer Generalabrechnung mit der gegenwärtigen Außenpolitik der Bundesregierung aus“. Vgl. WIRZ, Karl Theodor von und zu Guttenberg und das Zustandekommen der Großen Koalition, S. 425 . 
In Wahrheit führten aber nicht die taktischen Fehler der deutschen Seite zum Stillstand der Verhandlungen. Wie Couve de Murville in seinen Erinnerungen andeutet, hatte sich die französische Regierung aus Ärger über das Verhalten der Regierung Erhard entschieden, die Beratungen zu verschleppen. Kaum war in Bonn der Regierungswechsel über die Bühne gegangen, verhielt sich Paris weitaus entgegenkommender. So konnte die seit dem 1. Dezember 1966 amtierende Große Koalition unter Kanzler Kiesinger sehr rasch eine Einigung mit Frankreich erzielen ${ }^{515}$. Bereits am 21. Dezember regelten die beiden Staaten in einem Briefwechsel den Rechtsstatus der französischen Streitkräfte in der Bundesrepublik ${ }^{516}$ und setzten damit ein Zeichen für einen Neuanfang in den beiderseitigen Beziehungen.

515 Vgl. Couve de Murville, Außenpolitik, S. 217 und S. $219 \mathrm{f}$.

516 Für den Wortlaut der Schreiben der Außenminister Couve de Murville und Brandt vom 21. 12. 1966 vgl. Bulletin 1966, S. 1304 f. Vgl. dazu auch die Aufzeichnung des Ministerialdirektors Meyer-Lindenberg vom 19. 12. 1966, in: AAPD 1966, Dok. 401, S. 16621664. 


\section{Entspannung ohne Fortschritte in der deutschen Frage?}

\section{Schröders „Politik der Bewegung“}

Zweifellos ist wohl kein Begriff aus der politischen Terminologie Gerhard Schröders von Forschung und Öffentlichkeit so mißverstanden worden wie derjenige der Politik der Bewegung. Dies ist im wesentlichen darauf zurückzuführen, daß Schröder diese Formel, die er erstmals im Herbst 1963 zur Charakterisierung seiner Politik benutzte, nie eindeutig definiert hat. Auch im Auswärtigen Amt war man sich offenbar nicht ganz im klaren, welche Vorstellungen der Minister damit verband. So soll selbst der Pressesprecher des Amts, Hans Joachim Hille, nicht in der Lage gewesen sein, den Begriff plausibel zu erklären ${ }^{1}$. Schröder hat den Terminus Politik der Bewegung in der Öffentlichkeit nur ein einziges Mal näher erläutert. In einem Interview mit dem NDR am 4. November 1963 beschrieb er ihn folgendermaßen: „Wir brauchen in einer Situation wie dieser eine Politik, die absolut bereit ist, die Tatsachen neu zu analysieren. Und sie wird zu dem Ergebnis kommen, daß wir nicht weitergekommen sind, und wie ich glaube, kaum weiter kommen könnten, wenn wir sozusagen das Gegenteil einer Politik der Bewegung oder der Beweglichkeit betreiben wollen, nämlich eine Politik der Starre, eine Politik des Festungsdenkens, eine Politik des sozusagen im Graben-beharrens. Ich habe die Überzeugung, daß man Positionen, die man vielleicht für ganz gefestigt hält, nicht einfach dadurch festhalten kann, daß man nicht weitere Bemühungen um eine Verbesserung anstellt, sondern mehr oder weniger abwartet. Und deswegen müssen wir sorgfältig alle neuen Chancen abwägen in der Bereitschaft, Chancen zu ergreifen, wo immer sie sich zeigen mögen.“2 Aufgrund dieser Äußerung wurde die Politik der Bewegung zumeist mit der von Schröder initiierten Neuausrichtung der Ostpolitik der Bundesrepublik identifiziert ${ }^{3}$. Tatsächlich hatte sie jedoch nur indirekt damit zu tun. Auf der richtigen Spur befindet sich Rüdiger Marco Booz, der sie als offensive Komponente der Hallstein-Doktrin begreift; genauer gesagt, als einen Teil des Konzepts, die DDR im Ostblock zu isolieren ${ }^{4}$.

Korrekt ist, daß die Politik der Bewegung in der Tat eng mit Schröders Deutschland-Politik verbunden war. Die Überlegungen des Außenministers setzten bei dem Problem an, wie die Deutschland-Frage in die nach der Kuba-Krise im Herbst 1962 einsetzenden amerikanisch-sowjetischen Bemühungen um eine Entspannung im Ost-West-Konflikt eingebracht werden konnte. Er sah die Gefahr, daß ein Ende des Kalten Krieges die Aussichten auf eine Lösung der deutschen Frage schmälern würde: „Die Spannung habe aber [...] die Frage als solche offengehalten, während eine Entspannung dazu führen könnte, daß sie verschwindet. " ${ }^{5}$ Schröder sorgte sich zudem, daß zunehmend allein die Bundesrepublik ins Kreuzfeuer der sowjetischen Propaganda geriet. Nur Bonn, so war aus

1 Vgl. Kusterer, Der Kanzler und der General, S. 421.

2 Interview Schröders mit dem NDR am 4.11. 1963, in: Bulletin 1963, S. 1736.

3 So z.B. zuletzt McAdams, The New Diplomacy of the West German Ostpolitik, S. 541.

4 Vgl. Booz, „Hallsteinzeit“, S. 99.

5 Gespräch des Bundesministers Schröder mit dem amerikanischen Außenminister Rusk am 20. 9. 1963 in Washington, in: AAPD 1963, Dok. 349, S. 1162. 
Moskau immer wieder zu hören, stünde aufgrund seiner Forderungen nach Revision der Grenzen in Mitteleuropa einer Verbesserung des Verhältnisses zwischen den beiden Blöcken entgegen. Es galt aber für die Zukunft unbedingt zu verhindern, daß sich - wie es beim Atomteststopp-Abkommen geschehen war - „die zwei großen Weltmächte über alle möglichen Fragen einigten, ohne sich der deutschen Frage zu widmen"6. Der Westen, so Schröder, dürfte nicht darauf verzichten, den Status quo in Mitteleuropa in Frage zu stellen, andernfalls würde er sich zusehends verfestigen 7 . Wie er am 2. Oktober 1963 vor der CDU/CSU-Bundestagsfraktion erläuterte, müßte die Bundesregierung von einer „Politik des bloßen Nein" Abstand nehmen, weil sie in der Praxis zu einer Verschlechterung der deutschlandpolitischen Ausgangssituation führte. Seines Erachtens war der Status quo „nur durch Bewegung lebendig zu halten als eine Hoffnung für die Menschen in Berlin, in der Zone und im Bewußtsein der Welt, als eine der entscheidenden Fragen, wenn man wirklich Entspannung haben wolle, die man nur haben könne, wenn man an ihre Ursache herangehen will" 8 . Dies bedeutete für ihn zum einen, daß die Bundesrepublik für die Wiedervereinigung „mit allen denkbaren Mitteln kämpfen, aber keine starre Doktrin benutzen" sollte9, da Fortschritte nur bei mehr politischer Bewegung erreicht werden könnten ${ }^{10}$, zum anderen, daß der Westen bei Verhandlungen mit der UdSSR die ungelöste deutsche Frage nicht beiseite schieben dürfe. Bereits zwei Wochen zuvor hatte Schröder Rusk darauf hingewiesen, daß aus seiner Sicht auf Fortschritte bei den zentralen Fragen - also bei der Überwindung der Teilung Deutschlands - bestanden werden müßte, wenn mit der Sowjetunion Abmachungen über Randprobleme des Ost-West-Verhältnisses getroffen würden. Ansonsten würde nicht der Westen, sondern nur die UdSSR ihre Position verbessern" ${ }^{11}$ Unter einer "Politik der Bewegung" verstand er, nach „neuen Wegen zu suchen“, um das Verhältnis zum Osten aufzulockern, dabei aber das Deutschland-Problem nicht zu vergessen: „Zwischen der Lösung anderer Fragen und der Lösung der Deutschlandfrage bestehe ein Verhältnis wie zwischen kommunizierenden Röhren." 12 Schröder erklärte, daß sich die Bundesrepublik nur dann an Verständigungsbemühungen mit dem Osten beteiligen könnte, wenn die Westmächte an dem Ziel festhielten, die Lage in Mitteleuropa zu verändern ${ }^{13}$. Auch gegenüber Acheson machte er am 19. Oktober 1963 deutlich, daß nur „eine künstliche Entspannungsatmosphäre" entstünde, wenn die zentralen Fragen dabei außer acht blieben. Die Folge wäre ein Schwinden des Zusammenhalts des We-

6 Gespräch des Bundesministers Schröder mit Präsident Kennedy am 24.9. 1963 in Washington, in: ebenda, Dok. 361, S. 1217.

7 Gespräch des Bundesministers Schröder mit dem amerikanischen Außenminister Rusk am 20. 9. 1963 in Washington, in: ebenda, Dok. 349, S. 1160.

8 Protokoll der CDU/CSU-Fraktionssitzung am 2. 10.1963, ACDP VIII-001-1009/3.

9 So Schröder am 8. 1. 1964 vor der FDP-Fraktion. Zitiert nach SCHOLLWER, FDP im Wandel, S. 181, Anm. 3.

10 Vgl. ebenda, Eintrag vom 8. 1. 1964, S. 181.

11 Gespräch des Bundesministers Schröder mit dem amerikanischen Außenminister Rusk am 20. 9. 1963 in Washington, in: AAPD 1963, Dok. 349, S. 1158-1160.

12 Ebenda, S. 1160.

13 Vgl. ebenda, S. 1158-1160. 
stens und ein Erlahmen des Willens zur Verteidigung, obwohl die sowjetische Bedrohung in Wahrheit unverändert akut wäre. Nochmals bekräftigte er, daß Bonn alle Absprachen mit der UdSSR ablehnen würde, „wenn sie für Deutschland keine Verbesserungen mit sich brächten, weil durch diese anderen Abmachungen ja das deutsche Problem sozusagen begraben werde" 14 .

Die Politik der Bewegung bestand folglich aus einer defensiven und einer offensiven Komponente. In einem Interview des Außenministers mit dem Deutschlandfunk am 6. Oktober 1963 tritt besonders deutlich zutage, daß das Konzept auf zwei Säulen beruhte. Schröder legte dar, daß eine Vereinbarung, die der Westen mit der UdSSR treffe, weder zu einer Aufwertung oder gar Anerkennung der DDR führen, noch eine Diskriminierung Deutschlands zur Folge haben dürfte. Die Minimalforderung, die die Bundesrepublik an die westliche Entspannungspolitik stellte, lautete also, eine Zementierung bzw. Verschlechterung der Ausgangslage nicht zuzulassen. Soweit die defensive Seite der Politik der Bewegung. Darüber hinaus sollte der Westen deutschlandpolitisch aktiv bleiben und gegenüber Moskau die Teilung Deutschlands zur Sprache bringen. Um so bedeutsamer eine Vereinbarung mit der UdSSR wäre, um so mehr sollten nach dem Willen Schröders die Kernprobleme des Ost-West-Verhältnisses Berücksichtigung finden: „Je gewichtiger die militärische Entspannungsmaßnahme ist, desto stärker muß dabei die deutsche Frage ins Spiel gebracht werden."15 Dies war der offensive Teil seines Programms. Wenn Schröder den Standpunkt vertrat, man dürfe, obwohl die Sowjetunion ihre aggressiven Ziele nicht aufgegeben habe, „nicht im Festungsdenken verharren“, da eine "politische Maginot-Linie keine Sicherung" darstelle, dann wird aus dem Zusammenhang deutlich, daß er dabei nicht an eine Revision der bisherigen Deutschland-Politik dachte, sondern zum Ausdruck bringen wollte, daß die Wiederherstellung der staatlichen Einheit Deutschlands nur erreicht werden könnte, wenn man eine aktivere Politik betrieb ${ }^{16}$.

Mit der Politik der Bewegung suchte er Entspannungs- und Deutschland-Politik miteinander zu verbinden. Das Konzept war ohne Zweifel eine Reaktion auf den angloamerikanischen Wunsch nach einer Verständigung mit der UdSSR. Weder Briten noch Amerikaner waren zur Wiederaufnahme einer Politik der Stärke bereit, wie sie in den fünfziger Jahren gegenüber der Sowjetunion betrieben wurde. Lord Home erklärte kategorisch, der alte Kurs habe nicht nur keinen Erfolg gehabt, sondern auch zu einer Verhärtung der Fronten geführt ${ }^{17}$. Auch Rusk wies darauf hin, mit der bisherigen Politik sei man der Wiedervereinigung "nicht einen Zentimeter näher gekommen“ ${ }^{18}$. Schon allein im Hinblick auf die verteidi-

14 Gespräch des Bundesministers Schröder mit dem ehemaligen amerikanischen Außenminister Acheson am 19. 10. 1963, in: ebenda, Dok. 394, S. 1344.

15 Interview Schröders mit dem DLF am 6. 10. 1963, in: Bulletin 1963, S. 1544.

16 Gespräche des Bundesministers Schröder mit dem japanischen Außenminister Ohira am 7./8. 11. 1963 in Tokio, in: AAPD 1963, Dok. 410, S. $1420 \mathrm{f}$.

17 Vgl. das Gespräch des Bundesministers Schröder mit dem amerikanischen Außenminister Rusk und dem britischen Außenminister Lord Home am 27.9. 1963 in New York, in: ebenda, Dok. 367, S. 1243.

18 Gespräch des Bundesministers Schröder mit dem amerikanischen Außenminister Rusk am 20.9. 1963 in Washington, in: ebenda, Dok. 349, S. 1161. 
gungspolitische Abhängigkeit der Bundesrepublik von den Vereinigten Staaten konnte Bonn bei einer Kursänderung der westlichen Politik gegenüber Moskau auf Dauer nicht abseits stehen. Schröder gab deshalb den Verbündeten die $\mathrm{Zu}$ sicherung, daß die Unterschrift der Bundesrepublik unter das AtomteststoppAbkommen keine Ausnahme gewesen sei, sondern Bonn sich auch weiterhin an peripheren Entspannungsmaßnahmen beteiligen werde, wenn schließlich auch die "Beseitigung der Spannungsherde" in Angriff genommen und dem Selbstbestimmungsrecht in der DDR Geltung verschafft würde ${ }^{19}$. Die Bundesregierung, so versicherte er den NATO-Partnern, sei willens, "frei von Starrheit und Dogma“ zu handeln, falls der Westen sein bisheriges Ziel nicht aufgebe, nämlich: „Nicht nur die Freiheit dort zu sichern, wo sie besteht, sondern die Freiheit dort wiederherzustellen, wo sie verlorengegangen ist." 20

Wie wirkte sich nun die Politik der Bewegung auf die Haltung der Bundesrepublik zu bestimmten Entspannungsmaßnahmen aus? Was den bereits am 10. Mai 1955 von der UdSSR vorgebrachten Gedanken betraf, auf dem Territorium der Mitgliedstaaten von NATO und Warschauer Pakt Bodenbeobachtungsposten einzurichten, die Überraschungsangriffe unmöglich machen sollten ${ }^{21}$, verlangte Schröder, Deutschland dürfe nicht diskriminiert werden, indem diese nur auf dem Boden von Bundesrepublik und DDR tätig würden. Das Kontrollsystem sollte nach seinen Vorstellungen geographisch nicht begrenzt, zumindest so weit ausgedehnt wie möglich sein. Außerdem müßte eine Aufwertung der DDR ausgeschlossen werden 22. Daher sollte es zu keiner Unterzeichnung eines entsprechenden Abkommens durch Ost-Berlin kommen. Eine Anerkennungsgefahr bestand aber auch durch eine Stationierung westlicher Kontrollposten in der DDR, da diese, wenn sie ihrem Auftrag nachgingen, zwangsläufig mit den örtlichen Behörden in Kontakt treten würden. Aus diesem Grund schlug Schröder auf deutschem Territorium die Anwendung eines Vier-Mächte-Systems vor: Die auf beiden Seiten der ehemaligen Zonengrenze bestehenden alliierten Militärmissionen sollten die Aufgaben der Bodenbeobachtungsposten übernehmen ${ }^{23}$. Er stieß sich allerdings daran, daß die Sowjetunion ihren Vorschlag mit der Forderung nach einer Reduzierung der Streitkräfte verband. Der Außenminister warf Moskau vor, es

19 Rede Schröders vor dem Evangelischen Arbeitskreis am 3. 4. 1964 in München, in: BuLLETIN 1964, S. 505.

20 Rede Schröders vor dem NATO-Ministerrat am 15.12. 1964 in Paris, in: ebenda, S. 1729.

21 Diesen Vorschlag legte die UdSSR am 30.4 1957 und am 5. 5. 1958 in modifizierter Form erneut vor. Jetzt sollten die Kontrollposten nur noch in Zonen stationiert werden, in denen auch Luftbildaufnahmen erlaubt wären. Am 12.12. 1962 griffen ihn die USA auf und legten ihn der Konferenz des 18-Mächte-Abrüstungsausschusses in Genf vor. Vgl. dazu DOCUMENTS ON DiSARMAMENT 1945-1959, S. 466, S. 785 und S. 1033, bzw. DOCUMENTS ON DISARMAMENT 1962, S. 1217.

22 Vgl. das Interview Schröders mit dem NDR am 4. 11. 1963, in: BULLETIN 1963, S. 1738.

23 Vgl. die deutsch-britische Regierungsbesprechung am 15.1.1964 in London, in: AAPD 1964, Dok. 13, S. 59 f. In Potsdam existierte je eine amerikanische, französische und britische Mission. Auch die UdSSR verfügte in jeder der drei früheren westlichen Besatzungszonen über eine militärische Vertretung, nämlich in Frankfurt/Main, Baden-Baden und Bünde in Nordrhein-Westfalen. 
wolle mit Hilfe der Bodenbeobachtungsposten die westliche Position untergraben. Nach seiner Einschätzung verfolgte der Kreml damit das Ziel, die Vertreibung der USA aus Europa und die Schaffung einer atomwaffenfreien Zone in Deutschland zu erreichen ${ }^{24}$. Trotz der Bedenken erweckte die Bundesregierung jedoch weiterhin den Eindruck, als ob sie sich prinzipiell eine Beteiligung an einem Kontrollsystem dieser Art vorstellen könnte ${ }^{25}$. In Wahrheit hoffte Bonn aber, es werde nicht zu einer Vereinbarung kommen, wie Schröder am 15. Februar 1964 gegenüber Couve de Murville zugab. Aufgrund des allgemeinen Interesses an Entspannungsmaßnahmen könne es sich die Bundesrepublik jedoch nicht erlauben, sich offen gegen dieses Vorhaben zu stellen, erklärte er seinem französischen Amtskollegen ${ }^{26}$.

Auch den auf der Genfer Gipfelkonferenz der Vier Mächte im Jahr 1955 erstmals diskutierten sowjetischen Vorschlag, einen Nichtangriffspakt zwischen NATO und Warschauer Pakt zu schließen27, bewertete Schröder negativ. Er war der Ansicht, daß die UdSSR damit im Sinn habe, den Status quo in Europa vertraglich zu fixieren. Ebenso wie bei den Bodenbeobachtungsposten sah er zudem die Gefahr, daß nach Abschluß einer Nichtangriffsvereinbarung die Verteidigungsbereitschaft in den westlichen Staaten nachlassen könnte ${ }^{28}$. Selbstverständlich spielte in diesem Zusammenhang auch die Anerkennungsproblematik wieder eine Rolle. Die Diskussion um das Atomteststopp-Abkommen hatte zwar gezeigt, daß es verschiedene Möglichkeiten gab, eine völkerrechtliche Anerkennung auszuschließen, wenn die DDR einen internationalen Vertrag mitunterzeichnete, Schröder befürchtete aber, daß man ,in die Nähe einer laufenden Aufwertung“ der DDR käme, wenn derartige Verfahren zur Routine würden ${ }^{29}$. Nach seiner Überzeugung sollte eine Nichtangriffsvereinbarung ohnehin erst geschlossen werden, wenn in Europa ein für beide Seiten akzeptabler Zustand geschaffen wäre. Ein solches Abkommen konnte in seinen Augen nur die „letzte Verzierung der Torte" $\operatorname{sein}^{30}$. Priorität müßte zunächst eine befriedigende Regelung der Berlin-Frage sowie Fortschritte bei der Lösung des Deutschland-Problems haben ${ }^{31}$.

24 Vgl. das Gespräch des Bundesministers Schröder mit dem britischen Außenminister Butler am 9. 12. 1963, in: AAPD 1963, Dok. 459, S. 1580.

25 Vgl. das Gespräch des Bundeskanzlers Erhard mit Ministerpräsident Erlander am 9.3. 1964, in: AAPD 1964, Dok. 67, S. 329.

26 Vgl. das Gespräch des Bundesministers Schröder mit dem französischen Außenminister Couve de Murville am 15.2. 1964 in Paris, in: ebenda, Dok. 67, S. 329.

27 Am 21. 7. 1955 legte der damalige sowjetische Ministerpräsident Bulganin einen Entwurf für einen „Vertrag zwischen den in Europa bestehenden Staatengruppierungen (Grundprinzipien)“ vor. Für den Wortlaut vgl. DzD III/1, S. 191-195.

28 Vgl. das Schreiben des Bundesministers Schröder an den französischen Außenminister Couve de Murville vom 15. 8. 1963, in: AAPD 1963, Dok. 304, S. $1029 \mathrm{f}$.

29 Gespräch des Bundesministers Schröder mit dem britischen Außenminister Butler am 9. 12. 1963, in: ebenda, Dok. 459, S. 1582.

30 Ebenda, S. 1581.

31 Vgl. das Gespräch des Bundesministers Schröder mit dem amerikanischen Außenminister Rusk und dem britischen Außenminister Lord Home am 27.9. 1963 in New York, in: ebenda, Dok. 367, S. 1240. 
Moskau lehnte es jedoch kategorisch ab, in Verbindung mit einem Nichtangriffspakt die Deutschland-Frage zu erörtern ${ }^{32}$.

Hinsichtlich des geplanten Nichtverbreitungsabkommens für Kernwaffen, postulierte Bonn zunächst ein Junktim zwischen diesem Abkommen und dem Zustandekommen der MLF. Ab Dezember 1964 bemühte sich die Bundesregierung dann, von ihren Verbündeten Unterstützung für ihre Position zu erhalten, daß ein vertraglicher Verzicht der Bundesrepublik auf Atomwaffen von Fortschritten in der Deutschland-Frage abhängig gemacht werden müßte ${ }^{33}$. Obwohl sich die amerikanische Regierung 1964/65 bereits vom Projekt einer multilateralen Atomflotte verabschiedet hatte, versprach Rusk noch Anfang Juli 1965 Botschafter Knappstein: „There will be no non-proliferation treaty without MLF“34. Gleichzeitig erklärte er jedoch unmißverständlich, daß die Vereinigten Staaten „angesichts der weltweiten Bedeutung" eines Nichtverbreitungsvertrags eine Kopplung mit dem Deutschland-Problem ablehnten ${ }^{35}$. Ministerialdirigent Ruete legte daraufhin am 20. Juli 1965 der Führungsspitze des Auswärtigen Amts nahe, auf dieses Junktim zu verzichten ${ }^{36}$, aber Carstens und Schröder ließen sich nicht umstimmen ${ }^{37}$. Beide bestanden ferner darauf, ein Nichtverbreitungsabkommen müßte eine sogenannte Disclaimer-Klausel enthalten, derzufolge ein Beitritt der DDR nicht ihre völkerrechtlichen Anerkennung bedeute ${ }^{38}$. Anfang September 1966 regte Schröder ein abgestuftes Vorgehen an, um die Anerkennungsproblematik vollständig zu umgehen. Nach seinen Vorstellungen sollten nur die Atommächte einen Vertrag schließen, in dem sie sich verpflichteten, keine Kernwaffen weiterzugeben. Die NichtNuklearstaaten von NATO und Warschauer Pakt sollten hingegen gegenüber ihren jeweiligen Partnern einseitige Erklärungen abgeben, daß sie auf den Besitz von Kernwaffen verzichten würden ${ }^{39}$. Dieser Vorschlag stieß jedoch bei den Partnern der Bundesrepublik auf wenig Zustimmung ${ }^{40}$.

Auch das Vorhaben der Sowjetunion, eine Europäische Sicherheitskonferenz einzuberufen, wurde von Bonn überaus kritisch beurteilt. Am 27. April 1966

32 Vgl. ebenda, S. 1242; sowie das Gespräch des Bundesministers Schröder mit dem britischen Außenminister Lord Home am 14. 8. 1963, in: ebenda, Dok. 299, S. 1003-1006.

33 Vgl. dazu die Aufzeichnung des Ministerialdirigenten Ruete vom 20.7. 1965, in: AAPD 1965, Dok. 288, S. 1203-1205.

34 Drahtbericht des Botschafters Knappstein, Washington, an das Auswärtige Amt vom 9. 7. 1965, in: ebenda, Dok. 275, S. 1157.

35 Ebenda, S. 1156.

36 Vgl. die Aufzeichnung des Ministerialdirigenten Ruete vom 20.7. 1965, in: ebenda, Dok. 288, S. $1207 \mathrm{f}$.

37 Vgl. ebenda, S. 1208, Anm. 34; den Runderlaß des Staatssekretärs Carstens vom 21. 7. 1965, in: ebenda, Dok. 295, S. 1231 f.; sowie das Schreiben des Bundesministers Schröder an den amerikanischen Außenminister Rusk vom 27.7. 1965, in: ebenda, Dok. 306, S. $1285 \mathrm{f}$.

38 Vgl. den Runderlaß des Staatssekretärs Carstens vom 21.7. 1965, in: ebenda, Dok. 295, S. $1231 \mathrm{f}$.

39 Vgl. das Schreiben des Bundesministers Schröder an den italienischen Außenminister Fanfani vom 7. 9. 1966, in: AAPD 1966, Dok. 276, S. 1158-1161. Schröder griff damit einen Gedanken aus der sogenannten Friedensnote der Bundesregierung vom 25. 3. 1966 auf, auf die im folgenden Kapitel ausführlich eingegangen wird.

40 Vgl. ebenda, S. 1421, Anm. 3. 
hatte Gromyko im Anschluß an einen Besuch in Italien die Konstituierung einer Konferenz angeregt, die sich mit einer Reduzierung der Streitkräfte in Europa, der Schaffung einer atomwaffenfreien Zone sowie der deutschen Frage beschäftigen sollte $^{41}$. Am 5. Juli 1966 veröffentlichten die Staaten des Warschauer Pakts nach einer Tagung des Politischen Beratenden Ausschusses in Bukarest eine Deklaration über Frieden und Sicherheit - die sogenannte Bukarester Erklärung -, in der sie unter anderem diesen Vorschlag wiederholten ${ }^{42}$. Im Endeffekt machte sich der Ostblock damit de Gaulles Konzept zu eigen, die politischen Probleme in Europa könnten am besten in einem europäischen Rahmen gelöst werden. Die Bukarester Erklärung nahm sogar ausdrücklich Bezug auf das französisch-sowjetische Kommuniqué vom 30. Juni 1966, das anläßlich des Besuchs von de Gaulle in der UdSSR veröffentlicht wurde. Darin hatten Moskau und Paris verkündet: „Beide Regierungen stimmen darin überein, daß die Probleme Europas zunächst in einem europäischen Rahmen erwogen werden müssen." ${ }^{43}$ Das Auswärtige Amt bewertete es positiv, daß der Osten in der Bukarester Erklärung nun „ausdrücklich“ den Zusammenhang zwischen der europäischen Sicherheit und der Teilung Deutschlands anerkannte, lehnte aber die vorgeschlagene Sicherheitskonferenz $\mathrm{ab}^{44}$. Man unterstellte dem Kreml, nicht die Lösung der Deutschland-Frage im Auge zu haben, sondern die Absicht zu verfolgen, dort „den Status quo zu fixieren“. Für den Fall, daß eine solche Konferenz tatsächlich einberufen würde, hielt Bonn deshalb eine Beteiligung der USA für "unabdingbar" 45 . Erhard erwartete, daß ohne die Anwesenheit der Vereinigten Staaten auf einer solchen Konferenz über die Neutralisierung und Deklassierung Deutschlands verhandelt werden würde. Die Folgen, so der Kanzler, wären katastrophal: „Die Wiedervereinigung würde der sowjetisch-französischen Kontrolle unterworfen sein. Das wäre das Ende Europas. " ${ }^{46}$ Schröder verlangte zudem eine klare Zusage Moskaus, daß dort auch die Wiederherstellung der staatlichen Einheit Deutschlands auf der Tagesordnung stehen würde ${ }^{47}$ und die DDR an einer solchen Konferenz nicht teilnehmen dürfte ${ }^{48}$. Intern gab er die Parole aus, der sowjetische Plan dürfte keinesfalls in die

41 Vgl. ADG 1966, S. 12469. Vgl. ferner den Drahtbericht des Botschafters Herwarth von Bittenfeld, Rom, an das Auswärtige Amt vom 28. 4. 1966, PA/AA, Referat II A 4, Bd. 778; sowie die Aufzeichnung des Legationsrats I. Klasse Lankes vom 12.5. 1966, PA/AA, B 150, Aktenkopien 1966.

42 Für den Wortlaut der Deklaration der Teilnehmerstaaten des Warschauer Vertrages über die Festigung des Friedens und der Sicherheit in Europa vom 5. 7. $1966 \mathrm{vgl}$. DzD IV/12.2, S. 1061-1071.

43 Französisch-sowjetische Erklärung vom 30.6. 1966, in: EuROPA-ARCHIV 1966, D 389. Zu den Hintergründen der Bukarester Erklärung vom 5. 7. 1966 vgl. HACKER, Der Ostblock, S. 760-762.

44 Drahterlaß des Staatssekretärs Carstens an die Botschaft in Washington und die Ständige Vertretung bei der NATO in Paris vom 16. 6. 1966, in: AAPD 1966, Dok. 195, S. 830.

45 Vgl. ebenda, S. 831.

46 Deutsch-britische Regierungsbesprechung am 23.5. 1966 in London, in: ebenda, Dok. 158, S. 665.

47 Vgl. das Protokoll der CDU/CSU-Fraktionssitzung am 14.6. 1966, ACDP VIII-0011010/2.

48 Vgl. die Ausführungen Schröders im Bundestag am 23.9. 1966: BT STENOGRAPHISCHE BERICHTE, Bd. 61, S. $2897 \mathrm{f}$. 
Tat umgesetzt werden. Ebenso wie der Kanzler sah er darin einen Versuch Moskaus, unter dem Deckmantel der Entspannung die Bundesrepublik in der internationalen Politik zu diskriminieren: „Rüstet die Deutschen ab bis auf den Nullpunkt, bindet sie fest! Garantiert den anderen das System, die Teilung, definitiv! Die ganze famose Konferenz über europäische Sicherheit [...] wird doch überhaupt nur geplant mit diesem Ziel." 49

Im Grunde versuchte die Politik der Bewegung also das aus den fünfziger Jahren stammende Bonner Junktim zwischen Abrüstungsmaßnahmen und Fortschritten bei der Wiedervereinigung im Zeitalter der Entspannung aufrechtzuerhalten. Die Behauptung Couve de Murvilles, diese Politik habe zu einer „militantere[n] Haltung in der Deutschlandfrage" geführt ${ }^{50}$, trifft aber keineswegs zu. Die Position Bonns hatte sich nicht verhärtet. Im Gegenteil, Schröder bemühte sich, sie flexibel an die politischen Veränderungen anzupassen. Wie bereits geschildert, stimmte er ausdrücklich dem amerikanischen Konzept zu, zunächst Vereinbarungen über periphere Fragen mit der UdSSR anzustreben. Im Laufe der Zeit rückte die Regierung Erhard sogar immer mehr von ihrem Ansinnen ab, das Problem der deutschen Teilung in den Entspannungsprozeß mit einzubringen. Am Ende war sie bereit, die Forderung nach der Beseitigung der Spannungsursachen vorläufig zurückzustellen, sofern die mit dem Osten vereinbarten Abrüstungsmaßnahmen weltweite Gültigkeit besäßen ${ }^{51}$. Dennoch führte das ständige Drängen der Bundesregierung, die westliche Entspannungspolitik solle sich auch des DeutschlandProblems annehmen, dazu, daß der Dissens zwischen den Westmächten und der Bundesrepublik im Laufe der Zeit immer größere Ausmaße annahm. Auf dem Treffen der Außenminister der Drei Mächte und der Bundesrepublik am 6. Juni 1966 in Brüssel zeigte sich schonungslos, daß in der Deutschland-Politik keine gemeinsame Basis mehr bestand. Schröder verlangte dort, die Spannungen zwischen Ost und West dürften nicht vollständig abgebaut werden, weil die UdSSR ansonsten das Interesse an einer Lösung der deutschen Frage verlöre. Dieses Ansinnen wiesen seine drei westlichen Amtskollegen jedoch einmütig als abwegig zurück. Sie entgegneten, daß gerade wegen des Ost-West-Konflikts die DeutschlandFrage in den vergangenen zwei Jahrzehnten ein ungelöstes Problem geblieben sei ${ }^{52}$. Schröder mußte zu seinem Leidwesen erfahren, daß Frankreich, Großbritannien und die USA gewillt waren, den Kurs fortzusetzen, den der britische Außenminister Butler bereits am 9. Dezember 1963 in einem Vieraugengespräch offen angekündigt hatte, nämlich, gegenüber dem Osten Entspannungspolitik zu

49 Protokoll der CDU/CSU-Fraktionssitzung am 21.6. 1966, ACDP VIII-001-1010/2. Als Reaktion auf die Bukarester Erklärung vom 5. 7.1966, in der unter anderem auch die Forderung nach einer Auflösung von NATO und Warschauer Pakt erhoben wurde, verabschiedete der NATO-Ministerrat im Dezember 1966 den nach dem belgischen Außenminister benannten Harmel-Bericht. Vgl. dazu sowie zur Vorgeschichte der KSZE: GREwE, Rückblenden, S. 663-678.

50 COUVE DE MURville, Außenpolitik, S. 220.

51 Vgl. dazu die Aufzeichnung des Staatssekretärs Carstens vom 17. 10. 1966, in: AAPD 1966, Dok. 333, S. 1377.

52 Vgl. Couve DE Murville, Außenpolitik, S. $224 \mathrm{f}$. 
betreiben, „unabhängig davon, ob man einer Lösung der zentralen Fragen näherkomme oder nicht ${ }^{\text {“53. }}$.

\section{Ein eigener Beitrag zur Entspannung: Die „Friedensnote“ der Bundesregierung vom 25. März 1966}

Einer der aufsehenerregendsten ostpolitischen Schritte in der Amtszeit Schröders war die Note der Bundesregierung zur Abrüstung und Sicherung des Friedens vom 25. März 1966, die unter dem Begriff Friedensnote bekannt wurde. Sie bildete den „Anfang einer Offensive, die die Welt von der konstitutionellen Friedlichkeit der BRD überzeugen" sollte ${ }^{54}$. Ausgangspunkt für diese Initiative Bonns war eine Aufzeichnung des Leiters des Referats für politische und sozial-ökonomische Strukturfragen des Ostblocks im Auswärtigen Amt, Erwin Wickert, vom 10. Januar 1966, in der er der Bundesregierung empfahl, eigene Entspannungsvorschläge zu präsentieren, um der gegen die Bundesrepublik gerichteten kommunistischen Propaganda den Boden zu entziehen ${ }^{55}$. Die Führung des Auswärtigen Amts griff den Vorschlag auf, dachte aber zunächst nur an eine zusammenfassende Darstellung der Friedens- und Sicherheitspolitik Bonns. Am 2. Februar wies Carstens Ministerialdirektor Krapf an, in der Ostabteilung ein Memorandum vorzubereiten. Der Staatssekretär wollte damit in erster Linie neuen sowjetischen Attacken gegen die Bundesrepublik begegnen, die er für den im März stattfindenden XXIII. Parteitag der KPdSU erwartete. Wickert machte ihn jedoch darauf aufmerksam, daß Bonn aller Voraussicht nach nicht im Mittelpunkt des Parteitags stehen würde, da dieser sich hauptsächlich mit wirtschaftspolitischen und internen Fragen beschäftigen sollte. Gleichzeitig unterstrich er nochmals, daß es nicht genüge, lediglich den Standpunkt der Bundesregierung zur Deutschland-Frage zu wiederholen. Sollte die Note im Ausland Wirkung erzielen, müßte sie auch Anregungen zur Erhöhung der Sicherheit in Europa und zur weltweiten Abrüstung enthalten. Carstens war damit einverstanden ${ }^{56}$. Auch Schröder hielt es für notwendig, in das Memorandum neue Vorschläge zu diesen Bereichen aufzunehmen $^{57}$.

53 Gespräch des Bundesministers Schröder mit dem britischen Außenminister Butler am 9. 12. 1963, in: AAPD 1963, Dok. 459, S. 1582.

54 KRÜGER, Die deutsche Friedensnote, S. 367.

55 Vgl. die Aufzeichnung des Vortragenden Legationsrats I. Klasse Wickert vom 10. 1. 1966, in: AAPD 1966, Dok. 1, S. 3-6. Werner Link sieht in der Friedensnote die praktische Umsetzung des schon erwähnten Bundestagsbeschlusses vom 14.6.1961, in dem die Bundesregierung aufgerufen wurde, ihre Beziehungen zu den osteuropäischen Staaten zu verbessern. Vgl. LINK, Die Deutschland-Politik der Bundesregierungen Erhard und der Großen Koalition, S. 1695. In den Quellen findet sich aber kein Hinweis, daß sich die Autoren der Friedensnote diese Resolution zum Vorbild genommen hätten. Auch im Hinblick darauf, daß der Beschluß bereits fünf Jahre zurücklag, hat er die Abfassung der Note wohl nur indirekt beeinflußt.

56 Vgl. Blasius, Erwin Wickert und die Friedensnote der Bundesregierung vom 25. März 1966, S. 546.

57 Vgl. CARSTENS, Erinnerungen, S. 759. 
Die Federführung für die Abfassung der Note lag bei Wickert. Den sicherheitspolitischen Teil entwarf der Abrüstungsbeauftragte der Bundesregierung, Swidbert Schnippenkötter. Über Osterheld wurde der Text mit dem Bundeskanzleramt abgestimmt ${ }^{58}$. Schon am 24. Februar 1966 legte Wickert einen ersten Entwurf vor. Die Vorlage wurde mehrfach in Hausbesprechungen diskutiert und überarbeitet. Die daraus entstandene Fassung mit Datum vom 7. März wurde dem Kanzler sowie den Bundesministern Krone, von Hassel, Lücke, Schmücker, Dahlgrün und Mende vorgelegt. Am 15. März erhielten die Fraktionsvorsitzenden von CDU/ CSU, SPD und FDP, Barzel, Erler und Freiherr von Kühlmann-Stumm, den Entwurf. Am selben Tag wurden die drei Westmächte informiert ${ }^{59}$. Krone und Erler schlugen einige kleinere Modifikationen vor, die größtenteils noch berücksichtigt wurden ${ }^{60}$. Dagegen ging man auf britische und amerikanische Änderungswünsche nicht mehr ein. Das Auswärtige Amt lehnte es ab, die Note umzuformulieren, da die Veröffentlichung nicht verzögert werden sollte. Grundsätzlich waren die Drei Mächte aber mit dem Inhalt des Memorandums einverstanden. Die amerikanische Regierung hatte im übrigen ausdrücklich betont, daß ihre Änderungswünsche nur als Anregungen zu verstehen seien ${ }^{61}$.

Am 25. März 1966 wurde die Friedensnote den Staaten des Warschauer Pakts mit Ausnahme der DDR - sowie allen Staaten übergeben, zu denen die Bundesrepublik diplomatische Beziehungen unterhielt ${ }^{62}$. In erster Linie richtete sie sich aber an die Regierungen der osteuropäischen Staaten. Ihnen wurde bei der Übergabe mündlich mitgeteilt, die Bundesregierung habe den Wunsch, über ihre Vorschläge in einen umfangreichen Meinungsaustausch einzutreten. Ausdrücklich bat man um eine Stellungnahme ${ }^{63}$. Die Note, die gemäß der Präambel die Friedenspolitik der Bundesrepublik aufzeigen sollte, umfaßte insgesamt sechs Abschnitte. Im

$58 \mathrm{Vgl}$. HAFTENDORN, Sicherheit, S. 287f. Schröder bestand aber darauf, daß die Friedensnote letztendlich sein Werk war. Daß Carstens 1972 die Autorenschaft Wickerts preisgab (vgl. CARSTENS, Die deutsche Friedensnote vom 25. März 1966, S. 384), wurde - so erinnert sich Wickert - von Schröder mißbilligt: „Er allein trug die Verantwortung dafür, und deshalb sollte auch die gesamte deutsche Außenpolitik als von ihm ausgehend dargestellt werden." Vgl. Blasius, Erwin Wickert und die Friedensnote der Bundesregierung vom 25. März 1966, S. 544.

59 Vgl. den Entwurf vom 7.2. 1966 für eine Note der Bundesregierung, in: AAPD 1966, Dok. 58, S. 262-270; sowie ebenda, S. 262, Anm. 1. Die Aussage des Verkehrsministers und Vorsitzenden des Bundesvorstands der Sudetendeutschen Landsmannschaften, HansChristoph Seebohm, er hätte die Note vor der Veröffentlichung nicht zu Gesicht bekommen (vgl. HAFTENDORN, Sicherheit, S. 288), trifft also zu.

$60 \mathrm{Vgl}$. CARSTENS, Erinnerungen, S. 760. Zu den Änderungswünschen vgl. den Entwurf vom 7. 2. 1966 für eine Note der Bundesregierung, in: AAPD 1966, Dok. 58, S. 262; sowie die Aufzeichnung des Vortragenden Legationsrats I. Klasse Wickert vom 17.3. 1966, in: ebenda, Dok. 72, S. 317-319.

61 Vgl. die Aufzeichnung des Vortragenden Legationsrats I. Klasse Wickert vom 19. 3. 1966, in: ebenda, Dok. 73, S. 320 f; sowie BLAsIUS, Erwin Wickert und die Friedensnote der Bundesregierung vom 25. März 1966, S. 550.

62 Für den Wortlaut der Note der Bundesregierung vom 25. 3. 1966 vgl. DzD IV/12, S. 381385.

63 Vgl. dazu die Erklärung der Bundesregierung vom 29. 7. 1966, in: EUROPA-ARCHIV 1966, D $466 \mathrm{f}$. 
ersten Teil bekräftigte die Bundesregierung erneut ihr Ziel, die Wiederherstellung der Einheit Deutschlands anzustreben, beteuerte aber, sie werde die deutsche Frage „nur mit friedlichen Mitteln [...] lösen“64. In den folgenden Absätzen bekundete sie ihren Willen, an der Schaffung eines vereinigten Europa mitzuwirken, in dem alle Völker friedlich und harmonisch miteinander leben könnten. Deswegen, so verkündete Bonn, sei man stark an einer Verbesserung des Verhältnisses zu den osteuropäischen Völkern interessiert. An die Adresse Prags war die Versicherung gerichtet, daß das Münchener Abkommen „von Hitler zerrissen wurde und keine territoriale Bedeutung mehr hat "65. Die Note enthielt also „die Erklärung eines Verzichtes“ und erbrachte somit „eine Vorleistung im Dienste der Verständigung"66. Mit der Ankündigung, für die Wiedervereinigung „Opfer auf sich zu nehmen " 67 , bekannte sich Bonn „auch für die Zukunft zu einer grundsätzlichen Konzessionsbereitschaft"68. Gegenüber Warschau bekräftigte die Bundesregierung ihren Standpunkt, die polnische Westgrenze könne noch nicht abschließend fixiert werden, da „die Regelung der Grenzfragen nach den alliierten Vereinbarungen des Jahres 1945 bis zum Abschluß eines Friedensvertrages mit ganz Deutschland aufgeschoben ist und [...] Deutschland völkerrechtlich in den Grenzen vom 31. Dezember 1937 fortbesteht, solange nicht eine frei gewählte gesamtdeutsche Regierung andere Grenzen anerkennt"69. Dies war das letzte Mal, daß in einem offiziellen Dokument der Bundesrepublik als Gebietsstand Deutschlands auf die Grenzen vom 31. Dezember 1937 verwiesen wurde ${ }^{70}$. Zugleich stellte man aber eine gütliche Regelung in Aussicht: „Wenn zu gegebener Zeit die Polen und die Deutschen über die Grenze in dem gleichen Geiste sprechen, der den Ausgleich zwischen Deutschland und seinen westlichen Nachbarn herbeigeführt hat, dann werden auch Polen und Deutsche sich einigen."71 Die Grenzen vom 31. Dezember 1937 sollten dementsprechend bei Verhandlungen nur den „Ausgangspunkt" bilden 72 .

In den beiden folgenden Abschnitten wies die Bundesregierung entschieden den sowjetischen Vorwurf zurück, sie verfolge eine militaristische und revanchistische Politik, und unterstrich im Gegenzug ihren Friedenswillen. Ausdrücklich bestätigte sie ihren Verzicht auf den Besitz von Kernwaffen und verwies auf die 1954 in Paris dazu abgegebene Erklärung. Der fünfte Abschnitt enthielt Vorschläge zur Sicherung des Friedens und zur Verbesserung des Verhältnisses zwischen Ost und West. Die Bundesregierung regte an, daß alle Nicht-Nuklearstaaten ihrem Vorbild folgen und ebenfalls Verzichtserklärungen abgeben sollten. Zur Überwachung sei ein internationales Kontrollsystem einzurichten. Als flankierende Maßnahme müßten sich die Nuklearstaaten konsequenterweise zur Non-

\footnotetext{
64 Note der Bundesregierung vom 25. 3. 1966, in: DzD IV/12, S. 381.

65 Ebenda, S. 382.

66 KRÜGER, Die deutsche Friedensnote, S. 350.

67 Note der Bundesregierung vom 25. 3. 1966, in: DzD IV/12, S. 381.

68 KRÜGER, Die deutsche Friedensnote, S. 350.

69 Note der Bundesregierung vom 25. 3. 1966, in: DzD IV/12, S. 382.

70 Vgl. HACKER, Deutsche Irrtümer, S. 88.

71 Note der Bundesregierung vom 25. 3. 1966, in: DzD IV/12, S. 382.

72 KRÜGER, Die deutsche Friedensnote, S. 350.
} 
proliferation verpflichten. Bonn erklärte sich ferner bereit, eine Vereinbarung zur Einfrierung der Zahl der in Europa stationierten Kernwaffen sowie ihrer stufenweisen Reduzierung zu unterzeichnen, und griff damit den Rapacki-Plan zur Schaffung einer atomwaffenfreien Zone in Europa auf. Nach den Vorstellungen der Bundesregierung sollte diese aber den gesamten Kontinent umfassen und mit „entscheidenden Fortschritten bei der Lösung der politischen Probleme in Mitteleuropa" verbunden werden ${ }^{73}$. Weiterhin wurde also am Junktim zwischen Abrüstung und der deutschen Frage festgehalten ${ }^{74}$. Schließlich unterstützte Bonn den Gedanken, auf beiden Seiten des Eisernen Vorhangs ein Manöverbeobachtungssystem $^{75} \mathrm{zu}$ installieren, allerdings mit der Einschränkung, daß die DDR daran nicht beteiligt würde. Der spektakulärste Schritt war das Angebot an die osteuropäischen Staaten, mit ihnen Gewaltverzichtserklärungen austauschen. Um den Alleinvertretungsanspruch der Bundesrepublik nicht zu beeinträchtigen, bevorzugte Bonn jedoch anstelle einer gemeinsamen Erklärung der beiden Militärbündnisse, wie sie in den letzten Jahren diskutiert worden war, ein bilaterales Vorgehen. Zum Schluß der Note machte die Bundesregierung allerdings erneut ihren Standpunkt deutlich, „daß alle Bemühungen um Sicherheit, Abrüstung und Rüstungskontrolle nur dann entscheidenden und dauerhaften Erfolg haben, wenn man Schritt für Schritt auch die Ursachen der Spannung in der Welt beseitigt. In Europa heißt dies vor allem, die Deutschlandfrage in gerechter Weise zu lösen, indem man dem gesamten deutschen Volk das Recht gewährt, frei über seine politische Lebensform und sein Schicksal zu bestimmen." 76

Als Erhard am 25. März den Bundestag über den Inhalt der Note in Kenntnis setzte, reagierte das Plenum mit Zustimmung ${ }^{77}$. Dagegen wurde die Initiative der Bundesregierung in der Öffentlichkeit weitgehend kühl aufgenommen. Selbst regierungsnahe Zeitungen wie die Frankfurter Allgemeine äußerten sich reserviert. Weniger überraschend war hingegen, daß die Vertriebenenverbände sich mit kritischen Stellungnahmen zu Wort meldeten ${ }^{78}$. Das Echo im Ausland war geteilt: Während die neutralen Staaten sowie die Verbündeten der Bundesrepublik die Note begrüßten, stieß sie bei den eigentlichen Adressaten, den osteuropäischen Staaten, durchwegs auf Ablehnung. Bis Mitte Juli trafen in Bonn Antworten aus

73 Note der Bundesregierung vom 25. 3. 1966, in: DzD IV/12, S. 384.

74 Die Behauptung Christian Hackes, die Bundesregierung hätte mit der Friedensnote dieses Junktim aufgegeben (vgl. HACKE, Die CDU und die deutsche Frage, S. 93), ist also völlig aus der Luft gegriffen.

75 Am 11. Oktober 1965 schlug der Oberbefehlshaber der Streitkräfte des Warschauer Pakts, Marschall Gretschko, den Austausch von Manöverbeobachtern zwischen West und Ost vor. Diese Idee ersetzte praktisch das bislang in der Diskussion befindliche System von Bodenbeobachtungsposten. Gretschko bot an, die Beobachter entweder bei Manövern von NATO bzw. Warschauer Pakt oder nur bei rein sowjetischen bzw. amerikanischen Manövern einzusetzen. Für die Bundesrepublik kam nur die zweite Alternative in Frage. Vgl. die Aufzeichnung des Vortragenden Legationsrats I. Klasse Lankes vom 18. 1. 1966, in: AAPD 1966, Dok. 11, S. 32-36.

76 Note der Bundesregierung vom 25. 3. 1966, in: DzD IV/12, S. 385.

77 Vgl. die Erklärungen des Bundeskanzlers Erhard und der Abgeordneten Barzel (CDU/ CSU), Wehner (SPD) und von Kühlmann-Stumm (FDP), in: DzD IV/12, S. 385-392.

78 Vgl. HAFTENDORN, Sicherheit, S. $289 \mathrm{f}$. 
Warschau, Prag, Moskau und Budapest ein, in denen vor allem die Forderung nach Wiedervereinigung sowie das Festhalten Bonns an den Grenzen von 1937 kritisiert wurde ${ }^{79}$. Als die Bundesregierung am 29. Juli 1966 die 31 bislang eingegangen Antwortschreiben veröffentlichte ${ }^{80}$, stellte sie dennoch fest, die Friedensnote habe "die auf sie gesetzten Erwartungen zum großen Teil erfüllt" und „eine außergewöhnliche Aufmerksamkeit gefunden“. Man habe sich damit "wirkungsvoll in die Entspannungsdiskussion eingeschaltet". Die Weigerung des Ostens, mit der Bundesrepublik Gewaltverzichtserklärungen auszutauschen, beweise, daß die kommunistische Propaganda gegen die Bundesrepublik "unglaubwürdig“ sei $^{81}$. Schröder wertete es tatsächlich nicht als Mißerfolg, daß die Antworten der osteuropäischen Staaten negativ ausfielen. Angesichts der kommunistischen Kampagne gegen die Bundesrepublik sei der Inhalt der Schreiben keine Überraschung, äußerte er wiederholt. Ein positives Zeichen war für ihn, daß die Noten der Warschauer-Pakt-Staaten nicht gleichlautend formuliert waren. Er nahm deshalb an, der Osten habe sich nicht auf eine gemeinsame Antwort einigen können. Auch war seines Erachtens die Wirkung der Friedensnote größer gewesen, als die Reaktionen vermuten ließen. Der Außenminister verwies dabei auf die Schwierigkeiten der kommunistischen Machthaber, die Vorschläge Bonns in ihren Schreiben auf überzeugende Weise zurückzuweisen, da sie völlig in Widerspruch zu dem Bild standen, daß im Ostblock von der Bundesrepublik bislang gezeichnet wurde. Den differenzierten Stellungnahmen der osteuropäischen Staaten in ihren Antwortschreiben sei zu entnehmen, daß manche Anregungen wie der Gedanke, Gewaltverzichtserklärungen auszutauschen, sogar ihr Interesse geweckt habe ${ }^{82}$. Schröder meinte feststellen zu können, daß auch das Echo in der nichtkommunistischen Welt "ungewöhnlich zustimmend" ausgefallen sei ${ }^{83}$. Er zog daher ein positives Fazit und erkärte, daß nahezu alle mit der Note verfolgten Ziele erreicht worden seien $^{84}$.

Diese Analyse war sicherlich beschönigend. Vor allem in Anbetracht der negativen Reaktion des Ostens kann die Initiative der Bundesregierung gewiß nicht als ein großer Erfolg bezeichnet werden ${ }^{85}$. Dennoch äußerten sich bedeutende $\mathrm{Au}$ Benpolitiker der Bundesrepublik auch im Rückblick noch euphorisch über die

79 Für den Wortlaut der Antwortnoten der polnischen Regierung vom 28. 4. 1966, der tschechoslowakischen Regierung vom 7.5. 1966 und der sowjetischen Regierung vom 17.5. 1966 sowie des Kommuniqués des ungarischen Nachrichtenbüros vom 3.6. 1966 vgl. EUROPA-ARCHIV 1966, D 279-298 und D 470-474.

$80 \mathrm{Vgl}$. TEXTE DER BISHER EINGEGANGEN ANTWORTNOTEN AUF DIE NOTE DER BUNDESREGIERUNG ZUR DEUTSCHEN FRIEDENSPOLITIK VOM 25. MÄRZ 1966 bzw. Texte der Antwortnoten auf die Note der Bundesregierung, in: MODERNE WELT 1966, S. 397-440.

81 Erklärung der Bundesregierung vom 29. 7. 1966 anläßlich der Veröffentlichung der amtlichen Reaktionen auf die Note zur deutschen Friedenspolitik vom 25. 3. 1966, in: EUROPAARCHIV 1966, D $466 \mathrm{f}$.

82 Vgl. BT STENOGRAPHISCHE BERICHTE, Bd. 61, S. $2896 \mathrm{f}$; sowie die Rede Schröders vor dem NATO-Ministerrat am 7.6. 1966 in Brüssel, in: BULLETIN 1966, S. 643.

83 Vgl. BT STENOGRAPHISCHE BERICHTE, Bd. 61, S. 2897.

84 Protokoll der Sitzung des Auswärtigen Ausschusses vom 18. 7. 1966, ACDP, Nachlaß Krone I-028-034/2.

85 Vgl. HAFTENDORN, Sicherheit, S. 290. 
Friedensnote. Carstens nannte sie einen „Markstein in der deutschen Nachkriegspolitik“, der gleichsam den „Höhepunkt" der Regierung Erhard bildete ${ }^{86}$. Nach der Auffassung Hans-Dietrich Genschers hat die Note einem „Prisma“ ähnlich Schröders ostpolitische Grundsätze zusammengefaßt und gleichzeitig Akzente gesetzt, die die nachfolgenden Bundesregierungen aufgegriffen und ausgebaut hätten. Nach seiner Einschätzung hatte sie den Weg zur Unterschrift der Bundesrepublik unter den Nichtverbreitungsvertrag geöffnet und den Anstoß zu den Ostverträgen gegeben ${ }^{87}$. Im Gegensatz dazu betonte Osterheld die Kontinuität mit der bisherigen Deutschland-Politik. Anders als die Ostpolitik der Regierung Brandt/Scheel habe die Friedensnote nämlich nicht die Ursachen der Spannung außer acht gelassen ${ }^{88}$. Auch Carstens sah in ihr keinen Vorläufer zur sozialliberalen Ostpolitik, da sie dem Ziel der Wiedervereinigung eindeutig Priorität einräumte ${ }^{89}$.

Weitaus verhaltener fällt hingegen das Urteil der Wissenschaft aus. Zwar gibt Christian Hacke zu, daß die Note „in der historischen Distanz an Bedeutung gewonnen“ habe ${ }^{90}$, doch sei sie „zu vorsichtig“ formuliert gewesen: „Sie blieb ohne letzten inneren Antrieb, war vielmehr aus ,erwarteten“ äußerlichen Zwängen heraus motiviert, weil man in West und Ost drängte."91 Der amerikanische Politikwissenschaftler William Griffith ist ebenfalls der Meinung, daß es sich dabei nicht um eine weitreichenden Schritt Bonns gehandelt habe ${ }^{92}$. Auch Wolfram Hanrieder zählt die Note zu den „halbherzige[n] Initiativen“ der Regierung Erhard"3. Die wohl negativste Bewertung stammt von Peter Bender. Er kritisiert, daß die Bundesregierung weiterhin an der Option eines gemeinsamen Besitzes von Kernwaffen festhielt, die Ungültigkeit des Münchener Abkommens verneinte, die DDR aus den Entspannungsbemühungen ausklammerte und die polnische Regierung angriff, weil sie von Bonn die Anerkennung der Oder-Neiße-Linie verlangte. Bender erteilt ihr deshalb eine vernichtende Zensur: „Aus östlicher Sicht mußte diese Note nicht nur als Fortsetzung, sondern als Verschärfung der Bonner Politik erscheinen." 94

Um der Friedensnote gerecht zu werden, müssen bei ihrer Beurteilung auch die Absichten und Ziele, die Schröder mit ihr verfolgte, berücksichtigt werden. Wie er am 17. Mai 1966 vor dem Bundestag erklärte, bezweckte er mit der Initiative zweierlei: Zum einen wollte er die friedliche Politik der Bundesrepublik eindrucksvoll darlegen, zum anderen beabsichtigte er, bestimmte „Themen im inter-

86 CARSTENS, Die deutsche Friedensnote vom 25. März 1966, S. 383 bzw. S. 386.

87 GENSCHER, Neue Ansätze in Gerhard Schröders Ostpolitik, S. 85-90 (85).

88 Vgl. OSTERHELD, Außenpolitik, S. 303.

89 Vgl. CARSTENS, Die deutsche Friedensnote vom 25. März 1966, S. 390.

90 HACKE, Weltmacht, S. 127.

91 Ebenda, S. 129.

92 Vgl. GRIFFITH, Die Ostpolitik der Bundesrepublik Deutschland, S. 176.

93 HANRIEDER, Deutschland, S. 186.

94 BENDER, Die "Neue Ostpolitik“ und ihre Folgen, S. 117. Ebenso negativ äußert sich auch Manfred Görtemaker, der insbesondere die Nichteinbeziehung der DDR in das Gewaltverzichtsangebot beklagt. Vgl. GÖRTEMAKER, Geschichte der Bundesrepublik Deutschland, S. 426. 
nationalen Gespräch zu halten bzw. in das internationale Gespräch hineinzubringen“95. Was war damit gemeint? Aufschluß geben seine Ausführungen vor dem Auswärtigen Ausschuß des Bundestags zwei Monate später, in denen er seine Motive ausführlich erläuterte. Mit der Note, so legte der Außenminister dar, habe er beabsichtigt, den Anstoß zu einem Meinungsaustausch mit den osteuropäischen Staaten über Fragen der Abrüstung und der Sicherheit zu geben. Außerdem sei es ihm darauf angekommen, sie mit den Ansichten der Bundesregierung zu bestimmten Fragen vertraut zu machen und der diffamierenden Propaganda des Ostens mit konkreten Angeboten entgegenzutreten ${ }^{96}$. Schließlich wollte er dadurch zu einer Aufweichung des Ostblocks beitragen und gleichzeitig gegenüber den Verbündeten den Nachweis erbringen, daß Bonn die westliche Entspannungspolitik nicht zu blockieren gedachte ${ }^{97}$.

Der Vorwurf, die Friedensnote habe zu wenig Substanz gehabt, ist folglich unangemessen. Sie sollte ein erster Schritt gegenüber dem Osten sein, nicht mehr, aber auch nicht weniger. Dies hat Schröder auch mehrmals gegenüber der Öffentlichkeit deutlich gemacht. Obwohl die osteuropäischen Staaten auf die Initiative der Bundesregierung nicht eingingen, bekräftigte er immer wieder seinen Willen, die Bemühungen um eine Verständigung fortzusetzen ${ }^{98}$. Auch innerhalb der Regierung drängte er darauf, weiter aktiv zu bleiben. Am 17. Juli legte Erhard umfassend dar, welche weiteren Schritte auf der Grundlage der Friedensnote unternommen werden sollten. Der Außenminister appellierte an den Kanzler, nicht auf die noch fehlenden Antworten der rumänischen und bulgarischen Regierung zu warten, sondern den „nächsten Schritt so bald wie möglich folgen [zu] lassen, bevor die Wirkung unserer Friedensnote abklingt“. Er riet dazu, die Dinge selbst in die Hand zu nehmen, um die westliche Entspannungspolitik durch eigene Initiativen in die richtige Bahn zu lenken: „Andernfalls besteht die Gefahr, daß unsere Verbündeten Vorschläge machen, die vielleicht nicht in jedem Fall unseren Vorstellungen entsprechen. "Schröder zufolge gab es zu einer Beteiligung an den Verständigungsbemühungen des Westens gegenüber dem Ostblock keine Alternative. Falls sich Bonn gegen den Zeitgeist stelle, würden die Verbündeten, aber auch die Öffentlichkeit auf die Bundesregierung Druck ausüben, ihre Haltung zu ändern. Bonn, so der Außenminister, werde eine Verweigerungshaltung nicht durchhalten. Man dürfe aber nicht in eine Situation geraten, in der man der Entwicklung hinterhereile: „Dann allerdings haben wir es schwerer, die Richtung des Weges zu bestimmen." 99

95 BT STENOGRAPHISCHE BERICHTE, Bd. 61, S. 1841.

96 Vgl. das Protokoll der Sitzung des Auswärtigen Ausschusses am 18.7. 1966, ACDP, Nachlaß Krone I-028-034/2. Vgl. auch die Rede Schröders vor dem NATO-Ministerrat am 7.6. 1966 in Brüssel, in: BulletiN 1966, S. 643.

97 Vgl. die Vorlage für Bundesminister Krone für die Kabinettssitzung am 4. 8. 1966, Tagesordnungspunkt: Friedensnote, ACDP, Nachlaß Krone I-028-034/2.

$98 \mathrm{Vgl}$. die Reden Schröders auf der 13. Bundestagung des Evangelischen Arbeitskreises am 20. 5. 1966 in Bochum und vor dem NATO-Ministerrat am 7.6.1966 in Brüssel sowie das Interview Schröders mit NDR/WDR am 2. 7. 1966, in: BULLETIN 1966, S. 546, S. 643 und S. 714.

99 Schreiben Schröders an Erhard vom 17. 7. 1966, ACDP, Nachlaß Krone I-028-034/2. 
Wo aber sah er den Ansatzpunkt für eine neue Initiative? Obwohl eine Verbesserung des Verhältnisses zu Polen dringend geboten schien, wollte Schröder nicht mit Warschau den Anfang machen, da die polnische Regierung in ihrer Antwort "die intransigenteste Haltung, insbesondere in der Oder-Neiße-Frage" an den Tag gelegt habe. Auch Ungarn kam für ihn nicht in Frage, da die Antwort Budapests „am wenigsten Substanz" enthalten habe und ein solcher Schritt außerdem als „Verlegenheitslösung“ interpretiert werden konnte. Er plädierte statt dessen dafür, zunächst auf die ČSSR zuzugehen. Erst danach sollten die UdSSR, Ungarn und Polen folgen. Zwar sei auch das Echo in Prag "recht negativ" gewesen, doch hatte nach seiner Einschätzung die Friedensnote in der Tschechoslowakei Eindruck gemacht und zu lebhaften Diskussionen geführt. In einer Note an die ČSSR sollten vor allem zwei Dinge angesprochen werden, nämlich das Münchener Abkommen sowie der Vorschlag der Bundesregierung, einen Gewaltverzicht zu vereinbaren ${ }^{100}$. Die tschechoslowakische Regierung hatte gegenüber Bonn in ihrer Antwort auf die Friedensnote den Vorwurf erhoben, die Tatsache, daß die DDR in das Angebot, Gewaltverzichtserklärungen auszutauschen, nicht einbezogen sei, zeige, daß die Bundesregierung in Wahrheit beabsichtige, auf diese Weise ihre „auf die Annexion der Deutschen Demokratischen Politik [...] gerichtete Politik zu legalisieren" 101 . Schröder wollte deshalb nochmals ausdrücklich darauf hinweisen, daß Bonn das Deutschland-Problem allein über den Weg des Selbstbestimmungsrechts zu lösen gedachte. Um die Bedenken der Tschechoslowaken zu zerstreuen, wollte er ferner anregen, beide Regierungen sollten anläßlich der Abgabe von Gewaltverzichtserklärungen zusätzlich versichern, „daß sie eine Lösung der Deutschlandfrage nur mit friedlichen Mitteln wünschen und daß sie sich auch in dieser Hinsicht jeder Gewalt oder Drohung mit Gewalt enthalten werden"102.

Hinsichtlich des Münchener Abkommens wies er Erhard darauf hin, daß eine Verbesserung des Verhältnisses zur ČSSR nicht gelingen könne, wenn man diesem Problem aus dem Weg ging. Schröder war bewußt, daß es deswegen - wie die Reaktion auf die Friedensnote gezeigt hatte - Schwierigkeiten mit der Interessenvertretung der Sudetendeutschen geben würde. Doch seines Erachtens konnte die Bundesregierung einer Erörterung der Prager Forderung, die Bundesrepublik müsse die völkerrechtliche Ungültigkeit des Abkommens ex tunc anerkennen, nicht ausweichen. Er begründete dies folgendermaßen: „Für die Tschechen ist das Münchener Abkommen ein Trauma, das noch nicht überwunden ist; für die kommunistischen Propaganda aber ist es ein Mittel, um in der ganzen Welt Mißtrauen gegen uns zu säen. Indem man den Erklärungen der Bundesregierung Äußerungen von Funktionären der Landsmannschaften entgegenstellt, verdächtigt man uns, wir wollten die Sudetengebiete doch wieder in unseren Besitz bringen, wenn nicht mit Gewalt, so doch durch eine Verbindung von Heimatrecht und Selbstbestimmungsrecht. Die kommunistische Propaganda hat auch in der Öffentlichkeit der NATO-Staaten ein Echo gefunden, hat Zweifel an unserer Auffassung über

100 Ebenda.

101 Note der tschechoslowakischen Regierung an die Bundesregierung vom 5. 5. 1966, in: DzD IV/12, S. 651.

102 Schreiben Schröders an Erhard vom 17. 7. 1966, ACDP, Nachlaß Krone I-028-034/2. 
das Selbstbestimmungsrecht aufkommen lassen und wirkt unserer Wiedervereinigungspolitik entgegen. " Da die ungelöste Frage des Münchener Abkommens eine effektivere Deutschland-Politik blockierte, empfahl Schröder, sowohl moralisch wie rechtlich dazu Stellung zu nehmen. Die Bundesrepublik sollte die Umstände, unter denen das Abkommen geschlossen wurde, verurteilen und die Anregung machen, die juristischen Aspekte von einer Kommission von Experten aus beiden Staaten überprüfen zu lassen. Auf diese Weise wollte der Außenminister dieses Thema aus der politischen Diskussion herauslösen und einen konstruktiven Dialog mit der ČSSR einleiten. Innenpolitische Konflikte, so Schröder, seien dabei in Kauf zu nehmen, doch sei das Münchener Abkommen „keine Frage, die ausschließlich die Landsmannschaften etwas angeht, sondern ein Problem der Außenpolitik unseres ganzen Volkes, das die deutsche Ostpolitik, vor allem aber die

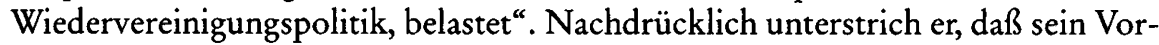
schlag "nicht bloß ein taktischer Zug“ sei. Er hielt es für dringend erforderlich, diese Problematik endlich abschließend zu regeln. Sollte dies gelingen, dann würde man einen wirklichen Schritt in Richtung auf eine deutliche Verbesserung der Beziehungen unternehmen, der nicht nur auf die osteuropäischen Staaten Eindruck machen würde: „Er würde [...] auch unseren Verbündeten zeigen, daß wir uns ernsthaft um Entspannung bemühen". Falls die Tschechoslowakei aber das Angebot zurückweisen würde, hätte die Bundesrepublik ihren Willen zur Verständigung nachhaltig unter Beweis gestellt, „während der Osten demonstrieren würde, daß es ihm gar nicht um eine wirkliche Entspannung geht " ${ }^{103}$.

Schröder war also in der Tat aufrichtig bestrebt, die Beziehungen zu den osteuropäischen Staaten zu verbessern. Selbstverständlich war die Friedensnote auch eine Reaktion auf den westlichen Druck, die Bundesrepublik sollte sich um eine Verständigung mit dem Ostblock bemühen. Der Außenminister war sich der Notwendigkeit bewußt, daß Bonn, um nicht in die Isolierung zu geraten, einen eigenen Beitrag zur Entspannungspolitik leisten mußte. Er hatte die Zeichen der Zeit erkannt und wollte sich nun an die Spitze der Bewegung setzen, selbst wenn er bezweifelte, daß die UdSSR ihre aggressiven Ziele aufgegeben und an einem Ausgleich mit dem Westen interessiert war ${ }^{104}$. Es ist ihm hoch anzurechnen, daß er trotz seiner massiven Zweifel am sowjetischen Friedenswillen nach Ansätzen suchte, eine allmähliche Normalisierung der Beziehungen zum Osten in die Wege zu leiten. Nicht gerechtfertigt ist das Urteil Helga Haftendorns, die Schröder unter Verweis auf die Friedensnote ein Festhalten „an den überkommenen Positionen in der deutschen Frage" ankreidet ${ }^{105}$. Die Note enthielt keine einzige deutschlandpolitische Aussage, die nicht ausdrücklich von den drei Westmächten geteilt wurde. Hinsichtlich der Oder-Neiße-Linie hatte Bonn die Bereitschaft zu einer einvernehmlichen Einigung mit Polen bekräftigt. Weder der Grenzvorbehalt bis zu einem Friedensvertrag noch die Forderung nach Gewährung des Selbstbe-

103 Ebenda.

$104 \mathrm{Zu}$ den Zweifeln des Außenministers am sowjetischen Friedenswillen vgl. die Rede Schröders auf der 13. Bundestagung des Evangelischen Arbeitskreises am 20. 5. 1966 in Bochum, in: BuLLETIN 1966, S. 544.

105 HAFTENDORN, Sicherheit, S. 293. 
stimmungsrechts für die Bevölkerung der DDR standen im Widerspruch zur westlichen Deutschland-Politik. Auch die Regierung Brandt/Scheel hat später am Fortbestand der Rechte und Verantwortlichkeiten der Vier Mächte für Deutschland keinen Zweifel gelassen. Mit seiner Intention, der Wiedervereinigung auf der Basis der von ihm initiierten Neuansätzen in der Ostpolitik näherzukommen, erfüllte Schröder den in der Präambel des Grundgesetzes verankerten staatlichen Auftrag, auf die Einheit Deutschlands hinzuwirken, an den jede Bundesregierung gebunden war. Das Bundesverfassungsgericht hatte dieses Wiedervereinigungsgebot erstmals im KPD-Verbotsurteil vom 17. August 1956 für rechtlich verbindlich erklärt und an dieser Rechtsprechung konsequent festgehalten ${ }^{106}$.

Schröders Stellungnahme zum Münchener Abkommen zeigt zudem, daß er sehr wohl bereit war, bestimmte Positionen zu überdenken. Daß die von ihm skizzierte Note an die ČSSR nie abgeschickt wurde, lag nicht in seiner Verantwortung. Obwohl er in seinem Schreiben an den Kanzler die Geheimhaltung seines Vorhabens als unerläßlich bezeichnet hatte, berichtete der Bonner General-Anzeiger in seiner Wochenendausgabe vom 30./31. Juli 1966, die Bundesregierung trage sich mit dem Gedanken, das Münchener Abkommen für ungültig zu erklären, und erwäge, auch der DDR das Angebot zu unterbreiten, Gewaltverzichtserklärungen auszutauschen ${ }^{107}$. Die Vertriebenenverbände waren gewarnt und konnten rechtzeitig in Bonn Protest einlegen. Der entscheidende Faktor war aber, daß Schröder für sein Konzept im Kabinett keine Unterstützung fand. Im Hinblick auf die im November 1966 stattfindenden Landtagswahlen in Bayern wurde darauf hingewiesen, die rund 1,5 Millionen im Freistaat lebenden Sudetendeutschen - mehrheitlich Wähler der CSU - könnten zur rechtsradikalen NPD abwandern, falls die Bundesregierung eine Initiative nach den Vorstellungen des Außenministers gegenüber der ČSSR beschließen würde ${ }^{108}$. Auch der innenpolitisch bereits schwer angeschlagene Kanzler wollte sich nicht noch zusätzlich mit den Vertriebenenverbänden anlegen und seinen Gegnern neue Munition liefern. Bis zum September bemühte sich das Auswärtige Amt dennoch, von Erhard grünes Licht zu bekommen, doch alle Vorlagen, so Erwin Wickert, „versandeten im Bundeskanzleramt"109.

\section{Das Eingeständnis des Scheiterns: „Die Zeit der aktiven Wiedervereinigungs- politik ist vorbei"}

Einen Wendepunkt in der amerikanischen Deutschland-Politik stellte die sogenannte Brückenschlag-Rede Johnsons vom 7. Oktober 1966 dar. Der Präsident betonte an diesem Tag vor der Nationalen Konferenz der amerikanischen Zei-

106 Vgl. dazu HACKER, Deutsche Irrtümer, S. 166-172.

107 Vgl. den Artikel „Klares ,Nein“ zu Münchner Vertrag“, in: GENERAL-ANZEIGER vom 30./ 31. 7. 1966, ACDP Pressearchiv, Sammlung „Gerhard Schröder“.

108 Vgl. die Vorlage für Bundesminister Krone für die Kabinettssitzung am 4. 8. 1966, Tagesordnungspunkt: Friedensnote, ACDP, Nachlaß Krone I-028-034/2.

109 Blasius, Erwin Wickert und die Friedensnote der Bundesregierung vom 25. März 1966, S. 553. 
tungskommentatoren in New York, die Entspannung zwischen West und Ost habe Vorrang vor der Wiederherstellung der staatlichen Einheit Deutschlands ${ }^{110}$. Das Ziel der westlichen Politik müsse sein, den Eisernen Vorhang allmählich abzubauen und schließlich eine "Aussöhnung mit dem Osten“ zu erreichen. Am Ende dieser Entwicklung würde dann die Überwindung der Teilung Deutschlands stehen. Johnson erklärte: „Wir müssen das Ost-West-Klima verbessern, um die Vereinigung Deutschlands im Rahmen eines größeren, friedlichen und blühenden Europa zu erreichen. "111 Der Präsident übernahm damit die Position de Gaulles, erst im Rahmen eines allgemeinen europäischen Ausgleichs könne die Wiedervereinigung erfolgen ${ }^{112}$. Johnson hatte damit erstmals auch offiziell eingestanden, daß die USA keine Chance sahen, in absehbarer Zeit die Einheit Deutschlands herbeizuführen.

Nur wenige Tage später, am Freitag, den 14. Oktober 1966, beschäftigte sich das Bundeskabinett ausschließlich mit der Sicherheits- und Deutschland-Politik. Zum ersten Thema referierte der Generalinspekteur der Bundeswehr, Ulrich de Maizière. Da sich Schröder an diesem Tag zu einem Besuch in Griechenland aufhielt, übernahm Staatssekretär Carstens die deutschlandpolitische Lagebeurteilung ${ }^{113}$. Grundlage seines Referats, das Klaus Hildebrand als „hellsichtig und weitblikkend" lobt ${ }^{114}$, war eine Denkschrift, die er drei Tage später dem Außenminister übergab ${ }^{115}$. Carstens zog vor dem Kabinett eine nüchterne, aber dafür um so deprimierendere Bilanz der bisherigen Deutschland-Politik. Seit 1945 hätten keinerlei Fortschritte bei der Wiederherstellung der staatlichen Einheit Deutschlands erzielt werden können, legte der Staatssekretär dar. Im deutschen Volk mache sich deswegen Niedergeschlagenheit breit; auch der Wille zur Wiedervereinigung lasse spürbar nach. Der Bau der Berliner Mauer im August 1961 habe die Tendenz einer inneren Entfremdung zwischen beiden Teilen Deutschlands noch gefördert. Erschwerend komme hinzu, daß weltweit die Unterstützung für die DeutschlandPolitik der Bundesrepublik im Schwinden sei. Selbst bei den engsten Verbündeten breite sich eine gewisse „Deutschland-Müdigkeit“ aus, stellte Carstens fest ${ }^{116}$. Gleichzeitig mache die DDR in den neutralen und blockfreien Staaten sowie in den Internationalen Organisationen Boden gut. Zu Recht führte er die Schwierigkeiten bei der Durchsetzung des Alleinvertretungsanspruchs auf die grundlegenden Veränderungen der Weltpolitik in den vergangenen Jahren zurück. Statt eine Strategie des roll back zu verfolgen und den Kommunismus zurückzudrängen, setze der Westen auf Entspannung und Verständigung mit dem Ostblock, konstatierte der Staatssekretär. Zwar halte Washington am Ziel der Wiedervereinigung

110 Für den Wortlaut der Rede des Präsidenten Johnson vor der Nationalen Konferenz amerikanischer Leitartikler in New York am 7. 10. 1966 vgl. DzD IV/12, S. 1478-1482.

111 Ebenda, S. 1481.

112 Vgl. MARCOWITZ, Option, S. 206.

113 Vgl. den Artikel „Schweigen Ehrensache“, in: DER SPIEGEL vom 24. 10. 1966, S. 27.

114 Hildebrand, Von Erhard zur Großen Koalition, S. 200.

115 Vgl. die Aufzeichnung des Staatssekretärs Carstens vom 17. 10. 1966, in: AAPD 1966, Dok. 333, S. 1374-1383. Vgl. ferner CARSTENS, Erinnerungen, S. $761 \mathrm{f}$.

116 Aufzeichnung des Staatssekretärs Carstens vom 17. 10. 1966, in: AAPD 1966, Dok. 333, S. 1378. 
unverändert fest, doch verträten die Amerikaner inzwischen die Ansicht, daß die Einheit Deutschlands erst am Ende eines Prozesses stehen könne, der die Normalisierung des Ost-West-Verhältnisses zum Ziel habe. Wie die Brückenschlag-Rede Johnsons eine Woche zuvor erneut gezeigt habe, lehnten die USA ein Junktim zwischen Fortschritten beim Deutschland-Problem und dem Abschluß entspannungsbildender Vereinbarungen mit der UdSSR ab. Carstens kam zu dem Schluß, daß die deutschlandpolitischen Forderungen Bonns nicht nur im Widerspruch zur Politik der Verbündeten, sondern der westlichen Entspannungspolitik sogar im Wege standen: „Bestimmte Entspannungsprojekte erscheinen dem Westen wichtiger als etwa die konsequente Unterstützung der Nichtanerkennungspolitik. "117 Zudem beschwöre das Streben der Bundesrepublik nach Wiederherstellung der staatlichen Einheit erhebliche Spannungen mit dem Osten herauf. Immer stärker konzentriere die sowjetische Regierung ihre verbalen Angriffe auf Bonn. Auf diese Weise entstünde „ein hohes zusätzliches Sicherheitsrisiko “ für die Bundesrepublik, das wiederum zu einer "besonders starken Abhängigkeit“ von der Sicherheitsgarantie der Vereinigten Staaten führe ${ }^{118}$.

Der Staatssekretär warnte das Kabinett, daß die Bundesrepublik wegen der zunehmenden Diskrepanz zwischen ihrer Politik und der ihrer Verbündeten in die außenpolitische Isolierung zu geraten drohe. Angesichts des Vordringens der DDR bestünde sogar die Gefahr der Selbstisolierung, wenn die Bundesregierung weiterhin auf die völkerrechtliche Anerkennung der DDR durch einen dritten Staat automatisch mit dem Abbruch der Beziehungen reagieren oder sich aus einer internationalen Organisation zurückziehen würde, sobald diese Ost-Berlin den Beitritt erlaube. Die jetzige Interpretation des Alleinvertretungsanspruchs gebe anderen Regierungen die Möglichkeit, die Bundesrepublik mit der Drohung zu erpressen, die DDR aufzuwerten. Nicht nur die neutralen Staaten, sondern selbst die Partner der Bundesrepublik würden sich zunehmend dieses Mittels bedienen, führte Carstens den Kabinettsmitglieder vor Augen. Er vergaß nicht zu erwähnen, daß die jetzige Deutschland-Politik zudem die außenpolitische Handlungsfreiheit der Bundesrepublik erheblich einschränkte. So werde dadurch beispielsweise die nach Auffassung des Auswärtigen Amts erforderliche Aufnahme diplomatischer Beziehungen zu den osteuropäischen Staaten blockiert ${ }^{119}$. Die Bundesrepublik lief nach Carstens' Einschätzung Gefahr, in eine Sackgasse zu geraten. Wie Krone in seinem Tagebuch festhielt, gipfelten die Ausführungen des Staatssekretärs alles in allem darin, „daß die Zeit der aktiven Wiedervereinigungspolitik vorbei sei; es laufe bei aller grundsätzlichen Bejahung unseres Rechtes auf Einheit durch die Westmächte auf jene Politik hinaus, wie sie in der Johnson-Rede umrissen sei“120. In der Tat konnte Carstens keinerlei Perspektiven hinsichtlich einer Überwindung der Teilung Deutschlands aufzeigen. Dennoch hielt er eine Anpassung der Deutschland-Politik der Bundesregierung für dringend geboten, „um größere außenpolitische Bewegungsfreiheit zu erlangen, um uns von einem übermäßig star-

117 Ebenda, S. 1380.

118 Ebenda, S. 1381.

119 Vgl. ebenda, S. 1378-1381.

120 KRONE, Aufzeichnungen, Eintrag vom 14. 10. 1966, S. 190. 
ken Druck zu befreien und um womöglich das schwindende Zusammengehörigkeitsgefühl zu stärken" 121 .

Welcher Art sollten aber nun die deutschlandpolitischen Kursänderungen sein? Carstens ging in seiner Bestandsaufnahme auf diesen Punkt nur sehr oberflächlich ein. Er dachte vor allem an eine Modifikation des Alleinvertretungsanspruchs, die Aufgabe des Junktims zwischen Entspannung und Fortschritten bei der Lösung der deutschen Frage, die Einführung einer "negativen Berlin-Klausel“ sowie eine Änderung der Haltung bezüglich des Grenzvorbehalts ${ }^{122}$. Entschieden sprach er sich aber dagegen aus, eine freundlichere Haltung gegenüber der DDR an den Tag zu legen. Da das Ulbricht-Regime der Bundesrepublik feindlich gegenüberstehe, sei eine friedliche Koexistenz nicht möglich. Ein Arrangement mit der UdSSR hielt Carstens deshalb sogar für wahrscheinlicher als ein einigermaßen verträgliches Nebeneinander mit der DDR. Schonungslos eröffnete er dem Kabinett jedoch, die Bundesrepublik werde selbst im Falle einer Änderung ihrer Politik nicht ganz aus dem Dilemma herauskommen, in dem man sich momentan befinde. Er prognostizierte, daß es zwangsläufig weiterhin Konflikte sowohl mit der Sowjetunion als auch mit den eigenen Verbündeten geben werde, solange sich Bonn das Ziel der Wiedervereinigung auf das Banner schreibe. Bei allen Entscheidungen, die man bezüglich der künftigen Gestaltung der Deutschland-Politik treffe, müsse aber unbedingt berücksichtigt werden, daß die Sicherheit der Bundesrepublik nicht beeinträchtigt werden dürfe ${ }^{123}$. Das Auswärtige Amt machte also unmißverständlich deutlich, daß die Verteidigung der Freiheit der Bundesrepublik Vorrang vor der Einheit haben müßte. Damit wurde Konrad Adenauers unumstößliche Wertetrias Freiheit, Friede, Einheit eindrucksvoll bestätigt.

Mende stimmte sogleich den Schlußfolgerungen Carstens' zu. Auch er war der Ansicht, daß die Deutschland-Politik an die weltpolitische Entwicklung angepaßt werden müßte, um Bonn wieder mehr außenpolitische Bewegungsfreiheit zu verschaffen ${ }^{124}$. Der FDP-Vorsitzende sprach sich jedoch klar gegen eine völkerrechtliche Anerkennung der DDR aus. Die technischen Kontakte sollten jedoch ausgebaut werden, da die Existenz eines zweiten deutschen Staats nicht länger ignoriert werden könne. Die Bundesminister Krone und Heck rieten, das europäische Element in der Politik der Bundesregierung zu verstärken, um die Abhängigkeit von den USA zu verringern ${ }^{125}$. Erhard äußerte sich nicht, rief die Anwesenden jedoch dazu auf, über diese Bankrotterklärung der bisherigen Deutschland-Politik nichts an die Öffentlichkeit dringen zu lassen: „Meine Herren, es ist ein Ehrenpunkt, darüber zu schweigen." 126 Weitere Konsequenzen zog der Kanzler aus den Ausführungen des Staatssekretärs nicht. Doch selbst wenn er gewillt gewesen wäre, eine Revision der Deutschland-Politik in die Wege zu leiten, hätte er sie nicht

121 Aufzeichnung des Staatssekretärs Carstens vom 17. 10. 1966, in: AAPD 1966, Dok. 333, S. 1382.

122 Vgl. ebenda; sowie CARSTENS, Erinnerungen, S. 762.

123 Vgl. die Aufzeichnung des Staatssekretärs Carstens vom 17. 10. 1966, in: AAPD 1966, Dok. 333, S. $1382 \mathrm{f}$.

124 Vgl. den Artikel „Schweigen Ehrensache“, in: Der SPIEgEL vom 24. 10. 1966, S. 27.

125 Vgl. CARSTENS, Erinnerungen, S. 762.

126 Vgl. den Artikel „Schweigen Ehrensache“, in: Der SPIEGEL vom 24. 10. 1966, S. 27. 
mehr umsetzen können. Mitte Oktober 1966 neigte sich die Kanzlerschaft Erhards rapide ihrem Ende zu. Vordergründig wegen erheblicher Differenzen über die Sanierung des Haushaltsdefizits zerbrach am 27. Oktober die Koalition mit der FDP. Am 30. November trat Erhard zurück, einen Tag später nahm die Große Koalition von CDU/CSU und SPD unter Kurt Georg Kiesinger ihre Arbeit auf 127 .

127 Der Sturz Erhards hatte viele Ursachen. Die allgemeine Unzufriedenheit mit dem Kanzler, seine Entscheidungsschwäche und die außenpolitischen Gegensätze in der Union hatten seine Position erheblich geschwächt. Vgl. HiLDEBRAND, Von Erhard zur Großen Koalition, S. 220-240. Die schmerzhafte Niederlage der CDU bei den Landtagswahlen in Nordrhein-Westfalen am 10. 7.1966 verstärkte die Zweifel an seinen Führungsqualitäten. Vgl. HENTSCHEL, Ludwig Erhard, S. 620f. Eine wichtige Rolle für die Regierungskrise im Herbst 1966 spielte auch der fehlgeschlagene Besuch des Kanzlers vom 24. bis 27. 9. 1966 in den USA. McGhee hatte im Vorfeld dem Präsidenten prognostiziert, daß sogar mit dem Sturz Erhards gerechnet werden müßte, wenn die Vereinigten Staaten der Bundesrepublik in der Frage der Devisenausgleichszahlungen nicht entgegenkommen würden. Vgl. MCGHEE, Botschafter, S. 291 f. Obwohl sich Johnson der prekären Situation des Kanzlers durchaus bewußt war (vgl. JOHNSON, The Vantage Point, S. 307), bestand er darauf, daß Bonn bis Jahresende das vereinbarte Auftragsvolumen in Höhe von 900 Millionen Dollar einhalten würde. Erhards Bitte um Stundung wies der Präsident barsch zurück. Vgl. dazu HENTSCHEL, Ludwig Erhard, S. 633-635; OsterHELD, Außenpolitik, S. 350-356. Zu den Gesprächen Erhards in den USA vgl. auch AAPD 1966, Dok. 297302, S. 1237-1268. Zum Devisenausgleichsproblem vgl. ROSENBACH, Der Preis der Freiheit, S. 724-744. Christian Hacke stellt zutreffend fest: „Die unbedingte Bündnistreue von Bundeskanzler Erhard gegenüber Präsident Johnson zahlte sich nicht aus." Vgl. HACKE, Weltmacht, S. 114. 